\title{
Un seul programme : Guide pour une approche pédagogique unifiée de la sexualité, du genre, du VIH et des droits humains
}

International Sexuality and HIV Curriculum Working Group

Nicole Haberland

Population Council

Deborah Rogow

Follow this and additional works at: https://knowledgecommons.popcouncil.org/departments_sbsr-pgy

Part of the Demography, Population, and Ecology Commons, Family, Life Course, and Society Commons, Gender and Sexuality Commons, International Public Health Commons, and the Medicine and Health Commons How does access to this work benefit you? Let us know!

\section{Recommended Citation}

International Sexuality and HIV Curriculum Working Group. 2011. "Un seul programme : Guide pour une approche pédagogique unifiée de la sexualité, du genre, du VIH et des droits humains," edited by Nicole Haberland and Deborah Rogow. New York: Population Council. 



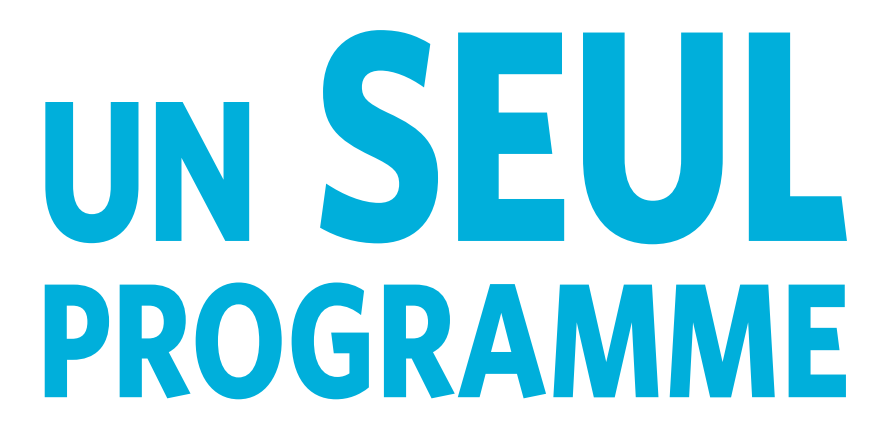

VOLUME 1 : GUIDE POUR UNE APPROCHE PÉDAGOGIQUE UNIFIÉE DE LA SEXUALITÉ, DU GENRE, DU VIH ET DES DROITS HUMAINS 


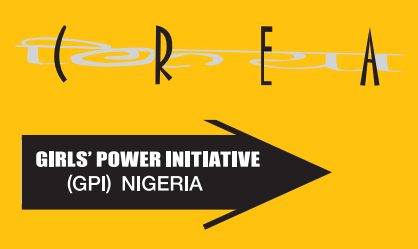

\section{CIPPF $=$}

\section{QIPPF $=$}

\author{
Région de L'hémisphère Occidental
}

$\bigcirc$

INTERNATIONAL WOMEN'S HEALTH COALITION

\section{Mexfam \\ Salud para tu familia}

(1) Population Council
Un seul programme : Guide et Activités pour une approche pédagogique unifiée de la sexualité, du genre, du VIH et des droits humains est le produit d'une initiative internationale réalisée par les représentants des organisations suivantes (par ordre alphabétique):

CREA (Inde) : Caroline Earle, Sunita Kujur, Geeta Misra

Girls Power Initiative (Nigeria) : Bene Madunagu, Grace Osakue

International Planned Parenthood Federation : Doortje Braeken

IPPF/Western Hemisphere Region : Jessie Clyde, Denise Kohn

International Women's Health Coalition : Kelly Castagnaro, Corinne Whitaker

Mexfam (Mexique) : Ofelia Aguilar

Population Council : Nicole Haberland, Deborah Rogow

L'initiative a rassemblé diverses perspectives et expertises techniques sur l'éducation des adolescents à la sexualité et prévention du VIH, dans l'espace droits et genre, de la gestion programmatique, de la recherche et du plaidoyer. Andrea Irvin a également participé à la conception de plusieurs sections. Cette traduction française a été réalisée avec le soutien de IPPF et a été révisée par Michelle Skaer.

\section{Rédaction : International Sexuality and HIV Curriculum Working Group Édition : Nicole Haberland et Deborah Rogow}

\section{Traduction : Geneviève Haines}

Coordination du projet : Michelle Skaer, Jonah Stuart Brundage, Amy Handler

Conception graphique : Emanuela Frigerio, Hyun Auh, C\&G Partners, New York City

Production : Mike Vosika, Christina Tse, Michelle Skaer, Edgar Peralta

Révision : Karen Tweedy-Holmes

Relecture : Gina Duclayan

Crédits photos des images de couverture : Introduction, Jacob Silberberg, avec l'autorisation de IPPF/WHR; unité 1, Manoocher Ceghati, avec l'autorisation de IRIN ; unité 2, Michael Newman, avec l'autorisation de PhotoEdit ; unité 3, Gabe Cooney, avec I'autorisation de IPPF/WHR ; unité 4, Maura Carroll ; unité 5, Melissa May ; unité 6, Ronn Aldaman ; unité 7, Neil Thomas, avec I'autorisation de IRIN ; unité 8, Eugene Martin ; fiches d'information, Helen Cole, avec l'autorisation de Photoshare. Tous autres crédits identifiés en regard de l'image.

Publié par The Population Council, New York.

Téléchargement gratuit depuis : www.unseulprogramme.org

Copyright (c) 2011 The Population Council, Inc.

Toute partie de ce volume peut être photocopiée sans l'autorisation des auteurs ou de l'éditeur, sous mention expresse de la source et distribution gratuite des copies. Toute reproduction commerciale est soumise à autorisation préalable écrite du Population Council. Prière de mentionner aussi toutes sources originales indiquées pour les activités.

ISBN: Guide: 978-0-87834-124-5; Activités: 978-0-87834-125-2; Set: 978-0-87834-126-9 
À la mémoire d'Enofe Duncan Osakue 
Les CHERCHEURS ont identifié l'inégalité de genre comme un facteur clé de la pandémie du sida.

Les $D E ́ C C D E U R S$ préconisent une éducation et sensibilisation à la sexualité et au VIH qui mettent l'accent sur l'égalité de genre et les droits humains.

Les EDUCATEURS veulent apprendre aux jeunes à développer l'esprit critique nécessaire à l'établissement de sociétés justes et sensibles. 


\section{UN SEUL PROGRAMME}

répond à leur appel. 


\section{remerciements}

Un seul programme : Guide et Activités pour une approche pédagogique unifiée de la sexualité, du genre, du VIH et des droits humains est le produit d'inestimables contributions individuelles, en provenance des quatre coins du monde.

Merci à Wendy Baldwin, Carmen Barroso, Kate Bourne, Judith Bruce, Vicente Díaz, Beth Fredrick, Adrienne Germain, Naana Otoo-Oyortey, Tim Shand et Victoria Ward pour leurs précieux conseils. À Maggie Díaz et à Juan Díaz, de Reprolatina, pour la vérification du GUIDE et de son contenu technique et clinique. À Evan Read pour ses illustrations originales et à Jared Stamm pour le site Web. À Nell Timreck et à Ernestine Heldring pour leur immense contribution à la dernière main. Merci, en particulier, à Mike Vosika et à Karen Tweedy-Holmes, pour leur soutien extraordinaire tout au long du processus de production. Et merci à tous nos amis et collègues qui ont généreusement accepté de partager avec nous leurs images photographiques.

Michelle Skaer, puis Jonah Stuart Brundage ont coordonné le projet avec autant d'intelligence que de bonne humeur : rien n'aurait été possible sans eux. Plus de 50 experts ont revu le manuscrit en cours d'élaboration, tandis que huit organisations participaient aux essais des activités types originales. Tous et toutes sont reconnus et salués à la page suivante (les affiliations institutionnelles applicables au moment de la révision sont indiquées aux seules fins d'identification). Nous leur sommes profondément reconnaissants de leur temps, avis et appui technique. La rédaction est seule responsable des erreurs ou omissions éventuelles.

Merci enfin à nos donateurs, sans qui Un seul programme n'aurait tout simplement pu exister : les fondations Ford Foundation, William and Flora Hewlett Foundation, The Libra Foundation, John D. and Catherine T. MacArthur Foundation, le Ministère britannique du développement international (DfID) et le Fonds des Nations Unies pour la population (UNFPA). Nous avons aussi bénéficié de l'appui financier de l'International Planned Parenthood Federation, d'IPPF/Western Hemisphere Region, de I'International Women's Health Coalition et du Population Council. 


\section{RÉVISION CONSULTATIVE}

Aziza Ahmed (International Community of Women Living with HIV/AIDS)

Lucy Atkin (Colibri Consulting and Hesperian)

Doris Bartel (CARE)

Marina Bernal (MULABI)

Jennifer Catino (EngenderHealth)

Esther Corona (Mexican Association for Sex Education and WAS)

Sarah Hawker Costa (Global Fund for Women)

Jane Cottingham (WHO)

Karen Fazekas (Family Health International)

Gill Gordon (International HIV/AIDS Alliance)

Nik Hartley (Students Partnership Worldwide)

Christine Heritier (Afghanistan Libre)

Rachel Jacobson (Global Youth Coalition on HIV/AIDS)

Magaly Marques (Planned Parenthood of Los Angeles)

Rafael Mazin (PAHO)

Alexander McKay (SIECCAN)

Prabha Nagaraja (TARSHI)

Rick Olson (UNICEF)

Christine Ricardo (Instituto Promundo)

Saira Shameem (Asian Pacific Resource and Research Centre for

Women - ARROW)

Robert Thomson (UNFPA)

Nell Timreck (Students Partnership Worldwide)

\section{ÉOUIPE D'ESSAI DES ACTIVITÉS SUR LE TERRAIN}

\section{Aahung (Pakistan)}

Asociación Demográfica Costarricense (Costa Rica)

Association for Sexual and Reproductive Health XY (Bosnie)

Belize Family Life Association (Belize)

Fundación Mexicana para la Planeación Familiar (MEXFAM)

(Mexique)

Girls Power Initiative (Nigeria)

Lesotho Planned Parenthood Association (Lesotho)

Reprolatina (Brésil)

\section{RÉVISION TECHNIQUE}

Anonymous (participation individuelle)

Gautam Bhan (participation individuelle)

Yvonne Bogaarts (World Population Foundation)

Jeff Buchanan (participation individuelle)

Margarita Díaz (Reprolatina)

Uyi-Oni Ekhosuehi (Optimal Health et Development Project)

Nadine Dimodi Ekotto (ALVF)

Chris Fung (USAID)

Tamara Gonçalves (CLADEM/Brésil)

Angela Heimburger (Human Rights Watch)

Ernestine Heldring (Scenarios USA)

Patty Herrera (Latino Community Solutions)

Laura Katzive (Center for Reproductive Rights)

Scott Kellerman (Population Council)

Martha Kempner (SIECUS)

Tang Kun (China Family Planning Association)

Katarina Lindahl (RFSU)

Eugenia López Uribe (Balance Promoción para el Desarrollo y Juventud)

Veronica Magar (CARE)

Lori Michau (Raising Voices)

Carmen Murguia (UNFPA)

Ratidzai Ndlovu (UNFPA)

Karen Newman (participation individuelle) ${ }^{\star}$

Suzyo Nthazie (Young African Advocates for Rights)

Sabina Rashid (BRAC University)

Nell Rasmussen (Danish National Board of Social Services)

Sundari Ravindran (Achutha Menon Centre for Health Science

Studies)

Meredith Sheehy (Population Council)

Joann Stemmermann (participation individuelle) ${ }^{\star}$

John Townsend (Population Council)

Lita Townsend (Cleveland Metropolitan Schools)

Wijit Wong (World Population Foundation)

Margot Zimmerman (participation individuelle) ${ }^{\star}$

*Apport technique préliminaire. 


\section{table des matières}

INTRODUCTION

\section{DROITS HUMAINS SONT NÉCESSAIRES POUR LA SANTÉ SEXUELLE ET}

LE BIEN-ÊTRE

valeurs et société

qu'entend-on par « droits humains »?

droits sexuels et génésiques

promotion des droits humains, droits sexuels et génésiques compris

glossaire - quelques notions sur les droits humains

\section{LE GENRE}

définir le «genre »

identité de genre

les normes et les rôles de genre se consolident pendant l'enfance et l'adolescence le genre et l'éducation

stéréotypes de genre dans les médias

le genre affecte la mobilité, le lien social et les espaces publics sûrs

le genre affecte la participation civique et politique

genre, travail et ressources économiques : au foyer et au dehors

le genre et le mariage

le genre et la religion

le genre et l'autonomie corporelle

le genre et la violence

la contrainte sexuelle est une forme de violence de genre

faire face à la violence de genre

les normes et les rôles de genre évoluent dans le temps

le genre : nos décisions et nos actes

changer le monde

glossaire - quelques notions sur le genre 
c'est quoi, la sexualité ?

les droits sexuels

la sexualité et la société

les normes sexuelles varient suivant les rôles de genre : « deux poids, deux mesures »

le désir sexuel

la diversité sexuelle

I'anatomie et le plaisir sexuel

l'expression sexuelle et le plaisir

le comportement sexuel

rapports sexuels ou non : motivations

le consentement sexuel et la contrainte

établir des relations sexuelles mutuellement respectueuses et responsables

inquiétudes relatives à la fonction sexuelle

le bien-être sexuel et le plaidoyer

glossaires - quelques notions sur la sexualité

\section{LES RELATIONS INTERPERSONNELLES}

introduction aux relations interpersonnelles

les relations dans nos vies

comment rendre nos relations plus satisfaisantes et respectueuses?

relations romantiques : faire la cour et sortir

tomber amoureux, I' « amour vrai » et la jalousie

l'activité sexuelle dans les relations interpersonnelles

relations intimes à long terme

relations à la dérive

rompre

normes changeantes

\section{APTITUDES À LA COMMUNICATION ET À LA DÉCISION}

facteurs qui affectent la communication

conseils pour une communication efficace

styles de communication directs ou indirects

parler à son ou sa partenaire de questions sexuelles et de santé sexuelle

prendre des décisions

exécuter ses décisions 
l'image du corps

la puberté

connaître son corps

les organes sexuels et génitaux

la fécondité et la reproduction (" d'où viennent les bébés »)

quand la grossesse se poursuit

découvrir son corps : un mouvement mondial

\section{LA SANTÉ SEXUELLE ET GÉNÉSIQUE}

le droit aux services de santé

$1^{\mathrm{re}}$ PARTIE : INFECTIONS SEXUELLEMENT TRANSMISSIBLES, VIH ET SIDA

infections sexuellement transmissibles (IST) et VIH et sida

méthodes de protection contre les IST et le VIH

pourquoi l'absence de protection et rôle de l'égalité de genre dans la lutte contre le sida

vivre avec le VIH et sida

droits et responsabilités de prévention des IST et du VIH

infections de l'appareil génital (IAG)

2e PARTIE : DÉCISIONS DE FÉCONDITÉ PERSONNELLE :

LA CONTRACEPTION ET L'AVORTEMENT (IVG)

la contraception

méthodes contraceptives

grossesse non planifiée et avortement (IVG)

PLAIDOYER POUR LA SANTÉ SEXUELLE, LES DROITS ET

L'ÉGALITÉ DE GENRE

réfléchir à ses propres attitudes

reconnaître ce qui est juste ou non

changer le monde autour de nous

obstacles au plaidoyer

le sens et la puissance du plaidoyer dans la vie

passer à l'action : projet d'apprentissage pratique 
INTRODUCTION (1) 


\title{
Un seul programme : de quoi s'agit-il ?
}

\author{
Un seul programme est une ressource pratique conçue pour aider à \\ l'élaboration de programmes d'enseignement visant, en particulier, les \\ domaines du genre, de la sexualité et du VIH.
}

Un seul programme touche à pratiquement tous les thèmes et sujets envisageables dans un programme d'éducation des jeunes sur les questions du genre, de la santé sexuelle, du VIH, de la sexualité, des relations, de la communcation, de la violence aux mains d'un partenaire intime, de la puberté, de la reproduction humaine, de la contraception, de l'avortement ou du plaidoyer en faveur de leurs propres droits. L’approche se veut vaste et complète, pour permettre à chacun de sélectionner le contenu et les activités qui répondent aux besoins particuliers de son contexte.

Mieux encore, Un seul programme adopte une approche intégrée des thèmes abordés. La recherche démontre un lien profond entre le contexte social des jeunes, leurs facteurs individuels et leur bilan de santé ultime. Aussi cette ressource entend-elle aider à envisager et à présenter tous ses sujets apparentés en un seul programme.

On notera, et c'est important, qu'Un seul programme introduit un élément de réflexion critique dans le processus d'apprentissage, renforçant ainsi l'éducation dans son ensemble. L'ouvrage aide en outre les pays à répondre à l'appel des Objectifs du Millénaire pour le développement. Il propose à tous égards une approche pratique inédite et fraîche à l'éducation des jeunes dans un monde divers et changeant.

Sept grands principes guident cette approche, tels que décrits à la page 3. Ces principes reposent sur les stratégies et les priorités définies par divers organismes mondiaux voués à la santé et à l'éducation : l'Assemblée générale de l'ONU, l'ONUSIDA, ${ }^{2}$ l'Organisation mondiale de la Santé, ${ }^{3}$ l'UNESCO, ${ }^{4}$ et la World Association for Sexual Health. ${ }^{5}$ L'élaboration d'Un seul programme a été confiée à un groupe d'experts internationaux dans le but d'assurer une perspective pertinente à l'éducation de tous les jeunes du monde, de l'Afrique au Pacifique, de l'Asie aux Amériques et de l'Europe au monde arabe.

Le but ultime d'Un seul programme est de développer la capacité des jeunes à s'assumer et à affirmer et défendre leur droit à la dignité, à l'égalité et à une vie sexuelle saine, satisfaisante et responsable. 


\section{SEPT PRINCIPES MOTEURS - Un seul programme est}

1 basé sur l'evidence, il repose sur des normes didactiques articulées par une recherche mondiale, ${ }^{6}$ tout en intégrant d'importantes observations sur les liens entre la dynamique du genre et les constats de santé sexuelle ;

2 complet, il contient une information exacte sur tous les thèmes psychosociaux et de santé nécessaires à un programme intégral d'éducation couvrant la sexualité, la prévention du VIH, le droit à l'abstention sexuelle et la vie familiale ; $^{7}$

3 basé sur les droits humains et les valeurs fondamentales, d'équité, de dignité humaine, de traitement égal, de participation et de droits universels à la base de la santé et du bien-être sexuels et génésiques ; ${ }^{8}$

4 sensible au genre, et à l'importance de l'égalité de genre ${ }^{9}$ et du milieu social dans son ensemble dans l'accès à la santé sexuelle et génésique et au bien-être général des garçons comme des filles ;

5 moteur de croissance intellectuelle et d'esprit critique, propice aux habitudes de l'esprit nécessaires à l'entendement des rapports entre le soi, les autres et la société et de leur effet sur la vie de tous : il favorise ainsi l'expansion de l'éducation à la sexualité et prévention du VIH aux classes d'études civiques, sociales, etc ;

6 propice à l'engagement civique à travers l'idée fondamentale que chaque personne compte et peut affecter positivement son monde : le programme aide à développer les compétences de plaidoyer indispensables à l'avènement d'une société plus juste et plus sensible ; et

7 adapté à la culture, en ce qu'il reflète les circonstances et réalités diverses des jeunes du monde.

\section{UN PROGRAMME, PLUSIEURS OBJECTIFS}

\section{RENFORCER CHEZ LES}

\section{JEUNES}

la capacité de décisions responsables et d'actes délibérés

la capacité de participer à la société et d'exercer leurs droits humains

l'esprit critique, et le niveau d'éducation général

le sens de leurs propres capacités

le sens du bien-être sexuel et de la satisfaction

RÉDUIRE CHEZ LES

ADOLESCENTS LES TAUX DE

grossesses non planifiées

infections sexuellement transmissibles, dont le VIH

activité sexuelle non désirée violence de genre 


\section{Un seul programme : pourquoi ?}

\section{FAIT}

Les jeunes qui ont acquis des normes de genre égalitaires présentent un meilleur bilan de santé sexuelle.

\section{FAIT}

Les accords internationaux préconisent l'éducation à la sexualité et l'égalité de genre.

"... nous savons comment changer la donne de l'épidémie [du sida]. . . II faut un changement positif réel qui rende les femmes et les filles plus fortes et plus confiantes et qui transforme les relations entre les femmes et les hommes à tous les niveaux de la société."

- M. Kofi Annan, ancien secrétaire général de I'ONU
La communauté mondiale a fait de la lutte contre le sida une priorité. La plupart des gouvernements ont aussi ratifié des accords honorant les principes de l'égalité de genre et des droits humains. Quel est le lien ? Et pourquoi l'égalité de genre et les droits humains sont-ils cruciaux à la santé et au bien-être sexuels?

Le fait est que les normes de genre affectent profondément la capacité des jeunes à prendre et vivre leurs décisions concernant leur propre vie sexuelle. Ainsi, il est impardonnable que l'acte sexuel, le mariage et la grossesse ne soient encore à ce jour, pour des dizaines de millions de filles, ni volontaires, ni éclairés. Les garçons aussi subissent souvent la pression d'attentes peu réalistes et même néfastes quant à leur virilité.

Les conséquences sont réelles. Dans les pays en développement comme dans le monde industrialisé, les études confirment combien les jeunes qui croient en l'égalité du genre présentent de meilleurs bilans de santé sexuelle, par rapport à ceux dont les attitudes seraient moins égalitaires. Ainsi, les jeunes qui estiment que les garçons doivent être « durs » et avoir plus d'autorité que les filles sont moins susceptibles d'utiliser le préservatif ou la contraception, plus susceptibles d'avoir de multiples partenaires et parfois plus susceptibles aussi de violence intime. Quant aux filles soumises à la domination masculine, elles font plus souvent état de séropositivité et de grossesses non planifiées. Témoin aussi de cette constellation de l'inégalité de genre et de bilans de santé sexuelle indésirables, la recherche révèle l'association entre la violence exercée par un partenaire intime et les taux supérieurs de grossesses

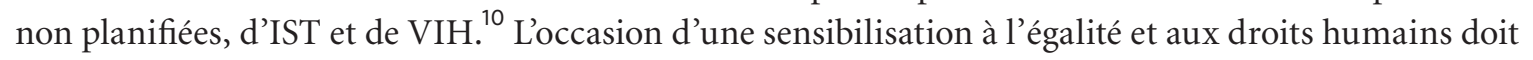
être donnée aux jeunes, en ce qu'ils affectent clairement leur vie sexuelle et, certes, leur bonheur.

\section{Malheureusement, les programmes d'éducation sexuelle ont tardé à se rendre à l'évidence. Peu couvrent les questions du genre et des droits de manière significative. Cette lacune est particulièrement inquiétante quand on sait l'impact statistiquement nul de bien des programmes sur les taux de grossesses non planifiées et d'IST."1}


La leçon — omise au péril de la vie des adolescents — est que l'égalité de genre et les droits humains sont bien plus que de nobles idéaux : ils sont la clé de la prévention du VIH et de la capacité des jeunes à mûrir en bonne santé et à vivre une vie sexuelle responsable et satisfaisante. N'est-ce d'ailleurs pas en réponse à la recherche et au nom de la dignité humaine que la communauté mondiale - États, société civile et organismes internationaux — préconise de plus en plus une éducation à la sexualité et contre le VIH qui englobe, par la même occasion, les questions du genre et des droits humains. De nouvelles ressources sont nécessaires à la présentation utile et efficace de ces concepts.

\section{Partout dans le monde, de nouveaux programmes pionniers d'éducation} à la sexualité et prévention du VIH prêtent davantage attention à l'égalité de genre et aux droits humains. Les résultats s'en révèlent d'ores et déjà fort encourageants. ${ }^{12}$ Le moment est venu d'en appliquer et tester plus largement les approches.

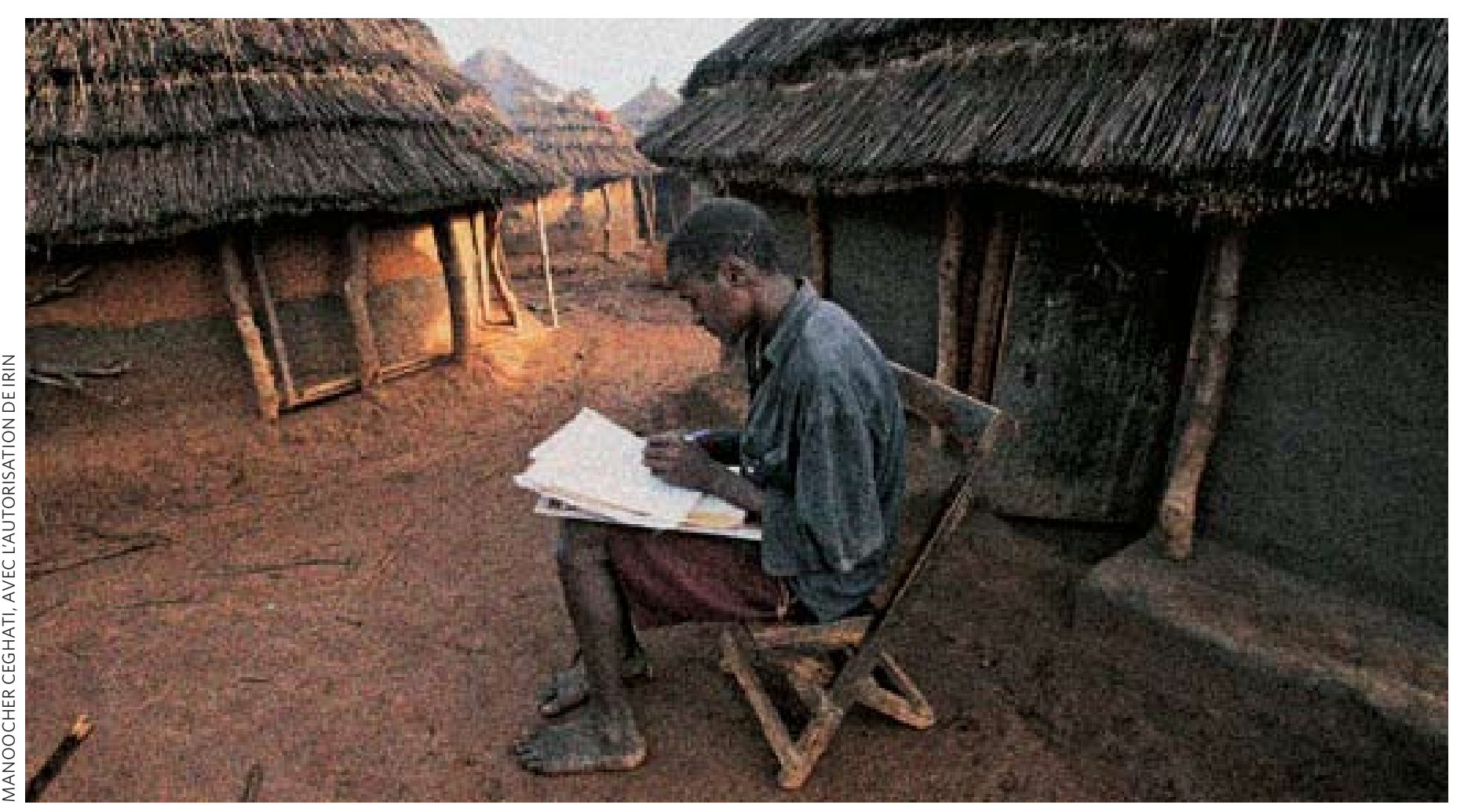




\section{Un seul programme : pour qui ?}

\section{Un seul programme s'adresse principalement aux concepteurs de}

programmes, aux enseignants et aux éducateurs communautaires responsables de

l'éducation dans les domaines de la sexualité et de la santé sexuelle (y compris le sida) et des études civiques ou sociales. Ce guide et son compagnon d'activités peuvent les aider, notamment,

- à élaborer ou modifier un programme complet (de durée appropriée) adapté à leur contexte ;

- à concevoir des unités plus concentrées (sur le genre ou la santé sexuelle, par exemple) ; et

- à documenter leurs plans de leçon-thème (sur le genre et les médias, par exemple, ou la décision sexuelle, la protection contre le VIH, la réflexion sur la masculinité, etc.)

\section{Un seul programme s'adresse aussi aux décideurs de la santé et de l'éducation,}

et aux cadres scolaires. Ce matériel peut aider ces professionnels à assurer que leurs initiatives

d'éducation à la sexualité et prévention du VIH répondent aux besoins d'apprentissage des jeunes et aux mandats de l'Assemblée générale de l'ONU (Objectifs du Millénaire pour le développement ${ }^{13}$ ), de l'ONUSIDA, de l'UNESCO, de l'OMS et autres organismes ${ }^{14}$. Les méthodes au cœur d'Un seul programme engagent en outre la réflexion de haut niveau (par recherche, critique et analyse, notamment) et renforcent la connexité des élèves à l'école. L'éducation à la sexualité et prévention du VIH devient, dans cette optique, un facteur de renforcement de l'éducation en général.

Partout dans le monde, l'éducation à la sexualité intervient dans des contextes culturels et politiques les plus divers. Un seul programme : Guide et Activités est conçu pour présenter adéquatement une information sensible dans les différents contextes d'Afrique, des Amériques, du monde arabe, d'Asie, d'Europe et du Pacifique. Le matériel comporte de nombreux exemples propres à différentes cultures. La section suivante (Un seul programme : où et comment) indique aux éducateurs et autres responsables comment l'adapter aisément à leur contexte particulier. 


\section{Un seul programme : où et comment?}

EN RÉPONSE À

LA DEMANDE DES ÉDUCATEURS

Un seul programme offre la base de programmes à offrir dans différents contextes. Il peut servir à la préparation de cours à enseigner dans les écoles (cours d'hygiène, de biologie, d'études sociales ou même de littérature), ou bien à celle de classes périscolaires ou programmes de communauté (dans le cadre des services de santé, programmes de jeunesse et autres formes d'éducation informelle), ou encore, par adaptation, à celle de cours pour adultes.

Le contenu et la durée des programmes d'éducation à la sexualité et prévention du VIH sont fort variables. Un seul programme est conçu pour permettre au lecteur d'identifier rapidement l'information et le niveau de détail désiré. Le contenu est notamment réparti en huit unités, subdivisées en sous-rubriques. Chacune présente une série d'énoncés clés, souvent assortis de détails ou d'exemples concrets issus de différents contextes culturels. L’utilisateur peut aisément sélectionner les unités, sous-rubriques et niveaux de détail qui répondent le mieux à ses besoins. L’approche la plus complète tirera parti des huit unités. Si le temps de préparation ou d'enseignement est cependant limité, la liste cicontre (marge droite) présente un exemple recommandé de contenu et d'activités

Le contenu de Un seul programme a été préparé pour les jeunes de 15 ans et plus, fréquentant l'école ou non. Les experts et décisionnaires voient cependant de plus en plus la nécessité d'entamer ce type d'éducation à de plus jeunes âges. La puberté et la jeune adolescence marquent un moment où les attitudes et comportements relatifs au genre s'ancrent plus distinctement et où les filles sont encore largement accessibles à travers le système d'enseignement formel. Les enseignants d'enfants de moins de 15 ans pourront s'inspirer du matériel présenté ici, en veillant bien sûr à tenir compte des exigences pédagogiques propres à une audience plus jeune. [Pour une liste des activités les plus propices et les mieux adaptées aux jeunes élèves, voir les premières pages du volume ACTIVITÉS. $]^{15}$

Enfin, Un seul programme : Guide et Activités est souple et adapté à de nombreuses cultures, en ce qu'il applique des principes universels aux diverses circonstances socioculturelles de la vie. Les éducateurs pourront bien sûr favoriser certaines sections par rapport à d'autres pour raisons culturelles ou politiques, ou selon les besoins particuliers de groupes spéciaux. Un panel de révision mondial a jugé Un seul programme utile à la conception de programmes d'enseignement adaptés aux besoins d'un large éventail de populations.
Exemple d'activités recommandées pour ceux disposant de moins de 14 heures de temps d'enseignement mais désireux d'inclure toute les unités :

unité 1 activité 4

unité 2 activités 5,9 (plus 7 ou 14)

unité 3 activités 18, 23

unité 4 activité 32

unité 5 activités 35, 36

unité 6 activités 41, 42, 44

unité 7 activité 50 (plus devoir en début d'activité 51) unité 8 activité $\mathbf{5 3}$ 


\section{Un seul programme : sommaire}

Ce double volume présente les éléments essentiels à une éducation et sensibilisation

à la sexualité et au VIH basée sur les droits, sensible au genre et participative.

\section{Volume 1: GU/DE}

Une introduction présentant un argument d'approche factuelle.

Sept unités de contenu (avec, chacune, Objectifs d'apprentissage, Contenu clé et Points de réflexion)

Une unité-projet finale (plaidoyer et application des leçons apprises).

22 fiches d'information

\section{Volume 2: ACTIVITES}

Méthodes d'enseignement efficaces

54 activités types

Ressources complémentaires

Les pages qui suivent décrivent brièvement les deux volumes. 


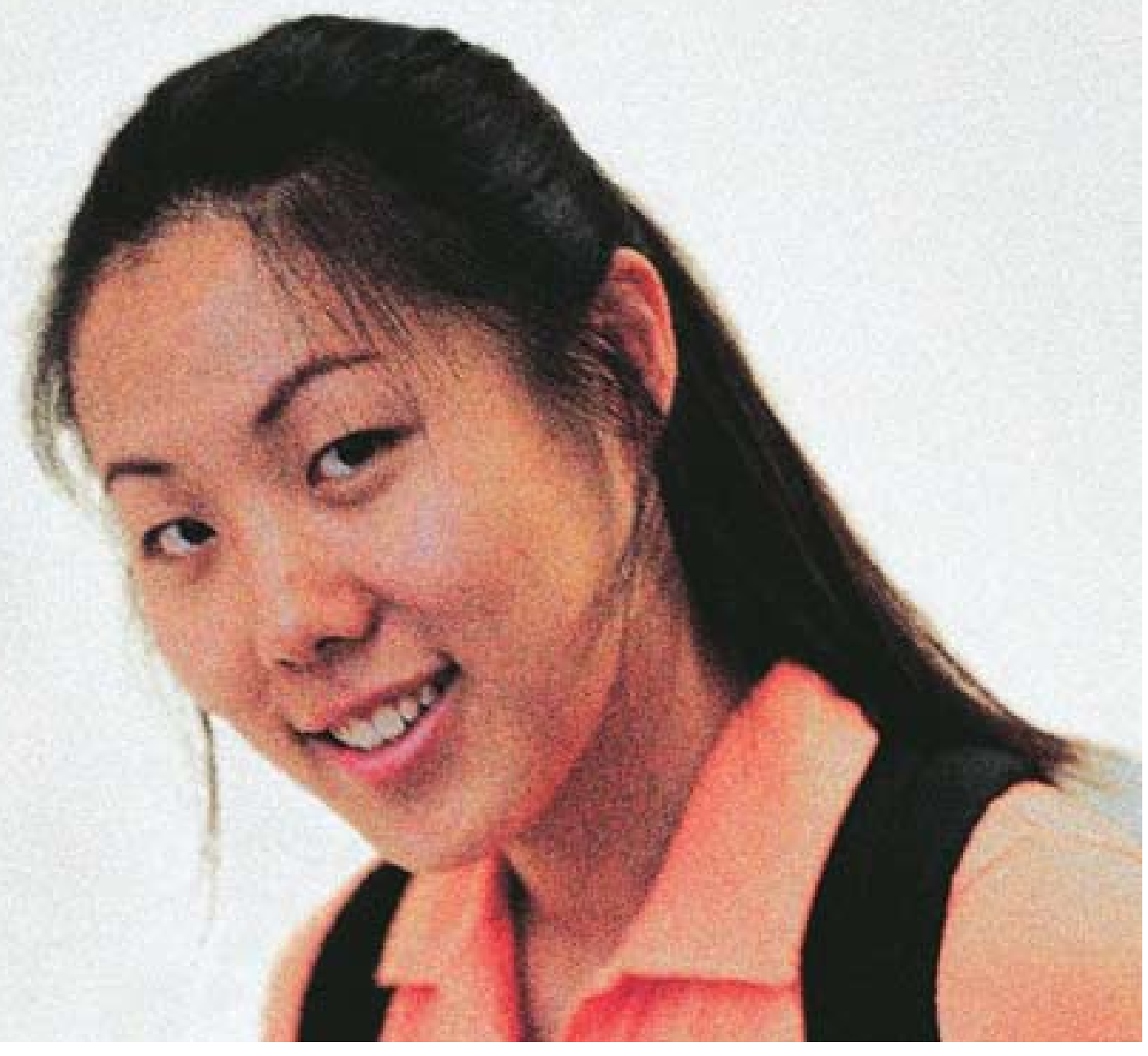

9 


\section{volume 1 : guide}

UNITÉS DE CONTENU : Les sept premières unités du GUIDE présentent l'information nécessaire à l'élaboration d'un programme qui intègre les thèmes du genre, des droits humains, de la sexualité, de la santé sexuelle et du VIH. Des « Points de réflexion » sont proposés en marge, pour illustrer la manière dont la matière peut servir à stimuler l'espritcritique des élèves, ainsi que pour aider l'enseignant à envisager le contenu de manière créative. Les encadrés orangés relient le contenu à des activités de classe intéressantes (décrites dans le volume compagnon companion ACTIVITÉS). Enfin, l'unité 8 présente le contexte et les directives de projets de plaidoyer et changement social.

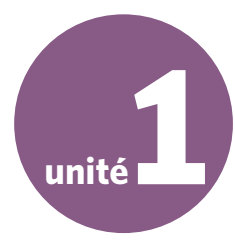

\section{DROITS HUMAINS SONT NÉCESSAIRES POUR LA SANTÉ SEXUELLE ET BIEN-ÊTRE}

Pour expliquer le rapport entre l'éducation à la sexualité et prévention du VIH et les droits humains, cette unité décrit le lien entre, d'une part, la santé sexuelle et le bien-être affectif et, d'autre part, la capacité pour la personne d'exercer ses droits fondamentaux (éducation, liberté d'expression, etc.) Ces droits incluent la protection de son corps, de sa sexualité et de sa santé. Ils doivent pouvoir être exercés avec confiance. Cette unité décrit comment les jeunes peuvent promouvoir le respect et protéger leur santé et leurs droits sexuels et génésiques comme ceux de leurs partenaires.

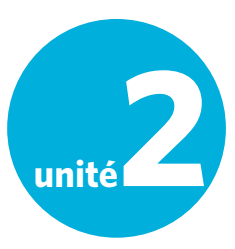

\section{LE GENRE}

Promouvoir l'égalité de genre est un impératif moral, au nombre des objectifs du Millénaire. Cette unité aide les enseignants à aborder efficacement la question du genre, pour les filles comme pour les garçons. Elle décrit le jeu des normes de genre dans la société (dans les relations familiales, à l'école, dans l'expérience de la violence, dans les médias et ailleurs) et explique l'effet des rôles de genre sur la sexualité et la santé sexuelle. Elle aiguise l'esprit critique des garçons et des filles et les mène à réfléchir utilement à leurs propres attitudes.

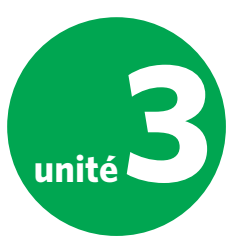

\section{LA SEXUALITÉ}

Cette unité aborde les aspects biologiques fondamentaux de la sexualité, mais elle souligne aussi ses bases sociales dans la vie humaine et la communauté. Elle examine l'effet des normes culturelles et de genre sur les attitudes, les pratiques, les expériences et le plaisir sexuels. Elle passe aussi en revue quelques préoccupations fréquentes au sujet de la vie sexuelle : le sentiment de pression à avoir des rapports non désirés ou non protégés, notamment.

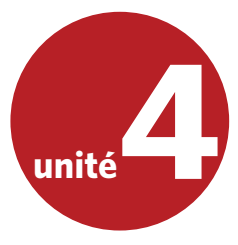

\section{LES RELATIONS INTERPERSONNELLES}

Le bien-être et la santé sexuelle dépendent de facteurs individuels aussi bien que d'influences sociales plus larges. Le but de cette unité est d'aider les adolescents à mieux comprendre leurs relations et à les aborder avec plus de confiance, par la réflexion et le renforcement de leur aptitude à communiquer. Elle se concentre tout particulièrement sur la gestion du maquis émotionnel des relations intimes et romantiques. 


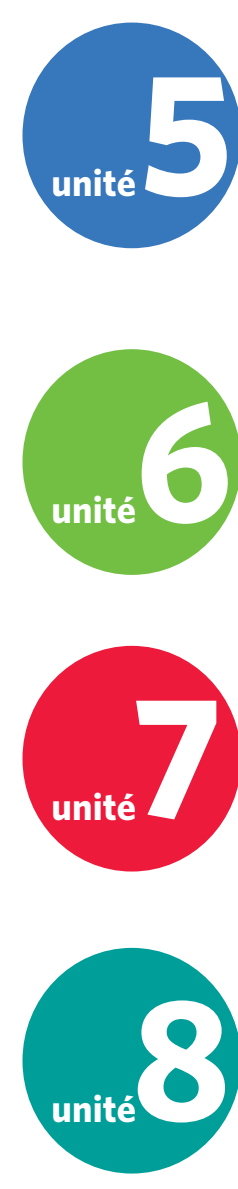

\section{APTITUDES À LA COMMUNICATION ET À LA DÉCISION}

Les personnes qui parlent de questions sexuelles avec leurs partenaires ont des relations plus satisfaisantes et jouissent d'une meilleure santé sexuelle. Les jeunes aiment apprendre comment parler de sujets intimes sans gêne et avec confiance. L'occasion leur en est cependant rarement donnée. Cette unité se concentre sur le renforcement de la communication, en particulier sur les questions de la sexualité, de la contraception et du VIH et sida. Elle comprend aussi une section sur la prise de décisions et leur mise en œuvre.

\section{LE CORPS, LA PUBERTÉ ET LA REPRODUCTION}

Comprendre leur corps habilite les jeunes à protéger leur santé et leur sexualité. L’unité 6 présente une information élémentaire généralement comprise dans les programmes scolaires d'éducation sexuelle, concernant la puberté, le corps et son fonctionnement, par exemple, mais dans l'optique, cette fois, du contexte social et des droits humains plutôt que dans celle plus étroite d'une simple description « clinique ».

\section{LA SANTÉ SEXUELLE ET GÉNÉSIQUE}

\section{( $y$ compris la prévention du VIH et la contraception)}

Cette unité se divise en deux parties. La première se concentre sur les infections sexuellement transmissibles, le VIH, le sida et les infections de l'appareil génital; la seconde, sur la contraception et l'avortement. L'accent est mis sur la prévention sanitaire tout au long de cette unité.

\section{PLAIDOYER POUR LA SANTÉ SEXUELLE, LES DROITS ET L'ÉGALITÉ DE GENRE}

Beaucoup de jeunes peuvent et désirent participer à la promotion du changement social en faveur d'un meilleur bien-être et d'une meilleure santé sexuelle, ainsi que d'une plus grande justice et égalité pour tous. Ce module guide les éducateurs, enseignants d'études civiques et sociales compris, dans les méthodes centrées sur l'apprenant propices à l'implication des jeunes dans leur communauté. Ces expériences pratiques viennent compléter et renforcer les connaissances acquises jusque-là. Elles apportent aux jeunes la satisfaction de voir comment ils peuvent faire une différence positive dans le monde.

\section{FICHES D'INFORMATION}

En fin de GUIDE, 22 fiches d'information sont proposées à titre de référence technique complémentaire sur certains sujets. Présentées par ordre alphabétique, ces fiches viennent renforcer l'information présentée dans certaines sous-rubriques des unités 1-7 du GUIDE (auxquelles elles font d'ailleurs clairement référence). 


\section{volume 2 : activités}

\section{MÉTHODES D'ENSEIGNEMENT EFFICACES}

Partout dans le monde, les programmes d'éducation à la sexualité et prévention du VIH sont souvent les premiers à recourir aux méthodes d'enseignement participatives. En faisant participer les jeunes activement à leur apprentissage, ces méthodes favorisent la réflexion personnelle, l'esprit critique et la discussion, tous propices à des attitudes plus égalitaires et au changement comportemental, y compris en matière de genre et de santé sexuelle. Plus largement, ces méthodes apprennent aux jeunes à aborder leur monde changeant avec confiance et imagination.

Aussi le volume ACTIVITÉS d'Un seul programme commence-t-il par une section consacrée aux approches pédagogiques interactives centrées sur l'apprenant. (Le GUIDE présente aussi quelques «Conseils à l'enseignant » au début de chaque unité). Ces ressources ne sauraient cependant se substituer à une formation et à un accompagnement adéquats des enseignants.

\section{ACTIVITÉS TYPES}

Le volume ACTIVITÉS propose 54 activités types correspondant au contenu spécifique du GUIDE (comme indiqué dans les encadrés orangés du GUIDE). Ces activités centrées sur l'apprenant ont été testées et peuvent être aisément adaptées d'une culture à l'autre. Elles peuvent aider les jeunes à établir le lien entre leur apprentissage et leurs propres expérienceset émotions. Elles sont conçues de manière créative et engageante pour les jeunes.

Les enseignants peuvent appliquer ces activités telles que présentées, ou bien les adapter ou en suivre l'exemple. La plupart sont adaptables aux situations où les apprenants ne savent ni lire ni écrire.

\section{RESSOURCES COMPLÉMENTAIRES}

Le volume ACTIVITÉS se termine par une liste de ressources techniques et matériels disponibles dans le monde. Chaque entrée inclut une brève description et les coordonnées d'accès à la ressource. 
Les décideurs et les organizations internationales préconisent une éducation à la sexualité, à la prévention du VIH et à la vie familiale basée sur les droits et l'équité de genre.

Un seul programme: Guide et Activités répond à leur appel. Tirant parti de la recherche sur les moteurs du comportement sexuel, il favorise l'épanouissement d'êtres réfléchis et sûrs d'eux, prêts à contribuer à l'établissement de sociétés justes et sensibles. 


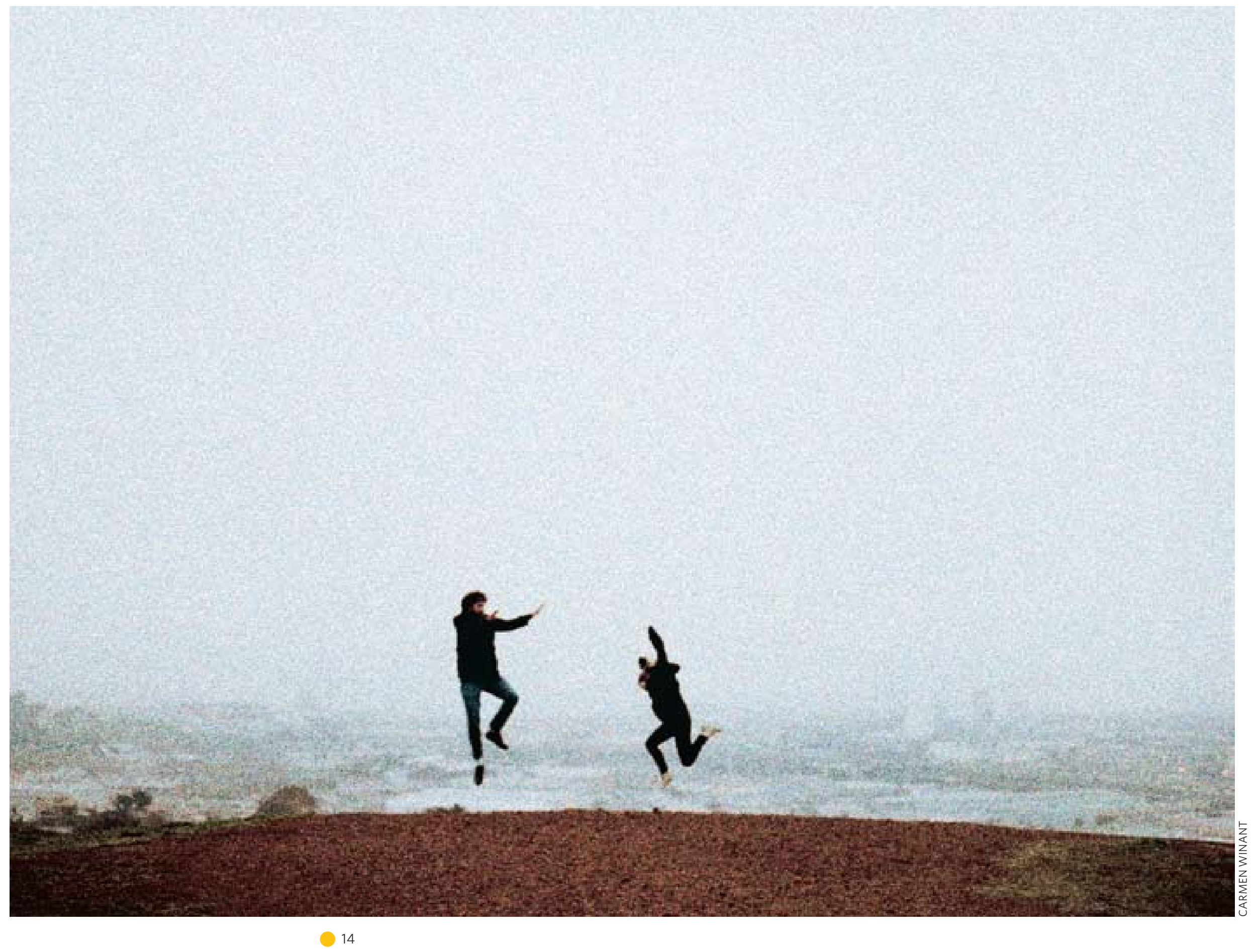




\section{NOTES}

$1<$ http://www.un.org/fr/millenniumgoals/>.

$2<$ http://data.unaids.org/pub/InformationNote/2008/20081031_ strategicframework_final_en.pdf> et <http://www.unaids.org/fr/ KnowledgeCentre/Resources/PolicyGuidance/OperationGuidelines/ gender_operational_guidelines.asp>.

$3<$ www.who.int/reproductive-health/strategy.htm>.

$4<$ http://portal.unesco.org/fr/ev.php-URL_ID=33618\&URL_DO=DO_ TOPIC\&URL_SECTION=201.html>. Aussi, voir des accents de I'UNESCO pour les droits humains et l'habilitation des femmes à l'éducation: <http://portal.unesco.org/fr/ev.php-URL_ID=33525\&URL_DO=DO_ TOPIC\&URL_SECTION=201.html>.

5 World Association for Sexual Health. 2008. Sexual Health for the Millennium. A Declaration and Technical Document. Minneapolis: World Association for Sexual Health.

6 Senderowitz, J. et D. Kirby. 2006. "Standards for curriculum-based reproductive health and HIV education programs." Arlington, VA: Family Health International/YouthNet.

7 Dans différents contextes, les programmes parlent de « dynamique de vie » ou d'éducation « à la vie familiale », « pour la santé » ou

« de la population ». Un seul programme aide les professionnels à développer leur programme (ou leurs plans de leçon) sous ces rubriques.

8 Ces droits humains ont reçu l'aval officiel de la plupart des nations et sont cités ailleurs dans ce document.

9 Dans ce document, l'expression « égalité de genre » signifie que tous les êtres humains - indépendamment de leur genre - sont égaux et on droit à un traitement égal. D'autres documents désignent ce concept pa |'expression d'« équité de genre ».

10 Dunkle, K., R. Jewkes, H. Brown, G. Gray, J. McIntyre et S. Harlow. 2004 "Gender-based violence, relationship power, and risk of HIV infection in women attending antenatal clinics in South Africa," The Lancet 363: 1415-1421; Jewkes, R., C. Vundule, F. Maforah et E. Jordaan. 2001. "Relationship dynamics and teenage pregnancy in South Africa," Social Science \& Medicine 52: 733-744; Karim, A.M., R. Magnani, G. Morgan et K. Bond. 2003. "Reproductive health risk and protective factors among unmarried youth in Ghana," International Family Planning Perspectives 29: 14-24; Koenig, M., I. Zablotska, T. Lutalo, F. Nalugoda, J. Wagman et R. Gray. 2004. "Coerced first intercourse and reproductive health among adolescent women in Rakai, Uganda," International Family Planning Perspectives 30: 156-163: Martin, S., L. Matza, L. Kupper, J. Thomas, M. Daly et S. Cloutier. 1999. "Domestic violence and sexually transmitted diseases: The experience of prenatal care patients," Public Health Reports
114: 262-268; Pleck, J.H., F.L. Sonenstein et L.C. Ku. 1993. "Masculinity ideology: Its impact on adolescent males' heterosexual relationships," Journal of Social Issues 49: 11-29; Pulerwitz, J. et G. Barker. 2008.

"Measuring attitudes toward gender norms among young men in Brazil: Development and psychometric evaluation of the GEM scale," Men and Masculinities 10(3): 322-338; Stephenson, R., M. A. Koenig, R. Acharya et T.K. Roy. 2008. "Domestic violence, contraceptive use, and unwanted pregnancy in rural India," Studies in Family Planning 39(3): 177-186; Zambrana, R.E., L.J. Cornelius, S.S. Boykin et D.S. Lopez. 2004. "Latinas and HIV/AIDS risk factors: Implications for harm reduction strategies," American Journal of Public Health 94(7): 1152-1158.

11 Voir, par exemple, Kirby, D., B. Laris et L. Rolleri. 2007. "Sex and HIV education programs: Their impact on sexual behaviors of young people throughout the world." Journal of Adolescent Health 40: 206-217. Kirby et coll. observent que deux tiers des programmes aboutissent sur I'autodéclaration d'un changement comportemental. Or, la plupart des évaluations de l'effet d'un programme d'éducation sexuelle/VIH sur les issues de santé sexuelle (taux de grossesses non planifiées ou IST) ne font pas état d'un impact statistiquement significatif.

12 DiClemente, R., G. Wingood, E. Rose, et al. 2009. "Efficacy of sexually transmitted disease/human immunodeficiency virus sexual riskreduction intervention for African American adolescent females seeking sexual health services: A randomized controlled trial," Archives of Pediatrics and Adolescent Medicine 163(12): 1112-1121; Haberland, N. 2010. "What happens when programs emphasize gender? A review of the evaluation research." Présenté à I'UNFPA Global Consultation on Sexuality Education, 30 novembre-2 décembre, Bogotá, Colombia; Jewkes, R., M. Nduna, J. Levin, et al. 2008. "Impact of Stepping Stones on incidence of HIV and HSV-2 and sexual behaviour in rural South Africa: Cluster randomized controlled trial," British Medical Journal 337:a506, doi: 10.1136/bmj.a506; Pulerwitz, J., G. Barker, M. Segundo et M. Nascimento. 2006. "Promoting more gender-equitable norms and behaviors among young men as an HIV/AIDS prevention strategy," HORIZONS Final Report. Washington, DC: Population Council.

13 Les OMD forment une liste de huit objectifs (dont réduire l'extrême pauvreté et la faim, assurer l'éducation primaire pour tous, promouvoir l'égalité des sexes et l'autonomisation des femmes et améliorer la santé maternelle) adoptés par l'Assemblée générale de l'ONU. Les $\mathrm{OMD}$ engagent la communauté internationale à adopter une vision plus large du développement et sont généralement acceptés en tant qu'échelle de mesure des progrès de développement réalisés.

14 Voir les notes 1 à 5

15 Suivant la demande, une version distincte pourra être adaptée à l'enseignement d'élèves plus jeunes. S'adresser à ce sujet aux éditeurs. 


\section{DROITS HUMAINS}

SONTNECESSAIRES

POUR LA SANHE

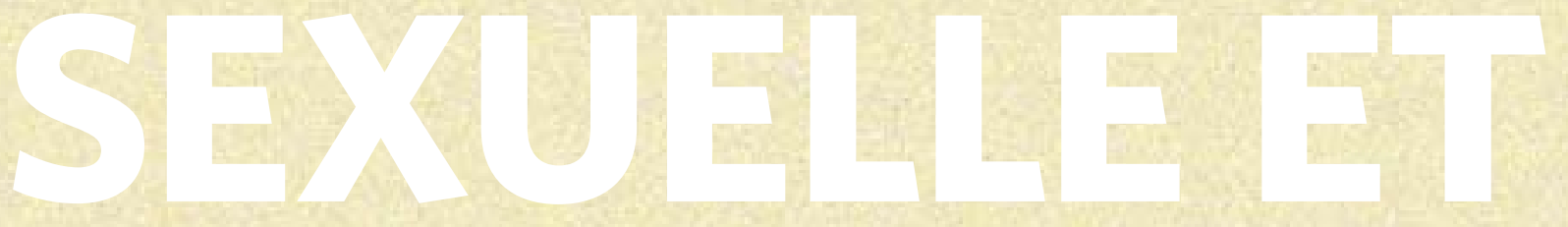

LEBIEN- ETRE 


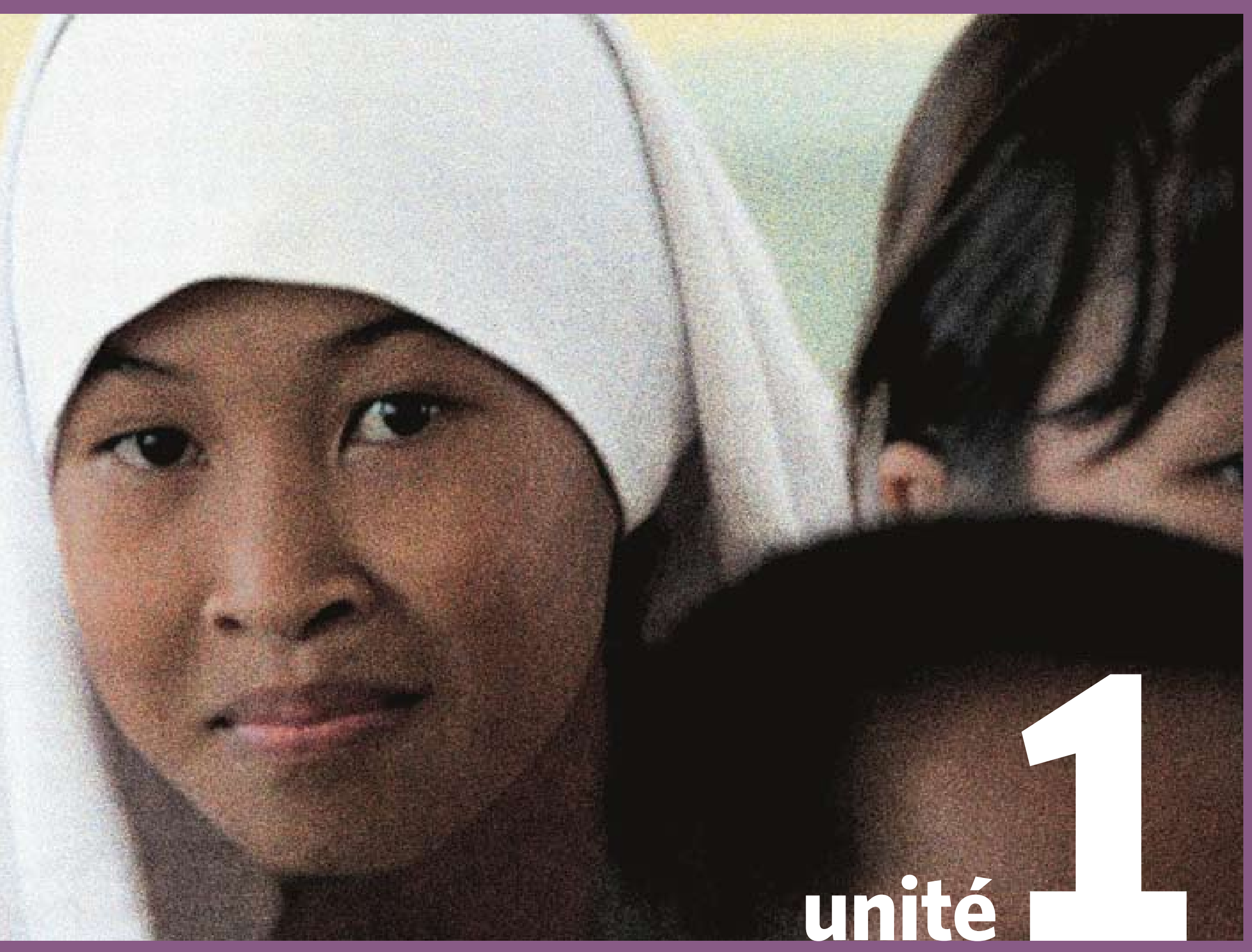




\section{panorama}

Il importe de parler des droits humains dans l'éducation à la sexualité et prévention du VIH car, pour vivre une vie sexuelle satisfaisante et sans risque, les jeunes doivent jouir de leurs droits fondamentaux : à la dignité, à la sécurité physique et à l'accès à l'information et aux services de santé, notamment. Seules les personnes aptes à exercer ces droits peuvent véritablement choisir d'avoir ou non des rapports sexuels, négocier l'usage du préservatif et la pratique contraceptive et obtenir les services dont elles ont besoin. La promotion des droits sexuels et génésiques responsabilise aussi les jeunes quant à la protection du bien-être et des droits d'autrui. Malheureusement, des centaines de millions d'êtres, jeunes surtout, restent vulnérables aux rapports sexuels forcés (et au risque dès lors accru de contraction du VIH ou de grossesse), à la violence, au mariage d'enfants et à l'opprobre jeté sur leur comportement sexuel. La violation des droits de la personne mine sa capacité de sexualité satisfaisante et sans risque toute sa vie durant.

Au courant des droits humains, les jeunes savent qu'ils comptent dans le monde. Cette unité présente un aperçu des droits sexuels et des droits humains, en ce qu'ils sont liés au vécu sexuel et à la santé sexuelle. 


\section{DROITS HUMAINS SONT NÉCESSAIRES POUR LA SANTÉ SEXUELLE ET LE BIEN-ÊTRE}

Les concepts des droits humains et des droits sexuels sont internationalement reconnus. Ils s'appliquent à toutes les régions du monde : Afrique, Amériques, Asie, Europe, monde arabe et Pacifique. Leur sens et leur implication sur la vie de la personne sont cependant souvent incompris. Ces quelques pages vous aideront à vous familiariser sur la question.

Attention à vos propres préjugés. Ne manquez pas d'évaluer les bases de votre opinion d'autrui.

N'oubliez pas que les droits humains s'appliquent à tous les êtres humains. Ils sont inaliénables. Certaines personnes ne peuvent cependant pas en jouir pleinement.

Soulignez que les êtres humains ont aussi des responsabilités, y compris le respect des autres et des droits de tous.

Présentez honnêtement la manière dont les institutions sociales (clubs sociaux, organisations religieuses, etc.) font parfois fi des droits de la personne ou admettent la discrimination.

Effectuez quelques recherches pour identifier les violations des droits humains relatives à la sexualité dans votre pays (mariage forcé, violence sexuelle ou situation des personnes vivant avec le $\mathrm{VIH}$ et sida, par exemple).

Présentez des exemples concrets (tirés des activités proposées dans le volume ACTIVITÉS ou de votre propre environnement). Les situations réelles peuvent aider les jeunes à comprendre que les droits humains ne sont pas seulement une idée abstraite.

En parlant des droits humains, aidez vos élèves à apprécier leur pouvoir et à comprendre qu'ils comptent dans le monde !

Plusieurs fiches d'information, en fin de volume, présentent ces sujets en plus de détails. 


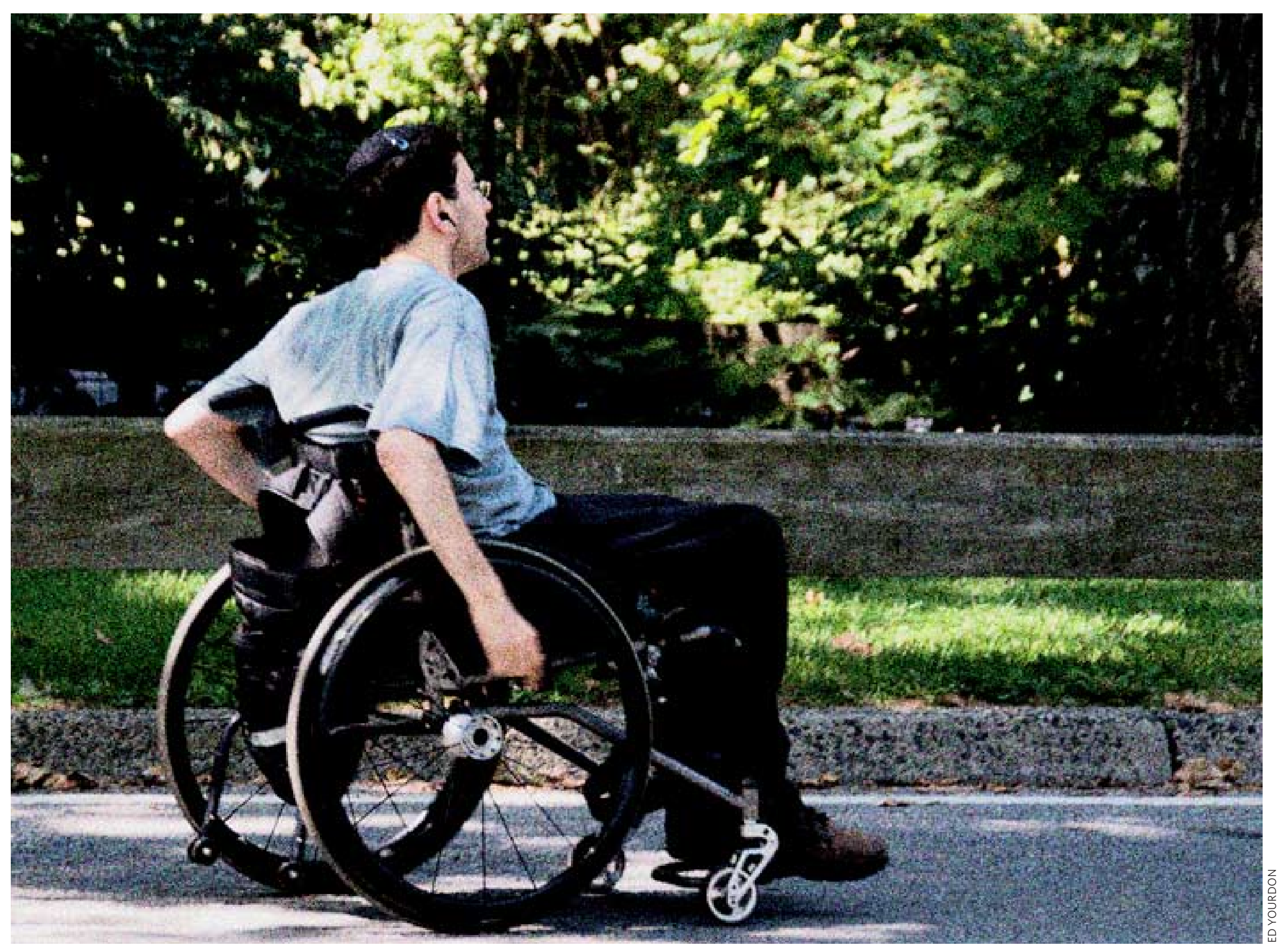




\section{DROITS HUMAINS SONT NÉCESSAIRES POUR LA SANTÉ SEXUELLE ET LE BIEN-ÊTRE}

Le matériel couvert dans cette unité prépare les élèves à :

\section{Objectifs cognitifs}

Identifier cinq droits fondamentaux, y compris deux de nature sexuelle ou génésique.

Discuter au moins deux circonstances propices à l'exercice des droits sexuels ou génésiques de la personne, et deux situations adverses. Expliquer en quoi ces situations peuvent affecter la santé sexuelle ou génésique.

Décrire un changement de loi ou politique affectant la vie sexuelle ou génésique de l'individu. Identifier une personne ou organisation à qui s'adresser pour la défense de droits sexuels ignorés.

Discuter, pour au moins deux droits, les responsabilités de protection, respect et assurance imputables à l'État, et les responsabilités imputables à l'individu.

\section{Objectifs affectifs}

Comprendre l'importance du respect dans les relations humaines, y compris romantiques et sexuelles.

Discuter leurs propres sentiments concernant l'équité du traitement inégal de certaines personnes.

Discuter leurs propres sentiments et attitudes concernant la violation d'un droit sexuel ou génésique qui leur paraît important et les conséquences de cette violation.

Décrire ce qu'ils considèrent être, pour eux-mêmes, une vie épanouie et satisfaisante.

\section{Objectifs de compétences}

Exprimer efficacement leurs idées sur l'égalité, la discrimination et d'autres aspects des droits humains. 


\section{comment nous nous traitons les uns les autres : valeurs et société}

On peut poser bien des questions sur la manière dont nous nous traitons les uns les autres dans la société. Ces questions s'appliquent à toutes les régions du monde. Certaines sont posées ici.

1 À quoi aspirent la plupart des gens, y compris les jeunes?

- La plupart des jeunes aspirent à une bonne qualité de vie, parfois appelée «bien-être».

- Le bien-être, c'est la chance de vivre heureux et en bonne santé ; la possibilité de vivre en sécurité et d'être respecté ; l'occasion de grandir et d'apprendre ; le désir de compter dans le monde, de poursuivre nos rêves et de vivre ensemble et en paix. Pour nous-mêmes, pour nos familles et pour nos communautés.

- La santé et le bien-être sexuels sont un aspect important du bien-être dans son ensemble.

\section{POINTS DE RÉFLEXION}

Le droit au bonheur et de pour suivre ses rêves appartient-il à tout le monde?

Qu'une personne « compte » pour les autres, ça veut dire quoi?

Quelle est notre responsabilité de traiter les autres avec respect?

Pour qui, la sécurité ?

Faut-il donner une voix égale à tous dans l'établissement des lois?

Ressources égales pour tous?

À qui le droit de décider de la protection de son corps ou de son avenir?

Ces questions s'appliquent aussi à la vie intime et sexuelle.
Q $\mathbf{2}$ Comment vivre ensemble - dans nos familles, nos communautés et nos sociétés - pour assurer à chacun et chacune la chance d'une bonne qualité de vie et de bien-être? 
3 D'où nous viennent nos idées sur la manière de nous comporter et de traiter les autres? Où apprend-on nos responsabilités vis-à-vis les uns des autres?

- Nous avons chacun nos idées de ce qui est juste ou non. Ces croyances incluent nos valeurs et attitudes à l'égard du corps, de la sexualité et des relations intimes.

- Nos propres valeurs et croyances nous paraissent souvent « naturelles». Elles sont cependant profondément influencées par nos familles, nos communautés et la société.

- Ces attitudes familiales, communautaires et sociétales sont nos «normes sociales» [voir le glossaire].

- Les sociétés adoptent des lois qui reflètent ces normes et précisent les comportements admis ou non. Les individus ou groupes qui détiennent le plus de pouvoir sont souvent les plus influents dans la détermination des normes sociales et des lois. Certaines lois, normes et valeurs individuelles ont trait à la sexualité.

- Les normes sociales évoluent dans le temps. Elles varient aussi d'une culture à l'autre.

- Nous sommes tous sous l'influence des normes sociales, mais chacun d'entre nous peut aussi développer ses propres pensées concernant la manière la plus juste de se comporter et de traiter les autres. Nos idées nous viennent de nombreuses sources : exemples à suivre, livres et réflexion individuelle.

4 Certains principes d'éthique sur la manière de nous traiter les uns les autres sont considérés universels : on les appelle les droits humains.

[Voir la section suivante.]

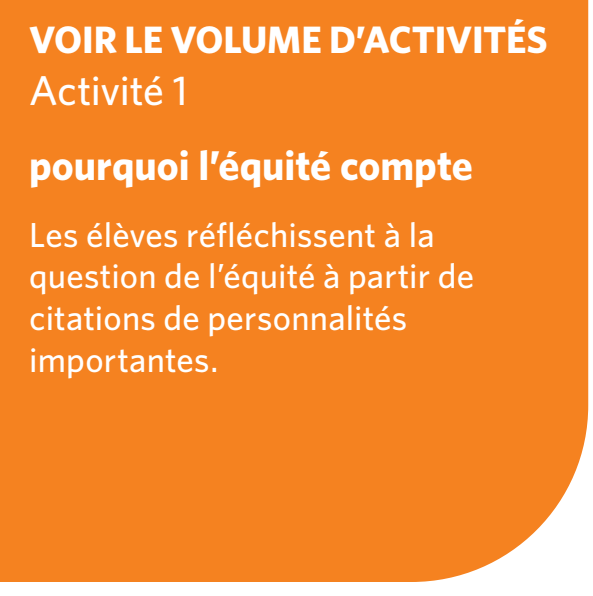

Voir le glossaire en fin d'unité pour une simple introduction aux concepts et termes clés. 


\section{qu'entend-on par « droits humains ॥ ?}

VOIR LE VOLUME D'ACTIVITÉS Activité 2

introduction aux droits humains

Les élèves dressent une liste de droits pour un nouveau pays et les comparent à la Déclaration universelle des droits de l'homme. Ils interviewent des adultes sur le sens des « droits humains ».

VOIR LE VOLUME D'ACTIVITÉS Activité 3

pouvoir, privilège et égalité

Les élèves réfléchissent au rapport entre le pouvoir social et le privilège ou la discrimination.
1 À chaque être humain reviennent certains droits et protections fondamentaux.

Notamment :

- le droit à un traitement égal devant la loi ;

- le droit à la nourriture, à l'eau, à un logement et à l'habillement ;

- le droit d'être traité avec respect et dignité ;

- la protection contre la torture ;

- la liberté d'expression;

- la liberté de pensée, de conscience et de religion;

- le droit de réunion et de participation à la société ;

- le droit à l'éducation ; et

- le droit à la santé, y compris l'accès à l'information et aux services.

2 Ces droits sont universels : ils s'appliquent à chacun d'entre nous, quels que soient notre sexe, âge, état matrimonial, identité ou comportement sexuel, identité de genre, race, ethnicité, origine nationale ou sociale, convictions politiques, citoyenneté, croyances religieuses, condition sociale ou économique, lieu de résidence, capacité physique et mentale ou état de santé. Ces droits sont inconditionnels et inaliénables.

- On entend souvent parler des droits humains, dans les discussions concernant la torture, notamment.

- Les droits humains couvrent aussi les droits économiques et sociaux, comme le droit à l'éducation et aux soins de santé. Ils s'étendent aussi à certains droits sexuels et génésiques précis. 
3 Les droits humains ont été reconnus par la communauté mondiale des nations (à I'ONU). Ils font l'objet d'accords internationaux formels ratifiés par la plupart des gouvernements. ${ }^{2}$

[Voir la fiche d'information sur les Accords de l'ONU.]

4 Les droits humains s'appliquent aux enfants. Leurs droits spécifiques ont été établis dans des accords internationaux tels que la Convention internationale des droits de l'enfant (CIDE - applicable à tous les jeunes de moins de 18 ans).

5 Tous les êtres humains ne jouissent malheureusement pas toujours de leurs droits.

6 La protection, le respect et l'assurance des droits humains incombent en partie aux gouvernements. En réalité, les pays n'assument cependant pas tous cette responsabilité dans une mesure égale.

Certains gouvernements adoptent des lois qui limitent les droits de certaines personnes, par exemple,

- en rendant illégale toute protestation politique ;

- en interdisant l'organisation syndicale ;

- en criminalisant l'activité homosexuelle entre adultes consentants; et

- en pardonnant ou en traitant avec indulgence le meurtre d'une femme ou d'une fille par son partenaire masculin ou par un membre de sa famille qui y perçoit une question d'« honneur ».

2 Principaux documents obligatoires sur les droits humains: Pacte international relatif aux droits économiques, sociaux et culturels (PIDESC, 1966) Pacte international relatif aux droits civils et politiques (PIDCP, 1966); Convention sur l'élimination de toutes les formes de discrimination à l'égard des femmes (CEDF, 1979); Convention internationale des droits de l'enfant (CIDE, 1989). Non exécutoire : Déclaration universelle des droits de I'homme (DUDH). Pour un exemplaire de la DUDH, voir l'Activité 2 dans le second volume. [Références aux droits particuliers dans les sections pertinentes des unités 1 à 7.$]$

\section{POINTS DE RÉFLEXION}

Quels sont les droits communs aux enfants (et adolescents) et aux adultes?

Quels autres droits faut-il honorer pour les enfants précisément parce qu'ils sont encore enfants ? Par exemple, quelles chances fondamentales faut-il leur assurer pour qu'ils soient heureux ?

Quelles occasions faut-il donner aux enfants pour qu'ils aient une meilleure chance de vie épanouie? Les enfants courent-ils des risques contre lesquels ils devraient être protégés?

En quoi la capacité et la responsabilité de comprendre et de protéger ses propres droits et ceux des autres se développent elles tandis que l'enfant mûrit? Donnez-en un ou deux exemples. 
7 La condition sociale et économique limite parfois les droits de l'individu.

Par exemple, la nationalité, le sexe, la race, la religion, l'âge, la classe/caste, les opinions politiques, l'identité sexuelle, l'état VIH ou la capacité physique ou mentale influencent généralement la possibilité de :

- s'instruire et de bien gagner sa vie ;

- bénéficier d'un traitement égal et juste devant la loi ;

- vivre à l'abri de la violence ;

- être traité avec respect et dignité ; et

- croire en ses rêves et les réaliser.

\section{II incombe à chacun de respecter les droits des autres. ${ }^{3}$}

- Quand on grandit dans le respect égal de chaque être humain, on apprend à respecter les droits humains.

- Souvent, quand on grandit dans le négativisme à l'égard de certains groupes de personnes, on finit par les traiter injustement et à leur refuser leurs droits.

- On attache parfois certaines caractéristiques à un certain groupe d'êtres humains, par «stéréotype ».

Par exemple : les garçons sont naturellement plus forts en maths que les filles; certains groupes sont paresseux ou manquent d'hygiène. Les stéréotypes présentent généralement une image inexacte ou faussée. Ils nous font voir les autres comme moins humains et facilitent l'acceptation de leur traitement injuste.

- Les caractéristiques personnelles de certains leur font subir une désapprobation sociale profonde : c'est l'opprobre. Dans certains contextes, l'opprobre peut frapper une personne pour des raisons de poids, de comportement sexuel, de religion, d'état de santé ou même de manque d'aptitude sportive.

- Quand une personne est traitée injustement en raison de son identité présumée (ou connue), on parle de " discrimination ». La discrimination est contraire aux droits humains. Elle est pourtant présente dans les familles, à l'école, au travail, dans la communauté et dans la société au sens large.

- La discrimination n'est pas seulement une question individuelle. Certains gouvernements et systèmes sociaux (tels que les écoles, les religions ou le marché de l'emploi) discriminent aussi.

- Quoi que nous pensions personnellement, il nous incombe à tous de respecter universellement les droits humains. 


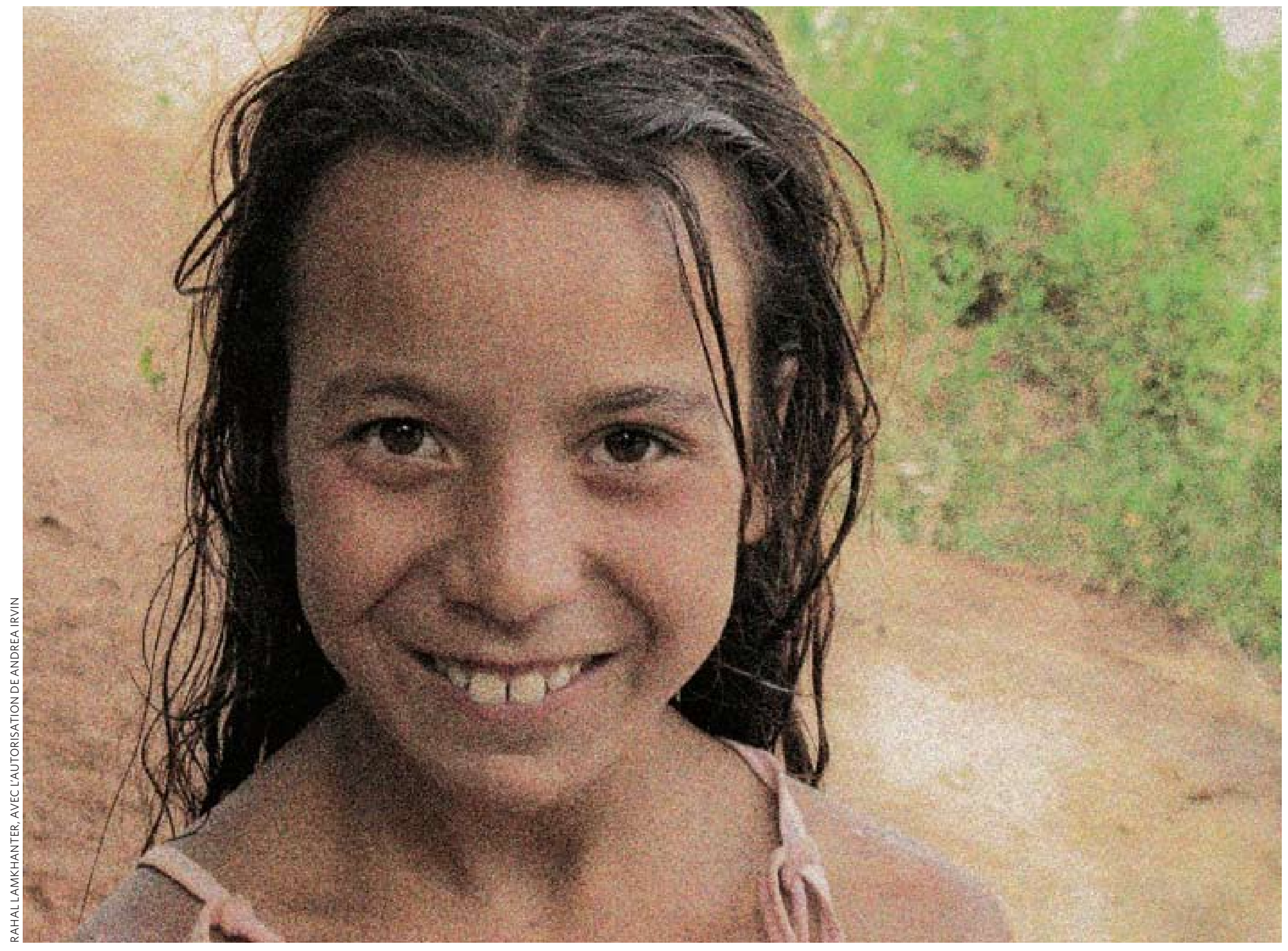




\section{droits sexuels et génésiques}

1 La vie amoureuse et sexuelle peut être une question de droits humains. Le respect de nos droits fondamentaux (par le gouvernement comme par autrui) est la clé ultime de nos choix intimes, sexuels et de procréation.

Par exemple :

- Chaque personne peut décider si, quand et avec qui elle aura une relation amoureuse et contractera une relation à long terme ou un mariage. Elle peut éviter d'être mariée trop jeune ou contre son gré. Elle peut aussi choisir d'avoir une relation intime avec une personne du même sexe.

- Elle peut décider si, quand, avec qui et dans quelles circonstances elle désire avoir des rapports sexuels (libres de toutes contraintes et violences). Elle peut négocier l'usage du préservatif et choisir un partenaire du même sexe.

- Elle peut décider si ou quand elle désire avoir des enfants, obtenir une information et des services contraceptifs, se faire avorter sans risque et adopter un enfant indépendamment de son état matrimonial et de son identité sexuelle.

2 Quand les droits humains ont trait à la sexualité ou à la reproduction, on parle de " droits sexuels » ou « droits génésiques ».

- Les droits sexuels et génésiques se chevauchent parfois. Les premiers concernent généralement plus le contrôle de l'individu sur son activité sexuelle et sa santé sexuelle, tandis que les seconds touchent généralement plus aux questions de contrôle de sa propre fécondité et procréation.

- Le consentement entre adultes est l'un des principes fondamentaux des droits sexuels et génésiques. L’accès à l'information et aux services est essentiel aussi.

- Beaucoup de ces droits sont reconnus dans les accords internationaux. ${ }^{4}$

4 Par exemple : la Convention sur l'élimination de toutes les formes de discrimination à l'égard des femmes (CEDF), le Programme d'action de la Conférence internationale sur la population et le développement (CIPD) et le Programme d'action de la quatrième Conférence mondiale sur les femmes (QCMF).
3 Les droits sexuels et génésiques s'appliquent aussi aux jeunes.

- Les enfants ont le droit de développer un sens positif de leur corps et de leur sexualité, à l'abri des sévices et des attouchements.

- Pour aider les enfants plus jeunes dans leurs décisions, la direction et les conseils d'adultes bienveillants doit tenir compte de leur intérêt, de même que de leur aptitude à exercer eux-mêmes leurs droits.

- Les droits et responsabilités des enfants évoluent à mesure du développement de leurs capacités.

- Les jeunes ont droit à l'information qui leur permette de protéger leur santé, sexuelle et génésique comprise. 
4 Dans le monde réel, beaucoup d'obstacles s'opposent à l'exercice des droits sexuels et génésiques des hommes et des femmes. Les conséquences sont souvent graves.

- Des millions de personnes subissent des violences sexuelles (rapports sexuels forcés, non consensuels ou imposés sous la menace de violence, notamment). [Voir aussi l'unité 2, pp. 70-71, et l'unité 3, pp. 106-107.]

- La violence sexuelle n'épargne personne, dans les deux sexes. Les filles et les femmes la subissent cependant de manière disproportionnée.

- La violence sexuelle intervient dans bien des contextes : au foyer, de même que dans les établissements tels que les prisons, les camps de réfugiés, les maisons de culte, les maisons de prostitution et les écoles mal surveillées.

- La pauvreté accroît souvent pour les jeunes (filles surtout) le risque de rapports sexuels non désirés, forcés ou non protégés. Les jeunes vivant dans la pauvreté échangent plus souvent leurs faveurs sexuelles pour survivre.

- Les filles vivant dans la pauvreté courent un plus grand risque de mariage précoce ou forcé, de grossesse non désirée, d'avortement non médicalisé et de trafic sexuel (déplacement forcé de personnes à des fins d'exploitation sexuelle).

[Voir la fiche d'information sur le Trafic sexuel.]

- Certains partenaires sexuels (y compris ceux qui paient en argent ou cadeaux) refusent de porter un préservatif.

- Certaines personnes souffrent d'opprobre, de honte, de peur ou de violence parce que leur identité sexuelle (ou leur comportement) n'est pas conforme aux normes sociales. Par exemple, celles perçues comme étant homosexuelles ou adoptant une identité de genre différente (les transsexuels) peuvent en subir les effets.

- La violence physique est fréquente à l'encontre des femmes enceintes dans certains contextes.

- Dans certains contextes, les filles subissent l'excision. [Voir la fiche d'information sur la Mutilation génitale des filles.]

- La discrimination est rampante à l'encontre de ceux qui cherchent à obtenir une information et des services de santé sexuelle, surtout quand ils sont jeunes ou qu'ils vivent avec le VIH et sida.

5 Ces obstacles économiques et sociaux et ces violations sont malheureusement si courants qu'ils en sont excusés, négligés ou culturellement admis. Ils peuvent prendre différentes formes suivant la région ou le pays.

6 Pour être maîtres de notre corps et le protéger, nous devons tous être traités avec respect et dignité : chaque être humain y a droit. 


\section{POINTS DE RÉFLEXION}

Nos attitudes sur les rôles de genre affectent notre comportement et notre santé sexuels.

La recherche montre que les jeunes qui croient aux rôles de genre « traditionnels » (les garçons doivent être durs et les femmes, soumises aux hommes, par exemple) tendent à avoir plus de problèmes de santé sexuelle. Ils utilisent moins le préservatif et la contraception. Ils sont plus souvent associés à la violence intime. Le $\mathrm{VIH}$ et les grossesses non planifiées sont plus courants dans les relations à haute domination masculine. De même, la violence aux mains d'un partenaire intime est liée à de plus hauts taux d'IST, de VIH et de grossesse non désirée. ${ }^{5}$

Par contre, les personnes aux idées plus « ouvertes » sur les rôles de genre et l'égalité sont moins associés à ces conséquences et présentent généralement de meilleurs bilans de santé sexuelle.

Comment expliquer ces conséquences?

5 Pleck et al., 1993 ; Martin et al., 1999; Jewkes et al., 2001; Karim et al., 2003 ; Dunkle et al., 2004 ; Koenig et al., 2004 Zambrana et al., 2004 ; Stephenson et al. 2006 ; Pulerwitz et Barker, 2008.
7 Tout le monde a le droit de savoir ce qui affecte son vécu, sa santé et ses sentiments sexuels. En particulier, les jeunes bénéficient de l'occasion de réfléchir à ces questions et de les discuter en profondeur. Ils sont dignes d'apprendre à opérer des choix éclairés. Nous avons tous le droit de jouer un rôle dans notre propre bien-être.

Ces énoncés touchent aux questions suivantes :

- les normes et les rôles de genre ;

- les droits humains, en particulier sexuels et génésiques;

- les responsabilités qui incombent à l'État, et à chaque personne, d'honorer ces droits ;

- le corps humain et la sexualité (y compris la puberté et la reproduction, l'intimité et le plaisir, les moyens d'éviter ou d'interrompre une grossesse non planifiée et l'information relative au VIH et au sida);

- le bien-être grandissant à l'égard de son corps et de ses propres valeurs changeantes; et

- le renforcement de notre aptitude à agir en notre nom propre et au nom de nos familles et communautés.

8 Apprendre ce que sont ses droits et être capable de les exercer peut produire un effet bénéfique considérable sur la santé sexuelle et génésique. 


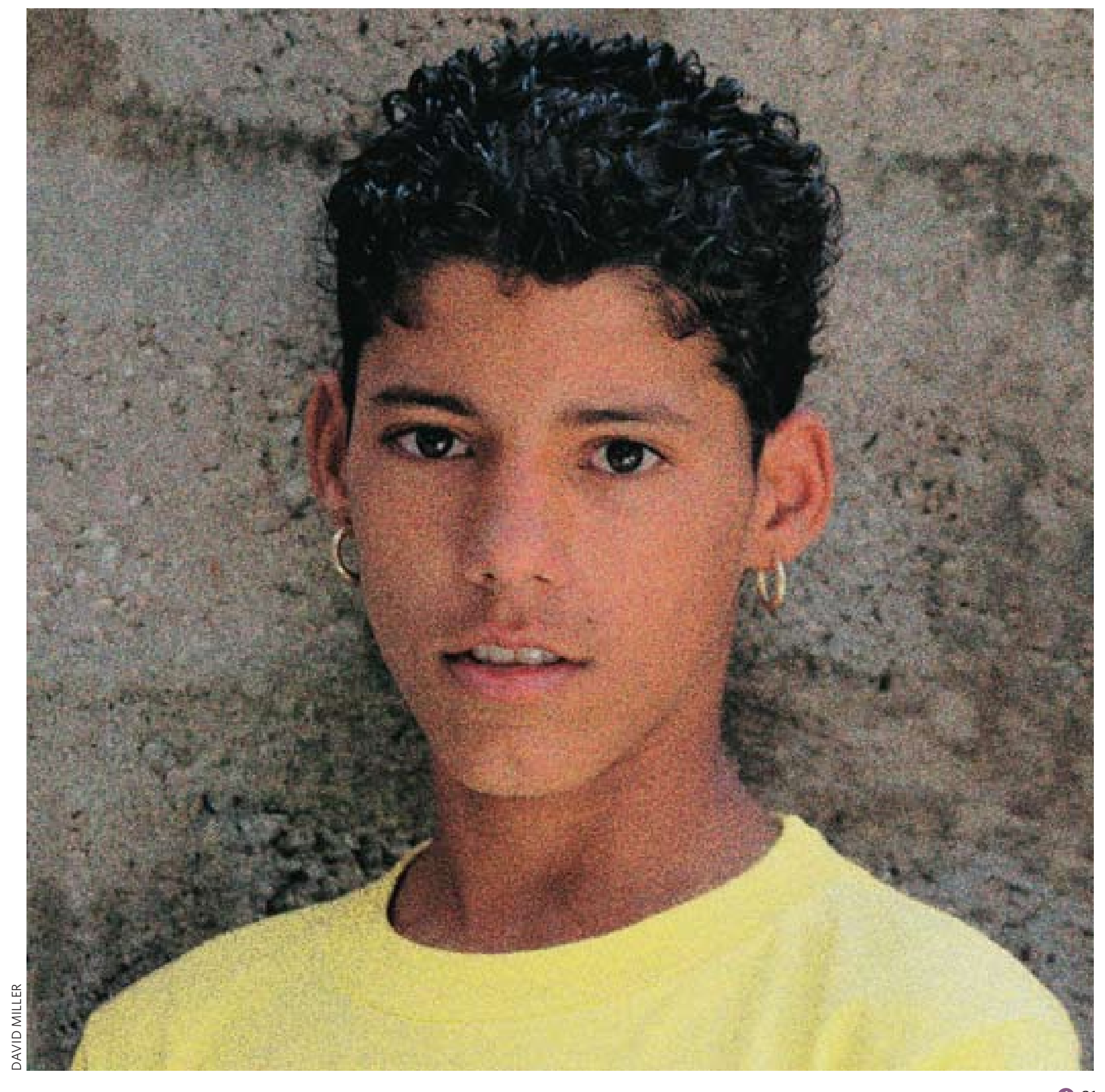

VOIR LE VOLUME D'ACTIVITÉS Activité 4

études de cas sur les droits sexuels et génésiques

Les élèves analysent et discutent des histoires vraies de violation des droits sexuels et génésiques. 


\section{promotion des droits humains, droits sexuels et génésiques compris}

\section{POINTS DE RÉFLEXION}

Pensez à vos propres valeurs et à l'équité dans votre vie.

À quoi aspirez-vous et de quoi avez-vous besoin ? Qu'aimezvous? Quelles sont vos valeurs? Qu'admirez-vous chez les autres? Que voulez-vous devenir, quels sont les obstacles à surmonter et comment?

Avez-vous des préjugés stéréotypés envers certains groupes?

Il peut être difficile de confronter ses préjugés. Mais chacun a en soi la capacité de réfléchir, de mûrir et de changer - pour se sentir, finalement, plus à l'aise avec soimême et avec autrui.

Avez-vous vécu une violation de vos droits ou été témoin de celle des droits de quelqu'un d'autre?

Est-il facile ou difficile de dénoncer les violations des droits humains? En quoi est-ce difficile et comment pourrait-on rendre la tâche plus simple?

\section{(๑) 1 L'équité et les droits humains importent pour beaucoup.}

2 II est possible de promouvoir l'équité et les droits humains dans la vie de tous les jours, y compris dans le contexte sexuel et génésique.

- En défendant un ami traité injustement, ou bien un camarade de classe ridiculisé parce qu'il est perçu comme étant homosexuel, ou une fille expulsée parce qu'elle est enceinte, ou encore un enseignant victime de discrimination parce qu'il est atteint du VIH ou du sida.

- En aidant les autres à comprendre qu'il y a dans la vie des occasions et des choix autres que ceux qui leur sont présentés : en aidant quelqu'un à résister à un mariage non consensuel ou aux pressions d'un gang, etc.

- En identifiant les personnes (ou organismes) de confiance capables de faire face à la discrimination.

3 II est possible de promouvoir l'équité et les droits humains dans nos communautés, y compris dans le contexte sexuel et génésique. On peut agir tantôt seul, tantôt dans le cadre d'une organisation.

- En accompagnant un ami ou une amie se rendant chez le directeur de l'école, à la police, dans une clinique de santé, etc.

- En parlant à nos connaissances des droits humains et des sujets qui nous sont chers.

- En invitant un leader local à s'élever contre un problème tel que la violence familiale.

- En veillant à ce que chacun et chacune (y compris soi-même) soient au courant des droits humains et comprennent que chacun et chacune comptent dans la communauté. 
Voir l'unité 8 pour plus de détails sur le passage à l'action.

4 II est possible de se joindre aux organisations et groupes qui défendent les droits sexuels et génésiques selon différentes approches.

Par exemple :

- marches contre les crimes haineux ;

- projets d'art dramatique pour adolescents sur la vie des sidéens;

- campagnes de sensibilisation communautaire à la mutilation génitale des filles ; et

- groupes de suivi et d'intervention communautaire contre la violence familiale, par exemple.

5 Certaines organisations préconisent aussi l'adoption de lois sur la protection des droits humains - droits sexuels et génésiques compris - pour les membres les plus marginalisés ou les plus vulnérables de la société surtout. Ce type d'organisation existe dans presque tous les pays.

Exemples de lois (relevant parfois aussi d'une juridiction religieuse) :

- assurer le droit de vote de chaque citoyen;

- proscrire le travail des enfants et assurer la sécurité des travailleurs ;

- protéger les membres de la communauté contre la brutalité policière ;

- criminaliser les délits « haineux » (menaces et violences basées sur l’identité d’une personne);

- assurer l'accès physique aux espaces publics, y compris pour les personnes handicapées ;

- proscrire la violence à l'encontre des femmes (en dehors comme au sein du mariage) ;

- assurer les droits des femmes au sein du mariage ;

- garantir les droits d'héritage des veuves ;

- proscrire les mariages d'enfants ;

- criminaliser le trafic sexuel; et

- protéger le droit de chacun de former une union civile, contracter mariage ou fonder une famille, avec une personne du même sexe ou de sexe opposé. 


\section{Certaines organisations œuvrent pour les droits humains au niveau mondial.}

Par exemple :

- Elles cherchent à étendre la liste des droits humains reconnus par l'ONU.

- Elles organisent des pétitions mondiales sur Internet contre les violations des droits humains.

7 Les adolescents peuvent être - et ils le sont - source de changement, y compris dans leur propre vie.

Les jeunes du monde entier peuvent se mobiliser pour les causes qui leur sont chères. Par exemple :

- en informant et sensibilisant les membres de leur famille et communauté ;

- en encourageant l'adoption de règles et pratiques qui leur paraissent justes ;

- en contribuant à la planification et à la mise en œuvre de programmes ; et

• en encourageant leurs amis à se joindre à leurs campagnes. 


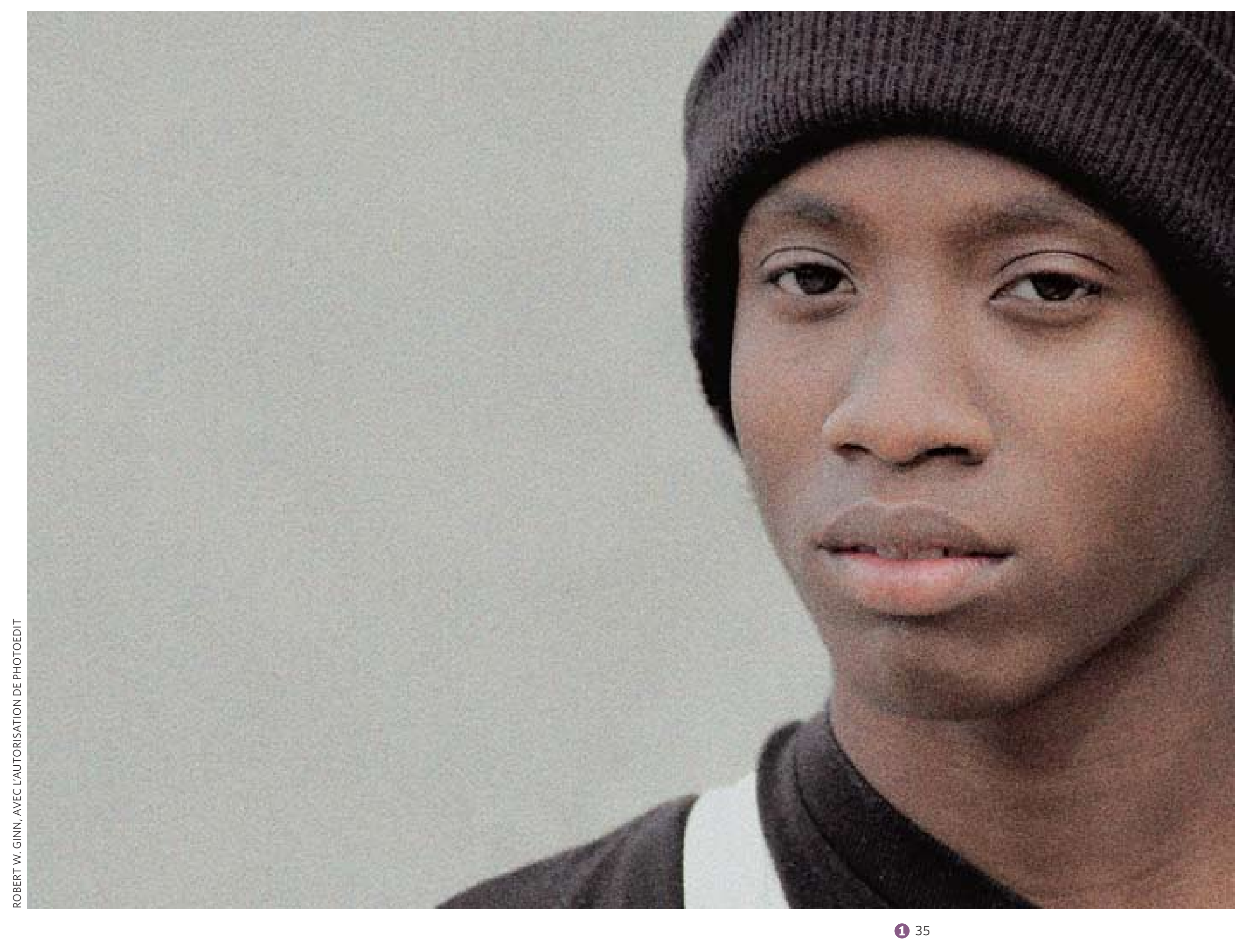




\title{
quelques notions sur l'individu et la communauté, les valeurs et les droits
}

\author{
Les brèves descriptions ci-dessous ont pour but d'aider l'utilisateur à clarifier \\ certains termes importants concernant la société et les droits humains. Partout \\ dans le monde, les éducateurs usent de créativité et de sensibilité pour \\ adapter ces concepts à leur propre contexte culturel et politique.
}

Communautés: Groupes de personnes partageant généralement certaines caractéristiques : croyances, besoins, cadre de vie ou de travail et identité. Il existe différents types de communautés. Leurs membres ont des droits et des responsabilités concernant le traitement les uns des autres.

Discrimination : Traitement injuste ou inégal basé sur l'apparence, le comportement ou l'identité (présumée ou réelle) de certaines personnes.

Droits humains : Protections et droits fondamentaux de tout être humain. Ces droits sont Inaliénables : ils ne peuvent être retirés à personne. Ils incluent notamment le droit à l'alimentation et au logement, à l'éducation, aux soins de santé, à la participation civique et à l'expression, au traitement égal devant la loi, au respect et à la dignité. La capacité des êtres à exercer pleinement leurs droits fondamentaux affecte pratiquement tous les aspects de leur existence.

II incombe aux gouvernements de respecter, de protéger et d'assurer ces droits. La plupart ont entériné des accords internationaux à cet effet. Les individus ont quant à eux le droit d'exiger des gouvernements qu'ils fassent respecter ces obligations et responsabilités. Ils ont aussi le droit d'exiger ce respect par leurs gouvernements.

Genre : Différences de rôles sociaux que les sociétés et familles attendent des garçons et des filles. II ne s'agit pas de la différence biologique entre les sexes. Le genre confère souvent, dans la famille et la société, un niveau de pouvoir et d'autorité distinct. 
Identité : Manière dont une personne se perçoit elle-même ou se décrit à autrui. La manière dont les autres perçoivent l'apparence ou le comportement d'une personne ne correspond pas toujours à l'idée que cette personne a de son identité. L'identité a généralement plusieurs facettes : une personne peut s'identifier comme étant un garçon, hindou et étudiant. L'identité peut venir de l'appartenance à une communauté. Elle peut changer avec le temps. (Le terme « identité » désigne aussi la reconnaissance officielle d'une personne par l'État : son nom, sa naissance, sa nationalité, etc.)

Normes sociales: Attentes concernant les actes ou pensées des membres d'une communauté. Les normes dominantes finissent par être considérées comme « naturelles » ou « normales », alors qu'elles varient en fait dans le temps et dans l'espace. Les normes poussent souvent les gens à se conformer aux attentes sociales. Elles influencent les attitudes et les comportements. Ceux qui agissent ou pensent différemment sont parfois considérés comme inférieurs plutôt qu'indépendants.

Opprobre: Profonde désapprobation sociale basée sur les caractéristiques personnelles d'un individu, parfois due à des croyances ou actes non conformes aux normes sociales. En certains endroits, le poids, le comportement sexuel, la religion ou l'état de santé sont causes d'opprobre.

Stéréotypes: Généralisations et suppositions basées sur l'identité ou le comportement d'une personne ou d'une communauté. Par exemple, l'idée que les filles sont faibles en maths est stéréotypée. Ces généralisations sont souvent inexactes ou même inventées. Les stéréotypes peuvent mener à l'opprobre, à la discrimination et à d'autres conséquences néfastes.

Valeurs : Ensemble de croyances qui régissent la vision du bien et du mal. Les valeurs varient d'un individu, d'une famille et d'une culture à l'autre. Certaines valeurs sont cependant reconnues comme pratiquement universelles et propres à l'éthique humaine. 


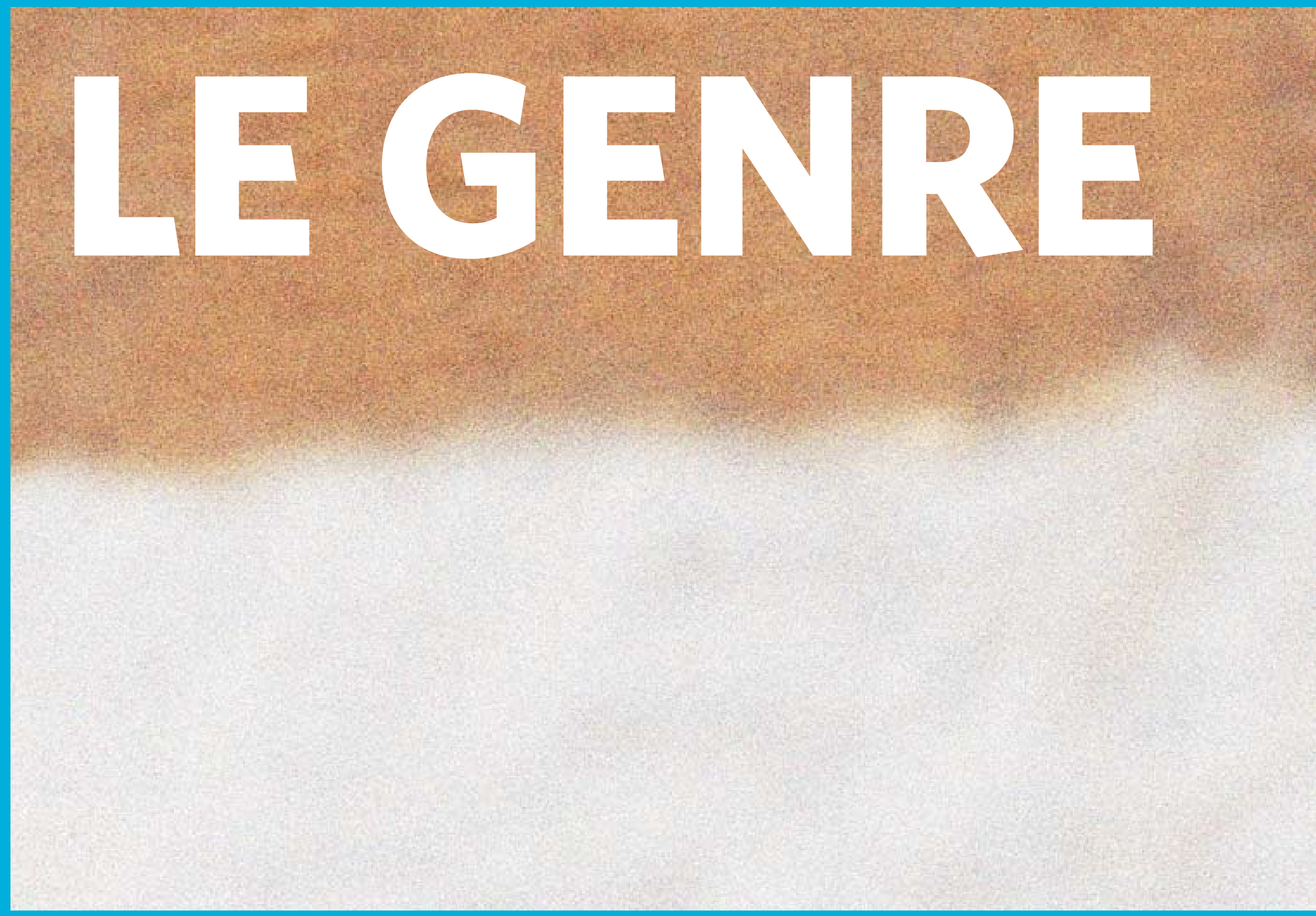




\section{panorama}

Les normes de genre affectent le bien-être, y compris la santé sexuelle et le risque de contraction du VIH. La plupart des pays ont identifié l'accès à l'égalité de genre tel un impératif moral, indispensable à la lutte contre le sida et au renforcement des familles et des sociétés. Partout, les normes et les rôles de genre changent. La sensibilisation des adolescents aux questions de genre est vitale en ce que les interventions durant cette période de formation peuvent avoir des répercussions radicales sur leur vie ultérieure.

Cette unité définit la notion de genre et explore l'effet des normes de genre sur la vie et la santé des garçons comme des filles. Elle suggère différentes manières d'aider les adolescents à imaginer le type de personne qu'ils désirent être, les types de relations qu'ils espèrent établir et le type de société qu'ils estiment juste et heureuse. 


\section{LE GENRE}

Soulignez que le mot « genre » s'applique tant aux garçons qu'aux filles.

Choisissez des exemples concrets (dans le volume ACTIVITÉs ou dans votre propre contexte) pour aider les élèves à comprendre que le genre n'est pas seulement une idée abstraite.

Répétez que les garçons, aussi bien que les filles, peuvent bénéficier de normes de genre moins rigides. N'oubliez pas que beaucoup d'élèves ont déjà choisi des rôles moins conventionnels et s'en portent parfaitement bien.

Dans une culture donnée, de même que d'une culture à l'autre, la dynamique de genre revêt plusieurs formes. Soyez sensible à sa nature (et à sa variabilité) locales.

Commencez par des exemples d'inégalité et de discrimination que les élèves reconnaissent (comme le racisme ou l'opprobre du VIH et sida), pour aider les élèves à comprendre et transposer ces phénomènes en ce qu'ils touchent au genre.

Le thème des rôles de genre risque de susciter un sentiment de défense ou d'hostilité. Soyez prêt à diffuser les querelles et à garder la discussion ouverte et respectueuse.

N'oubliez pas que beaucoup d'élèves ont été victimes de violences. La discussion doit être sensible et planifiée, dans une atmosphère rassurante, avec conseils d'orientation appropriés.

Soutenez les efforts des élèves face à leurs sentiments. Il est difficile mais possible et parfois libérant de remettre en question ses propres attitudes ou les normes de l'entourage.

Encouragez un cadre sûr de discussion franche. Peut-être serait-il utile de séparer les filles des garçons pour certaines activités et de les regrouper ensuite pour une discussion commune.

Les termes principaux sont définis dans le glossaire, à la fin de l'unité 2. Les fiches d'information en fin de volume apportent aussi une information complémentaire sur certains sujets. 


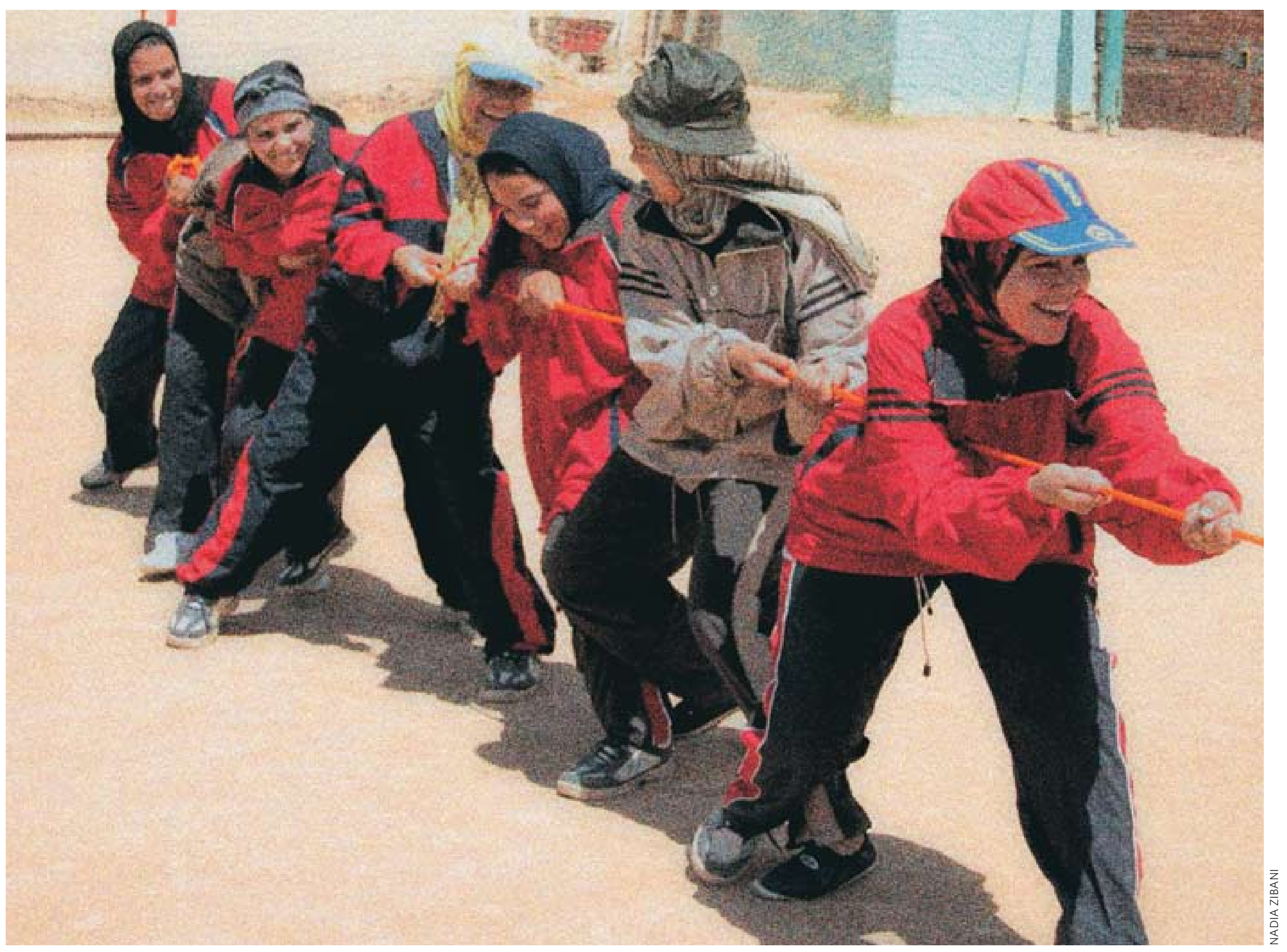




\section{LE GENRE}

Le matériel couvert dans cette unité prépare les élèves à :

\section{Objectifs cognitifs}

Faire la distinction entre le sexe et le genre.

Citer un exemple d'évolution des rôles de genre masculin ou féminin. Décrire ce que l'on peut faire pour encourager une évolution positive des rôles de genre.

Discuter de la manière dont l'inégalité de genre affecte l'accès à l'éducation, à l'espace public, aux services de santé, à la participation civique et à l'emploi.

Donner trois exemples de sources familiales et communautaires de rôles associés au genre.

Discuter l'emprise des institutions (mariage, famille, médias, etc.) sur les normes de genre.

Discuter comment les normes de genre perpétuent les mariages d'enfants, la mutilation génitale des filles et la violence (y compris sexuelle).

Expliquer comment les rôles de genre traditionnels peuvent accroître pour les femmes et les filles le risque de contraction du VIH et d'autres IST, ainsi que de grossesses non planifiées.

\section{Objectifs affectifs}

Comprendre que les normes de genre peuvent nuire au bien-être des garçons et des filles.

Discuter les rôles de genre qu'ils ont remis ou aimeraient remettre en question.

Clarifier leurs pensées sur la violence par un partenaire intime et la contrainte sexuelle.

Décrire comment la socialisation liée au genre affecte les sentiments de sécurité et l'estime de soi.

\section{Objectifs de compétences}

Faire preuve d'esprit analytique et critique dans l'explication de leurs idées. 


\section{définir le genre}

\section{POINTS DE RÉFLEXION}

Quels messages de comportement les filles reçoivent-elles au foyer, à l'école, de leurs chefs religieux et des médias? Et les garçons?

\section{Quels travaux typiquement féminins pourraient être} accomplis par des hommes?

Quels travaux typiquement masculins pourraient être accomplis par des femmes?

Les filles ont-elles des chances égales à celles des garçons dans votre société? Ailleurs? Les garçons sont-ils soumis à des pressions spéciales?

Les femmes ont-elles le même rôle qu'il y a 100 ans dans votre société ? Quelles différences voyez-vous?

Que pensent aujourd'hui les garçons de l'égalité de genre, par rapport à leurs pères ou grands-pères?
1 Dans chaque société, les normes et les rôles de genre influencent la vie des personnes, y compris leur vie sexuelle.

2 Les rôles de genre ne sont pas innés ou « naturels », ils sont appris. En réalité, presque tout ce qu'un garçon peut faire, une fille peut le faire aussi et vice-versa.

3 Dans chaque culture ou société, les gens ont des attitudes diverses à l'égard des rôles de genre et de l'égalité.

- 4 Les croyances relatives au genre varient aussi d'une culture (ou société) à l'autre.

- 5 Les rôles de genre changent dans le temps. Dans de nombreux contextes, les jeunes surtout embrassent aujourd'hui une plus grande égalité. 
Voir le glossaire en fin d'unité pour une simple introduction à ces concepts.
6 Une plus grande égalité et une plus grande souplesse dans les rôles de genre donnent à chacun une meilleure chance de plein épanouissement humain. Les rôles restrictifs limitent au contraire ces possibilités.

7 Malgré l'inégalité de genre, des millions de personnes cherchent chaque jour à réaliser leurs rêves. Même si toutes n'ont pas nécessairement les mêmes chances, beaucoup les réalisent en se battant pour une chance égale et en tirant le meilleur parti de chaque occasion gagnée.

8 L'accès à l'égalité de genre est un objectif clé poursuivi dans le monde entier.

- L'égalité entre les hommes et les femmes est une question de droits humains.

- L'égalité de genre est un élément clé de la lutte contre le VIH et sida, contre les mariages d'enfants, contre les grossesses non désirées et pour les grossesses à moindres risques.

- L'égalité de genre favorise l'épanouissement de communautés et sociétés saines et prospères.

- L'ONU a reconnu l'égalité de genre comme l'un des huit objectifs de développement clés à poursuivre.

- Des millions de personnes militent pour l'égalité de genre — dans les familles, à l'école, au travail, dans les communautés et à l'échelle des pays. [Voir la dernière section de cette unité. Voir aussi l'unité 8.]

1 Voir, par exemple, la Déclaration universelle des droits de l'homme (DUDH, 1948), la Convention sur l'élimination de toutes les formes de discrimination à l'égard des femmes (CEDF, 1979) et les objectifs du Millénaire pour le développement (OMD, 2000).
VOIR LE VOLUME D'ACTIVITÉS

\section{Activité 5}

toiles de mots homme-femme

En petits groupes, les élèves créent des « toiles de mots » sur la « masculinité » ou la « féminité » et discutent les raisons de leurs choix. 


\section{identité de genre}

1 À la naissance, les nouveau-nés sont identifiés comme étant de sexe masculin ou féminin suivant leurs organes génitaux. Souvent, le sexe de l'enfant est indiqué par son nom, ses vêtements, ses bijoux, etc.

2 Les enfants dont les organes génitaux ne sont pas clairement masculins ou féminins sont dits « intersexués ». Certains (intersexués ou non) ne sont pas sûrs de leur identité de genre ou s'identifient carrément avec le genre opposé à celui de leur éducation.

3 Presque tous les enfants se comportent de manière non conforme aux stéréotypes associés à leur genre.

Par exemple :

- Beaucoup de filles aiment le sport, excellent en maths et rêvent de diriger leur pays — tout en se sentant toujours filles.

- Beaucoup, si pas la plupart des garçons apprécient les relations interpersonnelles proches, la création artistique et le sentiment d'échapper aux pressions constantes de succès et de bravoure — sans pour autant se sentir moins garçons. 


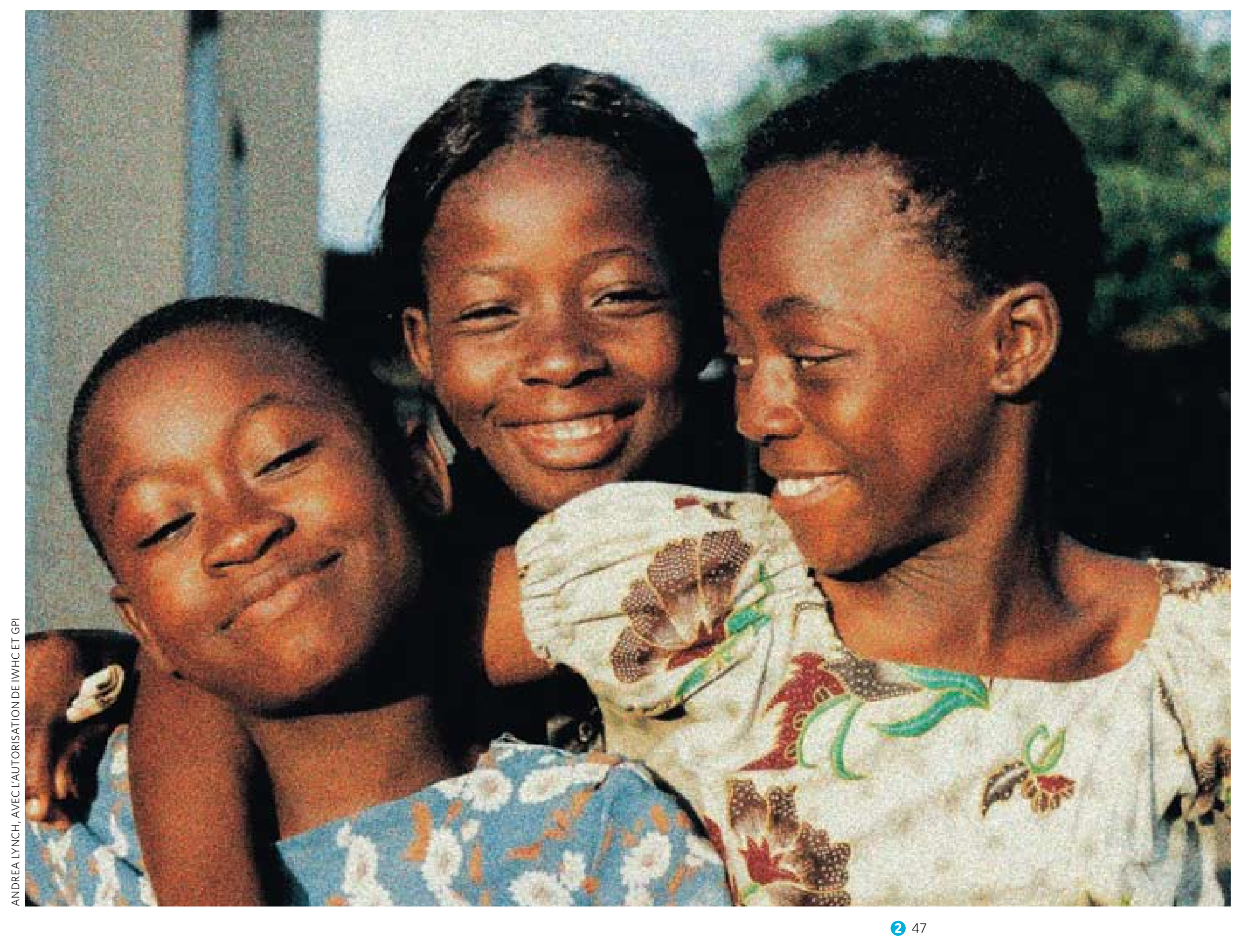




\section{les normes et les rôles de genre se consolident pendant l'enfance et l'adolescence}

1 Les rôles de genre attendus sont apparents dans la vie familiale.

Par exemple :

- Les membres de la famille reflètent les normes de genre dans leurs propres rôles et comportements. Selon la culture et la famille, les rôles masculins et féminins sont semblables ou différents.

- Les hommes et les femmes assument généralement des responsabilités et rôles différents dans les soins des enfants.

Ceux-ci commencent dès lors à observer et absorber les normes de genre.

2 Certaines familles traitent les garçons et les filles de manière égale.

Par exemple, les fils comme les filles sont encouragés et autorisés à :

- chercher à réussir sur la scène publique ;

- exprimer leurs sentiments de vulnérabilité ; et

- partager à égalité les tâches et travaux du ménage.

\section{Cette égalité n'existe cependant pas dans beaucoup de familles.}

Par exemple, dès la petite enfance :

- En cas de pénurie alimentaire, les filles ne sont pas nourries aussi bien que leurs frères.

- Les filles sont habillées différemment et reçoivent des jouets différents.

- Quand les ressources sont rares surtout, les familles travaillent plus dur pour assurer l'éducation de leurs fils. [Voir la section suivante sur le genre et l'éducation.]

- Dans certaines sociétés, les femmes sont considérées comme la propriété de leur mari. Les familles sont alors moins susceptibles d'investir leurs ressources dans l'alimentation et l'éducation de filles appelées à les quitter.

- Même si beaucoup de garçons ont certaines tâches à remplir, les filles doivent assumer plus de responsabilités ménagères et ont moins de temps libre que leurs frères.

- Les garçons apprennent à ne pas pleurer ni exprimer de sentiments de vulnérabilité.

- Les filles ne sont pas encouragées à s'affirmer ou sont dissuadées de participer à des sports " violents ».

4 Le langage - y compris des parents - renforce souvent les attentes relatives à chaque genre. 


\section{5 À l'approche de l'adolescence, les jeunes ressentent une pression accrue de se conformer aux rôles de genre déterminés par la culture.}

\section{6 À l'adolescence, les garçons partagent des expériences similaires.}

Malgré certaines variations culturelles, les garçons jouissent, partout dans le monde, de plus d'indépendance et de liberté que les filles. Ils ont plus de chances de participer à la vie publique, mais subissent aussi souvent plus de pressions de prouver leur hétérosexualité et leur virilité. Par exemple :

- en se montrant courageux et en s'affirmant ;

- en ayant de l'argent et en se préparant à subvenir aux besoins de leur famille ;

- en supprimant certaines émotions (de vulnérabilité, tendresse, etc.) ou comportements " féminins »;

- en choisissant la violence physique (contre des personnes qu'ils connaissent ou non);

- en devenant athlètes et en développant un corps musclé;

- en évitant les soins de santé ou en refusant même d'admettre qu'ils sont malades ou blessés ;

- en "prouvant » leur hétérosexualité (par des rapports hétérosexuels ou même par la paternité);

- en prenant le risque de rapports sexuels non protégés (et en accroissant ainsi leur risque d'IST); et

- en prenant des risques physiques (drogue, alcool ou conduite automobile dangereuse).

Les garçons peuvent être victimes de harcèlement ou de brutalité policière, surtout s'ils sont issus de groupes minoritaires, marginalisés, ou des bas quartiers. Ils sont parfois battus sauvagement sans véritable cause.

\section{7 À l'adolescence, les filles partagent des expériences similaires.}

Malgré certaines variations culturelles, les filles ont souvent l'occasion de développer davantage leurs sociabilité. Les normes de féminité les poussent cependant notamment à :

- s'occuper de leurs famille, mari et enfants ;

- se montrer dociles et soumises, minimiser leur intelligence, sous-estimer ou taire leurs idées et opinions ;

- accepter la limitation de leurs droits ;

- accepter la surveillance étroite de leur tenue, de leurs amitiés et de leurs allées et venues;

- veiller à ne pas blesser les sentiments des autres ;

- éviter les rapports sexuels avant le mariage, même si elles les désirent ; et

- céder aux rapports sexuels non désirés [voir la section sur la contrainte sexuelle et l'unité 3, pp. 106-107]. 
8 Les rôles de genre rigides affectent aussi la manière dont les personnes se traitent les unes les autres et contribuent notamment au suicide et à la violence.

- Ceux qui ne se conforment pas aux normes de genre dominantes sont taquinés, isolés ou menacés.

- Sont particulièrement soumis à l'opprobre : les individus perçus comme étant homosexuels, les garçons jugés efféminés, les femmes qui ont plusieurs partenaires sexuels ou les personnes qui adoptent une identité de genre différente de celle de leur éducation (les transsexuels).

9 Malgré les normes sociales, des millions de jeunes sont déterminés à « être euxmêmes » et à mieux réaliser leur potentiel humain. Ils croient en une plus grande égalité de genre et acceptent la diversité.

- Beaucoup de jeunes savent résister à la pression de se conformer à une image corporelle idéalisée.

- Beaucoup de filles ont confiance en soi et en leur propre capacité. Elles savent qu'elles peuvent se battre pour leur chance de travailler dur, de réussir et de réaliser leurs rêves.

- Beaucoup de garçons sont sûrs d'eux et résistent à la pression de prouver leur virilité.

- Beaucoup de garçons se sentent libres d'exprimer leurs émotions, même de vulnérabilité et de tendresse. Plus tard dans la vie, cette liberté pourra enrichir leur approche de la paternité et leur satisfaction.

- Beaucoup de jeunes célèbrent la diversité et la différence.

10 Partout dans le monde, les normes de genre changent. Les jeunes voués à l'égalité et à la justice sont le moteur du changement.

[Voir la section de cette unité intitulée le genre : nos décisions et nos actes.] 


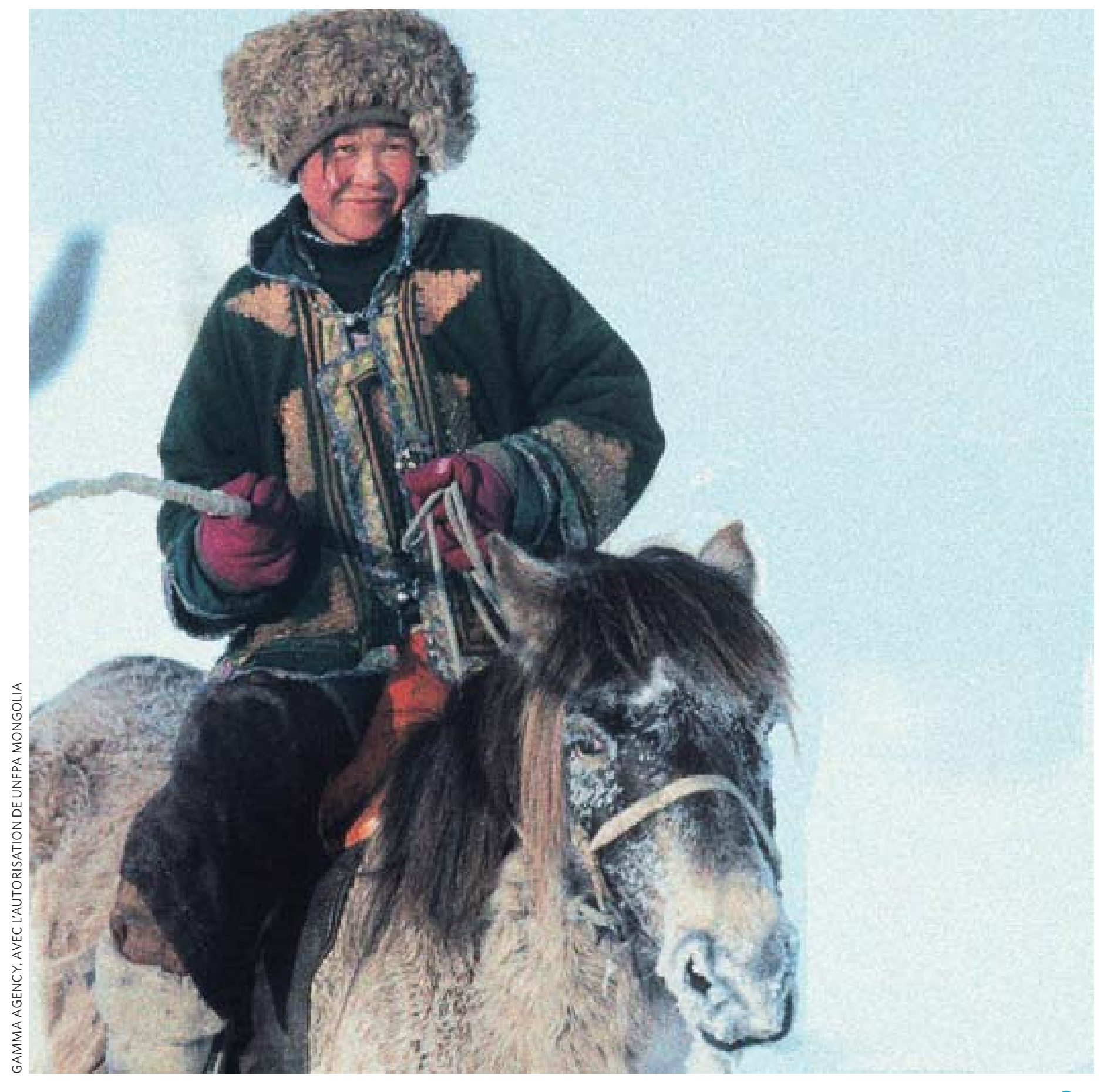

VOIR LE VOLUME D'ACTIVITÉS Activité 6

souvenirs d'enfance :

l'apprentissage du genre

Les élèves partagent un souvenir d'un moment où ils ont été traités d'une certaine manière en raison de leur sexe et évoquent leurs sentiments.

VOIR LE VOLUME D'ACTIVITÉS Activité 7

image de père

Les élèves rédigent une « lettre à leur père $»$. Ils discutent la manière dont les rôles de genre limitent la paternité. 


\section{le genre et l'éducation}

VOIR LE VOLUME D'ACTIVITÉS

\section{Activité 8}

projet de recherche : le genre à

\section{l'école}

Les élèves mènent une recherche sur le rôle du genre à l'école et présentent leurs conclusions.
Toute personne - sans distinction de race, sexe, langue, religion, origine sociale ou autre - a droit à l'éducation (Article 26.1, Déclaration universelle des droits de l'homme [DUDH], 1948 ; Article 13.1, Pacte international relatif aux droits économiques, sociaux et culturel [PIDESC], 1966 ; Article 10, Convention sur l'élimination de toutes les formes de discrimination à l'égard des femmes [CEDF], 1979 ; Article 28.1, Convention internationale des droits de l'enfant [CIDE], 1989).

1 L'éducation est un droit universel, mais dans bien des pays, les garçons ont plus de chances d'aller à l'école et de fréquenter de meilleurs établissements.

Exemples d'obstacles à la scolarisation des filles :

- moindre valeur accordée au développement des capacités des filles ;

- priorités économiques de la famille ;

- craintes pour la sécurité (et la réputation) des filles ;

- craintes de harcèlement ou de violence sexuelle de la part des enseignants ou des élèves masculins ;

- attentes de participation des filles aux travaux domestiques ;

- ressources inadéquates pour gérer la menstruation des filles;

- normes locales de mariage et de maternité précoces; et

- inégalité des chances, au détriment des filles instruites, sur le marché de l’emploi.

2 L'accès à l'éducation est essentiel à l'égalité de genre. En beaucoup d'endroits pourtant, l'école renforce les rôles de genre et les choix inégaux.

Par exemple :

- Les garçons exigent souvent plus de temps et d'attention de l'enseignant que les filles. Ils tendent aussi à assumer davantage les rôles de leadership.

- Les enseignants tolèrent le langage et les «blagues » dégradantes à l'égard des filles ou des minorités.

- Les élèves (surtout les filles) subissent le harcèlement sexuel des garçons ou des enseignants.

- Les élèves qui ne se conforment pas aux normes dominantes sont marginalisés.

- Les filles sont dissuadées de s'intéresser aux branches traditionnellement masculines (sciences et maths).

- Les garçons sont tenus à l'écart d'activités perçues comme féminines (certains sports et beaux-arts).

- Les garçons doivent être athlètes ou doivent démontrer leur virilité par l'emploi d'un langage désobligeant ou en se faisant remarquer en classe.

- Certains programmes d'éducation sexuelle et de prévention du VIH renforcent les stéréotypes de genre négatifs.

- Dans certains contextes, les filles ne peuvent pas fréquenter l'école si elles sont enceintes. 


\section{Certains espaces scolaires sont dangereux.}

- Dans certaines écoles, les filles courent le risque de rapports sexuels forcés, parfois par des adultes.

- Les jeunes perçus comme homosexuels et les transsexuels sont souvent la proie de violences.

- Les gangs mettent tous les jeunes en danger, en particulier les garçons.

- Même les enseignants courent parfois ces risques.

\section{Le matériel pédagogique renforce souvent les rôles de genre et les choix inégaux.}

\section{Partout dans le monde, on cherche à promouvoir l'égalité de genre au niveau de} l'éducation et à étendre l'accès à l'école pour tous.

- Les jeunes défendent le droit des filles à rester à l'école aussi longtemps que leurs frères.

- Certains gouvernements offrent une allocation aux familles pour qu'elles gardent leurs filles à l'école.

- Les éducateurs révisent leurs manuels et programmes pour les rendre plus équitables.

- Certaines communautés parrainent des programmes de lutte contre les gangs, la drogue et d'autres comportements qui mènent souvent les garçons à abandonner l'école.

\section{Partout dans le monde, plus de jeunes vont à l'école et y restent plus longtemps.}

- Apprendre a toujours été l'un des plus grands plaisirs de l'humanité.

- L'éducation est essentielle si l'on veut donner aux jeunes des capacités d'emploi utile face aux défis de la mondialisation.

- Tous les jeunes ont droit à l'éducation.

\section{POINTS DE RÉFLEXION}

L'école doit-elle assurer un espace sûr à tous ses élèves et enseignants? Est-ce le cas dans notre établissement?

Les écoliers apprennent les contributions d'éminentes personnalités à l'histoire, à la science, aux arts, à la littérature. Qu'apprennent-ils de la contribution des femmes?

Et de celle des minorités raciales ou ethniques?

Vos leçons ou manuels scolaires parlent-ils de l'apport de tous à la société ? Si vous utilisez des manuels, considérez-en le texte, mais aussi les images et les photographies.

Quelles attitudes les écoliers absorbent-ils si un programme exclut la contribution de certains groupes? 


\section{stéréotypes de genre dans les médias}

1 Les histoires pour enfants et les médias exercent une forte influence sur les normes de genre et les attentes des jeunes, qu'il s'agisse de la radio, de la télévision, du cinéma, des journaux et magazines, d'Internet ou de la publicité.

2 Les images et les messages médiatiques peuvent promouvoir des valeurs d'égalité, de respect et de dignité ... ou de manque de respect et d'inégalité.

3 Les histoires pour enfants et les médias renforcent souvent l'inégalité et le manque de respect.

Par exemple :

- en présentant des rôles masculins et féminins stéréotypés (l'homme-héros et la femme-victime, etc.), ainsi que des groupes raciaux ou ethniques, couples de même sexe et autres tout aussi stéréotypés ;

- en représentant des types de corps idéalisés et en les glorifiant ;

- en représentant les femmes et les filles de manière extrêmement sexualisée ; et

- en réservant aux hommes les postes les plus élevés et les plus visibles dans les émissions d'actualités et au cinéma.

\section{POINTS DE RÉFLEXION}

Comment les médias locaux dépeignent-ils les deux sexes?

Quels messages les contes de fées transmettent-ils sur la masculinité et la féminité ?

Existe-t-il d'autres médias qui donnent une voix à ceux omis, dénigrés ou stéréotypés dans les médias ordinaires? Si oui, quels sont-ils?
- 4 Partout dans le monde, les jeunes créent leurs propres médias et racontent leurs leurs propres histoires. Beaucoup de groupes cherchent à sensibiliser l'opinion publique sur les messages transmis par les médias. 


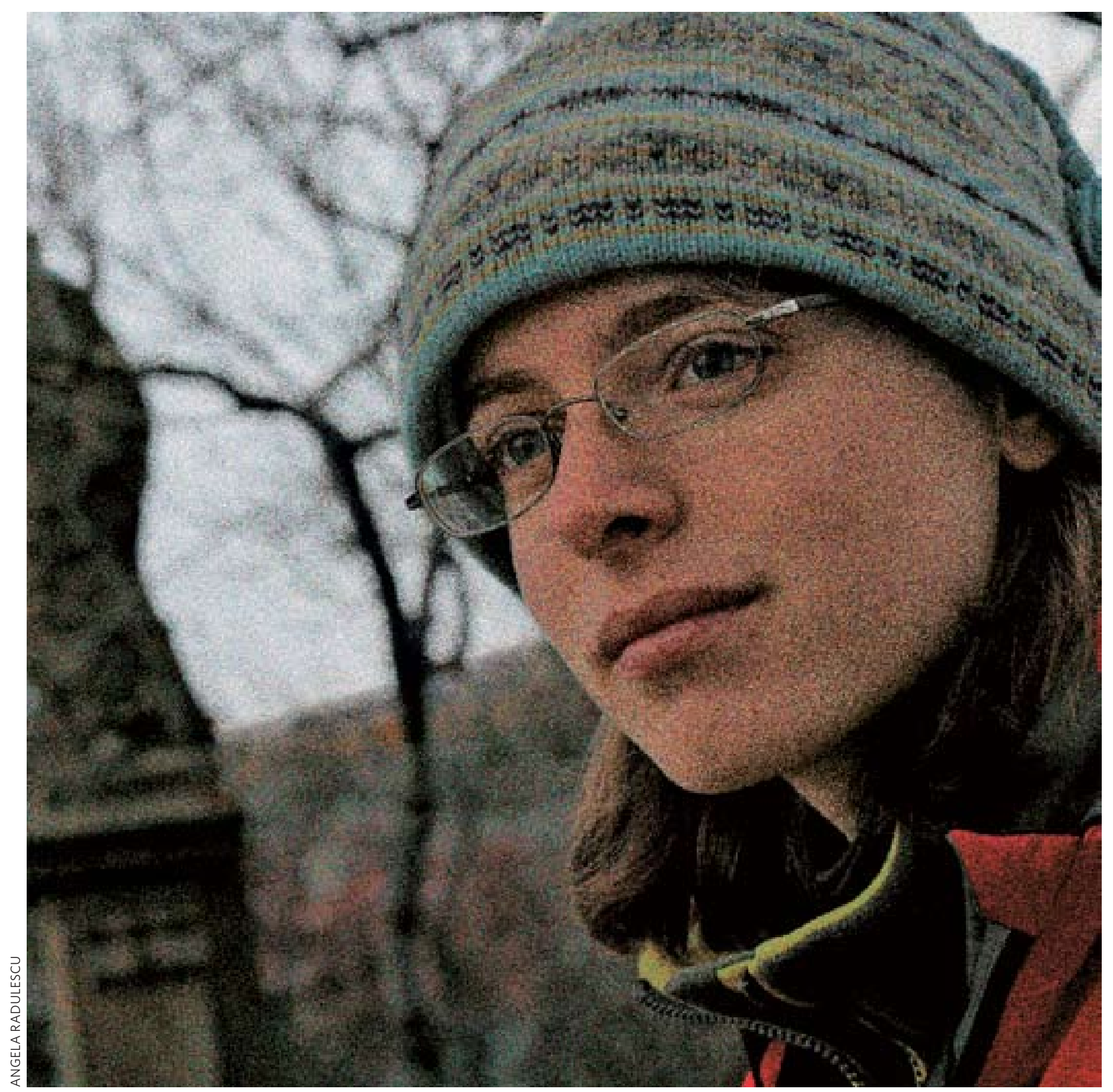

VOIR LE VOLUME D'ACTIVITÉS Activité 9

vente de stéréotypes : analyse de publicité

Les élèves créent un collage

d'images publicitaires d'hommes et de femmes. Ils analysent les messages de genre et créent une publicité non stéréotypée. 


\section{le genre affecte la mobilité, le lien social et les espaces publics sûrs}

Toute personne a le droit de circuler librement et de choisir sa résidence à l'intérieur d'un État (Article 13.1, DUDH, 1948).

Toute personne a le droit de participer à la vie culturelle de la communauté (Article 27.1, DUDH 1948; Article 15.1, PIDESC, 1966).

1 II est important de pouvoir circuler librement et sans danger. La personne y gagne l'accès à l'information, aux services et à l'emploi, ainsi qu'à des réseaux sociaux et de soutien. Le lien social en dehors du foyer est agréable. Il aide la personne à élargir ses horizons. L'isolement mène parfois à un état dépressif.

2 En beaucoup d'endroits, les normes de genre limitent la capacité des femmes à circuler librement dans leur communauté.

Par exemple :

- Les adolescentes sont généralement beaucoup moins libres que les garçons de quitter leur foyer et de circuler dans leur communauté. Elles ne peuvent donc souvent pas faire de sport, rendre visite à leurs amies, accéder aux services proposés ou se préparer à participer pleinement à la société.

- Dans certains contextes, les filles qui sortent seules risquent de se faire traiter de filles « légères ». Elles s'exposent potentiellement au harcèlement sexuel ou à la violence.

- Dans certains contextes, les femmes adultes sont isolées du monde extérieur. Elles doivent être accompagnées d'un parent de sexe masculin pour se rendre chez une amie, chez le médecin ou pour faire leurs achats. 


\section{Dans certains contextes, l'espace public est dangereux.}

Par exemple :

- Dans beaucoup de communautés économiquement faibles et de groupes minoritaires, les garçons sont sujets à la violence, au harcèlement ou à la brutalité policière et à l'incarcération.

- Dans les communautés en proie aux gangs et à un manque endémique d'emploi ou d'éducation avancée, les garçons peuvent être attirés par les gangs ou le trafic de drogue.

- Les garçons sont attirés en nombre disproportionné par la guerre et d'autres formes de combat.

- Les femmes et les filles qui vivent dans des camps de réfugiés ou de personnes déplacées, les nouvelles zones de travailleurs migrants ou autres communautés instables courent un risque élevé de violence, y compris sexuelle.

- En de nombreux endroits, les personnes perçues comme homosexuelles ou transsexuelles sont victimes d'agressions physiques parfois mortelles.

4 Malgré les tabous sociaux, beaucoup de jeunes refusent l'isolement. S'ils le peuvent, ils créent des espaces sûrs où se rencontrer. Par exemple, les filles mariées, les domestiques féminines, les personnes attirées par d'autres du même sexe, les jeunes transsexuels, les filles désireuses de faire du sport et les travailleuses du sexe ont réussi à établir de tels espaces.

VOIR LE VOLUME D'ACTIVITÉS Activité 10

I'espace genre

Les élèves tracent une carte de leur communauté et y indiquent les espaces sûrs et accessibles aux personnes de chaque sexe. Ils analysent l'effet des rôles de genre sur la participation à la vie civique. 


\section{le genre affecte la participation civique et politique}

Toute personne a le doit de prendre part à la vie politique et publique de son pays, y compris de voter et d'être éligible, ainsi que de bénéficier d'un accès égal à la fonction publique (Article 21, DUDH, 1948 ; Article 25, Pacte international relatif aux droits civils et politiques [PIDCP], 1966; Article 7, CEDF, 1979).

1 Tout le monde a le droit de participer à la vie publique, mais tout le monde n'est pas apte à exercer ce droit sur un pied d'égalité.

2 De nombreux obstacles sont opposés à la participation de certains groupes : les femmes et les filles, les pauvres, les handicapés, les homosexuels déclarés, les personnes âgées et les minorités ethniques et raciales, notamment.

Par exemple :

- Dans certains endroits, les femmes ne peuvent pas voter et occupent rarement de hautes fonctions publiques. Elles ont moins accès aux programmes de l'État et sont moins aptes à participer à la société.

- Même dans les contextes où les femmes occupent de hautes fonctions, la plupart souffrent toujours d'une profonde inégalité et de moindres occasions de participer à la société.

3 Malgré l'écart encore marqué dans la vie civique et politique, les femmes lèvent les obstacles qui leurs sont opposés en certains endroits.

VOIR LE VOLUME D'ACTIVITÉS Activité 11

femmes d'action : projet livre d'enfants

Les élèves créent un livre d'enfants consacré à une femme illustre.
- Les femmes occupent de hautes fonctions aux niveaux locaux et nationaux. Dans certains pays, les partis politiques doivent faire figurer au moins 30 à $50 \%$ de femmes sur leurs listes électorales.

- Les femmes dirigent aussi des organisations non gouvernementales de toutes envergures.

- Malgré de nombreux défis, d'éminentes leaders féminines sont visibles dans la vie communautaire et publique de chaque région du monde.

- Les femmes se sont organisées en groupes dynamiques de discussion et de promotion de l'autonomisation, de l'égalité et des droits fondamentaux des femmes.

- Beaucoup d'hommes cherchent activement à accroître l'accès égal des femmes à la vie civique et politique.

4 Rêvez grand et travaillez dur : vous pouvez accéder au sommet et faire une différence dans le monde! 


\section{genre, travail et ressources économiques : au foyer et au dehors}

Toute personne a droit au travail, au libre choix de son travail, à des conditions équitables et satisfaisantes et à la protection contre le chômage. Tous ont droit, sans aucune discrimination, à un salaire égal pour un travail égal (Article 23, DUDH, 1948; Articles 6, 7, PIDESC, 1966 ; Article 11, CEDF, 1979).

1 Toute personne, homme ou femme, est capable d'élever ses enfants, d'accomplir les tâches ménagères et d'occuper un emploi rémunéré en dehors du foyer.

2 Le plus souvent, pourtant, les pressions économiques - et les possibilités (y compris l'accès à l'argent) - varient suivant le sexe.

3 Partout dans le monde, les femmes et beaucoup d'hommes cherchent à étendre l'accès des femmes et des filles aux ressources.

Ils procèdent par exemple à travers :

- des politiques qui donnent accès aux femmes à la propriété ou qui encouragent l'embauche et la promotion des femmes et autres groupes sous-représentés sur le marché de l'emploi ;

- des programmes d'épargne et de microfinancement qui permettent aux femmes de participer à l'économie marginale, surtout dans les contextes où ces ressources vont principalement aux hommes ;

- des efforts d'amélioration des conditions d'emploi des travailleuses du sexe ;

- des programmes qui atteignent les femmes confinées à leur foyer ou enceinte ;

- l'éducation et la formation professionnelle, pour élargir les horizons des femmes sur les marchés de l'emploi ; et - des crèches et garderies abordables qui permettent aux parents de rechercher des emplois mieux rémunérés.

4 L'épanouissement de chacun et chacune au foyer, au travail et dans la communauté profite à tous.

Par exemple :

- Être mère ou père engagé et aimant peut être extrêmement gratifiant pour les parents comme pour les enfants.

- Tandis que les femmes rejoignent la population active, les hommes deviennent souvent des pères plus engagés.

- L'accès égal à l'éducation et à l'emploi offre plus d'options d'emploi aux jeunes. 


\section{le genre et le mariage}

À l'âge de la majorité, les hommes et les femmes ont le droit de se marier et de fonder une famille. Ils ont des droits égaux au regard du mariage, durant le mariage et lors de sa dissolution (Article 16.1, DUDH, 1948 ; Article 16.1, CEDF, 1979).

Le mariage ne peut être conclu qu'avec le libre et plein consentement des futurs époux (Article 16.2, DUDH, 1948; Article 16.1, CEDF, 1979). Les fiançailles et les mariages d'enfants n'auront pas d'effets juridiques... (Article 16.2, CEDF, 1979).

1 Beaucoup de gens établissent des relations à long terme (de toute une vie parfois) dans lesquelles ils vivent ensemble. Les raisons de ces relations de couple sont diverses:

Par exemple :

- les deux personnes s'aiment et sont heureuses ensemble ;

- elles désirent la compagnie l'une de l'autre;

- elles ont besoin de sécurité économique ;

- elles veulent avoir des enfants ; et

- leur communauté ou leur famille attend d'elles qu'elles aient des enfants.

2 Certaines personnes en relation de couple sérieuse se marient officiellement en droit ou religieusement. Les gens se marient pour diverses raisons.

Par exemple :

- Ils désirent honorer ou légitimer une relation intime dans le contexte des valeurs de l'un ou des deux partenaires ou de leur famille, communauté ou société.

- Ils désirent honorer ou légitimer leur procréation dans le contexte des valeurs de l'individu ou de sa famille, communauté, religion ou société.

- Ils désirent bénéficier d'avantages refusés aux personnes non mariées ou non admises au mariage, tels que des prestations de maladie ou prestations au survivant et l'approbation sociale des relations sexuelles.

- Ils se plient aux désirs ou à la volonté de leurs parents. (Dans certains contextes, les parents arrangent le mariage de leurs enfants, dans le but de leur assurer un bon parti ou de préserver leur réputation. Les parents marient aussi leurs filles pour soulager la pression économique qui pèse sur la famille.) Bien qu'infraction grave aux droits humains, le mariage d'enfants (avant l'âge de 18 ans) reste courant dans certaines régions. 
3 Certaines personnes en relation de couple sérieuse ne se marient pas officiellement, et ce pour diverses raisons.

Par exemple :

- Choix personnel : le couple ne ressent pas le besoin d'approbation officielle de l'État ou d'une institution religieuse.

- Le droit de se marier leur est refusé. La famille ou la société peut interdire le mariage homosexuel ou entre personnes de races, religions ou castes différentes.

- Le couple n'a pas les moyens (revenu ou dot) de se marier.

\section{Le mariage est une institution sociale complexe et profondément ancrée.}

- Il peut être source de nombreux avantages mutuels. Dans beaucoup de mariages, les deux partenaires se soutiennent l'un l'autre et soutiennent les droits l'un de l'autre.

- Le mariage peut aussi renforcer les normes de genre, de manière parfois injuste et préjudiciable.

\section{Certains mouvements sociaux préconisent une plus grande égalité et dignité au} sein du mariage.

Il s'agit notamment :

- des mouvements pour la légalisation du mariage homosexuel ;

- des campagnes contre la dot et les mariages d'enfants; et

- des réformes légales cherchant à assurer des règles d'héritage justes, à permettre à la femme comme à l'homme de demander le divorce et à criminaliser la violence conjugale, y compris le viol. 


\section{le genre et la religion}

Les gouvernements doivent prendre des mesures pour que les traditions, la religion et leurs expressions ne soient pas une cause de discrimination à l'égard des filles (Paragraphes 24 et 276.d, Programme d'action de la QCMF, 1995).

1 Les perspectives religieuses sur le genre et la sexualité sont nombreuses. Elles changent parfois avec le temps. Les attitudes religieuses varient aussi.

2 Beaucoup de gens ne sont pas toujours d'accord avec leur chef religieux sur les questions de genre et de sexualité. Les perspectives religieuses influencent cependant les croyances et comportements de beaucoup.

3 La religion ou les chefs religieux peuvent influencer les normes de genre (et sexuelles) de nombreuses manières. [Voir aussi l'unité 3, p. 88.]

- Certaines traditions religieuses sont plus égalitaires à l'égard du genre. D’autres sont plus patriarcales (basées sur un système de puissance masculine).

- Les religions varient dans leur influence sur les normes de genre, la sexualité et la fécondité. Les textes religieux peuvent aussi être interprétés sélectivement pour justifier ou rejeter certaines pratiques.

- Certains chefs religieux appuient l'information et l'accès à la contraception, au préservatif, à l'avortement et à l'éducation sexuelle, tandis que d'autres s'y opposent.

- Certaines religions reconnaissent des droits égaux à tous, indépendamment de leur identité sexuelle (y compris en ce qui concerne l'ordination). D'autres s'opposent à l'homosexualité et aux droits des homosexuels.

- Certaines religions ou chefs religieux renforcent les normes sexuellement différenciées, en consacrant la virginité et la fidélité des femmes au sein du mariage tout en admettant aussi la polygamie (pratique selon laquelle les hommes ont plusieurs épouses). D’autres non.

- Certaines religions et chefs religieux soutiennent l'égalité de genre en matière de divorce, d'héritage et de vie communautaire. D’autres lois ou pratiques religieuses limitent le mouvement des femmes ou leur refusent l'égalité (ou même tous droits) en matière de divorce, héritage ou autre, parfois à l'encontre du droit civil. 
4 Il est souvent refusé aux femmes de participer à la vie religieuse sur un pied d'égalité avec les hommes.

- Les femmes assument de nombreuses activités de soutien communautaire au nom de leurs institutions religieuses mais n'y ont pas accès aux postes de leadership.

- Certaines institutions religieuses interdisent aux femmes de prier avec les hommes.

5 Partout dans le monde, les gens, y compris de nombreux chefs religieux, cherchent à promouvoir les valeurs des droits humains et de l'égalité de genre au sein de leurs communautés.

- Les organisations Women Living Under Muslim Laws (femmes vivant sous les lois musulmanes) et Catholics for Choice (catholiques pour un libre choix) en sont deux exemples. 


\section{le genre et l'autonomie corporelle}

VOIR LE VOLUME D'ACTIVITÉS Activité 12

changer son corps

Les élèves identifient l'apparence féminine et masculine idéalisée dans leur culture et examinent les pratiques adoptées pour s'y conformer.
Tout individu a droit à la vie, à la liberté et à la sûreté de sa personne (Article 3, DUDH 1948; Articles 6.1 et 9.1, PIDCP, 1966). Nul ne sera soumis à ... des traitements cruels, inhumains ou dégradants (Article 5, DUDH, 1948; Article 7, PIDCP, 1966; Article 37.a, CIDE, 1989). Les États prennent les mesures efficaces appropriées pour abolir les pratiques traditionnelles préjudiciables à la santé des enfants (Article 24.3, CIDE, 1989).

Le mariage ne peut être conclu qu'avec le libre et plein consentement des futurs époux (Article 16.2, DUDH, 1948; Article 16.1, CEDF, 1979). Les fiançailles et les mariages d'enfants n'auront pas d'effets juridiques ... (Article 16.2, CEDF, 1979).

1 Nous sommes tous maîtres de notre propre corps. Cela inclut le droit de ne pas subir de violences, sévices sexuels et pressions nous poussant à la violence envers autrui. Être maître de son propre corps, c'est aussi décider si et quand on veut des rapports sexuels, si et quand on désire une grossesse et si on désire la poursuivre, et même si et comment on désire changer son apparence.

2 Cette maîtrise est source d'assurance, de sécurité, de santé et de plaisir. Elle permet d'explorer son identité. Malheureusement, les garçons comme les filles ont parfois l'impression d'être sous le contrôle physique et sexuel d'autrui. Le sentiment de n'être plus maître de son corps est profondément troublant et même traumatisant.

3 Nos valeurs familiales, nos institutions et normes sociales et religieuses et les lois en vigueur influencent la maîtrise que nous avons de notre corps. 


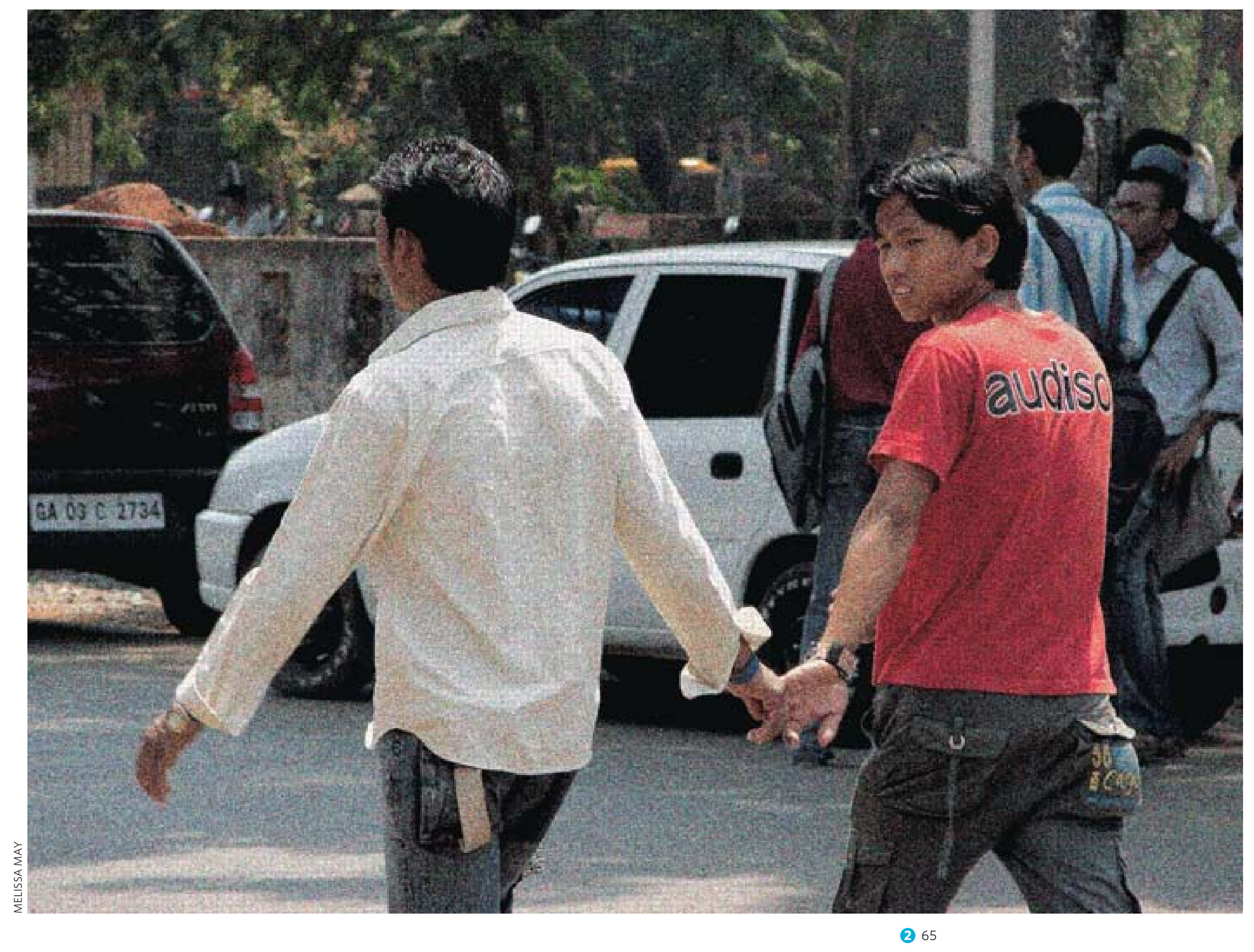




\section{POINTS DE RÉFLEXION}

Mises à part les pratiques forcées telles que la MGF, des millions de femmes et de filles subissent volontairement des procédures médicales risquées (ou adoptent des pratiques préjudiciables à leur santé) pour se donner une apparence conforme à un idéal culturel. Pensez à quelques exemples. Comment la société détermine-t-elle l'idéal féminin?

Pourquoi certaines personnes cherchent-elles à s'éclaircir la peau ? D'où vient l'idée qu'une couleur de peau est plus attrayante qu'une autre?

Pourquoi les filles et les femmes de certains endroits se priventelles de nourriture, ou pourquoi s'insèrent-elles des substances dessicatives dans le vagin?

\section{Presque partout, les femmes subissent un contrôle extérieur de leur corps plus} strict que les hommes.

Par exemple, les filles sont plus susceptibles :

- d'être élevées dans l'attente d'une faible maîtrise personnelle de leur propre corps ;

- d'être limitées dans leur expression sexuelle. Beaucoup endurent le viol et le harcèlement sexuel (avances malvenues, demandes de faveurs sexuelles ou autre conduite sexuelle verbale ou physique non désirée) ; et

- d'être limitées dans leur mobilité (par l'interdiction de se rendre dans la communauté, par exemple) ou dans leur habillement et d'avoir moins d'occasions de faire du sport.

\section{5 Les filles sont parfois soumises à un contrôle extérieur extrême de leur corps.}

Par exemple :

- la mutilation génitale [voir la fiche d'information en fin de volume] ; et

- le mariage précoce ou forcé.

\section{Les garçons subissent aussi la pression de s'engager dans des pratiques} potentiellement néfastes.

Par exemple :

- Certains jeunes hommes prennent des drogues dangereuses pour accroître leur masse musculaire.

- Dans certains contextes, les garçons subissent des rites traditionnels de passage à l'âge adulte souvent dangereux, tels que les rites de survie dans la jungle, la circoncision non médicalisée ou l'initiation sexuelle obligatoire dans une maison de prostitution. 
7 Les familles, les communautés, les religions et les gouvernements réglementent et punissent souvent les comportements (sexuels compris) non conformes aux attentes des normes de genre.

[Voir l'unité 3 sur la sexualité.]

Les sanctions varient dans leur intensité. Par exemple :

- on traite les filles sexuellement actives de «putes », alors qu'il n'existe aucun terme dégradant équivalent pour désigner les garçons hétérosexuels ;

- on approuve les conséquences juridiques et sociales sévères qui frappent les femmes infidèles alors que le comportement équivalent des hommes est admis ou même récompensé ;

- on criminalise les travailleuses du sexe, sans véritables conséquences légales pour leurs clients; et

- on criminalise l'homosexualité.

8 Partout dans le monde, parents et enfants défendent le droit des jeunes à l'autonomie corporelle et à la dignité. Beaucoup d'organisations poursuivent aussi cet objectif à travers la sensibilisation des communautés et la réforme légale.

9 Le corps de chacun, garçon ou fille, n'appartient qu'à lui ou à elle. Nul n'a le droit d'abuser du corps d'autrui, de le blesser ou de le violer. 


\section{le genre et la violence}

Tout individu a droit à la vie, à la liberté et à la sûreté de sa personne (Article 3, DUDH 1948; Articles 6.1 et 9.1, PIDCP, 1966). Nul ne sera soumis à ... des traitements cruels, inhumains ou dégradants (Article 5, DUDH, 1948 ; Article 7, PIDCP, 1966 ; Article 37.a, CIDE,1989).

1 Tout le monde désire se sentir à l'abri de la violence. L'être humain se sent généralement mieux quand il n'est pas violent.

2 L'incidence de la violence varie dans le temps et dans l'espace.

3 II existe de nombreux types de violence : la force physique, la menace, l'intimidation et la violence psychologique. La violence peut être commise par ou au nom de certains individus, groupes, organismes ou de l'État.

4 Les garçons sont plus violents que les filles et en sont aussi plus souvent victimes.

- Beaucoup de jeunes hommes sont conditionnés pour agir violemment ou y sont poussés.

- Les jeunes hommes sont particulièrement vulnérables à la violence en dehors du foyer : dans les guerres et les conflits civils, en prison et aux mains de gangs.

- Les femmes sont souvent sujettes à la violence interpersonnelle, souvent au foyer.

- Les êtres perçus comme non conformes aux normes de genre peuvent être sujets à la violence interpersonnelle.

5 La violence à l'encontre des femmes, des filles ou des personnes non conformes aux normes de genre dominantes est appelée « violence de genre ».

- Les filles sont particulièrement vulnérables à la violence de personnes qu’elles connaissent, partenaire intime compris.

- Cette violence peut être de nature sexuelle (attouchements ou rapports sexuels forcés). [Voir la section suivante sur la contrainte sexuelle.]

- Cette violence est d'intensité variable (coups, brûlure ou meurtre).

- Certaines personnes sont victimes de violences parce qu'elles sont perçues (à tort ou à raison) comme étant homosexuelles ou transsexuelles. La violence basée sur l'identité d'une personne est parfois appelée « crime haineux ».

- Toutes les violences de genre constituent une violation des droits humains. 

contrôle et dominance masculine.

Par exemple :

- Les filles sont souvent élevées dans l'attente d'une faible maîtrise personnelle de leur propre corps.

- Les garçons sont souvent élevés dans l'optique de la supériorité et de la domination de l'homme sur la femme.

- Beaucoup de filles sont élevées pour accepter le droit de l'homme à la violence ou la violence comme une expression de l'amour de l'homme. Certains blâment la victime plutôt que de tenir l'homme responsable.

- Dans les communautés où la violence à l'encontre des personnes non conformes aux rôles de genre attendus (homosexuels, transsexuels et féministes déclarées dans les sociétés conservatrices), les « crimes haineux » deviennent parfois un aspect courant de la culture.

7 Outre une violation des droits humains, la violence à l'encontre des femmes est un problème de santé publique de proportion épidémique.

- L'incidence de la violence de genre varie grandement suivant les circonstances historiques et les contextes sociaux.

- La violence faite aux femmes est souvent liée à la consommation masculine d'alcool et de drogue.

- Cette violence peut être cause de problèmes de santé physique ponctuels ou durables, ainsi que de troubles de la santé mentale tels que dépression et isolement. La violence de genre est aussi associée à une prévalence plus élevée du VIH et d'autres IST.

8 Hommes, femmes et jeunes luttent, au niveau local, national et international, contre la violence interpersonnelle, y compris toutes les formes de violence de genre. Leurs initiatives s'expriment sous la forme d'efforts de réforme légale, de campagnes de sensibilisation et de changement des normes. 


\section{la contrainte sexuelle est une forme de violence de genre}

Voir l'unité 3, pp. 106-107:

Le consentement sexuel et la contrainte.
Toute personne a le droit de vivre à l'abri de toutes formes de violence et contrainte sexuelles (Paragraphe 96, Programme d'action de la QCMF, 1995).

1 La contrainte sexuelle survient quand une personne en force (ou essaie de forcer) une autre à participer à un acte sexuel contre son gré. L'acte sexuel est contraint si une personne estime ne pas avoir le choix de refuser l'acte sans avoir à faire face à de sérieuses conséquences sociales ou physiques.

2 La contrainte sexuelle est une forme de violence. Elle reflète et renforce l'inégalité de genre.

- Les hommes comme les femmes peuvent être contraints à avoir des rapports sexuels non désirés, mais les femmes en sont plus souvent victimes.

- Certaines communautés ou lois tolèrent la contrainte sexuelle, plutôt que d’y voir un type de violence.

3 La contrainte sexuelle revêt différentes formes : manipulation affective, duperie, force ou menace physique, insistance verbale, attentes culturelles ou incitation économique. 


\section{La contrainte sexuelle s'exerce dans de nombreux contextes.}

Par exemple :

- Elle intervient souvent dans un contexte ou une situation habituellement considérée comme sûre : chez soi ou chez des amis ou parents, à l'école, dans un établissement de culte, au travail, avec un petit ami ou au sein du mariage.

- Elle peut aussi se produire dans d'autres circonstances : avec un étranger, en échange d'argent ou de cadeaux (avec des pairs ou des partenaires plus âgés), dans les situations de guerre, en prison, etc.

\section{Quel que soit le contexte, la contrainte sexuelle est une violation des droits} humains.

\section{Comme les autres formes de violence, la contrainte sexuelle a de} graves conséquences.

- Elle peut être source de problèmes affectifs, tels que sentiments d'insécurité, isolement, faible estime de soi et profonde dépression. Elle peut aussi être cause de blessure physique ou même de mort.

- Lacte sexuel contraint s'effectue souvent sans protection. Il est en fait lié à un risque accru de grossesse non planifiée et de contraction d'IST, VIH compris. [Voir l'unité 7.] 


\section{faire face à la violence de genre}

\section{POINTS DE RÉFLEXION}

Réfléchissez aux raisons pour lesquelles les femmes restent avec des partenaires violents. Est-ce pour des raisons économiques? De peur pour leur sécurité ou pour leur famille? D'inquiétude sur le qu'en-dira-t-on ? De manque d'options? Ou d'ignorance de leurs droits?
- 1 Dans certains cas, les hommes renoncent à la violence physique. Dans d'autres, les femmes quittent leur partenaire violent. Beaucoup restent cependant dans des relations violentes. [Voir l'unité 4.]

2 L'incidence de la violence de genre peut être réduite de différentes manières, en veillant notamment à ce que tous et toutes sachent qu'ils ont le droit de vivre sans violence, contrainte sexuelle comprise. [Voir les unités 3 et 8.]

3 Tout le monde peut renforcer son propre engagement et ses capacités de communication avec amis, famille et partenaire sur les problèmes liés à la violence de genre, y compris la contrainte sexuelle. Chacun peut encourager ses amis et amies à en faire autant.

4 De plus en plus de personnes (hommes et femmes), d'organisations, de communautés et de gouvernements s'attachent à réduire la violence.

Par exemple :

- en montrant comment résoudre les conflits sans violence et comment exprimer ses sentiments de manière respectueuse et efficace ;

- en soutenant les survivants et survivantes de la violence de genre et en leur offrant un refuge temporaire sûr où trouver aide et sécurité ;

- en changeant les attitudes qui tolèrent ou excusent la violence ou qui blâment la victime ;

- en prônant les normes qui font honneur à la diversité et la différence et qui soutiennent les garçons et jeunes hommes qui rejettent les rôles masculins agressifs;

- en informant les gens sur la violence, y compris les normes de genre qui la favorisent, les nombreux contextes dans lesquels elle survient, le droit de chacun et chacune à vivre sans violence et l'importance d'une responsabilité partagée pour réduire la violence ; et

- en défendant l'adoption et l'exécution de lois efficaces contre la violence. 


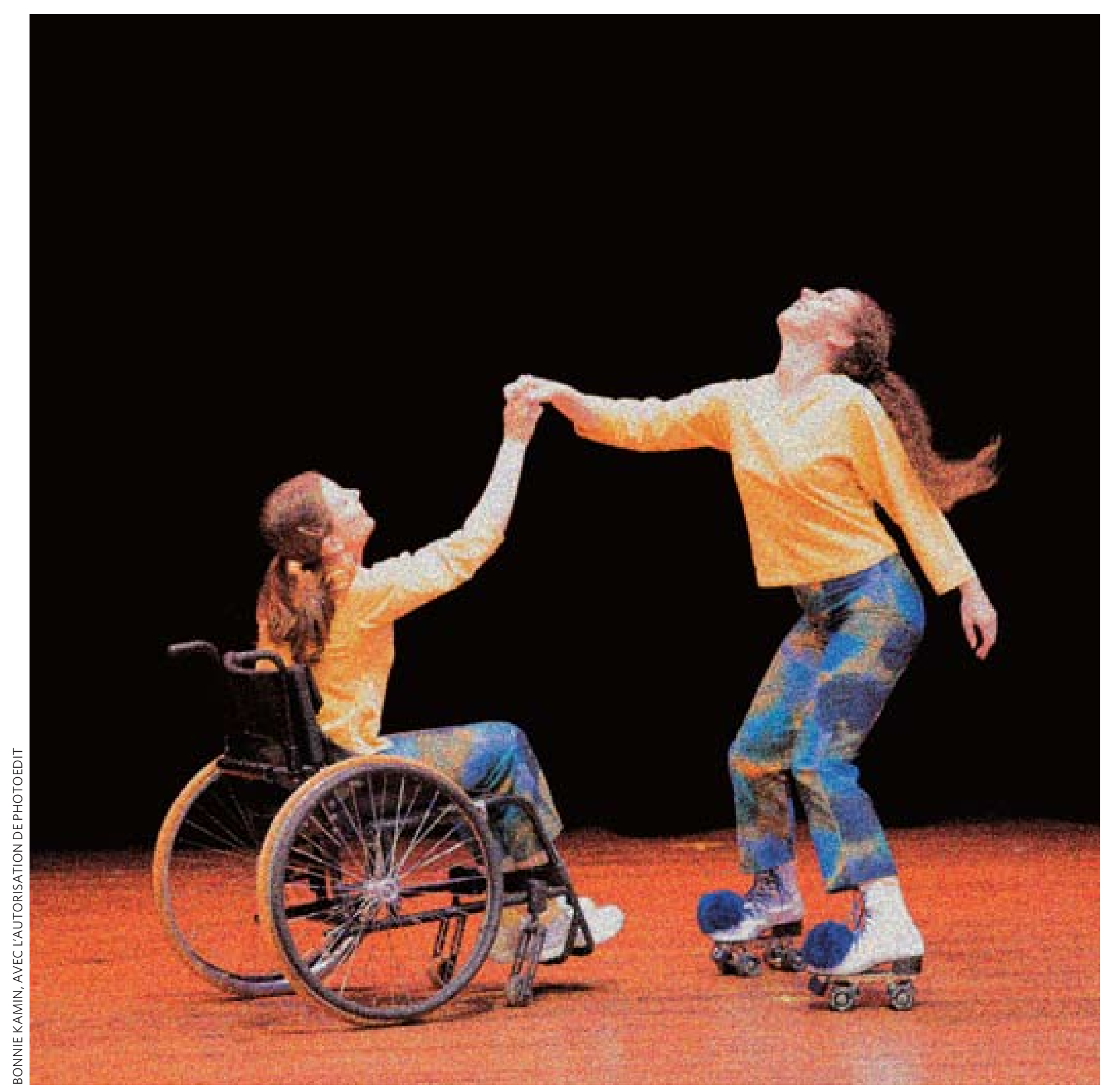

VOIR LE VOLUME D'ACTIVITÉS Activité 13

de la violence au respect dans les relations intimes

Les élèves explorent le respect et la violence dans les relations intimes à travers de petits sketchs. Ils discutent la promotion du respect dans leurs propres relations.

VOIR LE VOLUME D'ACTIVITÉS Activité 14

action contre la violence de genre

En petits groupes, les élèves développent des stratégies contre la violence faite aux femmes et les présentent sous forme de journal télévisé. 


\section{les normes et les rôles de genre évoluent dans le temps}

1 Les sociétés et les cultures sont en évolution constante. La condition humaine change, tantôt pour le meilleur, tantôt pour le pire.

Les rôles de genre évoluent aussi.

- Partout dans le monde, des millions de personnes cherchent activement à changer les normes de genre dans leur famille, à l'école et dans leur communauté.

2 Les rôles féminins changent un peu partout dans le monde, parfois rapidement.

- En beaucoup d'endroits, les filles ont de plus en plus accès à leurs droits.

- En quelques rares endroits pourtant, leur vie est soumise à de plus en plus de restrictions.

3 Les rôles masculins changent aussi, mais plus lentement.

- Les occasions pour les garçons de discuter et de modifier leur identité et leurs rôles restent limitées.

- Beaucoup de garçons ressentent les pressions contradictoires d'agir «en homme », selon la tradition, tout en devant aussi devenir plus respectueux et plus attentifs dans leurs relations avec les femmes.

- Des organisations masculines œuvrent, à l'échelle mondiale, pour mettre fin à la violence contre les femmes. Elles redéfinissent aussi la virilité pour permettre aux garçons et aux hommes de vivre une vie plus complète en leur qualité d'individus, de partenaires, de pères et de membres d'une société juste.

VOIR LE VOLUME D'ACTIVITÉS Activité 15

images de normes et rôles de genre changeants

Les élèves interviewent un grandparent sur les rôles et normes de genre de leur jeunesse et en discutent l'évolution.
4 Les attitudes à l'égard des homosexuels et des transsexuels changent rapidement en certains endroits.

5 La sensibilisation à la violence sexuelle s'accroît rapidement en certains endroits mais plus d'efforts sont nécessaires pour en réduire la prévalence. 


\section{le genre : nos décisions et nos actes}

Les États doivent prendre toutes les mesures appropriées pour éliminer les préjugés et les pratiques coutumières et autres fondés sur l'idée de l'infériorité des femmes (Article 5, CEDF, 1979).

1 Nous aspirons tous à réaliser tout notre potentiel humain.

2 Les normes et les stéréotypes que nous avons absorbés limitent cependant notre capacité de plein épanouissement.

3 Pour vaincre nos préjugés, nous devons identifier la manière dont ils ont affecté notre identité, notre développement personnel et nos choix de vie.

4 Pour réduire la discrimination de genre, il faut être capable de la reconnaître, d'y réagir et de s'y opposer.

5 La discrimination de genre est tantôt simple, tantôt difficile à reconnaître. Elle est parfois évidente : quand les garçons reçoivent les postes de leadership ou d'autres privilèges ou qu'une personne homosexuelle se fait insulter, par exemple. Mais elle peut être plus subtile et difficile à relever : quand on ignore l'opinion d'une personne en raison de son genre, notamment.

[Voir l'unité 8 pour plus de détails sur le passage à l'action.]

\section{POINTS DE RÉFLEXION}

Remettre en question les stéréotypes de genre exige une réflexion honnête et profonde sur ses propres expériences et attitudes.

Avez-vous jamais été traité/e d'une certaine manière en raison de votre sexe ? Quel effet cela vous a-t-il fait?

Quels comportements sexuels jugez-vous acceptables pour les femmes? Et pour les hommes?

Vous paraît-il juste que les filles aient plus de tâches ménagères que les garçons?

Ou qu'un garçon soit taquiné parce qu'il est « efféminé » ? 


\section{changer le monde}

1 Partout dans le monde, des millions de personnes, parfois adolescentes, œuvrent pour l'égalité sociale et de genre, pour l'assurance d'un plus grand bonheur dans leurs propres relations et vie, dans leur communauté et dans la société au sens large.

2 Les jeunes peuvent promouvoir l'égalité sociale et de genre en:

- évitant les formules désobligeantes et les blagues dégradantes ;

- s'élevant contre la discrimination et la violence de genre ;

- se rapprochant d'une personne marginalisée (et en lui offrant ainsi une aide parfois immense) ;

- veillant à assurer le traitement équitable des personnes vivant avec le VIH et sida ;

- demandant la réforme des lois qui pénalisent les personnes sur la base de leur identité sexuelle; et en

- devenant membres d'organisations telles que White Ribbon Campaign (un mouvement mondial d'hommes voués à mettre fin aux violences faites aux femmes).

VOIR LE VOLUME D'ACTIVITÉS Activité 16

plaidoyer

Les élèves composent une chanson ou écrivent un poème pour l'égalité de genre. 


\section{quelques notions sur le genre}

Les brèves définitions ci-dessous ont pour but d'aider l'utilisateur à clarifier

certains termes importants concernant le genre, tels qu'utilisés dans ce

document. Partout dans le monde, les éducateurs usent de créativité et de

sensibilité pour adapter ces concepts à leur propre contexte culturel et politique.

Égalité/inégalité de genre : Possibilités, charges et pouvoir social, politique et économique

égaux (ou inégaux) des hommes et des femmes. (L'équité de genre a un sens similaire.)

Genre : Idées sociales ou culturelles relatives à la masculinité (rôles, attributs et comportements masculins) et à la féminité (rôles, attributs et comportements féminins). Genre et sexe ne sont pas synonymes.

Normes de genre: Attentes ou croyances largement acceptées au sein de la communauté concernant la conduite ou la pensée masculine ou féminine. Les normes de genre se réfèrent aussi aux opinions sur la rigueur ou la constance avec lesquelles une personne doit se conformer à un rôle de genre ou l'autre.

Patriarcat : Système de domination masculine de la société, basé sur la croyance de supériorité du sexe masculin.

Rôles de genre : Rôles sociaux attribués par la société ou la famille aux personnes de sexe masculin ou féminin, concernant le comportement ou le type d'emploi attendu d'eux.

Sexe : Différence biologique qui distingue les hommes des femmes, déterminée par les gènes de la personne. Par exemple, seuls les hommes produisent le sperme et seules les femmes produisent des ovules et peuvent être enceintes. [Voir aussi la définition de l'intersexualité dans le glossaire de I'unité 3.] Sexe et genre ne sont pas synonymes. 


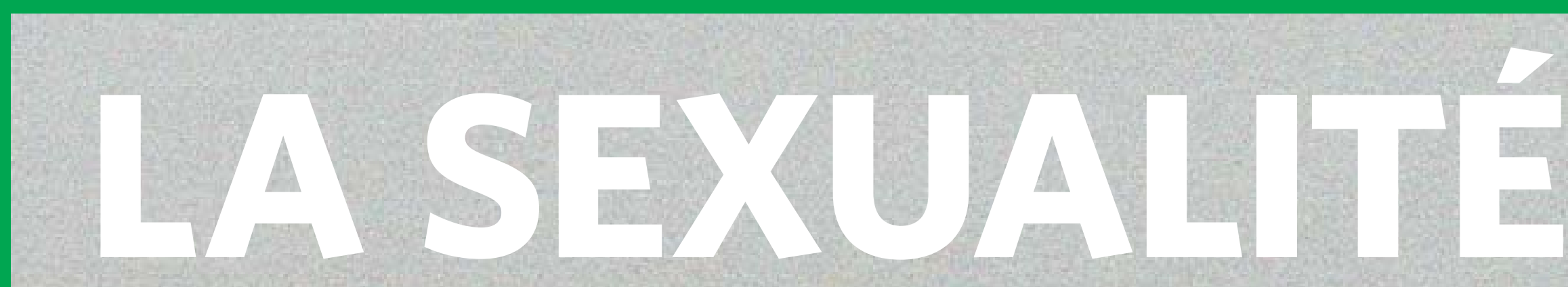




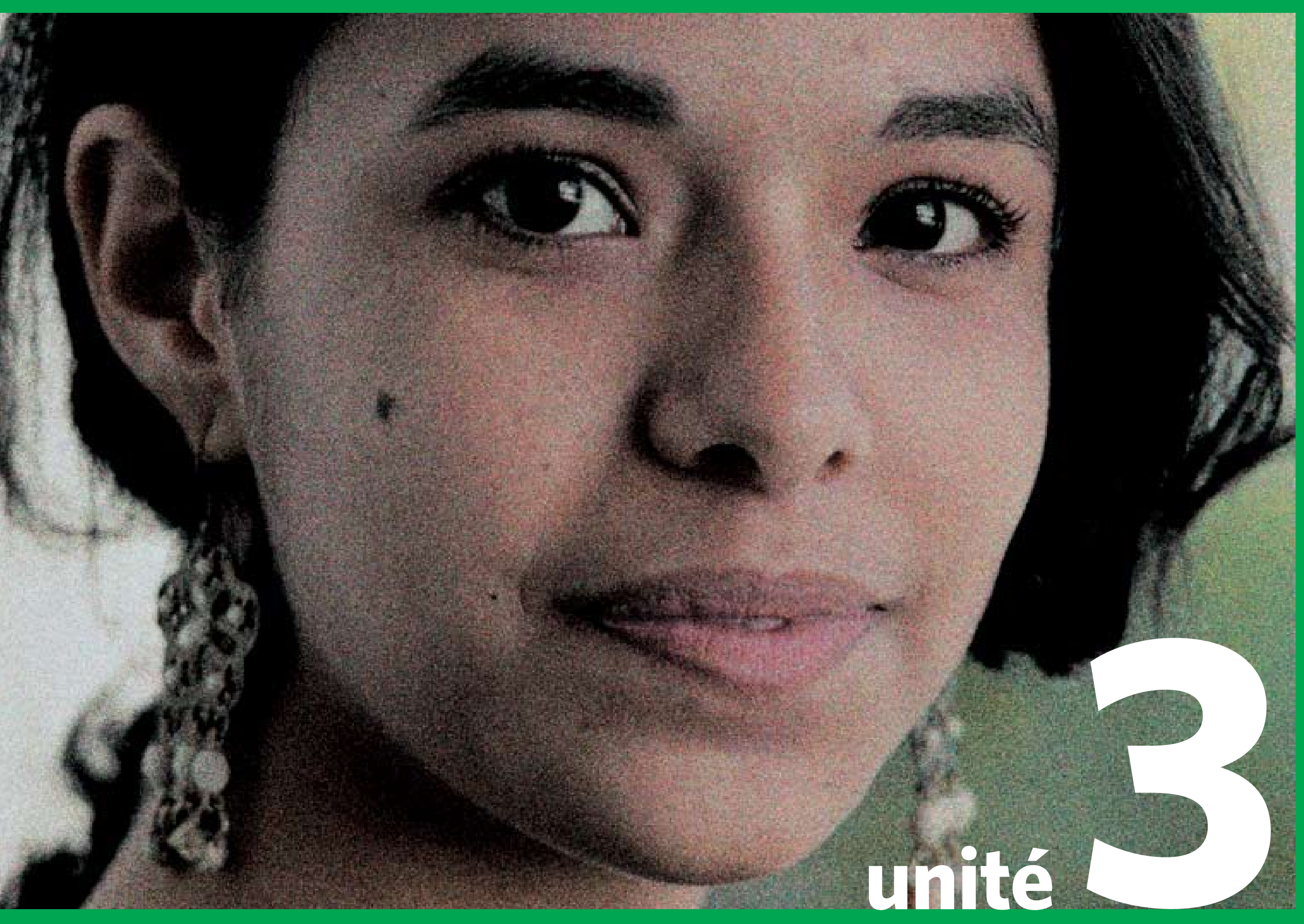




\section{panorama}

La sexualité peut être source de grand plaisir et donner un sens immense à la vie. L'activité sexuelle n'est qu'un aspect de la sexualité. Chaque être vit sa sexualité à travers ses sensations physiques, ses émotions, ses pensées, son identité et ses relations. Les normes culturelles, l'expérience individuelle et les hormones jouent toutes un rôle dans la manière dont on vit sa sexualité.

Cette unité aide les jeunes à comprendre ce qu'est la sexualité et quels facteurs affectent la manière dont ils la vivent et la perçoivent. Elle les aide à comprendre pourquoi les relations sexuelles nécessitent un certain niveau de maturité et à parler plus aisément de questions sexuelles. Elle souligne l'importance du consentement, de la réciprocité et du respect dans les relations sexuelles. 


\section{LA SEXUALITÉ}

Aidez les jeunes à comprendre le rapport entre la sexualité, le bien-être et la santé.

Couvrez les aspects positifs de la sexualité, sans oublier toutefois que beaucoup d'adolescents ne désirent pas avoir de rapports sexuels ou n'y sont pas prêts, d'un point du vue social ou de développement. Établissez clairement qu'une relation sexuelle sûre et confortable exige une certaine maturité et le pouvoir de négocier soi-même ses désirs ; ne manquez pas de soulignez l'importance de la réciprocité et du respect.

Prévoyez de discuter utilement le consentement sexuel. Beaucoup de jeunes ne sont encore sûrs ni de leurs propres désirs, ni de ceux de leur partenaire. Explorez les moyens d'assurer le consentement mutuel.

Ne laissez pas vos propres valeurs entrer en jeu dans l'éducation à la sexualité. Restez neutre et évitez d'imposer vos valeurs personnelles. Consultez les ressources aptes à vous aider à gérer votre embarras ou vos conflits éventuels vis-à-vis de la sexualité.

La discussion de la sexualité est parfois embarrassante. Une bonne préparation est utile.

Aidez vos élèves à comprendre et à utiliser sans gêne les termes propres. Si vous enseignez dans une langue qui ne possède pas de termes scientifiques pour certaines parties du corps, l'emploi naturel, avec aisance, du terme le plus approprié peut être utile.

Employez un vocabulaire respectueux et non offensif, concernant l'attirance homosexuelle, les filles sexuellement actives et les jeunes non conformes aux normes de genre conventionnelles surtout.

Certains sujets liés à la sexualité (la violence sexuelle et le sida, par exemple) peuvent éveiller des sentiments intenses et perturbants. Les élèves ne doivent pas se sentir sous la pression de divulguer leur propre expérience sexuelle. Veillez à soutenir vos élèves et à respecter leur confidentialité. Soyez cependant aussi conscient de l'obligation de rapport des cas de maltraitance de mineurs.

Encouragez un cadre sûr de discussion franche. Peut-être serait-il utile de séparer les filles des garçons pour certaines activités et de les regrouper ensuite pour une discussion commune.

Pour les questions sujettes à controverse dans votre contexte, consultez votre programme scolaire.

Plusieurs fiches d'information, en fin de volume, présentent ces sujets de façon plus détaillée. 


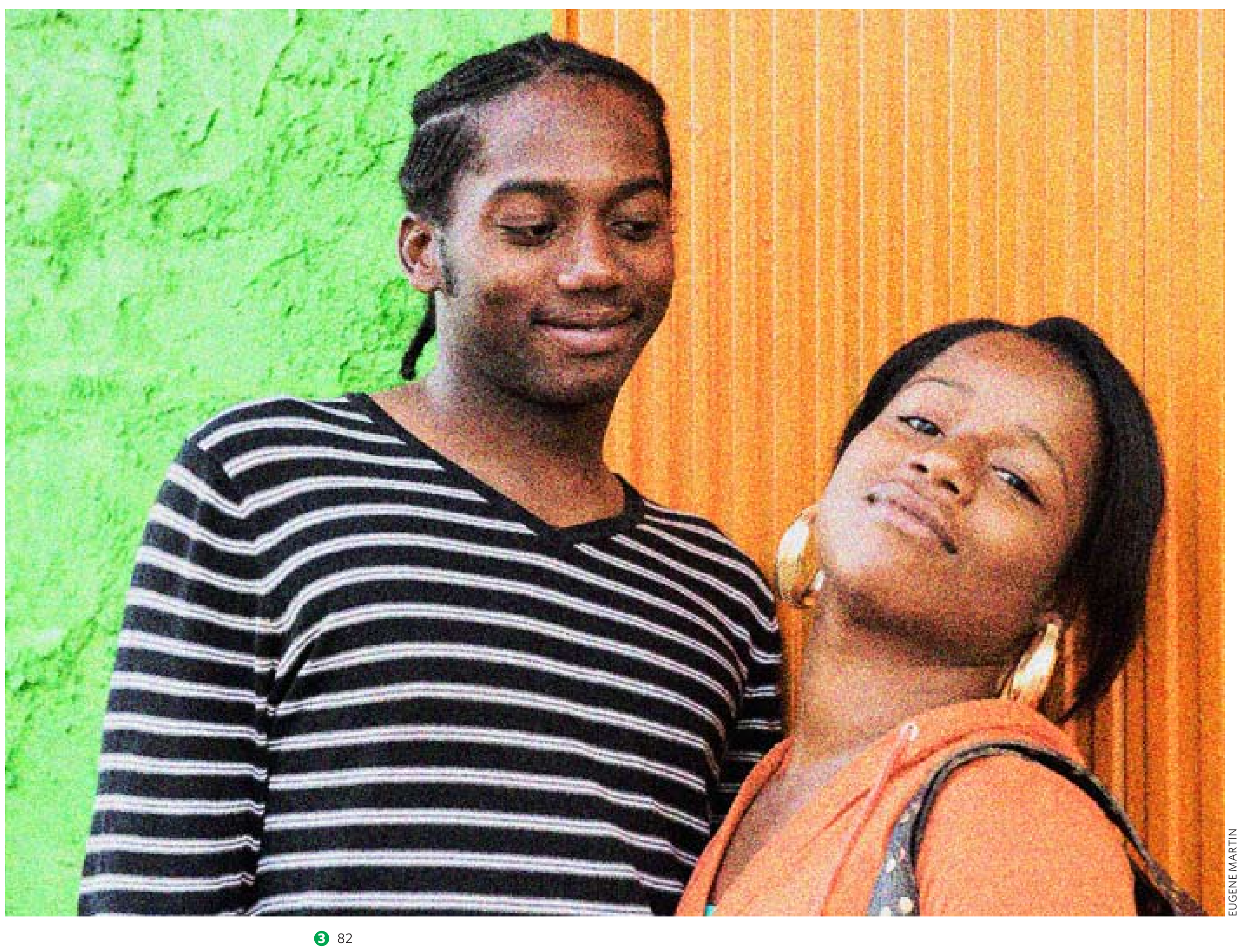




\section{LA SEXUALITÉ}

Le matériel couvert dans cette unité prépare les élèves à :

\section{Objectifs cognitifs}

Discuter au moins trois raisons pour lesquelles on désire avoir des rapports sexuels et au moins trois raisons pour lesquelles certaines personnes en ont sans les désirer.

Définir les concepts de respect, réciprocité et plaisir dans le contexte des relations sexuelles.

Définir et discuter au moins trois droits sexuels, y compris celui de refuser en toutes circonstances les rapports non désirés.

Expliquer au moins deux manières dont les normes sociales et les lois affectent les attitudes à l'égard de la sexualité et son expérience.

Discuter les normes sociales concernant diverses formes d'expression sexuelle et la manière dont ces normes ont changé ou évoluent.

Définir les concepts de consentement et d'abus/maltraitance dans le contexte des relations sexuelles.

Identifier les parties du corps qui jouent un rôle dans le plaisir sexuel.

Objectifs affectifs

Réfléchir aux moyens de promouvoir et protéger un sens positif et responsable de leur sexualité. Réfléchir à leurs propres sentiments, motivations et vécu de la décision sexuelle.

Définir et exprimer les attitudes à l'égard des normes de comportement et plaisir sexuel différentes pour les hommes et les femmes.

Clarifier leurs propres attitudes à l'égard de la diversité sexuelle. 


\section{c'est quoi, la sexualité ?}

1 La sexualité est une dimension de la vie. Elle se vit en pensées, en sentiments et en actes et pratiques.

- La sexualité peut s'exprimer en solitaire ou avec autrui.

- La sexualité inclut des désirs ou des pratiques impliquant une personne de l'autre sexe, du même sexe ou les deux.

- L'être humain est un être sexuel tout au long de sa vie. Durant certaines périodes de la vie, le désir sexuel est faible ou nul.

- On peut ressentir, à différents moment, différentes émotions liées à la sexualité : excitation, confusion, anxiété, bonheur, etc. Ces émotions peuvent être intenses, mais elles sont parfois faibles aussi.

2 Les sentiments d'aise et de confiance vis-à-vis de la sexualité s'acquièrent en grandissant. Ces sentiments sont aussi fonction de facteurs individuels, familiaux et sociaux, ainsi que du vécu.

[Voir plus loin la section sur la sexualité et la société en cette unité.]

3 La sexualité - exprimée individuellement ou dans une situation mutuellement consensuelle et respectueuse avec un partenaire - peut être source de plaisir et donner du sens à la vie. Elle peut renforcer le bonheur, le bien-être, la santé et la qualité de la vie, et nourrir l'intimité et la confiance entre les partenaires. 


\section{les droits sexuels}

Les droits fondamentaux des femmes comprennent le droit d'être maîtresses de leur sexualité, y compris leur santé en matière de sexualité et de procréation, sans aucune contrainte, discrimination ou violence, et de prendre librement et de manière responsable des décisions dans ce domaine. L'égalité entre les femmes et les hommes ... y compris le respect total de l'intégrité de la personne, exige le respect mutuel, le consentement et le partage de la responsabilité... (Paragraphe 96, Programme d'action de la QCMF, 1995).

\section{Chaque personne doit pouvoir profiter de sa sexualité.}

2 Un aspect critique de l'expérience sexuelle est qu'elle doit être volontaire et désirée par les deux partenaires.

[Voir plus loin la section sur le consentement sexuel et la contrainte en cette unité.]

- Le consentement sexuel implique une décision libre et volontaire d'activité sexuelle avec une autre personne.

- Une personne peut avoir des sentiments confus et conflictuels concernant son désir de rapports sexuels ou sa capacité de refuser des rapports non désirés. L’assurance du consentement est parfois compliquée.

- La capacité de véritable consentement des jeunes évolue à mesure qu'ils mûrissent.

\section{Certains aspects de la sexualité relèvent des droits humains; on parle alors souvent} de droits sexuels.

Les droits sexuels reposent sur des accords et pactes internationaux. Ils incluent le droit de :

- choisir ses partenaires sexuels et d'établir des relations délibérées et consensuelles ;

- accepter ou refuser l'acte sexuel ;

- exprimer sa sexualité, y compris le droit au plaisir, dans le contexte du consentement ;

- être maître ou maîtresse de son corps, sans violences ni exploitation de nature sexuelle ;

- obtenir une information et une éducation complètes et exactes, et avoir accès à tous les services; et

- se protéger contre les grossesses non désirées et l'infection, y compris le VIH.

\section{La sexualité implique aussi, pour tous, des responsabilités.}

Par exemple, la responsabilité :

- de s'assurer du consentement de l'autre ; et

- de protéger sa propre santé et celle de ses partenaires. [Voir l'unité 7, pp. 200-201.] 


\section{la sexualité et la société}

\section{POINTS DE RÉFLEXION}

Les attentes sociales et les lois affectent ce que l'on apprend et pense de la sexualité. Par exemple :

Dans quelle mesure parle-t-on ouvertement du corps et des sentiments de plaisir sexuel - dans les classes d'éducation sexuelle, les familles et la communauté ?

L'accès des adolescentes à

l'avortement sans risques est-il assuré?

Les couples homosexuels sont-ils traités avec respect?

Comment les handicapés sont-ils généralement traités, surtout en ce qui concerne leurs désirs et leurs droits sexuels?

Comment traite-t-on les personnes vivant avec le VIH et sida?

Comment les familles et communautés traitent-elles les femmes violées?
1 Tout le monde peut grandir et avoir une vie sexuelle sans risques et satisfaisante, sous le signe de la dignité, de l'égalité, de la responsabilité et du respect mutuel.

- 2 L'accès à cette vie sexuelle sans risques et satisfaisante dépend de la famille, de la communauté et de la société dans laquelle on grandit. Les normes sociales et même les lois relatives à la sexualité peuvent favoriser — ou miner — les sentiments de valeur personnelle, dignité, santé, appartenance et bien-être.

[Voir la section suivante sur la variation des normes sexuelles selon les rôles de genre.]

\section{La scolarisation des jeunes et la qualité de leur instruction peuvent affecter leur} vécu sexuel et leur santé.

- En beaucoup d'endroits, l'une des meilleures choses que les filles puissent faire pour protéger leur santé sexuelle et génésique est de rester à l'école.

- Les filles enceintes sont parfois forcées d'abandonner l'école.

- Beaucoup d'écoles favorisent l'égalité de genre et l'autonomisation des filles. Beaucoup sont pourtant encore victimes de harcèlement sexuel (et même de contrainte) à l'école ou sur le chemin de l'école. Les jeunes perçus comme homosexuels ou transsexuels sont aussi souvent harcelés. De plus en plus, les adolescents forment des groupes de soutien, parfois appelés alliances « homo-hétéro ».

- Tous les jeunes ont droit à l'information. ${ }^{1}$ De plus en plus d'écoles essaient de leur apporter une information utile qui leur permette de mener une vie sexuelle responsable et sans risques, à l'abri du VIH. Certains jeunes reçoivent aussi une information exacte sur la sexualité, le genre et les droits humains de leur famille, de leur communauté et des médias [voir le numéro 4 ci-après.]

1 Plusieurs accords internationaux sur les droits humains ont donné mandat aux gouvernements d'apporter aux jeunes une éducation qui leur permette de prendre eux-mêmes les décisions et les responsabilités concernant leur santé et de faire régner le respect mutuel concernant les questions de sexualité et de fécondité, dans le but ultime de l'égalité de genre (Paragraphes 107.a, 107.e, 281.e, Programme d'action de la QCMF, 1995; Articles 13.1 et 28.1, CIDE, 1989; Article 26.1, DUDH, 1948; Article 13.1, PIDESC, 1966; Article 10, CEDF, 1979). [Voir la section sur la sexualité et les droits sexuels.] 

influencent nos attitudes, nos sentiments et nos attentes de la sexualité.

- Si elles favorisent parfois des notions positives et exactes sur la sexualité, les images médiatiques en reflètent cependant souvent une approche étroite et trompeuse.

- Pourvu que le consentement et la sécurité soient assurés, il n’y a ni allure, ni comportement sexuel « correct » ou «incorrect». Bien au contraire, la diversité sexuelle existe partout.

\section{Tout le monde doit pouvoir participer à la vie politique, professionnelle et civique,} sans discrimination. Les normes sexuelles ne doivent opposer aucun obstacle à cette participation.

- Malheureusement, certaines personnes subissent discrimination, humiliation ou perte d'emploi parce qu'elles ne se conforment pas aux normes sexuelles dominantes. Par exemple, un homosexuel, une femme célibataire sexuellement active ou ayant plus d'un partenaire ou un sidéen peuvent en être victimes.

- Cette discrimination est contraire à de nombreux documents sur les droits humains. ${ }^{2}$

\section{Partout dans le monde, les jeunes grandissent sous l'influence de différentes attitudes et lois sur les relations sexuelles et le mariage.}

- La plupart des jeunes, mais pas tous, désirent former un couple et se marier.

- Dans certains contextes, les relations homosexuelles sont largement ou de plus en plus acceptées, y compris le droit de se marier ou de former une union légalement reconnue. Mais ce n'est pas le cas partout.

- Les personnes vivant avec le VIH et sida peuvent être confrontées à la peur ou à la discrimination en ce qui concerne le mariage, mais des millions de couples vivent un mariage heureux malgré le VIH.

- Dans certains contextes, la loi admet ou ignore toujours le viol conjugal (sans consentement d'un conjoint).

\section{POINTS DE RÉFLEXION}

Quelles impressions et idées de la sexualité tire-t-on des films, de la télévision et des clips vidéo?

L'attrait sexuel dépeint dans les médias reflète-t-il la réalité ?

Quelles impressions tire-t-on des médias sur la manière de se comporter dans un couple?

Comment les personnes ayant des rapports homosexuels sont-elles dépeintes au cinéma?

Comment les gens doivent-ils se sentir si leur apparence ou identité varie profondément de l'image médiatique présentée?

Comment les médias pourraientils présenter la diversité de la société?

Souvent, les médias présentent des images qui sexualisent les enfants, en particulier les filles. Quel en est l'effet sur les filles? Et sur les garçons? Et sur les adultes? 
7 Les religions et les chefs religieux ont des perspectives variables et cherchent parfois à influencer les normes et les politiques relatives à la sexualité et aux droits sexuels.

Ces normes et politiques concernent notamment [voir aussi l'unité 2, pp. 62-63] :

- l'éducation sexuelle ;

- l'abstinence et la virginité ;

- la contraception et l'avortement ;

- l'homosexualité ;

- la mutilation génitale ; et

- le mariage.

8 Les normes culturelles et les lois locales sur la sexualité ne sont pas statiques. Elles varient dans le temps et dans l'espace.

9 Dans leurs échanges avec la société, beaucoup de jeunes introduisent leurs attitudes indépendantes sur la sexualité et les droits. Les jeunes peuvent être fiers de leur personne et savoir qu'ils comptent dans la société.

VOIR LE VOLUME D'ACTIVITÉS Activité 17

débat sur l'éducation sexuelle

Les élèves débattent la question de savoir s'il faut informer les jeunes

sur la sexualité, le genre et la santé sexuelle ou limiter l'éducation à

l'abstinence jusqu'au mariage. 


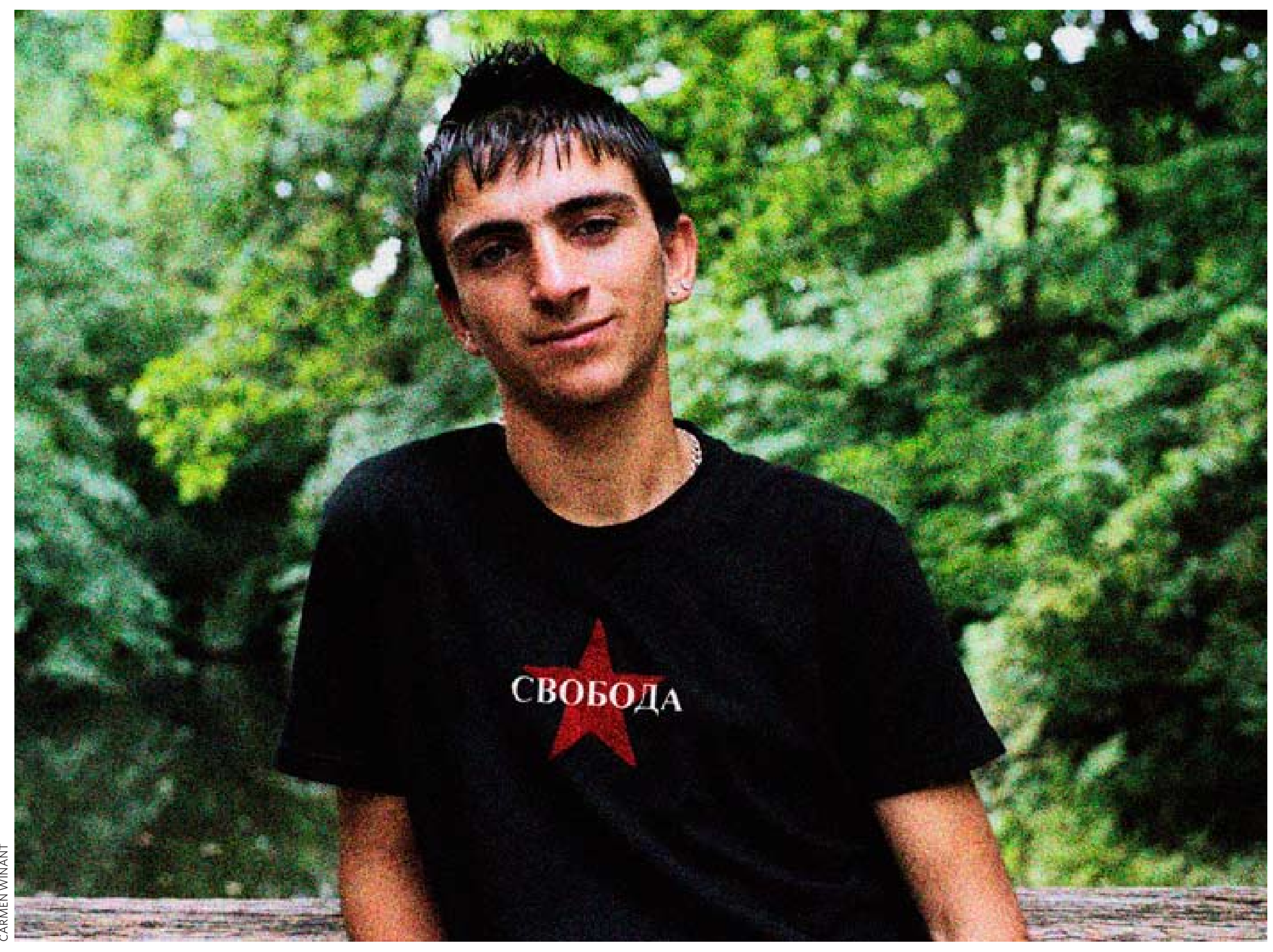




\section{les normes sexuelles varient suivant les rôles de genre : « deux poids, deux mesures »}

1 Les garçons sont souvent autorisés ou même poussés à être sexuellement actifs, pourvu que leurs désirs soient dirigés vers le sexe féminin.

Par exemple :

- Certains garçons sont encouragés et même disposés à différer leur activité sexuelle. Souvent, pourtant, ils subissent de fortes pressions de "prouver leur virilité » par une expérience hétérosexuelle précoce, répétée et parfois agressive.

- La prise de risques (même sexuels) est souvent attendue des garçons et des hommes.

2 Les filles reçoivent souvent des messages négatifs ou contradictoires.

- Beaucoup apprennent qu'elles ne doivent pas être sexuellement actives avant le mariage et sont même punies si elles le sont.

- On attend pourtant aussi d'elles qu’elles soient séduisantes. Les images médiatiques « sexualisent » parfois les filles dès un très jeune âge.

- Les filles sont souvent socialisées dans un esprit de soumission à leur petit ami, leur mari et aux hommes en général.

- Certaines filles sont poussées à avoir des rapports sexuels pour prouver leur fécondité.

3 Certaines attentes sont imposées aux garçons comme aux filles.

- Ceux et celles dont l'apparence ou le comportement dévie de l’attente sociale peuvent être harcelés ou menacés. Les garçons et les hommes jugés efféminés sont souvent traités de manière insolente ou cruelle.

VOIR LE VOLUME D'ACTIVITÉS Activité 18

- Beaucoup de jeunes ressentent la pression de changer leur apparence ou leur corps pour se conformer aux idéaux culturels de la séduction. Les filles subissent généralement ces pressions plus intensément que les garçons.

\section{premières impressions}

Les élèves examinent leur réponse à une histoire suivant qu'ils pensent que le personnage principal est une fille ou un garçon. 
4 Les normes sexuelles reflètent et renforcent souvent des attitudes étroites ou mal informées sur la sexualité d'autrui. Ces attitudes peuvent viser les personnes âgées, les pauvres, les membres de certains groupes ethniques ou raciaux, les handicapés ou les homosexuels.

5 On peut tous décider de la mesure dans laquelle on accepte les normes relatives à la sexualité, se plier à celles qu'on n'apprécie pas ou choisir de vivre selon ses propres convictions.

\section{POINTS DE RÉFLEXION}

L'expérience de l'être masculin ou féminin varie suivant le lieu ou le groupe. Par exemple :

Comment la société voit-elle les femmes plus âgées en ce qui concerne leur sexualité ?

Les hommes de certains groupes ethniques sont-ils vus comme extrêmement érotiques ou asexués?

Une personne perçue comme homosexuelle peut être sujette à l'opprobre. En va-t-il de même s'il se fait qu'elle est riche aussi?

Pourquoi les handicapées intellectuelles risquent-elles plus les maltraitances sexuelles?

Pensez à une personne que vous admirez et qui vit selon ses convictions et valeurs propres, même si elles diffèrent de celles de la société en général. Pensezvous qu'elle en subisse certaines difficultés ? Pourquoi admirezvous cette personne? 


\section{le désir sexuel}

1 Le désir sexuel (envie d'expression sexuelle ou sentiment d'attirance sexuelle) se vit de différentes manières. II n'y a pas de formule « normale » du désir sexuel.

- Presque tout le monde ressent le désir sexuel, parfois de manière intense. On peut désirer une autre personne (du même sexe, de l'autre sexe ou les deux) ou bien ressentir un désir plus général qui n’est pas nécessairement attaché à une autre personne.

- Dans une relation intime, une personne peut ressentir plus de désir sexuel que l'autre.

- Le niveau de désir sexuel d'une personne peut varier d'un moment à l'autre ou au fil de la vie. On peut ressentir un désir sexuel jusqu'à la fin de sa vie, bien que la réponse physique du corps puisse changer avec l'âge.

- Le désir sexuel survient en réponse à un large éventail de stimuli. Les préférences personnelles, l'expérience de la vie et les normes culturelles influencent ces réponses.

\section{Divers facteurs sociaux, affectifs et physiques façonnent le désir d'expression} sexuelle. Ces facteurs sont souvent interdépendants.

- Certains facteurs sont physiques : niveaux hormonaux, alcool et autres drogues, fatigue ou maladie.

- Certains facteurs sont affectifs : sentiment d'être respecté et compris dans une relation, ou souvenir de sévices sexuels.

- L’environnement social peut aussi influencer l'expression du désir. Par exemple :

- Un manque d'intimité ou des sentiments de nervosité ou de timidité peuvent compliquer l'expression du désir.

- Les normes de genre font que certains garçons se croient censés vouloir des rapports sexuels même s'ils ne les désirent pas. Par contre, les filles, les jeunes, les handicapés et les homosexuels apprennent parfois qu'il est inacceptable d'exprimer son désir sexuel. 


\title{
3 On confond souvent le désir ou l'attirance sexuelle avec d'autres expériences
} affectives ou physiques.

- Le désir sexuel et l'amour sont deux choses différentes, même si elles sont souvent confondues. On peut ressentir un désir sexuel avec ou sans amour (à l'égard d'une personne qu'on connaît à peine, par exemple). [Voir l'unité 4.]

- Le désir sexuel est différent aussi de la réponse sexuelle physique. Ainsi, un garçon ou un homme peut avoir une érection sans désir sexuel, ou bien il peut ressentir du désir sans avoir d'érection.

- Désir sexuel et activité sexuelle ne sont pas synonymes. Une personne éprouvant du désir peut choisir d’y répondre ou non. L'activité sexuelle n'est pas toujours le produit du désir. Elle peut ou non accroitre le désir.

\section{Pour beaucoup, le fantasme peut éveiller ou accroître le désir.}

- Il est normal, et non honteux, de penser à un acte sexuel.

- Le fantasme n'implique pas nécessairement le désir d'accomplir l'acte imaginé. Il n'implique pas non plus que son auteur va passer à l'action.

\author{
VOIR LE VOLUME D'ACTIVITÉS \\ Activité 19 \\ la vérité sur le désir \\ Les élèves répondent à un \\ questionnaire « vrai ou faux » sur le \\ désir sexuel et le genre.
}




\section{la diversité sexuelle}

\section{Note terminologique :}

On parle parfois d'orientation sexuelle ou d'identité sexuelle, entre autres termes, pour désigner l'attirance envers une personne du même sexe ou de sexe opposé. Dans ce document, les expressions identité ou diversité sexuelle désignent le vaste éventail de l'expression sexuelle. Les personnes attirées par celles du même sexe se disent homosexuelles ou préfèrent d'autres termes, tels que gays ou lesbiennes. Un terme approprié et respectueux dans un contexte ne l'est pas toujours dans d'autres. Les expressions attirance envers le même sexe et homosexuelle sont utilisées ici de manière interchangeable. Veillez à utiliser celle appropriée dans votre contexte.
1 D'abord et surtout, nous sommes tous humains. Tous semblables et différents des autres membres de nos familles, écoles, lieux de travail et communautés. L'écart est grand, notamment, dans nos apparences, nos pensées, nos talents et notre sexualité. Cette diversité de l'expérience humaine est universelle.

2 La variation des désirs, comportements et identités sexuels représente ce que l'on appelle la diversité sexuelle.

3 Certaines personnes éprouvent des sentiments d'amour, d'attirance et de désir sexuel envers d'autres de sexe opposé, du même sexe ou les deux. Il en va ainsi depuis toujours et dans toutes les sociétés, ouvertes ou non à l'homosexualité.

- Le terme hétérosexuel décrit les personnes qui désirent celles du sexe opposé. Homosexuel décrit celles attirées par d'autres du même sexe. Ces termes sont privilégiés dans certains contextes. Dans d'autres, d'autres termes sont utilisés (voir la note en marge).

- De même, les personnes transsexuelles (dont l'identité de genre diffère du sexe qui leur a été attribué à la naissance) peuvent être attirées vers d'autres du même sexe, du sexe opposé ou les deux.

- Une personne peut s'identifier ou non comme hétérosexuelle, homosexuelle (ou gay ou lesbienne) ou bisexuelle (attirée vers des êtres du même sexe aussi bien que du sexe opposé).

- Une personne peut recevoir l'étiquette d'une identité sexuelle qu'elle ne revendique pas. Certaines ne veulent pas être cataloguées en fonction de leur sexualité ou de leur identité sexuelle, indépendamment de leurs préférences.

- Les facteurs qui déterminent l'attirance d'une personne envers le même sexe, l'autre sexe ou les deux ne sont pas bien compris. Aucune religion, thérapie ou intervention médicale ne peut changer ces préférences. Les désirs, le comportement ou l'identité d'une personne peuvent varier dans le temps et selon les circonstances.

4 Les personnes hétérosexuelles, homosexuelles, bisexuelles et transsexuelles se retrouvent dans tous les types de famille, communauté, religion et profession. 


\section{Selon les principes des droits humains, chaque personne a le droit d'avoir des relations consensuelles avec qui bon lui semble.}

6 Dans chaque société, les sentiments varient à l'égard de la diversité sexuelle et de I'homosexualité.

- Certaines personnes célèbrent la diversité sexuelle. D’autres redoutent ou haïssent même les homosexuels. D’autres encore éprouvent des sentiments ambigus. L'homophobie désigne la peur ou l'aversion envers les homosexuels.

- Les sentiments individuels reflètent souvent les normes locales. Celles-ci varient, de l'opprobre et de la discrimination (refus de logement ou d'emploi) au rejet (taquineries), à la tolérance, à l'acceptation et au respect jusqu'à atteindre, finalement, la valorisation et l'acceptation totale de la diversité.

\section{Malheureusement, le rejet, l'opprobre et la discrimination à l'égard des êtres qui} désirent ou qui établissent des relations de même sexe sont répandus, au préjudice de ceux qui en sont victimes et de leurs droits humains.

- Les personnes ridiculisées pour leur attirance homosexuelle vivent parfois dans la honte et l'isolement.

- Là où l'homosexualité est cause d'opprobre, les personnes attirées par d'autres du même sexe peuvent éprouver des difficultés ou avoir peur de reconnaître leurs propres sentiments sexuels et de les gérer ouvertement.

- Certaines personnes s’identifient publiquement comme hétérosexuelles alors que leur désir sexuel est dirigé principalement (ou exclusivement) vers le même sexe.

- Les garçons qui n’agissent pas de manière « suffisamment masculine » peuvent être intimidés et forcés à adopter un comportement qui les met mal à l'aise. 
VOIR LE VOLUME D'ACTIVITÉS Activité 20

se sentir différent

Les élèves identifient les

sentiments d'appartenance ou

de différence par rapport aux

autres et réaffirment les droits des

minorités, y compris sexuelles.

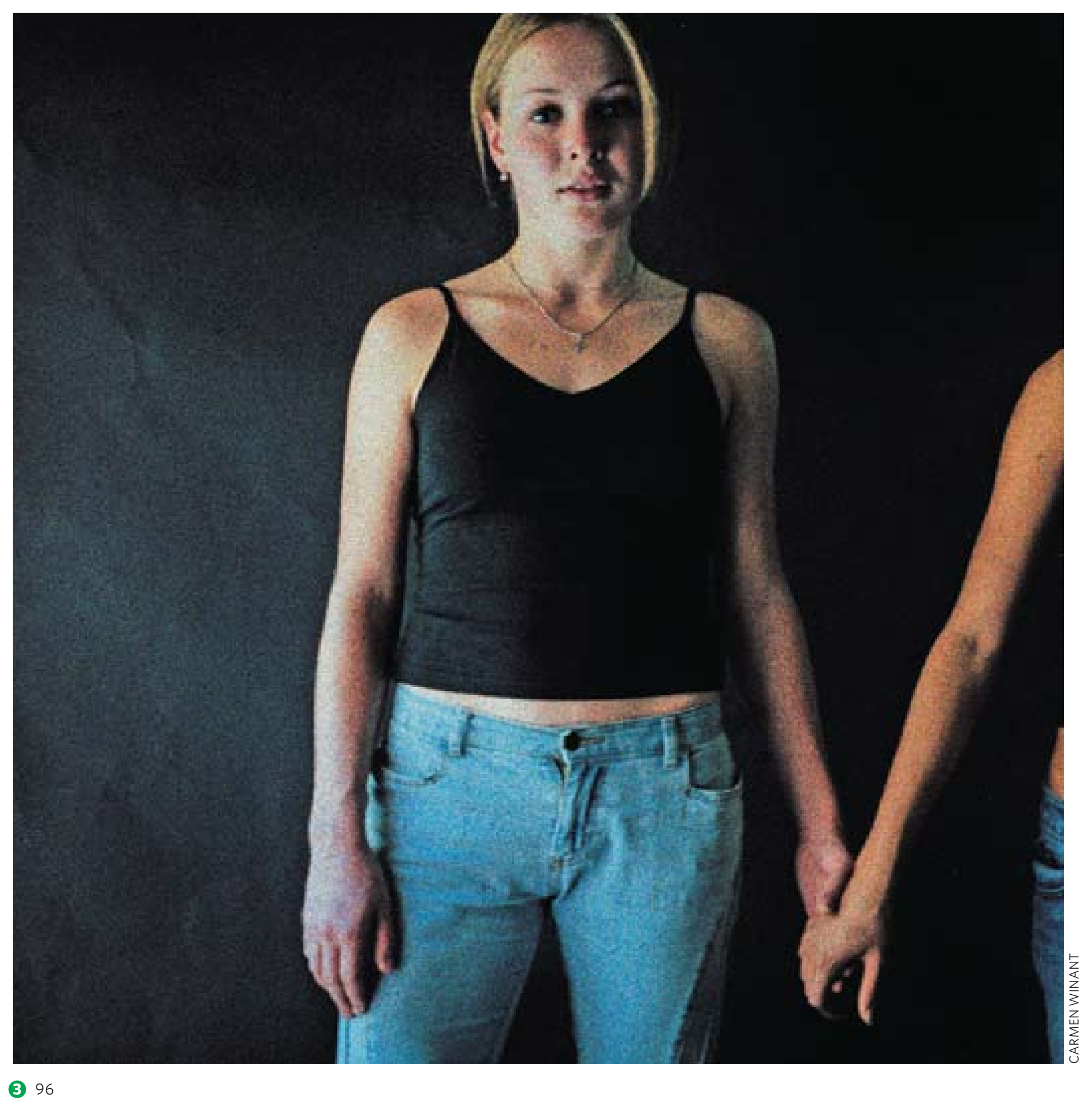


8 Tout le monde doit pouvoir participer à la vie politique, professionnelle et civique, sans discrimination. Les normes sexuelles ne doivent opposer aucun obstacle à cette participation.

9 La transition vers l'acceptation de la diversité sexuelle est en cours dans de nombreuses régions du monde.

- Des millions de personnes — homo- comme hétérosexuelles — défendent le droit de chacun de choisir ses partenaires sexuels et d'établir des relations basées sur le consentement mutuel.

- Partout dans le monde, les lycéens forment des alliances « homo-hétéro » pour s'opposer à l'homophobie et sensibiliser l'opinion à la diversité sexuelle.

- Nombre d'organisations pour les droits humains, les droits civils et la santé publique se sont prononcées au soutien des droits de toutes les personnes de choisir leurs partenaires sexuels et d'établir des relations basées sur le consentement mutuel.

- Les médias aident parfois aussi à promouvoir le changement des attitudes sociales et des lois relatives à la diversité sexuelle.

- Même dans les contextes conservateurs où les relations homosexuelles étaient jusque là taboues, il est aujourd'hui possible d'engager un débat respectueux et sensible sur la question.

10 La discrimination à l'encontre d'une personne sur la base de son identité sexuelle, de ses attirances et de son comportement consensuel est une violation des droits humains.

VOIR LE VOLUME D'ACTIVITÉS Activité 21

attirance vers une personne du même sexe : histoires vraies

Les élèves lisent trois récits d'adolescents qui se rendent compte qu'ils ne sont pas

hétérosexuels et discutent leurs réactions. L'information incorrecte est rectifiée. 


\section{l'anatomie et le plaisir sexuel}

\section{POINTS DE RÉFLEXION}

Le cerveau module beaucoup de fonctions de nature sexuelle. Comment le cerveau (ou l'esprit) influence-t-il par exemple l'expérience et le plaisir sexuels? Une stimulation sexuelle ou érotique dans une situation peut être nulle ou même déplaisante dans une autre. Pourquoi?
1 Le cerveau participe intensément au vécu et au plaisir sexuel. II répond à l'apport hormonal et traite les émotions. Selon certains experts, le cerveau est l'organe sexuel le plus important.

2 Toutes les parties du corps peuvent être sensibles au stimulus sexuel. Par exemple, on peut ressentir du plaisir sexuel au toucher du visage, du ventre, des mamelons, des oreilles, des jambes, etc. Chaque personne répond différemment et la réponse de chacun dépend de la situation.

3 Certaines parties du corps qui contribuent au plaisir sexuel sont spécifiques aux hommes ou aux femmes.

[Voir les fiches d'information sur l'Anatomie et le plaisir sexuel et l'Appareil sexuel et génital.]

- Chez les garçons et les hommes : le pénis, les testicules, le scrotum et la prostate.

- Chez les filles et les femmes : le clitoris, la vulve, le vagin et les seins.

- Le clitoris (pas le vagin) est l'organe du corps féminin le plus sensible à la stimulation sexuelle. La plupart des femmes atteignent l'orgasme (le point culminant du plaisir sexuel) par stimulation du clitoris (et non sous l'effet de la pénétration du pénis dans le vagin). Beaucoup ne le comprennent malheureusement pas.

4 La manière dont le corps répond effectivement à la stimulation sexuelle implique différents processus physiologiques.

Par exemple :

- Le cœur bat plus vite.

- Le sang afflue vers la région génitale. Chez les garçons et les hommes, cet afflux sanguin cause l'érection.

- Le corps sécrète des liquides. Chez les femmes, le vagin s'humidifie et, chez les hommes, le pénis peut émettre quelques goutes de liquide pré-éjaculatoire (différent du sperme émis par l'éjaculation).

- La réponse du corps à la stimulation sexuelle varie suivant les circonstances et d'une personne à l'autre. 


\section{l'expression sexuelle et le plaisir}

1 Le plaisir affectif et physique est important au bien-être sexuel. Les organismes de santé publique et de défense des droits soutiennent les droits de toutes les personnes à l'expression sexuelle. Ces droits incluent le droit de rechercher le plaisir dans un contexte de sécurité et de véritable consentement mutuel.

2 Le plaisir sexuel varie d'une personne à l'autre.

- On peut éprouver le plaisir sexuel en se touchant soi-même ou par expérience partagée (avec une personne du même sexe ou de l'autre). On peut aussi vivre ce plaisir sans attouchements.

- Les sources de plaisir sexuel peuvent inclure le fantasme, la parole, la lecture, le cinéma, les caresses, le baiser ou le contact génital.

- Pour que l'acte sexuel procure du plaisir, il faut savoir ce que l'on aime soi-même et ce qui plaît à l'autre.

3 Se toucher ou se caresser soi-même (au niveau des organes sexuels en particulier) pour se donner du plaisir sexuel porte le nom de masturbation.

[Voir la section suivante sur le comportement sexuel.]

- La masturbation est une façon importante de découvrir son corps et sa sexualité.

- La plupart des gens recherchent le plaisir par masturbation tout au long de leur vie, même quand ils ont un partenaire sexuel ou qu'ils sont mariés.

- La masturbation est un comportement sexuel sûr, sans risques physiques ni mentaux. 


\section{POINTS DE RÉFLEXION}

En quoi les attitudes diffèrent-elles à l'égard de la virginité féminine et masculine?

Comment traite-t-on les garçons qui ont eu plusieurs partenaires sexuelles? Et les filles?

Quels messages l'éducation à I'abstinence seule, le mariage d'enfants et la mutilation génitale des filles transmettent-ils sur le plaisir sexuel?

Les jeunes hommes comprennentils généralement comment les femmes atteignent l'orgasme (par stimulation du clitoris plutôt que par pénétration du vagin)?
4 L'excitation sexuelle peut atteindre un point culminant appelé orgasme. Outre un sentiment d'euphorie, l'orgasme produit des spasmes involontaires et la sécrétion de liquide (sperme chez l'homme ; lubrification génitale chez la femme).

[Voir la section précédente sur l'anatomie et le plaisir sexuel.]

- Beaucoup de femmes n'atteignent l'orgasme que par stimulation du clitoris. Dans la découverte de son propre corps, chaque fille doit avoir l'occasion d'apprendre la fonction du clitoris.

- Le plaisir orgasmique provient en partie d'une hausse du niveau d'endorphines, substances chimiques produites par le cerveau pour réduire la douleur et donner un sentiment de bien-être.

- L'orgasme peut être atteint sans rapports sexuels et l'acte sexuel s'accomplit parfois sans orgasme.

- La pression d'atteindre l'orgasme peut réduire le plaisir sexuel et rendre l'orgasme difficile ou impossible.

- Les femmes qui ont subi une mutilation génitale peuvent toujours éprouver un plaisir sexuel. [Voir la fiche d’information sur la Mutilation génitale des filles.]

๑ 5 Idéalement, dans une relation sexuelle, les deux partenaires cherchent à assurer le plaisir de l'autre aussi bien que le leur propre. Il est cependant parfois inculqué aux hommes comme aux femmes que les hommes (hétérosexuels surtout) ont davantage le droit de rechercher le plaisir sexuel.

6 Pourvu que l'activité sexuelle soit véritablement et mutuellement consensuelle et sans préjudice, il n'y a pas de vraie ou meilleure façon d'en profiter.

7 On désire généralement que son ou sa partenaire sexuelle éprouve du plaisir. Sans connaître son propre corps ou celui de l'autre, beaucoup ne savent cependant pas comment s'y prendre. Beaucoup ne savent par exemple rien du clitoris, ou n'osent pas parler de ce qui leur fait le plus plaisir. 


\section{le comportement sexuel}

1 Indépendamment de l'identité sexuelle, du genre ou de l'aptitude physique, on exprime et on vit sa sexualité à travers différents comportements sexuels. Aucune pratique sexuelle n'est meilleure (ou pire) qu'une autre - pourvu que les partenaires se respectent et y consentent pleinement sans se faire de mal.

\section{Les enfants s'intéressent à leur corps et à la reproduction.}

- La plupart des enfants se touchent les organes génitaux parce qu'ils en tirent du plaisir. Chez les petits enfants, cette masturbation n'a pas d'intention sexuelle. [Voir la section précédente sur l'expression sexuelle et le plaisir.]

- La masturbation est sans risques mais souvent découragée ou pire dans certaines cultures et religions. Beaucoup de parents ne savent par conséquent que dire à leurs enfants à son sujet.

- Les enfants qui découvrent leur corps peuvent explorer leur sexualité avec d'autres de l'un ou l'autre sexe.

\section{Le comportement sexuel est extrêmement varié.}

Les comportements ci-dessous sont courants :

- Pour beaucoup, la masturbation (se toucher soi-même) reste une pratique courante tout au long de la vie. Il s'agit d'un comportement sexuel sûr, sans risques physiques ni mentaux.

- Se caresser, s'embrasser, partager ses fantasmes érotiques, stimuler les organes génitaux de son partenaire de la main, se frotter l'un contre l'autre et d'autres pratiques peuvent mener à l'orgasme sans pénétration.

- Les relations buccogénitales impliquent le contact de la bouche sur les organes génitaux.

- Les rapports sexuels (parfois appelés acte sexuel) désignent l'activité sexuelle dans laquelle le pénis pénètre le vagin ou l'anus. D’autres formes de pénétration s'effectuent avec les doigts ou avec un objet.

4 II est possible de vivre une expérience sexuelle intime sans se toucher. Les pratiques sans pénétration (ni échange de liquides corporels) ne présentent pas les mêmes risques pour la santé que les rapports sexuels ou buccogénitaux.

VOIR LE VOLUME D'ACTIVITÉS Activité 22

comportement sexuel les mythes et les faits

Les élèves participent à un jeu dans lequel ils décident si les énoncés qui leur sont soumis sur le comportement sexuel sont vrais ou faux. Les idées fausses sont corrigées et discutées. 


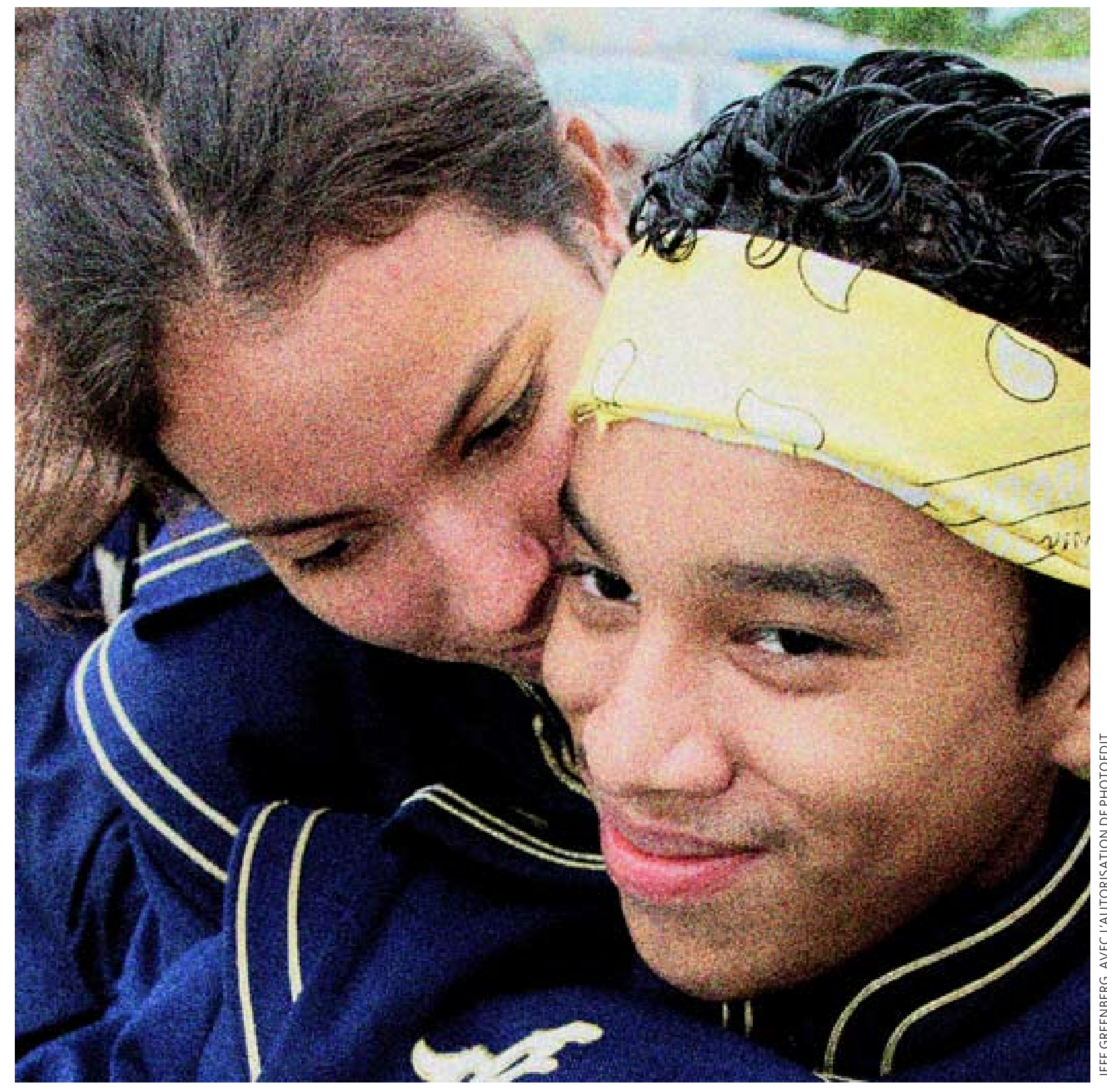




\section{rapports sexuels ou non : motivations}

1 Comme pour d'autres activités, les rapports sexuels répondent à différentes motivations, parfois multiples.

- Les raisons pour lesquelles on se sent motivé (ou non) à avoir des rapports sexuels tiennent souvent à l'âge, au sexe, à la situation économique de la personne, à l'intimité de la relation ou à d'autres circonstances.

- Les sentiments contradictoires ne sont pas rares : on veut et on ne veut pas, tout à la fois, avoir de rapports sexuels.

- Même jeune, on sait parfois clairement qu'on désire des rapports sexuels et pourquoi. Il arrive cependant souvent, aux jeunes surtout, de ne pas être sûr de soi sur ces questions.

2 On peut vouloir des rapports sexuels en réponse à un désir sincère.

Par exemple :

- pour donner ou pour recevoir du plaisir ;

- pour découvrir sa propre sexualité et ses sentiments ; et

- pour exprimer son intimité, son rapprochement et son amour.

3 Les rapports sexuels sont parfois le moyen d'arriver à d'autres fins. Même s'ils sont consensuels et sans risques, une personne peut décider d'avoir des rapports sexuels pour satisfaire à d'autres besoins ou obligations sociales.

Par exemple :

- pour « gagner» ou « garder» l'amour de quelqu'un ;

- pour éviter une querelle ou une situation potentiellement violente ;

- pour rehausser sa stature sociale;

- pour prouver sa virilité ou sa féminité ;

- pour l'expérience ou pour assouvir sa curiosité ;

- pour défier l'autorité des adultes ;

- pour démontrer son pouvoir sur autrui;

- en échange d'avantages matériels (cadeaux ou argent), de nourriture ou d'articles de première nécessité ;

- pour accomplir son obligation conjugale; et

- pour avoir des enfants. 


\section{Une personne peut avoir une ou plusieurs raisons courantes et acceptables de ne}

pas avoir de rapports sexuels.

Par exemple :

- Elle ne les désire tout simplement pas, même sans raison particulière.

- Elle se sent trop jeune pour avoir des rapports sexuels.

- Elle estime que sa relation avec l'autre n'a pas encore atteint le stade où ils devraient avoir des rapports sexuels. Elle estime que l'autre n'est pas assez « sérieux », elle n'est pas « amoureuse » ou elle ne veut pas se marier.

\section{VOIR LE VOLUME D'ACTIVITÉS}

\section{Activité 23}

\section{pourquoi (ou pourquoi pas)}

Les élèves choisissent s'ils sont d'accord ou non avec une série d'énoncés sur les raisons d'avoir — ou non - des rapports sexuels.

\section{VOIR LE VOLUME D'ACTIVITÉS}

Activité 24

sur la ligne : le continuum entre le choix sexuel et la contrainte

Les élèves placent des études de cas sur le continuum entre les rapports sexuels forcés et ceux volontaires et désirés et discutent le droit de refuser.
- Elle ne fait pas suffisamment confiance à l'autre, n'est pas à l'aise ou pas suffisamment intime avec l'autre pour avoir des rapports sexuels. Ou elle ne ressent pas assez de respect et de réciprocité dans la relation.

- Elle ne se sent pas à l'aise dans la situation où elle se trouve.

- Les garçons, en particulier, peuvent s’inquiéter de leur performance sexuelle : sauront-ils maintenir leur érection ou éjaculeront-ils trop vite?

- Elle redoute le risque d'une grossesse.

- Elle s'inquiète du VIH ou d'autres IST ou a peur d'infecter son partenaire.

- Elle redoute les conséquences possibles sur son rang social.

- Avoir des rapports sexuels dans la situation où elle se trouve est contraire à ses valeurs ou à sa morale.

- Sa religion, ses parents ou sa communauté condamnent les rapports sexuels avant le mariage.

- Elle a peur de répondre à son attirance envers une personne du même sexe qu'elle.

- Elle n’a pas éprouvé de plaisir lors de ses rapports sexuels passés. Ils représentent un aspect ennuyeux de sa relation.

- Elle ne se sent pas bien, elle est fatiguée, inquiète, troublée ou fâchée. 
5 Certaines personnes ont des rapports sexuels parce qu'elles y sont contraintes ou forcées. Ces abus sont généralement qualifiés de viol, violence sexuelle, contrainte sexuelle ou agression sexuelle et constituent une violation des droits de humains. Ils sont toujours inacceptables et la victime n'est jamais coupable.

[Voir l'unité 2, pp. 70-71.]

- Les deux sexes peuvent être contraints à avoir des rapports sexuels non désirés. Le problème affecte cependant plus souvent les filles et les femmes.

- Les jeunes - y compris les petits enfants — sont également vulnérables à la contrainte sexuelle.

6 La limite entre les rapports sexuels volontaires désirés et les rapports forcés est parfois difficile à distinguer. II s'agit plutôt d'un continuum.

Pensez par exemple aux circonstances suivantes :

- quand le désir de répondre aux besoins de son partenaire devient une obligation importune ;

- quand une personne ne sait pas comment affirmer son désir ou ses besoins propres, ou qu'elle ne pense pas avoir le droit de refuser ; ou

- quand une personne craint que le refus de rapports sexuels ne mène à de graves conséquences telles que la violence (coups ou viol), la rupture ou la perte d'un emploi.

- Les rapports sexuels sont parfois volontaires mais non désirés.

\section{POINTS DE RÉFLEXION}

Dans quels types de situation une personne peut-elle accepter d'avoir des rapports sexuels même si elle ne les désire pas?

Quelles sont selon vous les meilleures raisons d'avoir des rapports sexuels? Et les pires?

Comment s'assurer du véritable consentement de son ou sa partenaire ? Est-ce simple? 


\section{le consentement sexuel et la contrainte}

\section{Voir l'unité 2, pp. 70-71:}

La contrainte sexuelle est une forme de violence de genre.

\section{VOIR LE VOLUME D'ACTIVITÉS}

\section{Activité 25}

\section{question de consentement}

Les élèves apprennent le concept du consentement sexuel. Ils l'explorent à travers l'étude de de cas, la mise en scène et la discussion.
1 Consentir, c'est accepter de faire quelque chose. Donner son consentement sexuel, c'est accepter d'avoir des rapports sexuels. Tout le monde a le droit de donner ou de refuser son consentement sexuel, et la responsabilité de respecter le droit d'autrui à donner ou refuser ce consentement.

2 La contrainte sexuelle survient quand une personne en force (ou essaie d'en forcer) une autre à participer à un acte sexuel contre son gré. La personne contrainte peut être forcée physiquement à avoir des rapports sexuels, ou elle peut redouter les conséquences sociales ou physiques de son refus.

- La contrainte sexuelle affecte les deux sexes. Les filles et les femmes en sont cependant plus souvent victimes.

- La contrainte sexuelle s'exerce de différentes manières : par manipulation affective, duperie, force ou menace physique, intimidation ou incitation économique, pour n'en citer que quelques-unes.

- Les rapports sexuels forcés et le viol peuvent survenir partout (y compris chez soi, dans sa famille ou dans une relation intime, ou dans les endroits considérés sûrs tels que les écoles ou les maisons de culte).

- Leur prévalence est supérieure en temps de guerre, dans les camps de réfugiés, dans les prisons, le travail du sexe et les situations de trafic ou d'esclavage sexuel. [Voir la fiche d'information sur le Trafic sexuel.]

- Toucher le corps d'autrui sans son consentement peut aussi être une forme de contrainte. Si quelqu'un vous touche et vous met mal à l'aise, vous avez le droit de lui dire d'arrêter.

3 Quelles que soient les circonstances dans lesquelles elle se produit, la contrainte sexuelle peut avoir de graves conséquences.

- La contrainte sexuelle peut être source de problèmes affectifs, tels que sentiments d'insécurité, isolement et profonde dépression. Elle peut aussi être cause de blessure physique.

- Les rapports sexuels contraints sont plus susceptibles que ceux consensuels d'aboutir sur une grossesse non planifiée, la contraction du VIH ou celle d'autres infections sexuellement transmissibles. 
4 La question du consentement sexuel n'est pas toujours claire. Quelles sont les limites d'un comportement approprié ou non en ce qui concerne l'assurance du consentement?

- À tout moment, vous avez le droit de changer d'avis sur ce que vous jugez acceptable et de vous défendre si vous estimez n'être pas bien compris(e) ou respecté(e). Vous pouvez refuser un acte sexuel même entamé.

- Consentir à un acte ou une expérience ne veut pas dire consentir à tout autre. Une personne qui consent une fois à une expérience a le droit de la refuser par la suite.

- Parce qu'ils ont appris à obéir aux adultes, les garçons et les filles croient parfois devoir accepter les rapports sexuels demandés par un adulte. Les filles, qui ont souvent appris à se plier à la volonté des garçons et des hommes, taisent parfois aussi leurs propres désirs. Il ne s'agit pas là d'exemples de consentement vrai, libre et éclairé.

- Il est parfois difficile de se défendre quand quelqu'un vous touche d'une manière qui vous met mal à l'aise. Si vous vous trouvez dans cette situation, parlez-en à un adulte de confiance.

\section{De nombreux facteurs affectent la capacité de consentir véritablement à des} rapports sexuels. Par exemple, la maturité de la personne, sa conscience de ses droits, sa maîtrise des aspects fondamentaux de son existence importent toutes. Pouvoir parler ouvertement de la prévention des infections et d'une grossesse non désirée entre aussi en jeu dans le consentement.

\section{La prostitution peut être consensuelle ou non.}

- Certaines personnes choisissent le travail du sexe de leur propre gré. D’autres y trouvent leur seul moyen de subsistance ou y sont forcées par duperie ou autres pressions. [Voir la fiche d'information sur le Trafic sexuel.]

- Certaines personnes défendent le droit à la prostitution entre adultes consentants et s'opposent à l'opprobre et aux conséquences légales qu’elle engendre.

7 Quel qu'en soit l'endroit, le moment ou le mode, la contrainte sexuelle est une violation des droits humains. Dans de nombreux pays, les éducateurs peuvent orienter ses jeunes victimes vers une assistance appropriée.

\section{POINTS DE RÉFLEXION}

Quelles sont les conditions d'un consentement véritable?

Quel est le niveau de jugement affectif, de maturité et de capacité requis pour prendre des décisions sexuelles éclairées?

Les gens savent-ils tous qu'ils ont le droit de refuser l'activité sexuelle?

Pourquoi a-t-on parfois besoin de plus de temps pour démêler et exprimer ses sentiments?

Est-il facile pour les jeunes d'exprimer leurs désirs sexuels et d'assurer que leurs partenaires en fassent autant?

Le consentement d'une personne qui ignore l'état $\mathrm{VIH}$ de son ou sa partenaire est-il véritable?

Certaines personnes, même jeunes, ont des rapports sexuels en échange de cadeaux ou d'argent. Leur consentement est-il valable et véritable?

La drogue ou l'alcool affectent-ils le jugement ou la capacité de la personne à prendre des décisions sexuelles éclairées? 


\section{établir des relations sexuelles mutuellement respectueuses et responsables}

1 Plusieurs facteurs contribuent, toute la vie, à une expérience sexuelle mutuellement satisfaisante, responsable et sûre.

Notamment :

- savoir que vous et votre partenaire avez tous les deux les mêmes droits et assurer ensemble le respect, le consentement et la responsabilité mutuels ;

- se traiter l'un l'autre sur un pied d'égalité, en tant qu'êtres humains plutôt que de simples corps ;

- se sentir à l'aise pour parler de ce que chaque partenaire désire ou ne veut pas ;

- respecter le droit de l'autre de refuser ce qui le ou la met mal à l'aise ou en danger ;

- être honnête l'un envers l'autre ;

- sentir l'intimité ;

- se sentir aimé(e) ;

- pratiquer des méthodes sûres et efficaces pour se protéger l'un l'autre contre les grossesses non désirées et les infections sexuellement transmissibles, y compris le VIH ;

- s'efforcer de se protéger l'un l'autre contre tout préjudice affectif;

- être conscient(e) de ses propres désirs et niveau d'aise comme de ceux de son ou sa partenaire ; et

- pouvoir donner et accepter le plaisir.

2 Nous pouvons tous apprendre à enrichir nos relations sexuelles d'un plus grand respect, de responsabilité et de satisfaction. 


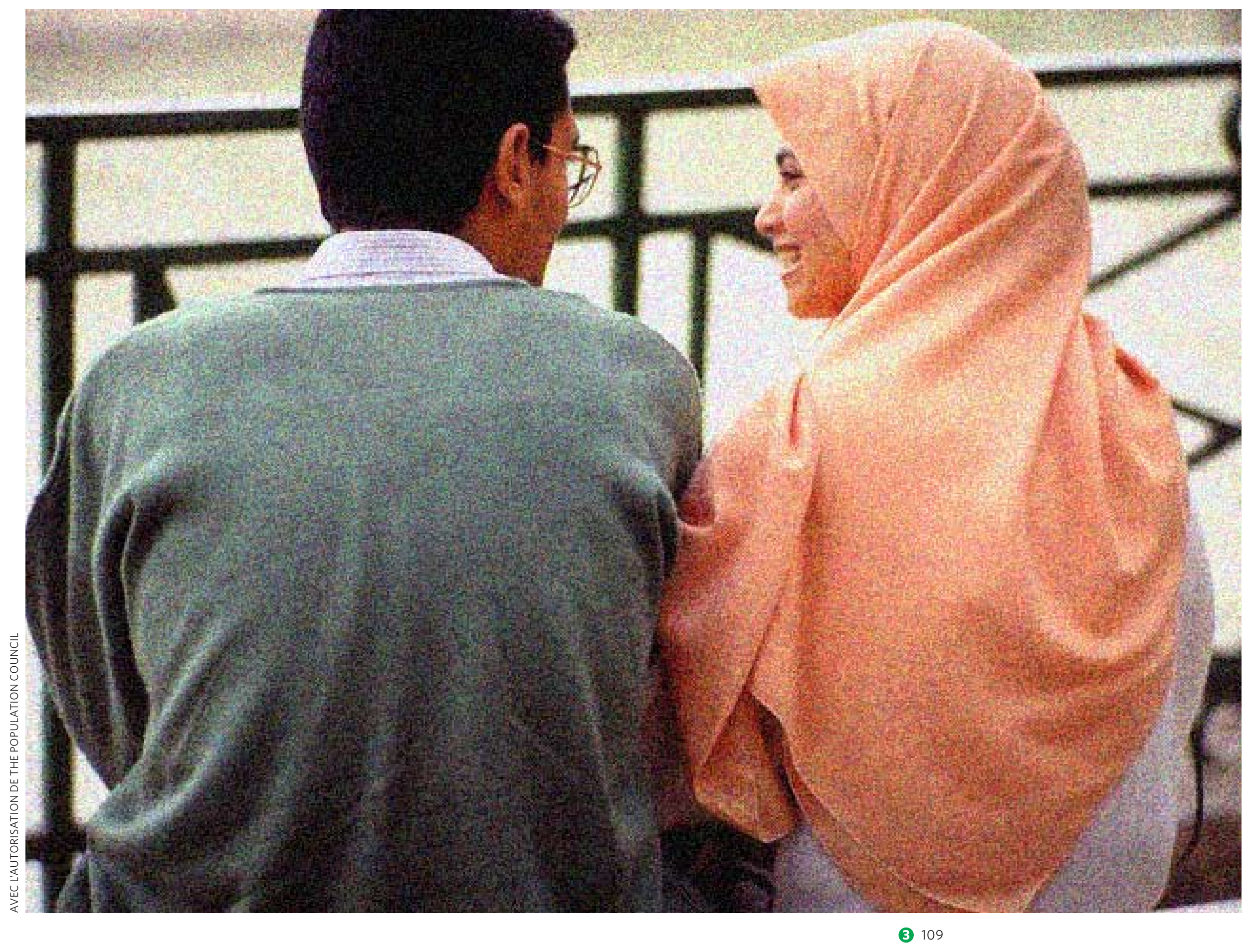




\section{inquiétudes relatives à la fonction sexuelle}

1 Beaucoup de personnes s'inquiètent, à un moment ou à un autre, du bon fonctionnement de leurs réponses sexuelles.

- La plupart des inquiétudes relatives à la fonction sexuelle ont trait aux sentiments et aux circonstances de la personne. Elle s'inquiète par exemple de ses organes, de son charme ou de sa "performance » sexuelle. Peut-être a-t-elle été exposée à des attitudes sexuelles négatives ou vécu une expérience sexuelle perturbante. Elle éprouve des sentiments négatifs envers son ou sa partenaire. Elle redoute une IST, le sida ou la grossesse. Elle ignore peutêtre la variation normale de la réponse sexuelle ou ne sait pas parler de ses besoins sexuels.

- Moins souvent, les problèmes de fonction sexuelle sont dus à des facteurs physiques (maladie, alcool, drogues, etc.).

2 Certains soucis sexuels sont courants chez les hommes et les garçons.

Par exemple :

- ne pas pouvoir avoir ou maintenir une érection adéquate pour des rapports sexuels. Presque tous les hommes ressentent cette inquiétude à un moment ou l'autre de leur vie ;

- éjaculer trop vite ou avoir le sentiment de ne pas être maîtres de leur éjaculation ;

- ne pas atteindre l'orgasme ou l'atteindre plus lentement qu'ils ne le souhaiteraient; et

- ne pas pouvoir aider leur partenaire à atteindre l'orgasme.

3 Certains soucis sexuels sont courants chez les femmes et les filles.

Par exemple :

- ne pas atteindre l'orgasme ou l'atteindre plus lentement qu'elles ne le souhaiteraient;

- ne pas répondre à la stimulation sexuelle; et

- éprouver une douleur persistante lors des rapports sexuels (parfois signe d'infection).

4 Beaucoup de personnes (indépendamment de leur genre ou identité sexuelle) traversent des périodes de désintérêt sexuel. La situation peut poser problème si le désir des deux partenaires est trop inégal.

5 La communication franche et respectueuse avec l'autre peut rétablir le sentiment d'aise et de satisfaction. Si un problème persiste ou nuit au bien-être sexuel, il peut être utile de parler à un conseiller de confiance. 


\section{le bien-être sexuel et le plaidoyer}

1 Chacun et chacune doit avoir l'occasion de développer une capacité de vie sexuelle sûre, consensuelle et agréable, engagée à son propre gré.

2 On peut défendre la santé, le plaisir et le respect dans ses propres relations sexuelles.

La promotion de relations sûres et respectueuses implique par exemple qu'il faut :

- apprendre à respecter l'autre et à exprimer ses propres besoins (cela requiert savoir et expérience) ;

- communiquer ses sentiments pour assurer santé, plaisir et compréhension mutuels ; et

- attendre, avant d'avoir des rapports sexuels, que les deux partenaires aient la maturité et la prestance sociale nécessaires à l'assurance d'une bonne communication, d'un respect et d'un consentement mutuels et de rapports sûrs et confortables.

3 Partout dans le monde, les défenseurs des droits sexuels et génésiques - groupes communautaires, prestataires de santé, jeunes et autres - prônent plus de respect, de réciprocité et de valorisation du consentement dans les relations sexuelles. Ils œuvrent pour:

- une meilleure éducation sexuelle ;

- la promotion de l'égalité de genre ;

- l'abrogation des lois qui criminalisent les rapports sexuels consensuels entre adultes (l'activité homosexuelle, notamment);

- la reconnaissance des droits sexuels des handicapés ; et

- un meilleur accès aux services de santé sexuelle et génésique (accès à la contraception et à l'avortement légal médicalisé, ainsi qu’au dépistage, conseil et traitement confidentiels du VIH).

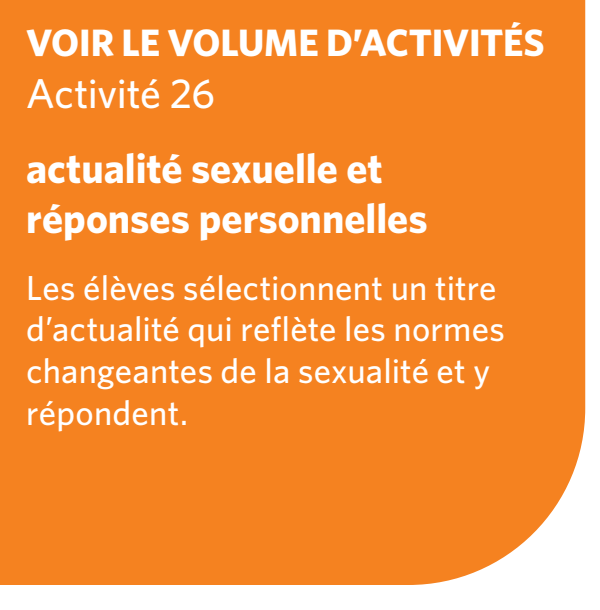




\section{quelques notions sur la sexualité}

Les brèves définitions ci-dessous ont pour but d'aider l'utilisateur à clarifier certains termes importants concernant la sexualité, tels qu'utilisés dans ce document. Partout dans le monde, les éducateurs usent de créativité et de sensibilité pour adapter ces concepts à leur propre contexte culturel et politique.

Bien-être sexuel : Sentiment de bien-être ayant trait à la sexualité et à la vie sexuelle.

Bisexualité : Attirance ou désir, comportement ou identité dirigés vers les deux sexes.

Désir sexuel : Désir d'expression sexuelle ou sentiment d'attirance sexuelle.

Diversité sexuelle : Éventail des désirs, identités et comportements sexuels.

Droits sexuels et génésiques: Droits humains relatifs à la vie et à la santé sexuelles et génésiques. Par exemple : droit de décider si, avec qui et dans quelles circonstances une personne a des rapports sexuels; droit de mener une grossesse à terme ou non ; protection contre la violence sexuelle.

Fonction sexuelle : Réponses physiologiques faisant partie de la sexualité.

Hétérosexualité : Sexualité entre un homme et une femme.

Homosexualité : Sexualité entre personnes du même sexe. Dans certains contextes, on parle d'orientation sexuelle pour désigner l'attirance ressentie envers le même sexe ou le sexe opposé. Dans ce document, les expressions « identité sexuelle » et « diversité sexuelle » désignent le vaste éventail de l'expression sexuelle, y compris l'attirance ressentie envers le même sexe ou le sexe opposé. 
Identité sexuelle : Manière dont les personnes s'identifient concernant différents aspects de leur sexualité, y compris leurs préférences et attirances sexuelles. Peut également inclure les types de relations qu'elles désirent établir. L'identité sexuelle d'une personne n'est pas nécessairement identique à son désir ou son comportement sexuel.

Intersexué : Qui présente des chromosomes sexuels, des organes génitaux et/ou des traits sexuels secondaires qui ne sont ni exclusivement masculins, ni exclusivement féminins.

Normes sexuelles: Normes sociales qui façonnent notre compréhension, nos attitudes et notre vécu de la sexualité.

Rapports sexuels: Les rapports sexuels désignent souvent la pénétration du pénis dans le vagin. Les rapports buccogénitaux impliquent le contact de la bouche sur un organe sexuel du ou de la partenaire et les rapports anaux, la pénétration du pénis dans l'anus du ou de la partenaire.

Sexualité : Manière dont les personnes vivent et s'expriment en tant qu'êtres sexuels. De nombreux facteurs contribuent aux comportements, aux relations, aux sentiments, à l'identité, aux désirs et aux attitudes sexuels. L'un de ces facteurs est de nature biologique, en particulier les hormones sexuelles. Un autre tient à la personnalité et au vécu individuel et un autre encore est la culture, qui influence les attitudes, les attentes et l'interprétation de la sexualité. Les normes culturelles affectent aussi les lois et les politiques relatives à la sexualité. Tous ces facteurs se croisent et interagissent toute la vie durant. 


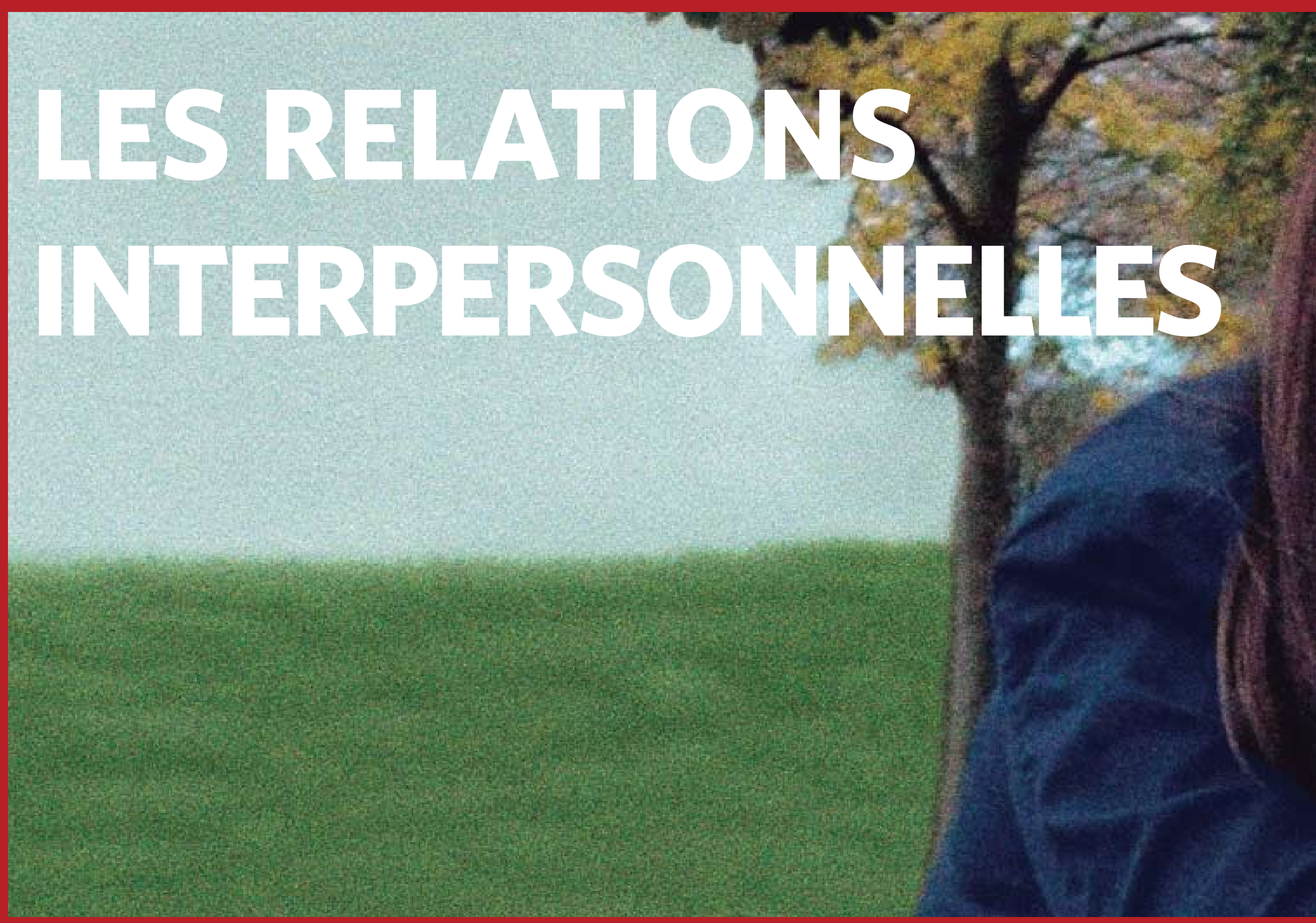




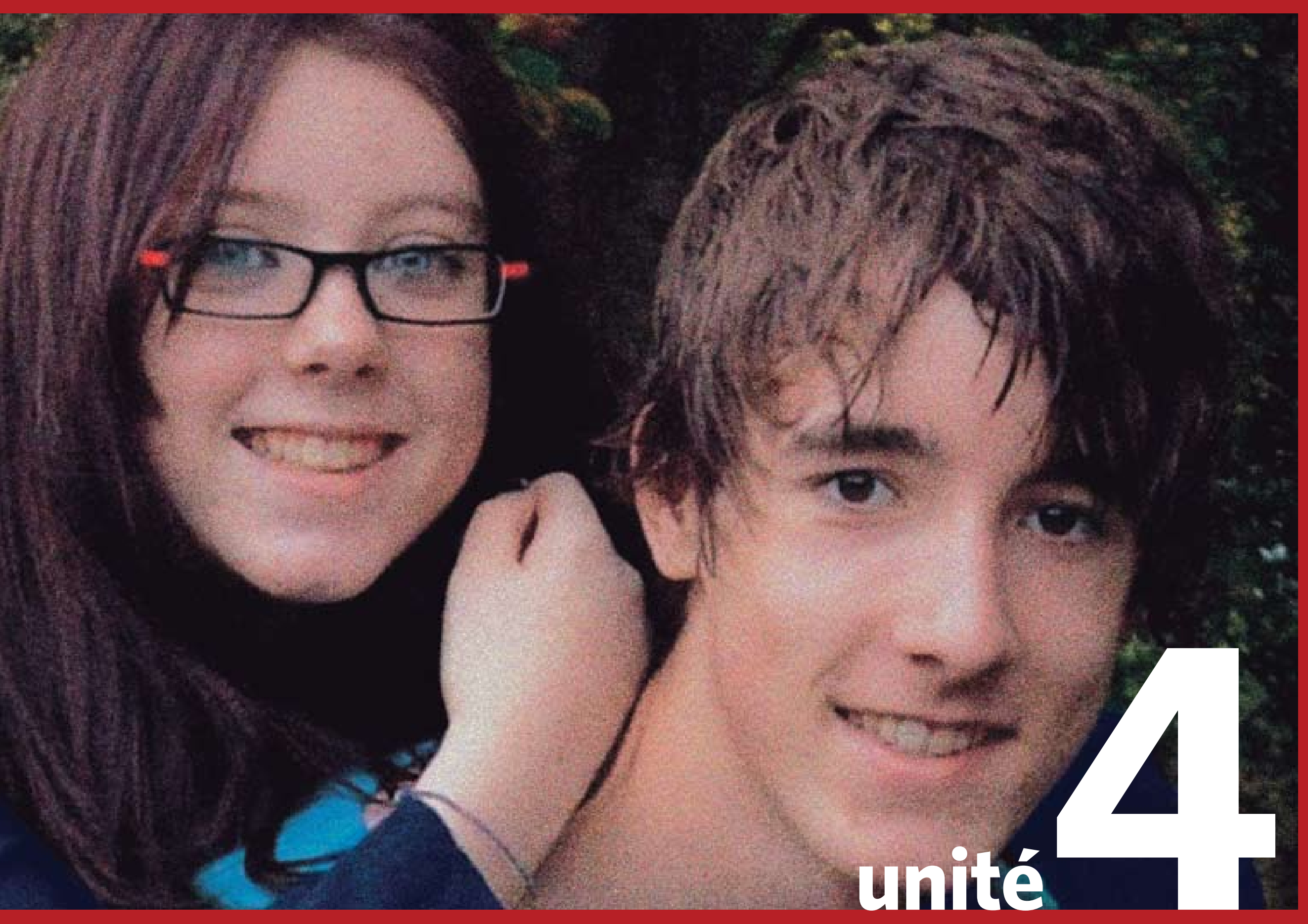




\section{panorama}

Quand on pense aux relations interpersonnelles, on se réfère généralement à la personnalité ou au vécu individuel. Mais nos relations sont aussi influencées par la société. Par exemple, les différences de pouvoir, les représentations médiatiques des relations et d'autres facteurs influencent nos idées sur les relations personnelles. Pendant l'adolescence, les jeunes peuvent éprouver des sentiments différents, parfois intenses, face au tumulte de certains aspects de leurs relations.

Cette unité explore différents types de relations, y compris les relations romantiques ou sexuelles. Elle encourage les jeunes à réfléchir aux qualités qu'ils recherchent dans leurs propres relations intimes. 


\section{LES RELATIONS INTERPERSONNELLES}

L'interaction représente le meilleur et le pire de l'expérience humaine. Les relations aimantes donnent un sens à la vie de beaucoup et sont en somme souvent le sens de la vie.

Commencez par concentrer votre approche sur les différents types de relations humaines, pour aboutir plus spécifiquement sur les relations romantiques et intimes.

Le rapport entre l'enseignant et ses élèves est aussi une forme de relation interpersonnelle. Même si l'enseignant détient l'autorité, les principes fondamentaux de respect et de dignité s'appliquent toujours à l'interaction entre l'enseignant et l'élève.

Validez les connaissances de vos élèves : ils ont tous l'expérience de relations humaines.

Laissez vos élèves partager leurs expériences ou les garder privées.

Invitez vos élèves à réfléchir à la nécessité de respect, de sensibilité et d'attention aux droits humains dans les relations avec les personnes atteintes du VIH - à l'école, dans la communauté, dans la famille étendue ou ailleurs. Cette considération est particulièrement importante dans les contextes où la prévalence du VIH est élevée.

Cette unité aborde des sujets auxquels les jeunes sont généralement fort sensibles et concernant lesquels ils se posent beaucoup de questions. Prévoyez suffisamment de temps pour permettre de nombreux exercices et une discussion approfondie. 


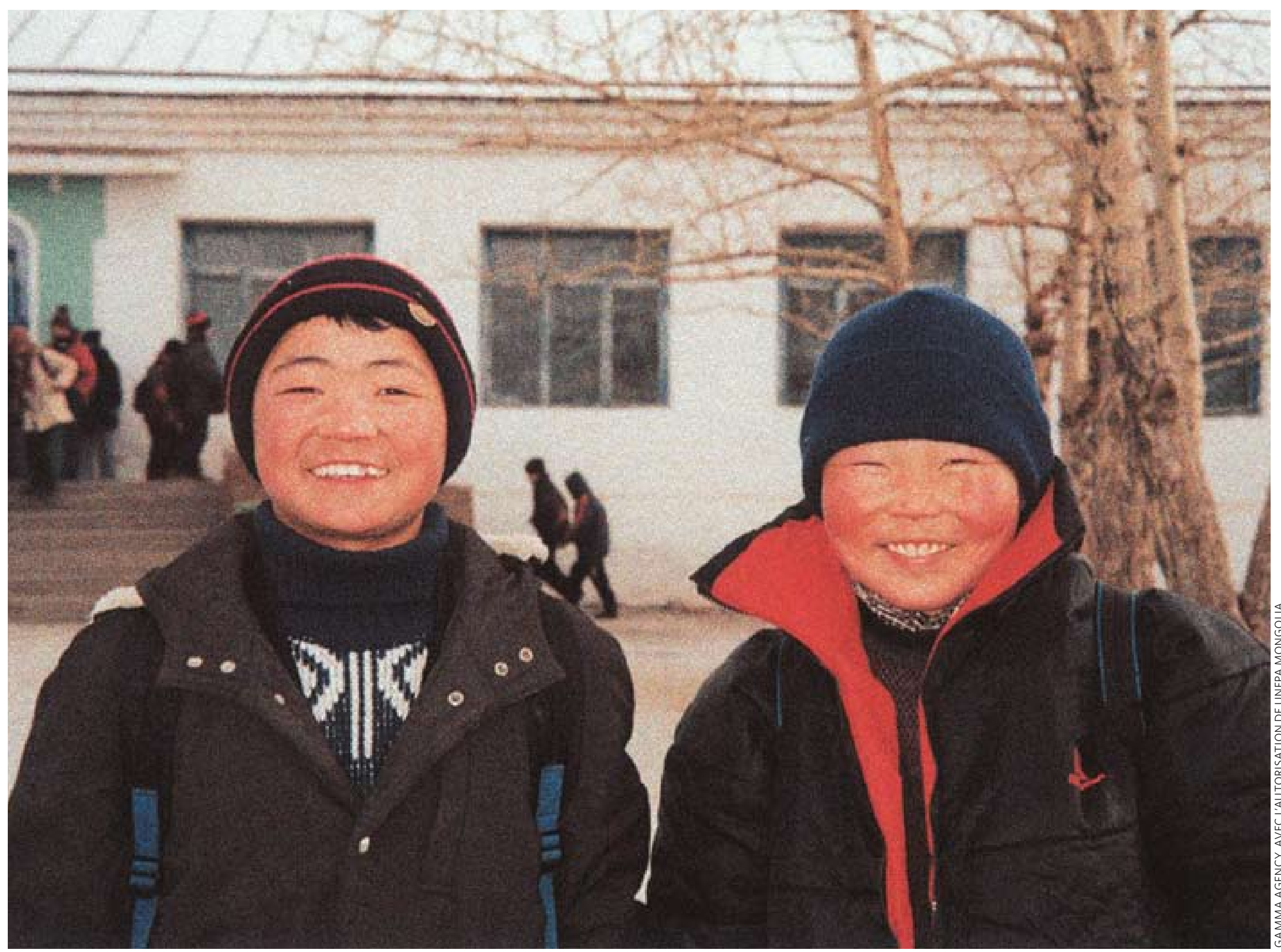




\section{LES RELATIONS INTERPERSONNELLES}

Le matériel couvert dans cette unité prépare les élèves à :

\section{Objectifs cognitifs}

Décrire le droit fondamental d'établir des relations et d'être traité avec respect et dignité.

Décrire différents types de relations et de structures familiales.

Décrire deux facteurs personnels et deux facteurs sociétaux ou culturels utiles ou contraires aux relations satisfaisantes et mutuellement respectueuses.

Discuter les sujets dont il faut pouvoir parler à l'aise et avec maturité pour assurer des relations sexuelles sans risques, respectueuses et consensuelles.

Discuter au moins deux grandes difficultés propres aux relations intimes des jeunes.

Objectifs affectifs

Réfléchir à la différence entre l'amour et l'engouement et en citer quelques exemples personnels.

Réfléchir à la nature de leurs relations et au type de relations qu'ils désirent avoir dans leur propre vie.

Réfléchir honnêtement à leur propre maturité et facilité de communication pour assurer que leurs expériences intimes soient désirées, sûres, respectueuses et agréables.

Apprécier l'importance de la connaissance de ses droits et responsabilités, de la communication et du soutien personnel et professionnel pour gérer ou rompre une relation à la dérive.

Identifier ce qu'ils croient être leurs sources de pouvoir et d'impuissance et la manière dont ils intègrent ces perceptions dans leurs relations interpersonnelles.

[Pour les objectifs de compétences, voir l'unité 5 : aptitudes à la communication et à la décision.] 


\section{introduction aux relations interpersonnelles}

L'égalité entre les femmes et les hommes en ce qui concerne la sexualité et la procréation, ... exige le respect mutuel, le consentement et le partage de la responsabilité ... (Paragraphe 96, Programme d'action de la QCMF, 1995).

1 Les relations interpersonnelles sont les associations, relations ou affiliations sociales entre deux personnes ou plus.

- Les relations interpersonnelles sont importantes au bonheur de la plupart des gens.

- Les relations humaines peuvent satisfaire aux besoins affectifs, sociaux, physiques, intellectuels et économiques.

- La culture façonne la manière dont on voit le monde et les relations humaines. Celles-ci changent à mesure que la culture évolue.

2 Chaque personne, dans chaque société, a de nombreux types de relations.

- Ces relations incluent ses liens avec les membres de sa famille, ses amis, ses collègues, ses voisins, ses connaissances, son petit ami ou sa petite amie, ses enseignants, ses camarades de classe, etc.

- Les relations interpersonnelles varient aussi en qualité, selon qu'elles présentent plus ou moins de franchise, de confiance, de communication, d'intimité, de partage, de pouvoir, de respect, d'affection, etc.

- Les relations peuvent être centrées ou non sur ce que les personnes ont en commun : on peut être voisins, camarades de classe, collègues, membres d'un même club, fidèles d'une même église, mosquée ou temple, membres d'un groupe d'accompagnement du sida ou visiteurs d'un même site social sur Internet.

- On exprime ses sentiments les uns envers les autres de nombreuses manières différentes.

VOIR LE VOLUME D'ACTIVITÉS Activité 27

mes relations

Les élèves créent une représentation visuelle de leurs relations.
3 On peut établir de nouvelles relations tout au long de sa vie. On peut aussi en rompre. Il peut arriver qu'une relation soit nuisible au bien-être de l'un, de l'autre ou des deux. Personne n'est obligé de rester dans une relation. 


\section{les relations dans nos vies}

1 On a différents types de relations, y compris d'amour, tout au long de sa vie. En règle générale, les premières relations importantes s'établissent avec les membres de sa famille. Les jeunes enfants attendent de leurs parents et autres adultes de confiance un amour inconditionnel.

- Les familles revêtent différentes formes. Leurs membres peuvent être biologiquement apparentés ou non.

- La famille étendue comprend généralement des parents autres que ceux de la famille immédiate, et parfois aussi des personnes sans relation biologique.

- Beaucoup de familles incluent un ou plusieurs enfants adoptés.

- La famille peut vivre ensemble sous le même toit ou être séparée, par choix ou selon que les circonstances l'exigent : pour raison d'emploi, de migration, de service militaire ou d'emprisonnement, par exemple. Ces situations peuvent séparer les membres d'une famille de manière durable ou permanente.

- Quand la famille a des enfants, ils peuvent vivre avec deux parents (de sexes différents ou de même sexe), avec un parent, avec un ou plusieurs membres de la famille étendue ou sous la tutelle d'un adulte.

- Certains enfants grandissent sans la protection fiable d'un adulte, mais avec l'amour d'un frére ou d'une soeur aînée.

\section{Comme toutes les autres, les relations familiales évoluent.}

Par exemple :

- En beaucoup d'endroits du monde, plus de femmes sont chefs de famille que dans le passé.

- En beaucoup d'endroits, les attitudes sociales à l'égard de la paternité changent. De plus en plus de pères nouent une relation étroite avec leurs enfants et partagent la responsabilité de leur éducation, surtout dans les situations où les femmes rejoignent la population active.

- Dans les endroits où le sida, la guerre ou d'autres causes ont fait de nombreuses victimes, beaucoup d'orphelins vivent avec d'autres parents ou en orphelinat.

- Les attitudes culturelles s'ouvrent à la diversité des familles. Plus de couples homosexuels peuvent vivre ouvertement et beaucoup élèvent des enfants. Ces parents élèvent les enfants de mariages antérieurs, adoptent ou recourent à la procréation médicalement assistée (insémination artificielle ou mères porteuses).

3 L'amitié est une forme de relation interpersonnelle parmi les plus importantes.

\section{POINTS DE RÉFLEXION}

Pourquoi forme-t-on des relations d'amitié?

Quelles sont les qualités de I'amitié : la confiance, I'affection? Quoi d'autre?

Dans certaines cultures, les jeunes deviennent souvent amis, sans sexualité, avec d'autres de sexe opposé. Dans d'autres, la pratique est moins courante. Pourquoi ?

Que peut apporter une amitié avec une personne issue d'un milieu ou d'un groupe différent? 
VOIR LE VOLUME D'ACTIVITÉS Activité 28

que se passe-t-il entre ces deux-là?

Les élèves lisent les récits de relations caractérisées par

l'inégalité sociétale. Ils identifient les inégalités et discutent leurs effets sur les relations.

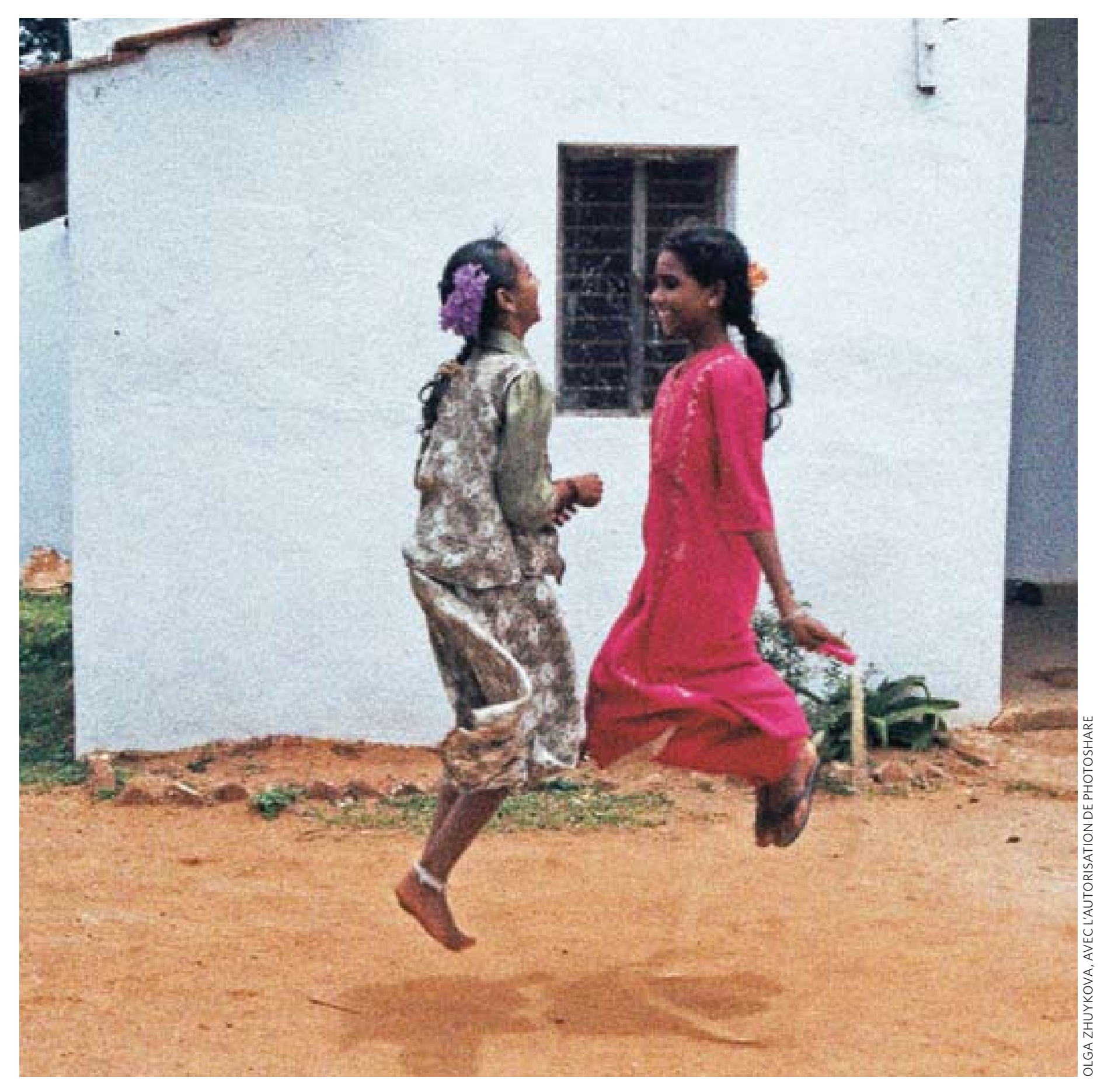

(4) 122 


\section{comment rendre nos relations plus satisfaisantes et respectueuses?}

1 Tous le monde désire des relations satisfaisantes basées sur le respect mutuel.

2 Certaines qualités personnelles aident à établir ces relations satisfaisantes et basées sur le respect l'un de l'autre:

- le respect de soi, la conscience et l'acceptation de ses propres sentiments et valeurs;

- la sensibilité aux sentiments des autres et le respect de leur dignité et de leurs droits ;

- les attentes partagées ;

- l'honnêteté et l'authenticité ;

- l'aptitude à la communication [voir l'unité 5] ;

- la réciprocité ; et

- l'affection, le temps passé ensemble et l'attention accordée l'un à l'autre.

3 L'appui de la société au sens large peut aussi être favorable aux relations positives. L'inégalité sociétale peut cependant nuire au respect mutuel et au sentiment d'aise au sein des relations.

- Les parents, les chefs religieux et les médias peuvent apprendre aux jeunes à se respecter mutuellement indépendamment de leur race, religion, ethnicité, genre, rang, aptitude physique, état VIH, etc.

- Les écoles et les organisations communautaires peuvent rapprocher les jeunes de milieux différents pour éviter leur isolement et manque de familiarité.

- Les écoles et les familles peuvent sensibiliser les jeunes à l'inégalité et leur faire comprendre combien les différences de pouvoir peuvent nuire aux relations satisfaisantes basées sur le respect mutuel.

\section{POINTS DE RÉFLEXION}

Avez-vous connu une situation où une personne se considérait supérieure aux autres ou était en position d'en maltraiter une autre?

Quels genres d'expériences avezvous partagés avec une personne différente de vous-même et qu'en avez-vous appris? 


\section{relations romantiques : faire la cour et sortir}

1 Faire la cour et sortir avec quelqu'un font référence à une interaction sociale susceptible de mener à une relation romantique ou sexuelle.

2 Les normes et pratiques de cette interaction varient énormément dans le monde.

- En beaucoup d'endroits, ces pratiques font partie de la coutume. Ce n'est cependant pas le cas dans toutes les cultures et pour tous les gens.

- Quand la pratique est interdite, on trouve parfois d'autres moyens de communiquer (Internet, par exemple).

- Là où le mariage arrangé est coutumier, les jeunes époux se marient sans s'être fait la cour ni être sortis ensemble. Les parents (ou la communauté) arrangent le mariage ou identifient le conjoint potentiel de leur enfant.

- Beaucoup de couples, mais pas tous, dont le mariage a été arrangé finissent par s’apprécier et former une union heureuse.

3 Que gagne-t-on à faire la cour et à sortir avec quelqu'un?

- On y gagne l'occasion de développer ses aptitudes interpersonnelles et à reconnaître, honorer et exprimer ainsi ses propres sentiments, à reconnaître ceux des autres et à mieux comprendre ce qu'on valorise, aime et apprécie dans une autre personne.

- On y gagne une occasion de compagnie et de nouvelles expériences.

- On y gagne l'occasion de découvrir petit à petit un(e) partenaire romantique ou sexuel(le) potentiel(le).

4 À quel âge commence-t-on à faire la cour ou à sortir avec quelqu'un?

- L'âge auquel les jeunes commencent à courtiser varie largement d'une personne et d'une culture ou société à l'autre.

- L'âge auquel les parents autorisent les jeunes à courtiser ou sortir avec quelqu'un varie largement — au sein même des communautés et d'une communauté ou culture à l'autre.

- Beaucoup d'adultes se font aussi la cour et sortent avec d'autres. 


\section{5 À qui fait-on la cour ou avec qui sort-on?}

- On sort généralement, mais pas toujours, avec une personne plus ou moins du même âge. En certains endroits, les hommes adultes font la cour aux filles encore jeunes. La différence d'âge favorise un déséquilibre de pouvoir dans la relation.

- On sort souvent, mais pas toujours, avec une personne du même groupe social. Mais il arrive qu'une personne sorte avec une autre d'origine raciale, ethnique, religieuse, socioéconomique ou de caste différente. Certaines familles et communautés, mais pas toutes, voient la chose d'un bon œil.

- On peut sortir avec quelqu'un du même sexe ou de sexe opposé.

\section{Comment commence-t-on à faire la cour ou à sortir avec quelqu'un?}

- Les gens se rencontrent au travail, à l'école, par l'intermédiaire de la famille, d'amis communs, de réseaux sociaux, dans la communauté, sur Internet ou ailleurs.

- Dans les contextes hétérosexuels, il incombe souvent aux garçons et aux hommes de faire le premier pas. Là où les conventions sont moins strictes, les filles et les femmes prennent aussi l'initiative. Beaucoup appréhendent l'idée de demander un premier rendez-vous.

\section{Que fait-on quand on sort avec quelqu'un ou qu'on lui fait la cour?}

- On peut faire différentes choses : converser, aller se promener, prendre un thé ou un café, aller au cinéma, assister à une manifestation communautaire, aller à une fête ou rendre visite à des amis ou à la famille.

- On peut faire ces choses à deux ou avec un groupe d'amis, ou sous la surveillance d'un membre de la famille ou d'un chaperon, selon les coutumes définies par les normes locales.

- On se fait parfois la cour, même pendant longtemps, par Internet ou quelque autre forme de communication.

- Une personne peut se sentir à l'aise, excitée, nerveuse ou anxieuse à l'idée de sortir avec quelqu'un.

- Certaines personnes ne sortent qu'une fois ensemble, ou elles se font la cour pendant plusieurs années.

- Se faire la cour peut être l'occasion de développer confiance et amitié. Par exemple, les jeunes peuvent se parler de leurs valeurs, de leurs espoirs et de leurs rêves, ou de leurs soucis ou inquiétudes. 


\section{Qui paie quand on sort ensemble?}

- Il n'est pas nécessaire de dépenser de l’argent pour sortir avec quelqu’un. Les pratiques varient sinon. Beaucoup partagent les frais de la sortie. Le garçon ou l'homme est parfois censé payer, ou la personne la mieux lotie.

- L’arrangement financier doit convenir aux deux. Les dépenses d'une personne ne doivent pas mettre l'autre mal à l'aise ou lui imposer d'autres obligations non désirées, y compris l'acte sexuel.

\section{Le contact sexuel ou physique intime est-il requis?}

- Les personnes qui sortent ensemble peuvent ressentir une attirance physique l'une envers l'autre et les deux peuvent désirer un contact sexuel (y compris se ternir par la main, s'embrasser, se caresser, etc.).

- Dans un contexte de confiance, de réciprocité et de respect, ces expériences peuvent être merveilleuses et excitantes. Elles donnent la chance de découvrir ses propres sentiments et réponses sexuels.

- Pour beaucoup, le partage d'une expérience sexuelle implique affection, intimité ou amour. Pour certains, le sexe et l'amour ne sont pas toujours liés. Même sans amour, il peut y avoir confiance, respect et plaisir.

- Certaines personnes se sentent à l'aise à l'idée d'avoir des rapports sexuels. Elles se munissent à l'avance de préservatifs ou autres contraceptifs. (Le préservatif masculin comme féminin évite la grossesse et protège contre le VIH et d'autres infections.) D’autres ont des rapports non planifiés ni discutés avec leur partenaire, parfois sans avoir prévu la moindre forme de protection.

- Il est important de parler de la question des rapports sexuels, pour s'assurer du consentement l'un de l'autre, se sentir plus à l'aise et assurer la sécurité l'un de l'autre. [Voir l’unité 5, p. 150.]

\section{Que faire en cas de pression sexuelle?}

- Personne n'est jamais obligé, pour aucune raison, d'avoir un contact sexuel non désiré, même si l'autre a dépensé de l'argent ou si les deux sortent ensemble ou se font la cour depuis longtemps.

- Malheureusement, la contrainte sexuelle est courante, même lors de rencontres de groupe. Ce grave problème social est parfois appelé « viol par une connaissance ». Il est plus fréquent encore en présence d'alcool ou de drogue, en l'absence de responsabilisation sociale des comportements ou en l'absence de personnes de confiance dans les environs. Il importe pour les jeunes de s'informer sur les circonstances dans lesquelles les viols se produisent dans leur communauté. 


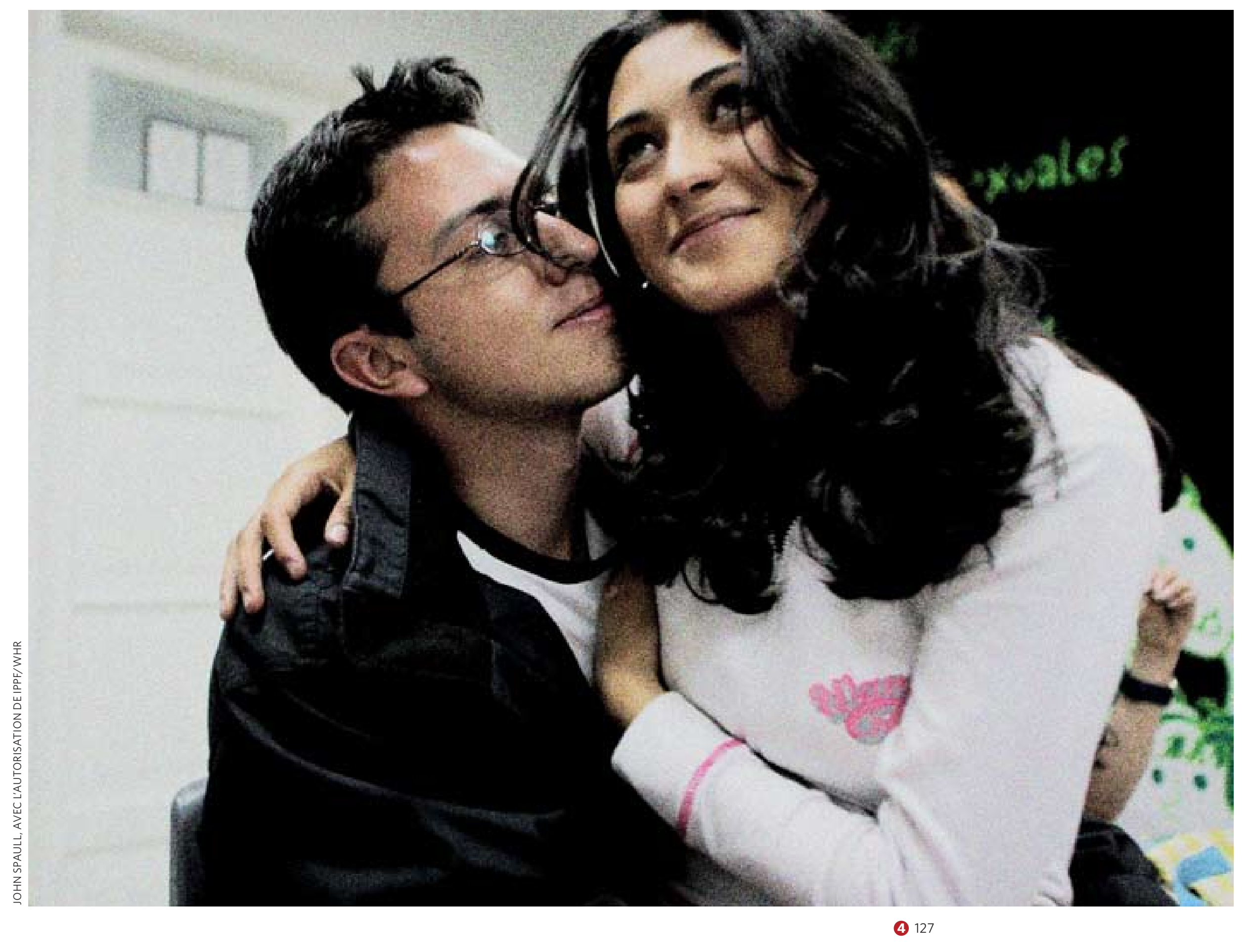




\section{tomber amoureux, I' « amour vrai " et la jalousie}

1 Les idées sur « l'amour » varient suivant l'endroit.

2 «Tomber amoureux » implique généralement des sentiments de passion, d'attirance sexuelle et d'excitation. On parle parfois de « béguin ».

- Tomber amoureux est souvent une expérience palpitante.

- Une relation romantique implique parfois (pas toujours) des sentiments d'engagement et d'intimité.

- Tomber amoureux n'est pas toujours réciproque.

- Tout le monde peut tomber amoureux : les adultes comme les adolescents.

- On peut ne tomber amoureux qu'une fois dans la vie, plusieurs fois ou de nombreuses fois.

\section{POINTS DE RÉFLEXION}

Quels messages les contes de fées transmettent-ils aux enfants sur l'amour? Et les clips vidéo?

Ces messages sont-ils réalistes? Quels types d'attentes placent-ils sur les jeunes hommes? Et sur les jeunes femmes?

L'amour romantique est-il nécessaire au bonheur?
3 En grandissant, les enfants absorbent de nombreux messages sur l'amour.

4 Qu'est-ce que « l'amour vrai »? Aimer, c'est vouloir profondément le bien-être et le bonheur de la personne aimée. Le fait d'aimer et d'être aimé peut être source d'une joie profonde et donner du sens à la vie.

- L'amour est l'une des plus fortes émotions humaines. Il inspire de belles œuvres d'art, de littérature et de musique.

- Il existe de nombreuses et diverses façons d'aimer quelqu'un.

- On peut éprouver de l'amour pour sa famille immédiate ou étendue, pour ses amis proches, pour ses partenaires ou pour son conjoint de même sexe ou de sexe opposé.

- L’« amour vrai » fait souvent référence à l'attachement intime que l'on ressent envers un partenaire, au-delà du stade de l'engouement.

- Il est souvent difficile de distinguer les sentiments d'affection, d'amour romantique, de désir sexuel et d'amour vrai.

- La culture de chacun transmet des messages sur ce qu'est l'amour, qui on doit aimer (ou non) et comment il convient d'exprimer son amour (ou non). 
5 La jalousie peut intervenir quand une personne a l'impression qu'une relation qu'elle valorise est menacée.

- La jalousie (dans tous les types de relations, y compris romantiques) fait référence à des sentiments d'envie, de possessivité, de vulnérabilité, de colère et de ressentiment.

- La plupart des personnes éprouvent des sentiments de jalousie à un moment ou à un autre.

- Dans les relations romantiques, la jalousie peut porter sur un rival réel ou imaginaire. Il se peut aussi qu'une personne sente sa relation menacée par la dévotion d'un partenaire à sa famille, ses amis ou son travail.

\section{Certaines personnes expriment leur jalousie par des menaces, par la violence ou} par un comportement possessif ou manipulateur.

- Ces comportements ne sont pas de l'amour et n'en sont jamais l'expression.

- La violence et la contrainte sont une démonstration de pouvoir sur une autre personne. Elles sont toujours contraires aux droits de la personne qui en est victime, quel que soit le sentiment, de jalousie ou autre, exprimé.

- La personne jalouse aussi bien que son ou sa partenaire peuvent bénéficier d'un dialogue honnête et respectueux sur les sentiments l'un de l'autre. Chacun peut aussi bénéficier de l'aide d'un ami, d'un adulte de confiance ou d'un conseiller.

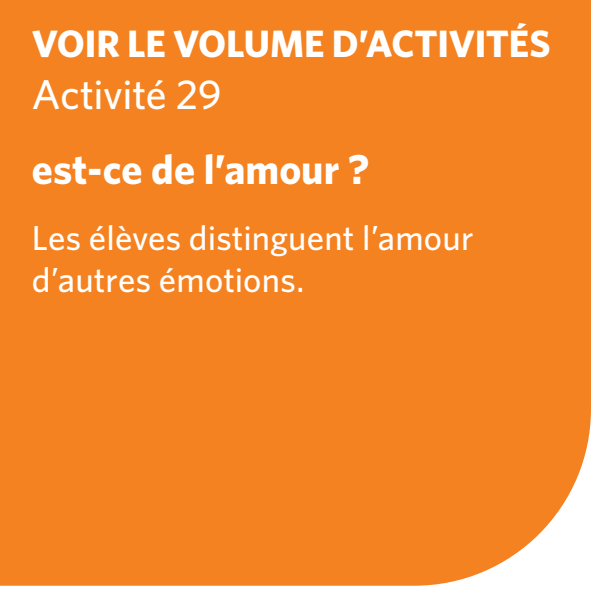




\section{l'activité sexuelle dans les relations interpersonnelles}

\section{Que peut apporter une relation sexuelle satisfaisante?}

- Les relations sexuelles satisfaisantes rapprochent les partenaires, donnent du plaisir et enrichissent la vie.

- Les rapports sexuels doivent être désirables, agréables et sans risques.

- Personne n’est jamais obligé d'avoir un contact sexuel non désiré.

\section{POINTS DE RÉFLEXION}

L'excitation sexuelle n'élimine pas les sentiments souvent contradictoires sur le contact sexuel intime et ce qu'il implique.

Quelles pourraient être les conséquences de l'expression de ses sentiments contradictoires et de ses doutes à l'égard de l'acte sexuel?

\section{2 Sait-on toujours si l'on désire ou non un contact sexuel intime ?}

3 Pour une personne sexuellement active, quels facteurs contribuent à une relation sexuelle affectivement satisfaisante pour les deux partenaires, responsable et sûre?

En plus des facteurs qui contribuent à la qualité des relations interpersonnelles en général (voir p. 123), les relations sexuelles en particulier sont plus agréables, satisfaisantes et sûres quand les deux partenaires :

- se sentent intimes et appréciés, et pas un simple corps utile à l'objet de l'acte sexuel;

- sont sûrs du consentement, du respect et de la responsabilité l'un de l'autre ;

- sont capables de donner et de recevoir le plaisir sexuel ;

- se sentent à l'aise pour parler de ce que chacun désire ou non ;

- respectent le droit l'un de l'autre de refuser ce qui le ou la met mal à l'aise ;

- partagent la responsabilité de méthodes sûres et efficaces contre les grossesses non désirées et les infections sexuellement transmissibles, y compris le VIH ;

- savent l'état VIH (et autres IST) l'un de l'autre ; et

- parlent de leur intention ou non d'avoir d'autres partenaires sexuels. Les personnes qui n'ont qu'un ou une partenaire sexuel(le) forment une relation monogame autrement dit « rester fidéle ». 


\section{Pourquoi les jeunes se sentent-ils parfois poussés par un petit ami ou une petite amie à avoir des rapports sexuels?}

Les jeunes disent notamment avoir des rapports sexuels non désirés pour les raisons suivantes :

- sous l'effet de la pression de leurs pairs ;

- pour prouver leur amour ou essayer d’obtenir un engagement sérieux ;

- pour ne pas blesser l'autre ou son amour propre ;

- parce qu'ils sortent ensemble depuis un bout de temps ;

- parce qu'ils ont déjà décidé de passer à l'acte même si l'un des deux a changé d'avis ;

- parce que l'autre est en position de puissance ou d'autorité (en raison de son âge, de sa popularité, de ses ressources, de son genre, etc.);

- sous la pression de membres de la famille, d’aînés ou de dirigeants communautaires ;

- pour obtenir de l'argent ou des cadeaux ; et

- parce que l'alcool ou la drogue ont altéré leur jugement ou leur capacité de résister.

Malheureusement, même dans les relations établies, les contraintes, les abus ou les violences sexuels sont courants. Tout le monde peut en être victime, mais les filles et les femmes le sont le plus souvent. Les abus sexuels sont nuisibles et jamais justifiés. La faute n'en est jamais celle de la victime. La contrainte sexuelle est associée à un risque accru de transmission du VIH. [Voir l'unité 2, pp. 70-71 et l'unité 3, pp. 106-107.]

\section{Atteindre un haut niveau d'aise, de communication et de maturité dans les relations sexuelles est un processus appris et qui prend du temps.}

- Parce qu'ils s'engagent dans des relations sexuelles avant d'avoir atteint ce niveau de maturité, beaucoup de jeunes peuvent se sentir gênés, anxieux ou honteux, et inquiets au sujet du VIH et de la grossesse.

- Les garçons et les hommes surtout peuvent ressentir la pression de se montrer sexuellement "performants ». Ils n'osent pas admettre leur ignorance ou leur manque d'expérience. Quant aux filles et aux femmes, il peut leur paraître inconvenant de parler du préservatif ou de leurs propres désirs sexuels.

- La pratique et l'encouragement peuvent aider tous les jeunes à surmonter ces pressions et à apprendre à communiquer avec plus d'assurance.

VOIR LE VOLUME D'ACTIVITÉS Activité 30

décider d'avoir ou non des rapports sexuels

Les élèves examinent les indicateurs de maturité, de conscience de soi, d'auto-efficacité et d'aptitude à communiquer dont les jeunes ont besoin pour négocier une relation sexuelle confortable et sans risques. 


\section{relations intimes à long terme}

\section{II existe différents types de relations aimantes et sérieuses à long terme.}

- La plupart des gens sont élevés dans l'idée qu'ils vont nouer une relation avec un partenaire de sexe opposé, se marier, avoir des enfants et rester unis pour le restant de leur vie.

- La réalité, pour des millions d'individus, est plus complexe. Il existe différentes formes de relations sérieuses à long terme. On peut avoir plusieurs relations durables durant sa vie. On peut rester célibataire, de son propre gré ou parce que les circonstances le veulent ainsi. Et on peut s'engager dans une relation hétérosexuelle ou homosexuelle.

- De son propre gré ou sous l'effet de circonstances indépendantes de sa volonté, on peut : vivre ensemble en permanence ou non; accepter d'être monogame ou d'avoir plusieurs partenaires sexuels ; élever ses enfants seuls ou avec d'autres membres de la famille; se marier et/ou s'engager pour la vie envers l'autre.

\section{POINTS DE RÉFLEXION}

Plusieurs facteurs contribuent à la compatibilité à long terme entre deux personnes.

Quelle importance accordez-vous aux valeurs partagées, à l'amitié, à la compatibilité intellectuelle, à l'attirance sexuelle, au sens des responsabilités partagées à l'honnêteté, à l'engagement partagé, à l'harmonie avec la belle-famille et la famille étendue, à la vie spirituelle et religieuse partagée, au respect mutuel des droits l'un de l'autre?
๑ 2 Une relation intime sérieuse à long terme peut être le produit de différentes circonstances. Elle peut naître, par exemple, d'une idylle, d'une amitié ou d'un arrangement entre deux familles.

3 La nature du mariage et des relations intimes à long terme varie dans le temps et dans l'espace.

- En beaucoup d'endroits, une nette proportion de couples vivent en union sans se marier.

- Dans de nombreuses sociétés, on trouve soi-même ses propres partenaires intimes ou son conjoint. Ailleurs, la famille choisit pour son enfant un ou une partenaire convenable, qui renforce la structure sociale ou les deux.

- La plupart des sociétés interdisent le mariage à plus d'une personne à la fois. Là où elle existe, la polygamie s'exprime presque toujours sous la forme d'un mari ayant plusieurs femmes et non l'inverse.

- Bien qu'en déclin, la coutume des mariages d'enfants affecte encore des millions de filles dans le monde.

- Dans certaines sociétés, les femmes choisissent de se marier plus tard ou de rester célibataires.

- Dans certains contextes, les hommes se marient à un âge plus avancé que dans le passé car ils n’ont pas les moyens de subvenir aux besoins d'une famille. 
4 Partout dans le monde, certains couples se marient ou établissent des relations à long terme basées sur l'égalité de genre et les droits humains, même au défi des normes locales.

[Voir l'unité 2, pp. 60-61.]

- En beaucoup d'endroits, les attitudes s'ouvrent à l'égard du mariage de personnes d'origines (religieuses, raciales, sociales ou autres) différentes.

- Certaines sociétés débattent ou soumettent au scrutin le droit des couples homosexuels à se marier ou à former une union civile comportant les mêmes droits et responsabilités que le mariage.

5 Beaucoup, au sein de relations durables, s'inquiètent de la transmission du VIH à leur partenaire ou conjoint. Un partenaire peut être infecté et l'autre pas, ou l'un ou l'autre peut avoir d'autres partenaires sexuels. L'information, l'accès au préservatif et le dépistage et conseil confidentiels sont essentiels à l'assurance de stratégies préventives au sein des couples.

[Voir l'unité 7, $1^{\text {re }}$ partie.]

VOIR LE VOLUME D'ACTIVITÉS Activité 31

vivre ensemble

Les élèves se penchent sur l'évolution des coutumes relatives au mariage et à la structure familiale.

VOIR LE VOLUME D'ACTIVITÉS Activité 32

ce que je recherche

Les élèves listent les qualités de leur partenaire à long terme rêvé(e) et analysent leur liste dans la perspective du genre. Ils renforcent ce qu'ils ont appris en écrivant une lettre ou en composant une chanson pour leur partenaire imaginaire. 


\section{relations à la dérive}

1 Toutes les relations - même stables et heureuses - traversent des périodes difficiles ou frustrantes. Certaines sont plus profondément ou chroniquement en danger que d'autres.

Signes d'une relation à la dérive :

- grave déséquilibre dans le respect de la dignité et des droits de chacun ;

- sentiments de manque d'authenticité personnelle (« ne pas pouvoir être soi-même») ;

- sentiments de solitude et d'isolement ;

- absence de valeurs partagées ou d'intérêts communs ;

- sentiment de mépris durable envers son partenaire ;

- épisodes de violence physique, sexuelle ou psychologique, ou menace de violence; et

- relation sexuelle extérieure inattendue de la part d'un partenaire.

La résolution constructive et non violente des problèmes rencontrés exige effort et compétence. [Voir l'unité 5.]

VOIR LE VOLUME D'ACTIVITÉS Activité 33

I'amour à la dérive

Les élèves terminent le récit de relations à la dérive et réfléchissent aux causes de rupture. 


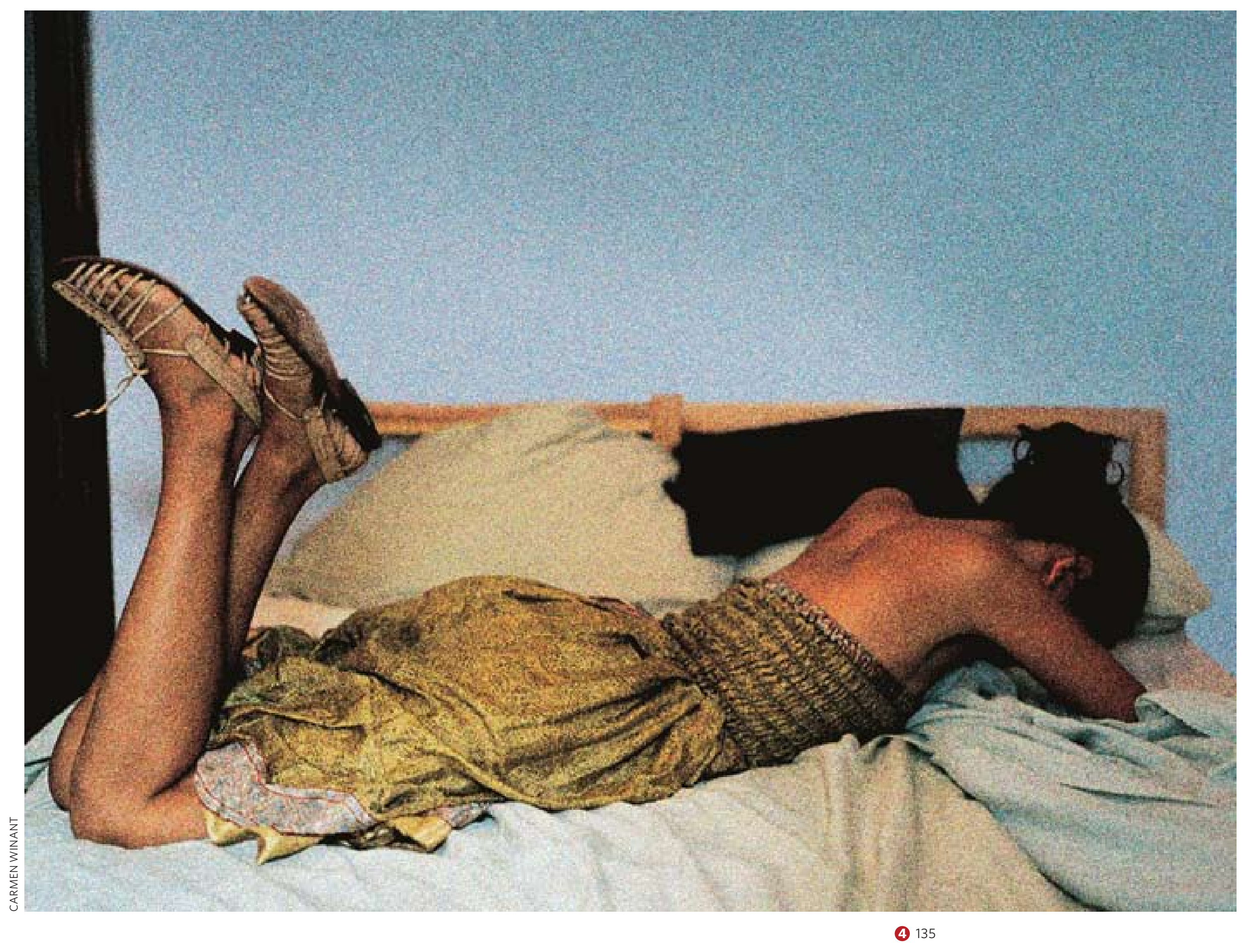




\section{rompre}

1 Personne ne devrait être forcé à s'engager dans une relation, à se marier ou à rester dans une relation.

- La rupture n'est pas toujours mutuelle. Même dans le cas du mariage, la plupart des pays reconnaissent le droit d'un partenaire à mettre fin à la relation.

- Tout le monde devrait avoir le droit de demander le divorce, pour de nombreuses raisons. Par exemple : le non-respect des droits du conjoint demandeur, ou l'échec du mariage malgré de longs efforts de résolution des incompatibilités du couple.

- La rupture peut être associée à de profonds sentiments de tristesse, de blessure, de solitude, de colère et d'échec. Elle peut aussi être source de soulagement et de bonheur. 


\section{normes changeantes}

1 Les attitudes et les normes relatives aux relations interpersonnelles sont en évolution perpétuelle.

2 Chaque jour, nous choisissons le ton de nos relations avec autrui. Ces choix créent et recréent le sens des relations dans notre vie.

3 Les gens parlent aujourd'hui avec leurs amis et parents de ce que représente pour eux une relation respectueuse et sans risques.

Par exemple :

- Beaucoup parlent à leur famille et amis de relations non traditionnelles telles que les relations homosexuelles ou d'une religion, caste ou race à l'autre.

- Beaucoup de jeunes encouragent leurs amies et sœurs à éviter les hommes plus âgés qui leur offrent argent ou cadeaux en échange de faveurs sexuelles.

- Une conversation respectueuse et honnête peut aussi aider les gens à réfléchir à leurs propres préjugés.

4 Beaucoup soutiennent publiquement les relations plus respectueuses et moins risquées à tous les niveaux de la société.

Par exemple :

- Les jeunes jouent un rôle important dans la sensibilisation aux problèmes tels que le viol par une connaissance ou l'opprobre jeté sur les personnes atteintes du VIH.

- Les campagnes pour un meilleur accès aux médicaments et services prolongent la vie des personnes infectées et leur donnent l'espoir et la confiance nécessaires à l'établissement de relations durables.

- Des milliers d'hommes se joignent aux campagnes contre les violences faites aux femmes et pour l'établissement de relations interpersonnelles plus paisibles et plus harmonieuses.

[Voir l'unité 8 pour plus de détails sur le passage à l'action dans sa vie et sa communauté.] 


$$
\begin{aligned}
& \text { APTITUDES À LA } \\
& \text { COMMUNICATION } \\
& \text { ET Á LA DÉCISION }
\end{aligned}
$$




\section{panorama}

Savoir s'exprimer pour être compris et savoir comprendre ce que les autres essaient de dire sont des aptitudes importantes, et qui aident à s'assumer. Elles aident aussi à développer des relations basées sur la compréhension et la satisfaction mutuelles. Elles peuvent aider à résoudre les conflits de manière respectueuse et sans violence.

Le rang de certaines personnes dans la communauté influence leur aptitude à exprimer leurs besoins, leurs désirs et leurs sentiments à autrui et affecte parfois aussi leur capacité d'exécuter leurs décisions. Tout le monde peut apprendre à communiquer plus efficacement.

Cette unité explore les difficultés souvent rencontrées par les jeunes quand il s'agit de communiquer et de prendre des décisions relatives à la sexualité. Elle leur apprend d'autres aptitudes utiles dans ce contexte et leur donne l'occasion de les renforcer. 


\section{APTITUDES À LA COMMUNICATION ET À LA DÉCISION}

Répartissez les élèves par paires, pour qu'ils apprennent et pratiquent leurs aptitudes à la communication deux à deux. Les jeux de rôle sont aussi utiles et amusants.

Veillez à présenter des exemples concrets de communication et de prise de décision, auxquels vos élèves peuvent se raccrocher dans leur vie.

La plupart des élèves doivent développer et pratiquer d'autres aptitudes pour apprendre à communiquer aisément leurs sentiments sur les questions du sexe et de la sexualité. Les sujets sensibles incluent la communication de son état HIV, de ce qui donne du plaisir ou non, ou la décision de communiquer ou non, et comment, son attirance envers le même sexe.

Montrer l'exemple, par l'écoute active et la réponse sans jugement, est un aspect important de l'enseignement de ces aptitudes.

N'oubliez pas l'importance de la communication non verbale et faites attention à votre propre langage corporel. Le corps peut envoyer un message contraire à ce que l'on dit.

Veillez à créer un espace sûr où tous les élèves puissent communiquer ouvertement, y compris ceux généralement plus timides devant les autres. Évitez cependant de faire pression sur qui que ce soit et veillez à ne pousser personne à parler d'une question personnelle ou sensible. 


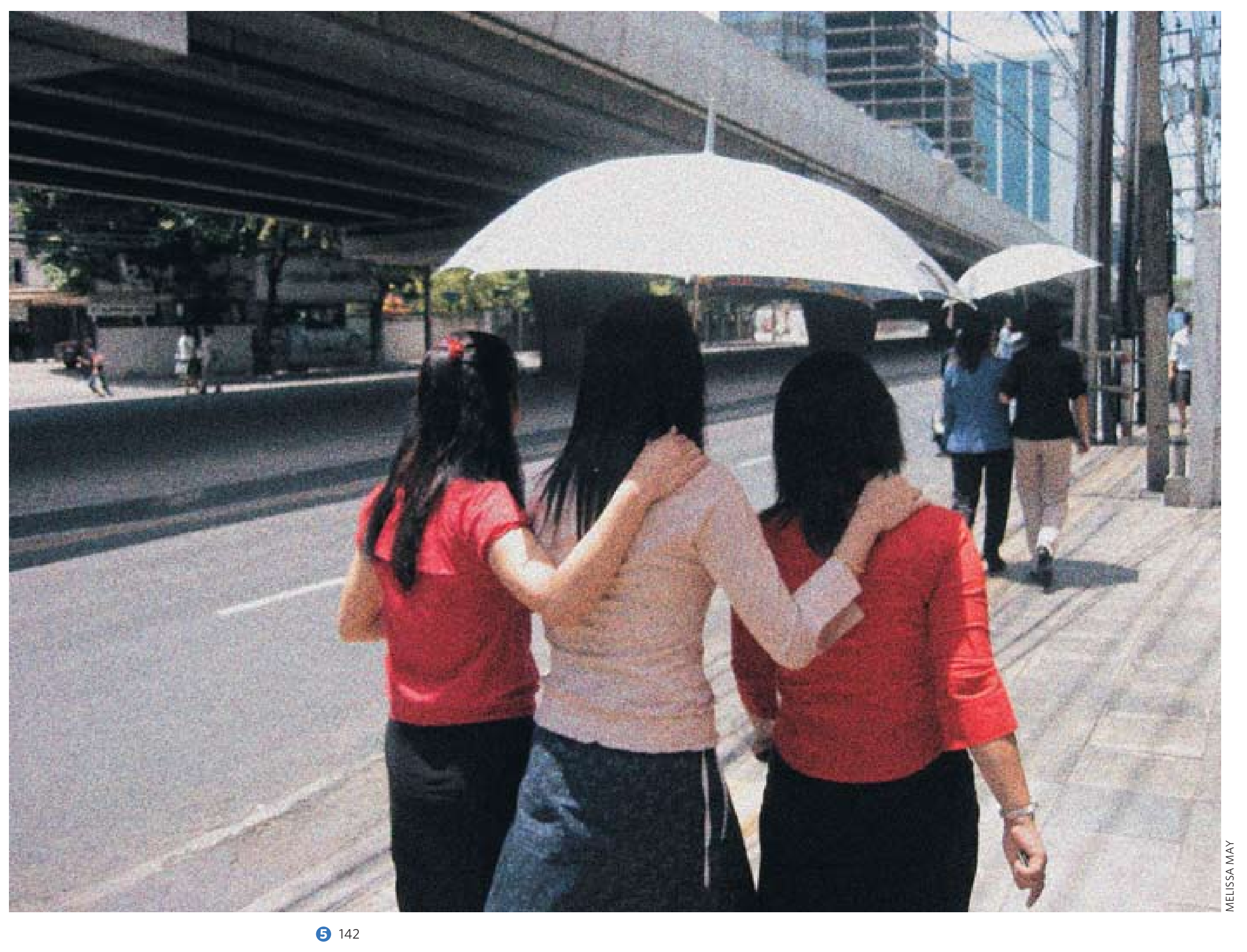




\section{APTITUDES À LA COMMUNICATION ET À LA DÉCISION}

Le matériel couvert dans cette unité prépare les élèves à :

\section{Objectifs cognitifs}

Expliquer pourquoi il peut être difficile de parler de sexualité ou du VIH.

Identifier une situation de décision sexuelle courante mais qui peut mettre mal à l'aise une personne qui ne possède pas de bonnes aptitudes de communication ou de décision.

\section{Objectifs affectifs}

Apprécier l'importance de bonnes aptitudes de communication dans les relations interpersonnelles.

Réfléchir honnêtement à leur propre maturité et facilité de communication pour assurer que leurs expériences intimes soient désirées, sûres, respectueuses et agréables.

Apprécier la difficulté qu'éprouvent beaucoup de jeunes à communiquer clairement et avec assurance qu'ils ne veulent pas avoir de rapports sexuels.

Objectifs de compétences

Démontrer l'usage d'au moins trois aptitudes de communication fondamentales et d'au moins trois comportements susceptibles d'entraver la communication claire.

Démontrer une capacité accrue de communiquer clairement lors d'une conversation entre partenaires sur leur désir véritablement mutuel d'intimité physique.

Démontrer une capacité accrue de communiquer clairement lors d'une conversation sur la manière de se protéger contre l'infection (y compris le VIH) et une grossesse non désirée.

Démontrer la compréhension des concepts fondamentaux de la prise de décision. 


\section{facteurs qui affectent la communication}

1 Savoir s'exprimer pour être compris, et savoir comprendre ce que les autres essaient de dire sont des aptitudes importantes, et qui aident à s'assumer.

- Ces aptitudes aident à développer des relations basées sur la compréhension et la satisfaction mutuelles.

- Elles peuvent aider à résoudre les conflits avec respect et sans violence.

- Elles contribuent au sentiment de bien-être, à l'égard de soi-même et de ses relations.

2 II existe différents styles et aptitudes de communication.

- La tradition orale et expressive varie d'une culture à l'autre.

- Les styles de communication dépendent aussi du tempérament individuel de la personne et du style appris pendant l'enfance.

- Les normes de genre affectent souvent la capacité d'une personne à communiquer et son style. Les hommes et les femmes peuvent communiquer de manières différentes.

- Renforcer ses aptitudes à la communication aide à transmettre clairement opinions, besoins et sentiments.

- On peut apprendre à communiquer efficacement et sans gêne par-dessus les cultures et autres obstacles.

\section{POINTS DE RÉFLEXION}

Dans une conversation entre une personne riche et une autre de classe socioéconomique ou caste inférieure, laquelle se sent vraisemblablement plus libre d'exprimer ses idées et ses sentiments? Et entre un homme et une femme?

Comment assurer le respect des besoins, des sentiments et du droit de communiquer de tous, sans égard au rang social ?
@3 Être perçu comme ayant moins de « pouvoir social » ou de stature sociale qu'un autre peut affecter profondément la capacité et le style de communication d'une personne.

4 La plupart des gens peuvent acquérir de bonnes aptitudes de communication. À force de pratique, tout le monde peut communiquer plus efficacement. 


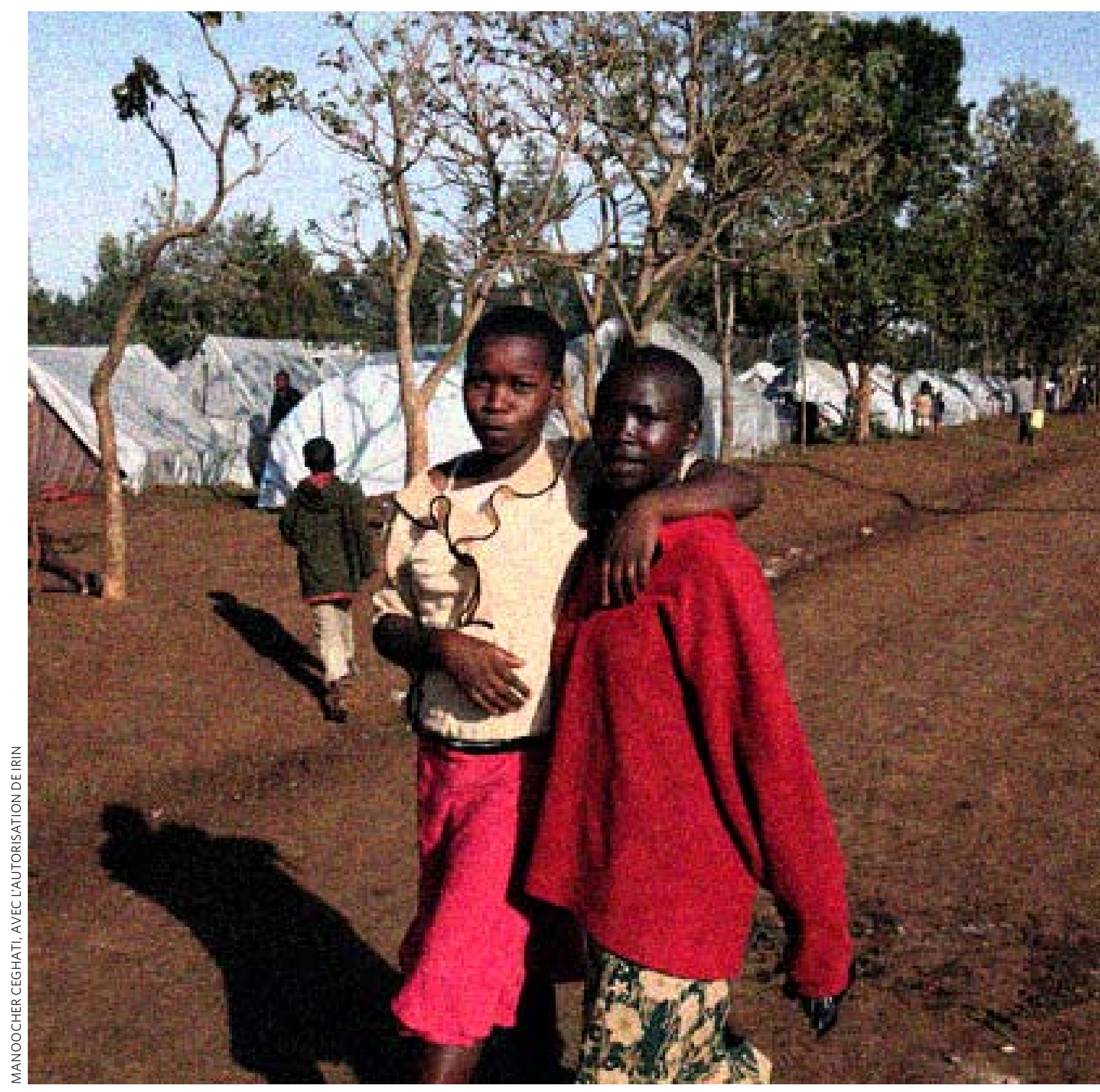

VOIR LE VOLUME D'ACTIVITÉS Activité 34

ai-je dit cela ? Différents styles de communication

Les élèves analysent différentes manières de répondre verbalement à une situation inconfortable et font la distinction entre la communication agressive, assurée et passive. 


\section{conseils pour une communication efficace}

1 La communication est claire quand le message qu'une personne entend transmettre est identique à celui que l'autre comprend.

- La communication s'effectue de manière verbale et non verbale.

- Il est important de vérifier que le message transmis a été compris correctement, surtout quand il touche à un sujet difficile ou sensible.

2 Dans chaque situation, l'un des comportements les plus utiles à la qualité de la communication est l'écoute attentive et respectueuse. Les normes culturelles influencent cependant les types de communication jugés appropriés.

3 L'écoute active, sans jugement, peut enrichir la communication.

Quand on écoute, il est utile :

- d'essayer de comprendre la personne qui parle ;

- de valider la personne qui parle en disant par exemple, « Je comprends », ou « En effet »;

- d'établir le contact oculaire, en regardant la personne dans les yeux;

- de donner des signaux non verbaux positifs, tels qu'un sourire, un signe de la tête, etc. ; et

- de demander plus de détails ou d'explications.

VOIR LE VOLUME D'ACTIVITÉS Activité 35

\section{écoute active}

Les élèves démontrent les comportements qui enrichissent (ou entravent) la communication. 


\section{Certains comportements peuvent enrichir la communication.}

Exemples de comportements constructifs :

- exprimer ses sentiments et commencer ses phrases par « Je » plutôt que par « Tu » ou «Vous »;

- reconnaître que chacun a le droit d'avoir ses propres sentiments et opinions ;

- éviter de se montrer trop dominant et de porter jugement ;

- énoncer aussi clairement que possible ce que l'on veut ou ce que l'on ne veut pas; et

- aider à identifier les solutions possibles aux problèmes.

5 De nombreux comportements peuvent entraver la communication.

\section{POINTS DE RÉFLEXION}

Quand on essaie de communiquer, que ressent-on quand:

On est interrompu ou pas entendu?

On est critiqué, étiqueté ou, ou injurié ? On est accusé ou jugé ?

On a l'impression que

l'autre essaie de dominer la conversation?

On reçoit des messages non verbaux négatifs, comme un froncement de sourcils? 


\section{styles de communication directs ou indirects}

1 Certaines personnes communiquent de manière directe et ferme. D'autres, de manière plutôt indirecte.

2 La communication directe et ferme, verbale ou non, envoie généralement un message clair.

VOIR LE VOLUME D'ACTIVITÉS Activité 36

pratiquer la communication affirmative

Les élèves analysent les

comportements affirmatifs, parlent des implications culturelles et pratiquent la communication affirmative dans des situations d'abus de droits.

\section{VOIR LE VOLUME D'ACTIVITÉS} Activité 37

cinq étapes pour

communiquer au sujet d'un conflit

Les élèves apprennent un modèle en cinq étapes pour communiquer clairement et avec respect au sujet d'un conflit interpersonnel.
Par exemple :

- Une personne qui communique avec assurance exprime ses sentiments ou pensées de manière directe.

- Une personne peut parler à la première personne pour exprimer ses sentiments et pensées («Je n’aime pas quand tu me parles ainsi » ou « Je suis contente que tu m’aies accompagnée à la clinique »).

- Le contact oculaire ou d’autres messages non verbaux établissent une communication directe.

3 La communication indirecte peut aussi être verbale ou non verbale, mais elle transmet souvent un message moins précis ou moins défini.

Par exemple :

- Une personne peut éviter l'expression spécifique de son opinion ou de ses sentiments (par exemple : « On m’a dit qu'on peut tomber enceinte la première fois », plutôt que « Pas si tu ne mets pas de préservatif»).

- Une personne peut éviter de terminer une phrase ou d'établir le contact oculaire.

4 Il est parfois difficile de déterminer le meilleur moyen de s'exprimer, directement ou indirectement.

- Les normes sociales et de politesse, le rang social ou les attentes de genre imposent parfois la communication indirecte. Il est important de savoir comment s'affirmer de manière efficace dans sa propre culture.

- La communication indirecte n'est pas toujours claire.

- Certaines personnes ont parfois l'impression de ne pas être entendues. Il leur serait peut-être utile de pratiquer une forme d'expression plus claire, plus directe et plus répétitive.

- La communication directe et ferme ne doit pas être agressive. On peut communiquer de manière claire et directe sans manquer de respect pour les sentiments et les pensées des autres. 


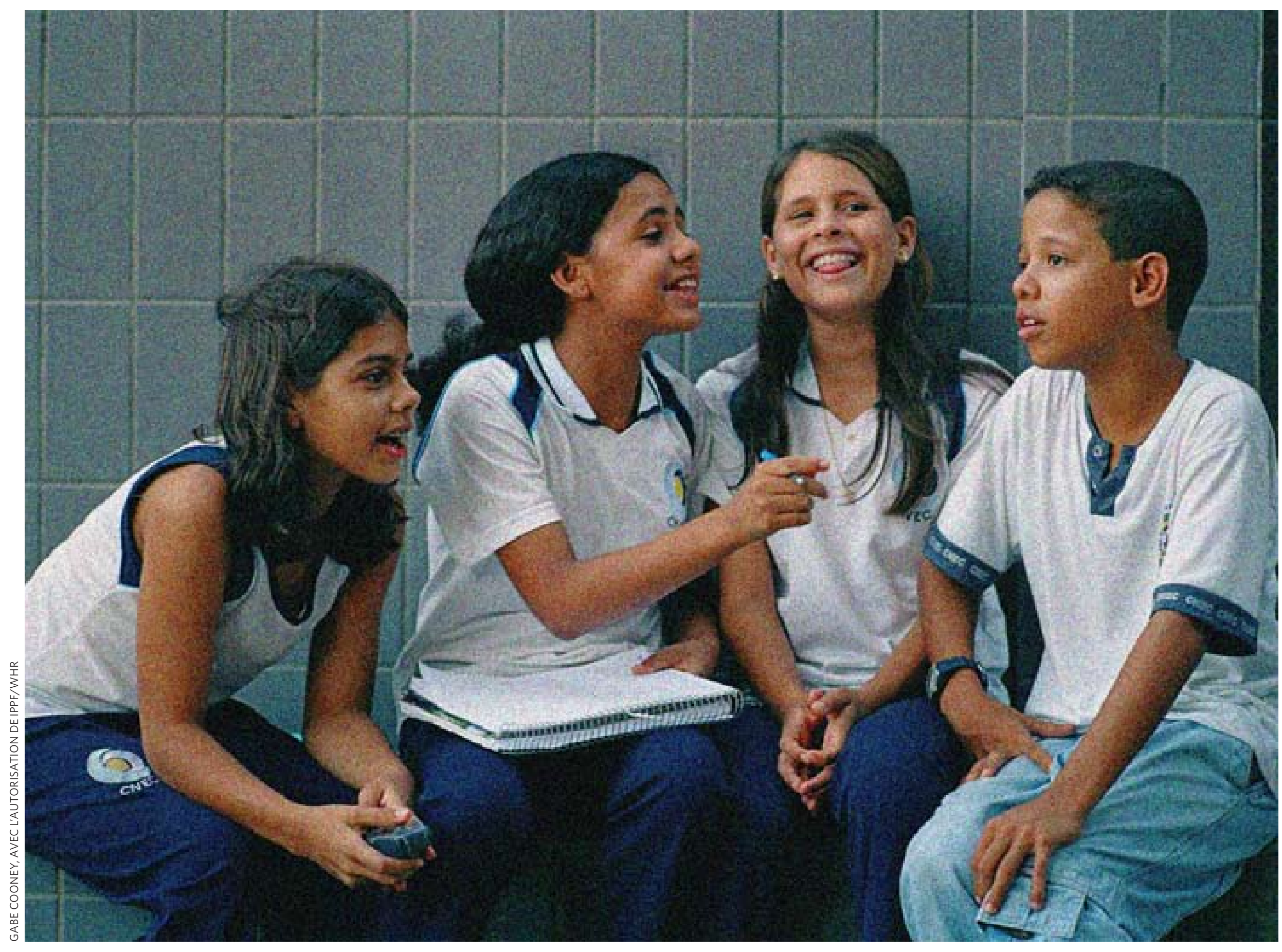




\section{parler à son ou sa partenaire de questions sexuelles et de santé sexuelle}

1 La communication est un aspect important de la relation sexuelle.

2 La communication avec le ou la partenaire est importante pour assurer que les deux consentent à l'activité sexuelle.

3 La communication efficace peut aider à protéger son propre bien-être et celui de son ou sa partenaire.

Notamment :

- la protection contre les infections sexuellement transmissibles, y compris le VIH ;

- la protection contre les grossesses non désirées ; et

- la réduction du risque de conflit susceptible de devenir violent.

4 La communication peut accroître la confiance mutuelle et le plaisir.

5 La communication est importante à la clarification des attentes et des limites.

Notamment :

VOIR LE VOLUME D'ACTIVITÉS

- les attentes et limites relatives aux sentiments;

- celles relatives à l'échange d'argent ou de biens matériels; ou

- celles relatives à d'autres facteurs.

parler sexe et santé sexuelle

Par discussion et jeu de rôle, les élèves pratiquent les aptitudes

verbales et non verbales

nécessaires à la communication sur

les comportements, les décisions

et la santé sexuelle.

6 Les normes de genre affectent souvent la manière dont les personnes communiquent ou non sur les questions de nature sexuelle.

7 Tout le monde peut apprendre à communiquer aisément et efficacement sur la sexualité. La pratique aide!

(5) 150 


\section{prendre des décisions}

En grandissant, il est important d'apprendre à faire preuve de bon sens dans ses décisions. Les décisions satisfaisantes sont généralement le fruit d'une réflexion en plusieurs étapes:

\section{Étape 1 : Considérer toutes les options.}

- Beaucoup de décisions présentent des options auxquelles on ne pense pas toujours.

- D'autres personnes peuvent aider à identifier ces options.

Étape 2 : Identifier les avantages et les inconvénients de chaque option.

- Considérer notamment le préjudice potentiel de chacune à soi-même et à autrui.

- Dresser par écrit la liste des conséquences potentielles de chaque option.

Étape 3 : Si la situation s'y prête, s'informer ou demander conseil.

Étape 4 : Prendre une décision provisoire.

- Considérer si la décision prise sera facile ou non à changer par la suite.

Étape 5 : Au besoin, reconsidérer la décision prise.

Essayez de prendre tout le temps nécessaire à chacune de ces étapes. Les décisions bien réfléchies sont souvent les plus satisfaisantes.

\section{POINTS DE RÉFLEXION}

Beaucoup de décisions de nature sexuelle peuvent être complexes. Pensez par exemple à celles-ci :

Avoir des rapports sexuels ou non. Insister ou non sur l'usage du préservatif avec un partenaire récalcitrant.

Rompre ou non.

Avoir ou non des rapports sexuels dans le but d'obtenir un cadeau ou l'argent nécessaire aux frais d'école.

Révéler ou non le résultat d'un test $\mathrm{VIH}$.

Interrompre ou non une grossesse non planifiée.

Révéler ou non à ses parents une attirance romantique ou sexuelle envers une personne du même sexe. 


\section{exécuter ses décisions}

Une fois la décision prise, il faut un plan d'exécution, défini clairement, avec toutes les étapes nécessaires :

\section{Étape 1 : Considérer les facteurs qui faciliteront l'exécution.}

Par exemple :

- parler à ses parents quand ils ne sont pas sous pression ;

- rechercher quelqu'un qui a pris et exécuté une décision similaire (par exemple, une fille qui a décidé de rester à l'école ; un ami qui a déjà invité quelqu'un à sortir avec lui ; une personne qui s'est fait tester pour le VIH) ; et

- trouver le moyen d'obtenir l'argent ou les ressources nécessaires à l'exécution de la décision.

Étape 2 : Réfléchir aux obstacles probables. Cette étape est importante, car certaines décisions sont très difficiles à exécuter. Les obstacles suivants peuvent être rencontrés :

- manque d'argent (pour payer le transport jusqu'à la clinique ou pour acheter ses livres scolaires, par exemple) ;

- manque d'accès aux services (écoles et cliniques difficiles d'accès, par exemple) ;

- restrictions légales (à l'avortement ou à l'accès des adolescents non mariés à la contraception, par exemple) ;

- peur des conséquences sociales (de se déclarer homosexuel, de s'opposer à la mutilation génitale, de résister au mariage précoce, d'être vue dans une clinique de planification familiale, d'accepter un emploi propre à l'autre genre, etc.); et

- coûts personnels (rejet d'un partenaire auquel on refuserait l'acte sexuel ou dont on exigerait l'usage du préservatif, ou perspective d'un diagnostic potentiellement mortel, etc.)

\section{Étape 3 : Répéter l'exécution de sa décision en privé ou sans risques.}

\section{Par exemple :}

- écrire ou répéter la révélation de sévices sexuels à un adulte de confiance ;

- essayer le préservatif (masculin ou féminin);

- se préparer avec un(e) ami(e) de confiance; et

- déterminer s'il convient, et comment, de communiquer sa décision à toute autre personne affectée. 
Étape 4 : Discuter la décision et le plan avec une personne dont on a l'appui.

Par exemple :

- parler à un conseiller de son intention d'interrompre une grossesse ;

- parler à une personne qui s'est déjà soumise à un test de dépistage du VIH ; ou

- trouver un service ou une communauté en ligne pour parler avec une personne qui envisage de changer de genre.

Étape 5 : Trouver le moyen le moins risqué d'exécuter sa décision.

Par exemple :

- se faire accompagner pour confronter un partenaire violent ; ou

- rechercher un allié parmi les dirigeants de la communauté avant de lancer une campagne en faveur de l'éducation à la sexualité.

Étape 6 : Si la situation s'y prête, s'informer ou demander conseil.

Étape 7 : En cas d'obstacles, élaborer un autre plan d'action ou repenser la décision.

Étape 8 : Ne pas oublier que même en l'absence d'obstacle, on a toujours le droit de réévaluer ses décisions et de changer d'avis.

VOIR LE VOLUME D'ACTIVITÉS Activité 39

exécuter une décision

difficile

Les élèves apprennent les étapes fondamentales de mise en œuvre d'une décision et créent une bande dessinée présentant l'exécution d'une décision difficile. 
LE CORPS,

LA PUBERTÉ ET LA

REPRODUCTION 


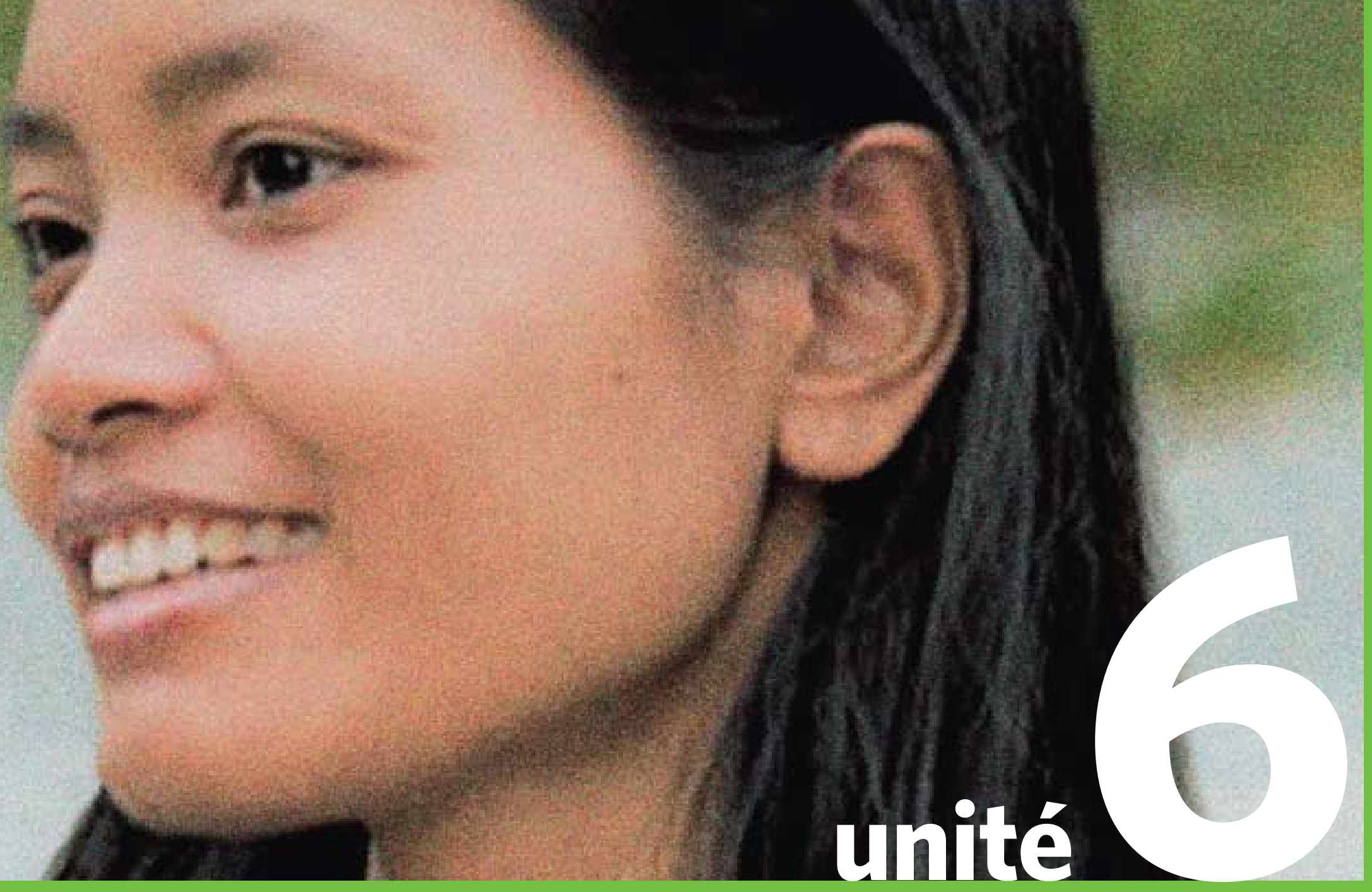




\section{panorama}

Le corps humain est beau sous toutes ses formes. Les jeunes ont le droit de grandir et d'acquérir un sentiment de familiarité et de confiance vis-à-vis de leur corps, qui leur permettra aussi de prendre mieux soin de leur santé sexuelle. Les jeunes ont aussi besoin d'une bonne alimentation, d'exercice physique, d'une information adéquate et de services de santé pour garder leur corps en bonne forme.

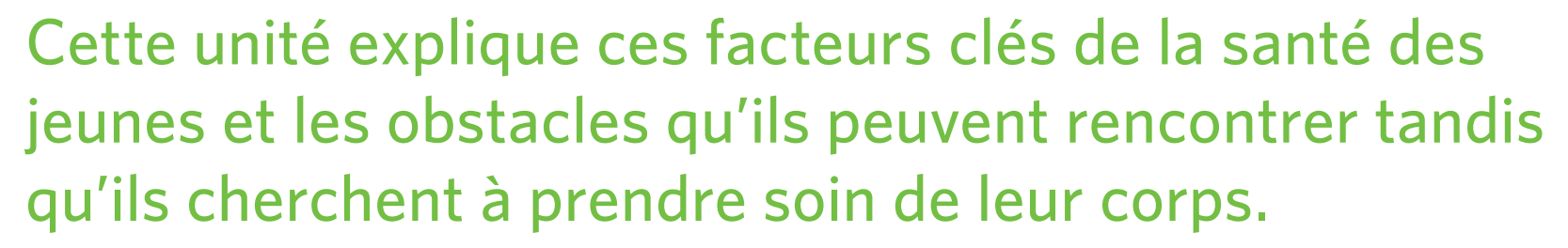




\section{LE CORPS, LA PUBERTÉ ET LA REPRODUCTION}

Lors de la discussion de sujets tels que la puberté, les types de corps et l'appareil génital, n'oubliez pas que les jeunes s'inquiètent souvent de savoir s'ils sont « normaux ». Mettez l'accent sur l'immensité de ce qui est naturel et évitez les termes tels que « anormal », etc.

L'emploi des termes propres, pour décrire les parties du corps, met les élèves plus à l'aise.

N'oubliez pas que le comportement sexuel de vos élèves dépend largement de facteurs sociaux tels que leurs attitudes sur les questions de genre. Même si vous êtes plus habitué à présenter une information de nature technique, considérez que les ressources telles que les fiches d'information remplissent parfaitement cette tâche et vous permettent de consacrer plus de votre temps limité aux sujets qui requièrent réflexion et dialogue.

Plusieurs fiches d'information, en fin de volume, présentent les sujets abordés dans cette unité de manière plus détaillée. 


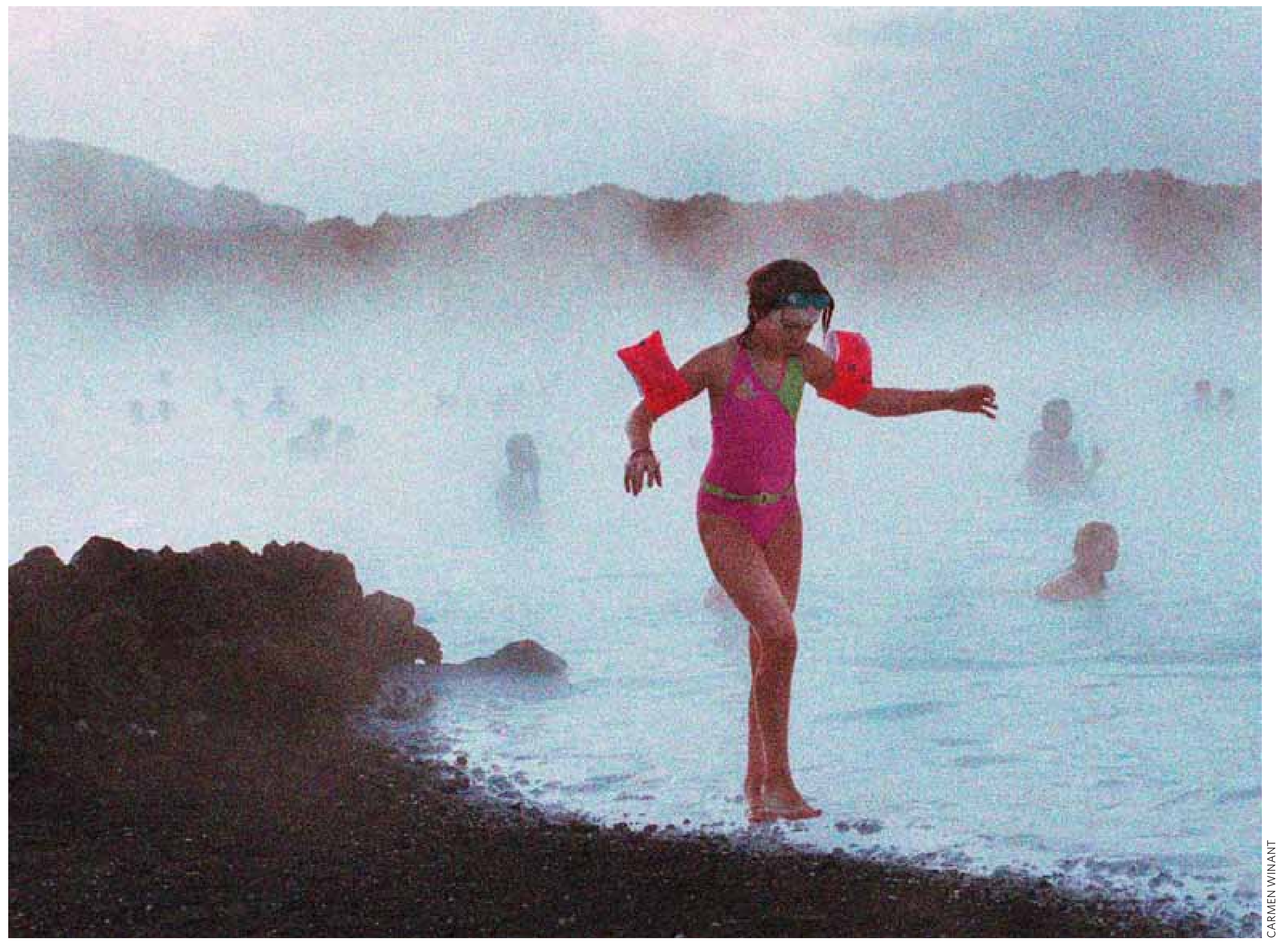




\section{OBJECTIFS D'APPRENTISSAGE}

\section{LE CORPS, LA PUBERTÉ ET LA REPRODUCTION}

Le matériel couvert dans cette unité prépare les élèves à :

\section{Objectifs cognitifs}

Discuter au moins deux changements physiques, ainsi que deux changements sociaux ou culturels qui affectent les jeunes à la puberté et en quoi ils diffèrent pour les filles et pour les garçons.

Citer au moins deux avantages de la connaissance de son corps pour la santé et le bien-être sexuels.

Décrire l'appareil sexuel et génital masculin et féminin et expliquer le principe de la fécondation et de la reproduction.

Expliquer le rôle des deux sexes dans la stérilité.

\section{Objectifis affectifs}

Discuter (verbalement ou par écrit) la manière dont les normes de genre affectent l'image du corps.

Identifier un aspect de leur corps dont ils sont satisfaits.

Identifier et discuter (verbalement ou par écrit) au moins une inquiétude ou crainte concernant leur capacité de protéger leur santé sexuelle. 


\section{I'image du corps}

1 Le corps humain varie dans son apparence. Il n'y a pas de type de corps « parfait » ou « normal », quoi qu'en disent la culture et les médias.

\section{Apprendre à accepter son corps - en avoir une image positive - est un aspect important de l'estime de soi.}

- Changer son apparence peut être une expérience amusante, parfois utile à l'exploration de son identité.

- L'image qu'on se fait de son corps affecte l'aisance avec laquelle on aborde la vie sociale, l'activité physique et la sexualité.

- Il peut être particulièrement difficile d'acquérir cette aisance dans les communautés qui rejettent le handicap physique.

\section{POINTS DE RÉFLEXION}

Plusieurs facteurs peuvent limiter la confiance que l'on ressent à l'égard de son corps et de son apparence. Par exemple :

Les messages et images reçus des médias sur les types de corps beaux, désirables et acceptables sont-ils réalistes et flexibles? Et ceux et celles transmis par la publicité ? Ou par la communauté, la famille et les amis?

Est-il facile de gérer la pression des idéaux imposés par la culture sur le corps et son apparence ? Est-il plus facile ou plus difficile de gérer cette pression pendant l'adolescence?

Que ressentent les personnes taquinées ou ridiculisées à cause de leur corps ou de leur apparence?

\section{3 Plusieurs facteurs individuels et sociaux affectent la confiance qu'on ressent à} l'égard de son corps.

Parmi ces facteurs:

- connaître son propre corps ;

- comprendre que son corps n'appartient qu'à soi-même ;

- intérioriser les normes sociales qui célèbrent ou rejettent différentes apparences et aptitudes corporelles ;

- comprendre que les apparences « idéales » varient suivant la culture et l'époque ;

- recevoir une réaction positive ou négative à l'égard de son corps, indépendamment de son degré de conformité à l'idéal culturel ;

- être physiquement actif et en bonne santé ;

- comprendre ses désirs physiques, y compris celui d'éviter les relations sexuelles non désirées, désagréables, non respectueuses, contraintes ou violentes; et

- disposer de lois et de systèmes d'accompagnement qui permettent aux personnes handicapées de vivre pleinement leur vie, de manière indépendante ou avec une assistance ancrée dans le respect. 
4 Les filles et les femmes subissent souvent une pression sociale intense concernant leur apparence physique.

- Leur rang social est souvent lié à leur apparence.

- Les pratiques culturelles (des concours de beauté à la mutilation génitale) renforcent la pression exercée sur les jeunes femmes en ce qui concerne les idéaux culturels de beauté.

- Les filles et les femmes sont souvent l'objet de commentaires et harcèlements sexuels perturbants, déplaisants et menaçants.

- Les femmes, et surtout les filles, sont plus vulnérables que les garçons aux sentiments négatifs à l'égard de leur corps, qui débouchent parfois sur des troubles du comportement alimentaire.

- Les filles qui se font une image négative de leur corps (ou qui ont une faible estime de soi en général) croient parfois devoir accepter les rapports sexuels pour être aimées et approuvées.

\section{Les hommes et les garçons s'inquiètent parfois aussi de leur apparence.}

- Ils peuvent ressentir la pression d'être forts et athlétiques pour prouver leur virilité.

- Ils peuvent aussi être sujets aux commentaires et harcèlements sexuels.

- Certains garçons développent aussi des troubles de l'alimentation.

- Les garçons estiment souvent que l'admission de leurs préoccupations ou la demande d'aide sont moins acceptables, socialement, pour eux qu'elles ne le sont pour les filles. 
6 Presque toutes les personnes atteintes d'un handicap physique ou d'une maladie chronique peuvent vivre pleinement leur vie, y compris leur sexualité. Souvent pourtant, ces personnes subissent différentes formes de discrimination et d'isolement physique et social.

- Cet opprobre mine leur confiance en leur corps et en leur capacité de vivre pleinement leur vie sociale (et sexuelle).

- La discrimination ou l'opprobre affectent aussi leur capacité de logement, d'emploi et d'accès à l'espace public.

- Partout dans le monde, les personnes handicapées (de même que celles vivant avec le VIH et sida) se mobilisent contre l'opprobre et la discrimination et pour le plein respect de leur droit à vivre une vie sexuelle satisfaisante et à participer pleinement à la société.

7 S'ils y sont encouragés, tous les jeunes peuvent se sentir à l'aise face à leur apparence physique. Ils peuvent aussi trouver d'autres sources d'estime et de valorisation de leur personne : en se concentrant sur leur réussite scolaire, leurs talents créatifs, etc.

\section{VOIR LE VOLUME D'ACTIVITÉS}

\section{Activité 40}

\section{ce que vous voyez en moi}

Les élèves parlent des pressions relatives à l'apparence. Par écrit,

ils décrivent les caractéristiques

physiques qui leur plaisent en euxmêmes, puis entendent celles non physiques que les autres admirent

en eux. 


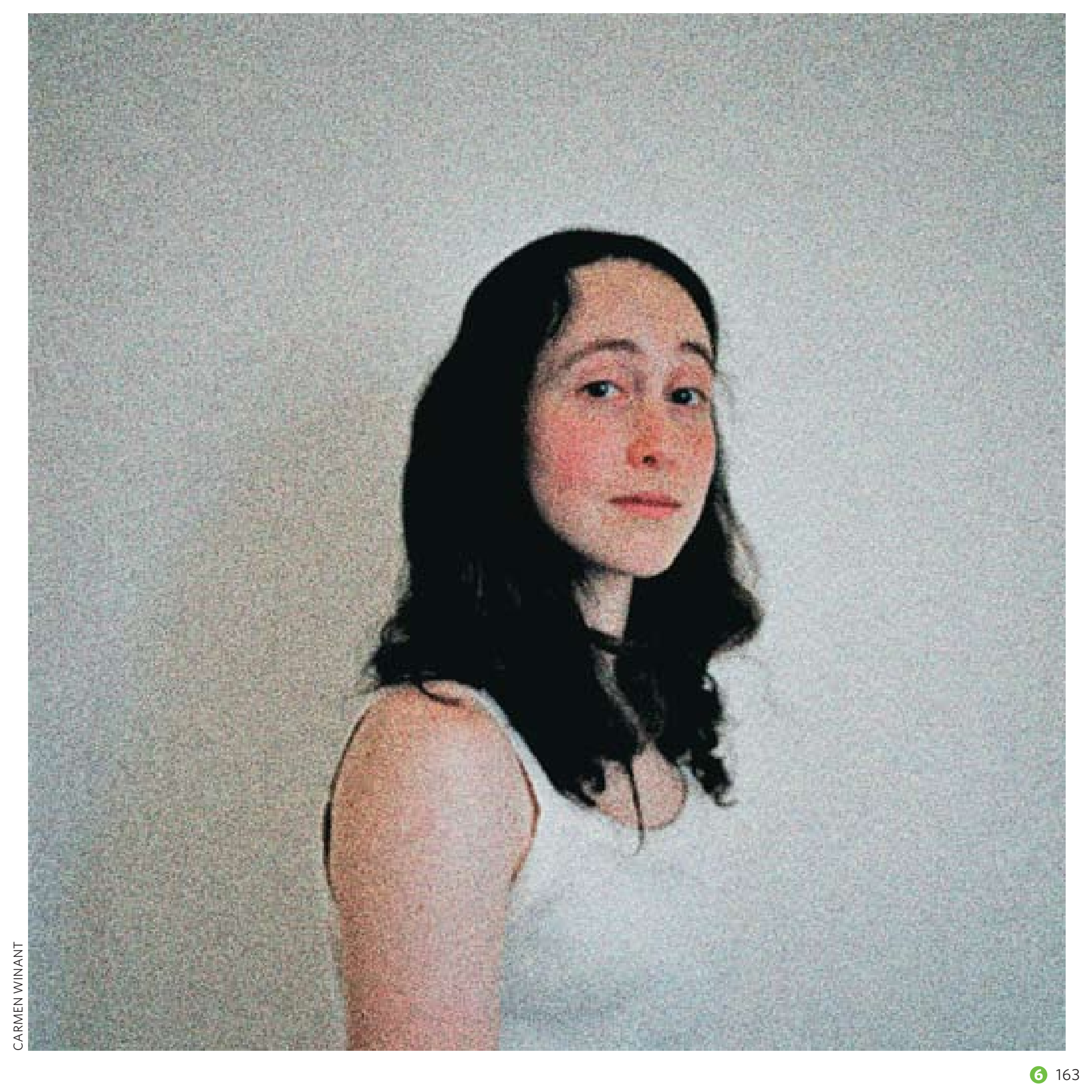




\section{la puberté}

Voir les fiches d'information sur

la Puberté masculine et la Puberté féminine.
1 À l'approche de l'adolescence, le corps commence à produire des substances chimiques - appelées hormones - à l'origine de changements physiques et psychiques. Cette période de changement est appelée « la puberté ».

2 La puberté intervient plus tôt chez certains que chez d'autres.

- Les gènes, la nutrition, l'activité physique et la maladie affectent l'âge de la puberté.

- Les filles atteignent généralement la puberté plus tôt que les garçons.

\section{3 À la puberté, les organes sexuels et génitaux commencent à mûrir.}

- Pour les filles, les changements physiques associés à la puberté sont, notamment, le début de la menstruation, l'apparition des seins et celle de la pilosité axillaire et pubienne.

- Pour les garçons, il s'agit, entre autres changements physiques, des premières éjaculations nocturnes involontaires, de la production de sperme, de l'apparition de la pilosité faciale, pubienne et corporelle et de la mue de la voix. 
- Les aspects physiques aussi bien que sociaux de la puberté font changer les perceptions des jeunes à leur propre égard et à l'égard des autres.

- Pour beaucoup d'adolescents, la puberté éveille la curiosité sexuelle et ils explorent leur sexualité seuls, avec un ami ou une amie ou avec un(e) partenaire romantique ou sexuel(le).

\section{5 À la puberté, à l'aube de leur développement sexuel, les jeunes découvrent que leurs proches - et la société au sens large - les traitent différemment.}

- Certaines cultures pratiquent des rituels, qui célèbrent pour la plupart le passage à l'âge adulte. Certains peuvent cependant porter préjudice à la personne. [Voir la fiche d'information sur la Mutilation génitale des filles.]

- Les familles et les communautés attendent souvent des adolescents qu'ils assument de plus grandes responsabilités et leur accordent parfois plus de liberté.

- Souvent, les familles et les communautés exercent sur les adolescents une forte pression pour qu'ils se conforment aux rôles de genre attendus d'eux. 
6 Les rôles de genre se précisent nettement à la puberté, creusant souvent le fossé de l'égalité entre les garçons et les filles.

[Voir l'unité 2.]

Par exemple :

- Les garçons doivent se montrer forts et courageux.

- Il leur est parfois interdit d'exprimer certaines émotions, telles que la vulnérabilité ou la tendresse.

- Ils subissent souvent la pression de devenir sexuellement actifs pour prouver leur hétérosexualité, alors que l'activité sexuelle des filles est généralement désapprouvée par la société. [Voir l'unité 3, pp. 90-91.]

- Dans certains contextes, la puberté marque une sérieuse restriction de la liberté des filles. Certaines doivent quitter l'école, elles sont soumises à une stricte discipline vestimentaire et comportementale, et elles doivent parfois assumer de nouvelles responsabilités ménagères.

- Les filles, en particulier, deviennent l'objet d'avances sexuelles, pas toujours bienveillantes.

- Dans certains contextes, la puberté marque l'âge nubile des filles.

- Les garçons comme les filles peuvent subir de fortes pressions, allant parfois jusqu'à l'opprobre, concernant leur identité sexuelle ou de genre.

7 La puberté est une période de croissance physique rapide, pendant laquelle il est particulièrement important de prendre soin de son corps. Les jeunes se trouvent souvent confrontés aux problèmes de santé propres à l'adolescence, y compris la nécessité d'une activité physique saine et d'une bonne alimentation, et parfois aussi aux risques de la drogue et de l'alcool.

[Voir la fiche d'information sur la Nutrition, l'activité physique et l'abus de substances toxiques.]

Les élèves analysent les changements sociaux qui affectent

les garçons et les filles pendant l'adolescence. 


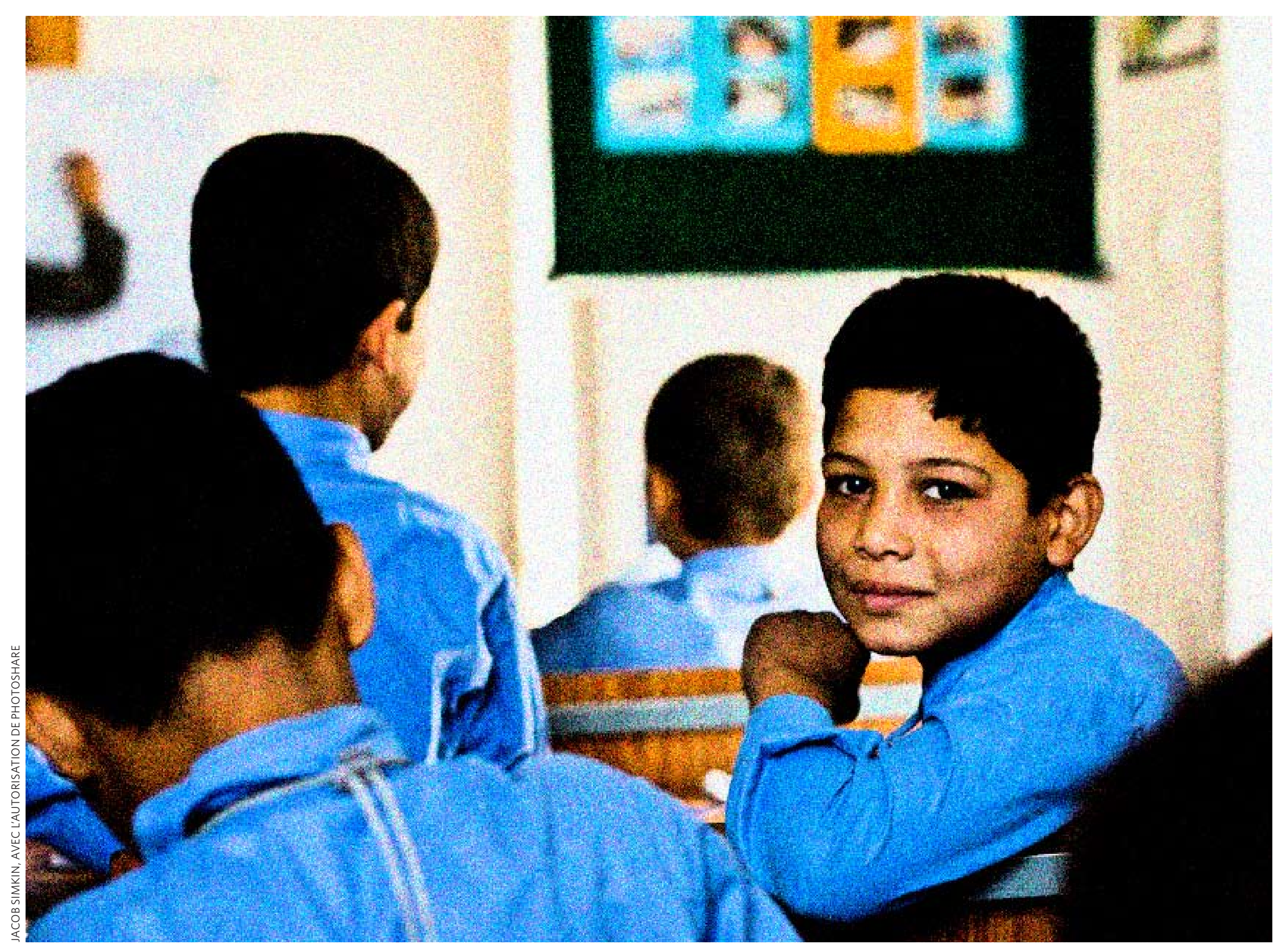




\section{connaître son corps}

Les adolescentes devraient notamment pouvoir accéder à une information et à des services qui les aident à comprendre leur sexualité et à se protéger contre les grossesses non désirées, les maladies sexuellement transmissibles et les risques de stérilité en résultant. Il faudrait également enseigner aux jeunes gens à respecter l'autodétermination des femmes et à partager les responsabilités avec elles dans les questions de sexualité et de procréation (Paragraphe 7.41, Programme d'action de la CIPD, 1994).

1 Découvrir son corps peut être passionnant et aide à s'assumer.

2 Connaître son corps est bénéfique à la santé sexuelle et au bien-être.

On en tire par exemple :

- le sentiment que son corps est à soi, et qu'il n'y a pas de raison de le redouter ;

- pour les filles, la capacité de prévoir et de gérer la menstruation ;

- la capacité de découvrir ce qui procure le plaisir sexuel ;

- la capacité de communiquer ses sentiments et ses pensées sur l’acte sexuel et la procréation ;

- la capacité d'éviter les grossesses non désirées ;

- la capacité de reconnaître les symptômes de certaines infections; et

- la capacité de protéger son droit à la dignité et au respect.

VOIR LE VOLUME D'ACTIVITÉS Activité 43

le saviez-vous?

Une grille de mots croisés et un exercice aident les élèves à apprendre et réviser quelques faits intéressants sur le corps et la reproduction. 
3 La société envoie souvent aux jeunes des messages faux et nuisibles au sujet du corps sexuel, parfois préjudiciables jusqu'à l'âge adulte.

4 Beaucoup de jeunes décident eux-mêmes de s'informer sur leur corps et de partager ce qu'ils ont appris avec leurs pairs.

5 Partout dans le monde, jeunes et adultes cherchent à promouvoir des messages plus exacts et positifs au sujet du corps et de la sexualité. 


\section{Les organes sexuels et génitaux}

Voir les fiches d'information sur

l'Appareil sexuel et génital

et l'unité 3, p. 98.
1 Certains organes participent à la reproduction, au plaisir sexuel ou aux deux.

Par exemple, côté masculin :

- Le pénis participe au plaisir sexuel et à la reproduction.

- Les testicules sont essentiels à la reproduction et ils contribuent au plaisir sexuel.

Côté féminin :

- Lutérus ne participe qu'à la reproduction.

- Le clitoris est le seul organe dont le seul rôle est le plaisir sexuel.

\section{D'autres organes jouent aussi un rôle dans la sexualité et la reproduction.}

Par exemple :

- La peau peut produire une réponse sexuelle au toucher.

- Le cerveau traite les émotions et sécrète les hormones qui affectent les sentiments et la fonction sexuelle et génitale.

\section{Les normes de la communauté relatives à la sexualité et au genre façonnent} souvent les attitudes à l'égard du corps et peuvent donner naissance au mythe.

En certains endroits, par exemple, on ne sait pas nécessairement que :

- l'acte sexuel implique bien plus que les organes sexuels et représente bien plus que l'orgasme ;

- l'hymen (fine membrane à l'entrée du vagin) déchiré n'est pas nécessairement signe de perte de virginité : il peut se déchirer sous l'effet de l'activité physique de l'enfance ;

- le vagin s'autonettoie naturellement ; les « douches vaginales » sont inutiles et souvent nuisibles; ou

- en beaucoup d'endroits, la longueur du pénis semble inquiéter plus les hommes que leurs partenaires féminines.

\section{Certaines personnes désireuses de changer de genre ou de sexe recourent aux} hormones et/ou à la chirurgie pour transformer leurs organes génitaux.

- Ces procédures sont compliquées et coûteuses, mais elles sont cruciales pour ceux qui s’y soumettent.

- Les adultes désireux de changer de sexe devraient avoir accès à un conseil approprié pour les aider à prendre leur décision et avoir la liberté de prendre cette décision. 


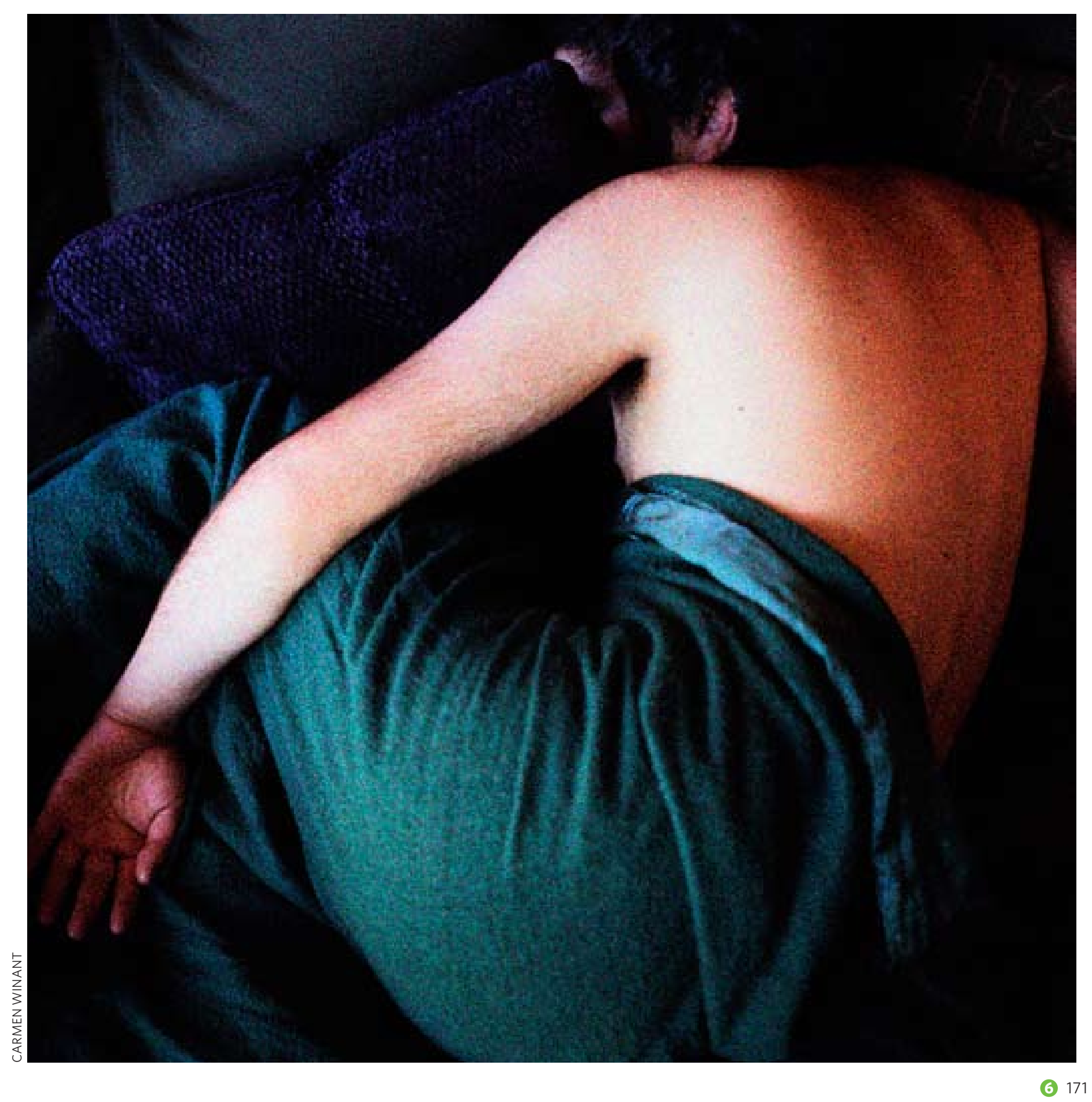




\section{La fécondité et la reproduction (" d'où viennent les bébés ॥)}

1 Une femme ou un couple peuvent choisir d'avoir des enfants ou non. Ce choix est un droit fondamental.

[Voir l'unité 7, 2e partie, concernant la prévention ou l'interruption d’une grossesse non désirée.]

2 Biologiquement, la fécondité féminine est la capacité de la femme d'avoir une grossesse aboutissant sur une naissance. Côté masculin, il s'agit de la capacité d'apporter un sperme sain apte à produire une grossesse saine.

- La fécondité de la femme varie au fil de son cycle menstruel [voir la fiche d'information sur le Cycle menstruel]. La fécondité de l'homme n'est pas cyclique.

- Les hommes aussi bien que les femmes peuvent être stériles ou peu féconds. La stérilité a de nombreuses causes, y compris les IST, la maladie, les toxines environnementales et les facteurs génétiques ou physiques, parfois réversibles.

- La fécondité décline naturellement avec l'âge de la femme comme de l'homme, bien que ce déclin intervienne plus tôt chez la femme. [Voir les fiches d'information sur la Stérilité et le Cycle menstruel.]

\section{La grossesse est le produit de nombreuses étapes.}

[Voir la fiche d'information sur la Reproduction et la grossesse.]

- À la puberté, les filles commencent à ovuler : elles libèrent généralement un ovule mûr durant chaque cycle menstruel.

- Dès la puberté, les garçons produisent des millions de cellules minuscules appelées spermatozoïdes.

- Quand un spermatozoïde s'unit à un ovule (fécondation), un embryon peut se former. Le sexe de l'embryon est déterminé par le spermatozoïde de l'homme, pas par l'ovule de la femme.

- Il y a grossesse si l'embryon se fixe à la paroi de l'utérus. Cet embryon devient foetus si la grossesse se poursuit. 
4 Le plus souvent, la grossesse est le produit de rapports hétérosexuels, quand le pénis pénètre dans le vagin et que l'homme éjacule son sperme.

- On utilise différentes expressions pour désigner les rapports sexuels, notamment « faire l'amour ». (Ces termes sont parfois utilisés aussi pour d'autres comportements sexuels.)

- Pour qu'une grossesse viable se produise, les conditions suivantes doivent être remplies :

- La femme doit être proche du moment de son cycle menstruel où l'un de ses ovaires libère un ovule mûr dans la trompe de Fallope correspondante (selon le processus de l'ovulation). [Voir aussi l'unité 7, page 212.]

- L'homme doit avoir une érection et éjaculer dans le vagin de la femme ou à son entrée.

- Un grand nombre de spermatozoïdes doivent remonter jusqu'à la trompe de Fallope, où un seul doit s'unir à l'ovule (fécondation) et l'ovule fécondé doit descendre vers l'utérus de la femme et se nicher dans sa paroi.

- La grossesse peut survenir que la femme ait un orgasme ou non.

5 La grossesse peut être suscitée autrement que par des rapports vaginaux.

- Les personnes qui ne réussissent pas à concevoir, n’ont pas de partenaire sexuel ou ont un partenaire de même sexe, peuvent recourir à d'autres méthodes de conception.

- Plusieurs approches médicales permettent l'union d'un ovule et d'un spermatozoïde [voir la fiche d'information sur la Stérilité et la procréation assistée].

6 Suivant la région ou le pays, seuls 40 à $70 \%$ des grossesses aboutissent sur une naissance vivante. Les 30 à $60 \%$ restants se terminent par un avortement spontané, une l'interruption volontaire de grossesse ou la naissance d'un enfant mort-né. 


\section{quand la grossesse se poursuit}

1 Chaque jour, des milliers de femmes et de filles choisissent de poursuivre ou d'interrompre leur grossesse.

[Voir l’unité 7, pp. 214-217.]

2 Pour celles qui la poursuivent, la grossesse et l'accouchement se déroulent généralement sans problèmes majeurs. Mais il arrive qu'ils s'accompagnent de graves complications, y compris la mort de la mère ou de l'enfant.

[Voir les fiches d'information sur la Reproduction et la grossesse et sur l'Accouchement et l'allaitement pour plus de détails sur la promotion d'aboutissements sains pour les mères et leurs nourrissons.]

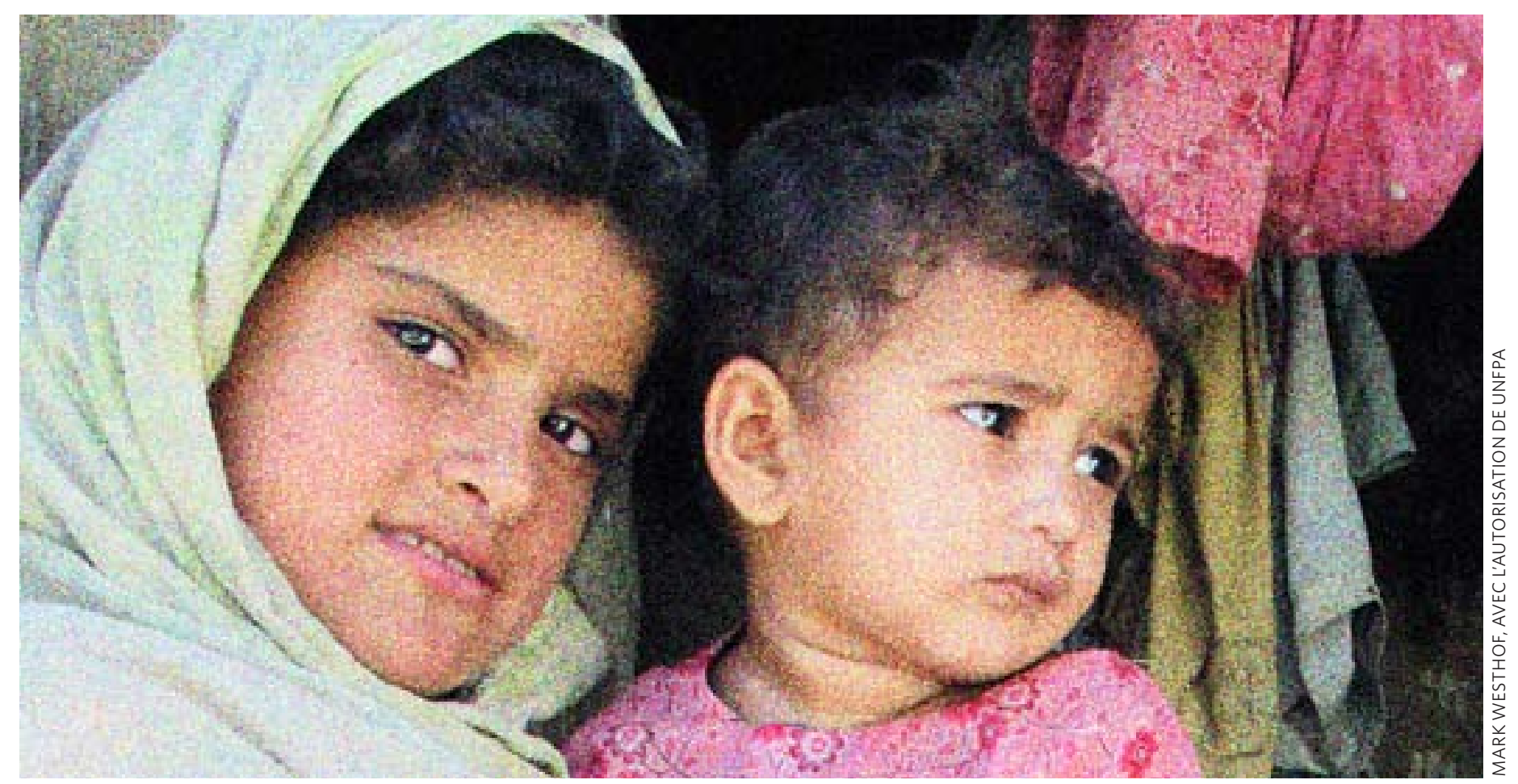

(6) 174 

problèmes liés à la grossesse et à l'accouchement.

- L'accès à des soins de santé adéquats en cours de grossesse et d'accouchement est un droit fondamental, mais souvent négligé.

- Beaucoup de filles et de femmes souffrent de lésions aiguës ou durables durant la grossesse ou l'accouchement, surtout lorsqu'elles sont mal nourries, jeunes adolescentes ou privées d'accès à des soins obstétricaux d'urgence. Un problème grave se présente quand le bassin de la mère est trop étroit pour permettre le passage de l'enfant. Faute d'intervention chirurgicale immédiate, le tissu vaginal se déchire vers d'autres parties du corps et cause une fuite permanente d'urine ou de matières fécales : c'est la fistule obstétricale, rarement réparée faute encore de moyens chirurgicaux. [Voir la fiche d'information sur l'Accouchement et l'allaitement.]

- À l'échelle mondiale, le manque d'accès à des soins médicaux adéquats contribue à plus d'un demi-million de décès de femmes et de filles par an, soit une mort par minute.

\section{Même dans les contextes moins démunis, certaines pratiques relatives à la} grossesse et à l'accouchement peuvent être nuisibles à la mère et/ou l'enfant. Les défenseurs de la santé féminine et de nombreux prestataires médicaux s'en inquiètent.

Parmi les pratiques parfois remises en question :

- les césariennes inutiles ;

- l'abus d'antidouleurs et d'autres médicaments pendant la grossesse ;

- la préférence du lait maternisé au lait maternel ; et

- la séparation systématique de la mère et du nouveau-né. 


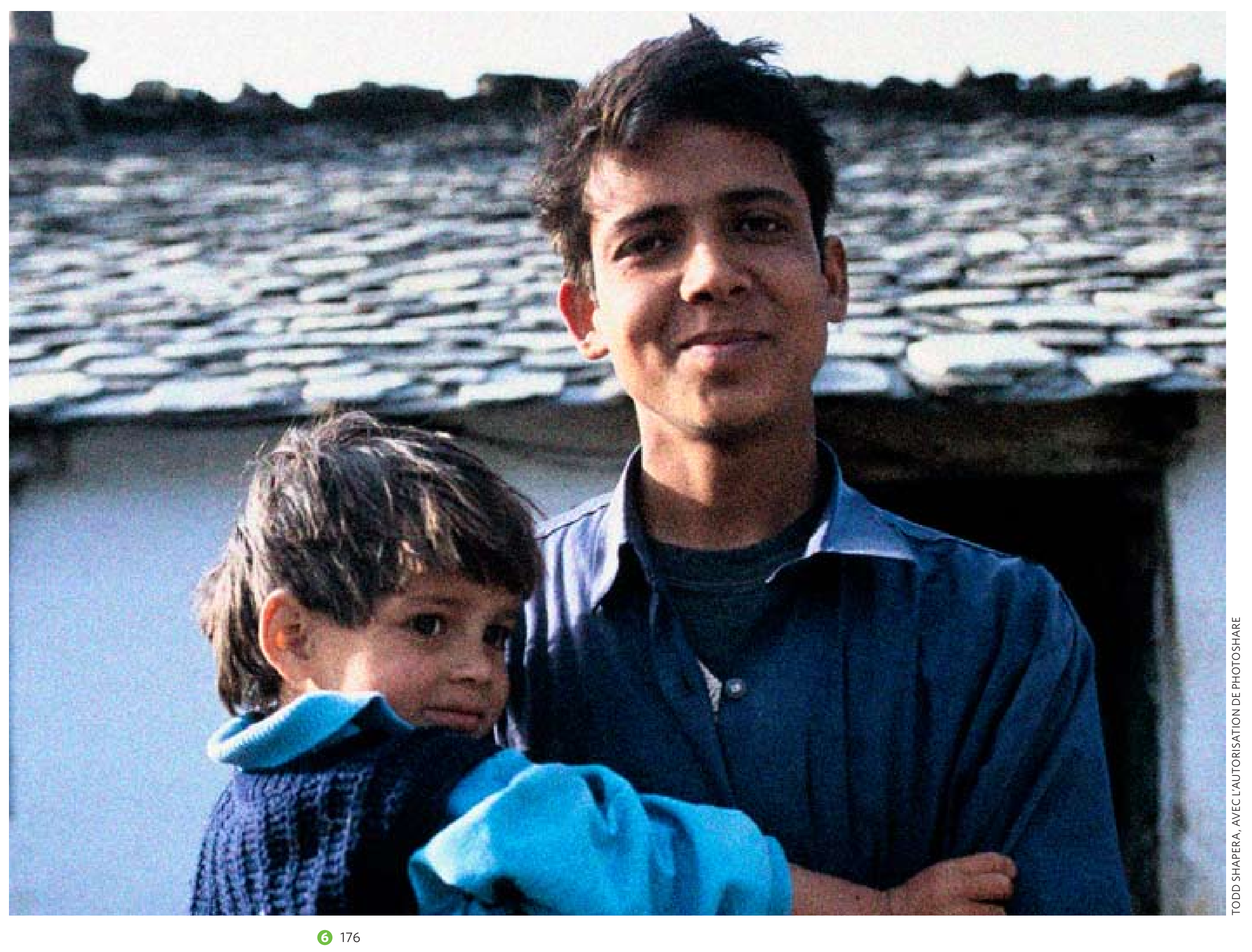


5 Les normes culturelles relatives à l'accouchement (y compris le rôle du partenaire masculin) varient largement et évoluent.

- En beaucoup d'endroits, le rang des femmes dépend en partie de leur fécondité. Là où elles peuvent briller sur d'autres plans de la vie, toutefois, elles ressentent moins la pression d'avoir des enfants.

- Pour certains, la grossesse et l'accouchement ne doivent intervenir qu'au sein de la relation socialement sanctionnée du mariage. De plus en plus d'autres estiment que les enfants peuvent grandir heureux et en bonne santé indépendamment de la forme de leur famille.

- De plus en plus, les hommes jouent un rôle plus actif pendant la grossesse et l'accouchement. Ils assistent aux visites de soins prénatales, aux classes de préparation à la naissance et à l'accouchement et, tout aussi important, ils participent activement aux soins du nouveau-né et de l'enfant.

\section{Tous les couples ne choisissent pas d'avoir des enfants, mais ceux qui le désirent} en vain (parce que stériles) peuvent être profondément déçus ou rejetés.

- La femme est souvent «blâmée » pour la stérilité du couple, même si la cause du problème peut tout aussi bien venir de l'homme.

- Dans certains contextes, les hommes des couples incapables de concevoir sont autorisés à prendre une autre femme (ou sa famille peut en rechercher une pour lui).

\section{Les couples stériles peuvent adopter différentes approches.}

Par exemple :

- Les femmes peuvent apprendre à identifier le moment de l'ovulation (la période féconde de leur cycle; voir la fiche d'information sur le Cycle menstruel).

- Différentes techniques de procréation assistée sont disponibles. Parfois compliquées, les procédures sont coûteuses et pas toujours efficaces. [Voir la fiche d'information sur la Stérilité et la procréation assistée.]

- Beaucoup de couples stériles, de même que certains couples féconds, adoptent leurs enfants.
VOIR LE VOLUME D'ACTIVITÉS Activité 44

la procréation : pas toujours une affaire privée

Les élèves découvrent une quinzaine de problèmes génésiques modernes (de la paternité adolescente à la sélection du sexe), les résument et y réagissent.

VOIR LE VOLUME D'ACTIVITÉS Activité 45

chaque minute de chaque heure : la grossesse et la mort

Les élèves lisent les récits de décès maternels. Par sketchs et discussion, ils explorent la manière dont ces décès auraient pu être évités. 


\section{découvrir son corps : un mouvement mondial}

1 Partout dans le monde, les personnes, femmes et filles surtout, se sont mises à découvrir et à enseigner les fonctions de leur corps, y compris l'appareil sexuel et génital et la santé.

2 Dans pratiquement tous les pays, des groupes formels et informels proposent des ateliers d'entraide, des programmes de théâtre et émissions de radio et de la documentation sur le corps humain.

3 Beaucoup de groupes d'abord axés sur l'aide à la découverte de son corps militent aussi en faveur de plus vastes changements sociaux.

Ils préconisent notamment :

- une meilleure éducation à la sexualité dans les écoles et les communautés ;

- la fin des pratiques culturelles néfastes ;

- des services de santé sexuelle et génésique plus accessibles et plus respectueux de la personne ;

- une prévention et un traitement plus efficaces des cancers de l'appareil génital [voir la fiche d'information sur les Cancers de l'appareil génital] ;

- l'adoption de lois qui protègent les droits sexuels et génésiques ; et

- de nouvelles normes communautaires qui appuient la responsabilité partagée des hommes et des femmes sur les questions de santé sexuelle et génésique. 


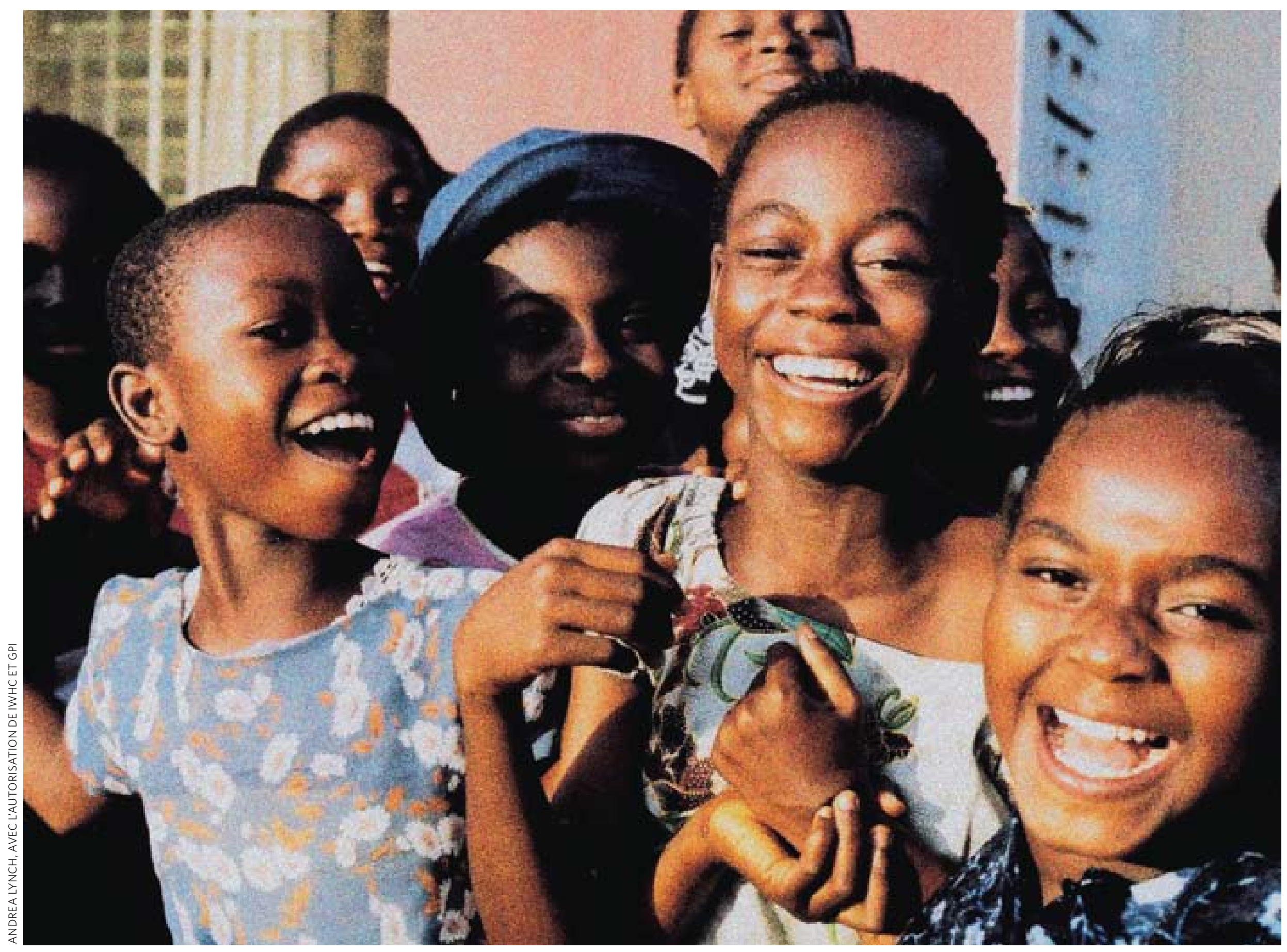




$$
\begin{aligned}
& \text { LA SANTÉ } \\
& \text { SEXUELLE } \\
& \text { ET GÉNÉSIQUE }
\end{aligned}
$$




\section{panorama}

La sexualité et la reproduction peuvent être sources de profonde satisfaction, de plaisir et d'épanouissement. Mais les rapports sexuels peuvent aussi être cause de problèmes de santé si les deux partenaires ne veillent pas à se protéger, personnellement et l'un l'autre, contre le risque d'une grossesse non planifiée ou d'une infection (y compris à VIH). Une démarche essentielle à l'amélioration du bien-être sexuel et génésique consiste à assurer l'accès à l'information et aux services. Il importe aussi de créer des conditions sociales plus justes (y compris l'égalité de genre et le respect des droits de tous) qui permettent à tous et à toutes de contrôler les circonstances dans lesquelles ils ou elles ont des rapports sexuels.

Cette unité présente une information fondamentale pour aider les jeunes à garder leur corps à l'abri des risques et en bonne santé. 


\section{CONSEILS À L'ENSEIGNANT}

\section{LA SANTÉ SEXUELLE ET GÉNÉSIQUE}

Cette unité est la dernière rubrique de « contenu » d'Un seul programme. (L'unité 8 présente un module de développement et pratique de compétences civiques.) La santé sexuelle et génésique est abordée en dernier lieu car ses bilans individuels sont souvent le produit des facteurs sociaux et personnels couverts dans les autres unités.

Les fiches d'information proposées en fin de guide peuvent être utiles à l'élaboration d'un programme ou à l'enseignement de cette rubrique. La connaissance scientifique et l'information essentielle à la santé évoluent cependant en permanence et il importe donc de se référer aussi à des sources fiables d'information à jour et pertinente au niveau local.

Parler du VIH et du sida exige une sensibilité extrême de la part de l'enseignant, surtout dans les contextes à prévalence élevée.

Évitez d'employer des mots tels que « naturel » ou « normal » pour décrire les aspects de la sexualité qui ne sont en fait que le reflet de conventions ou normes culturelles adoptées.

Plusieurs fiches d'information, en fin de volume, présentent les sujets abordés dans cette unité de manière plus détaillée. 


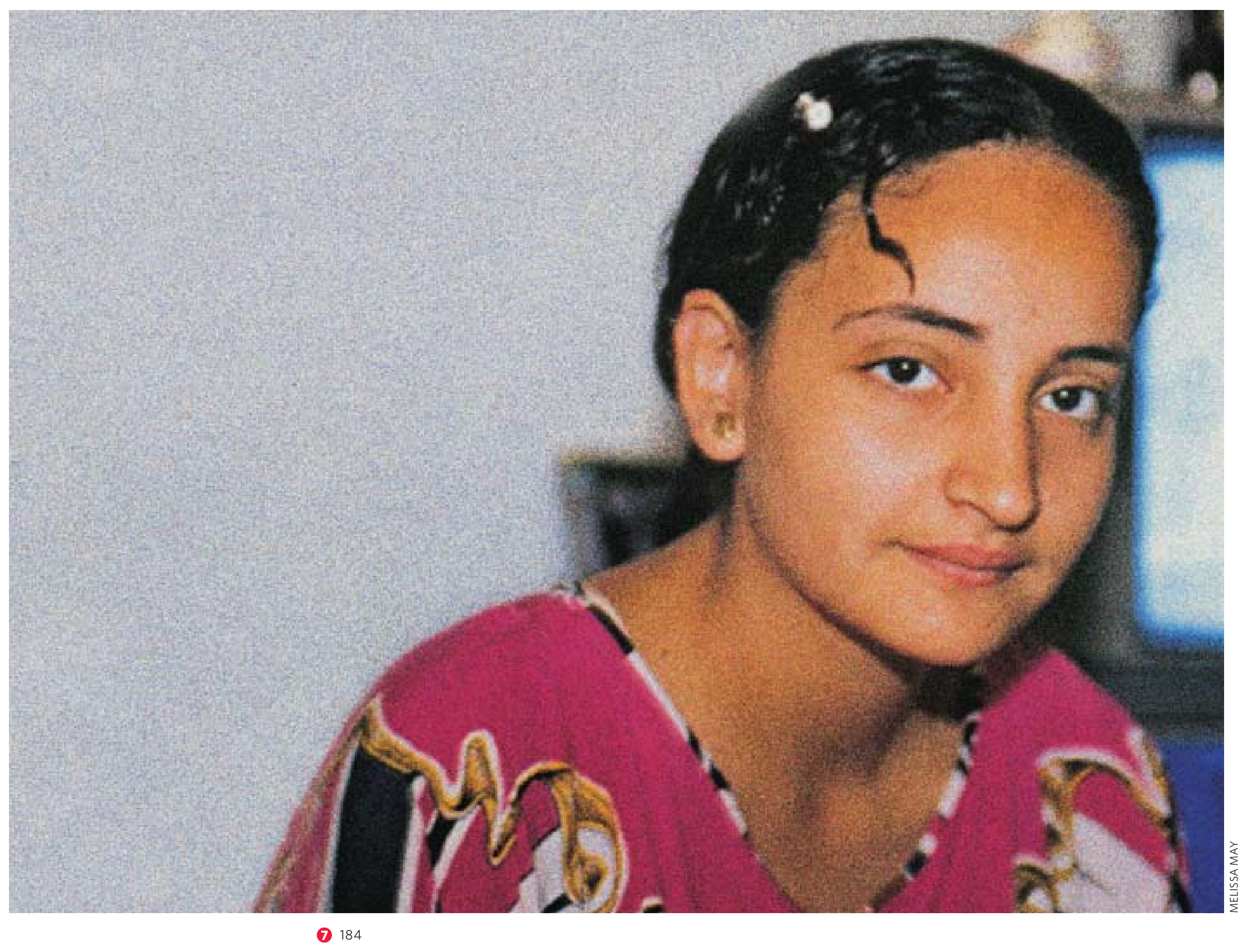




\section{LA SANTÉ SEXUELLE ET GÉNÉSIQUE}

Le matériel couvert dans cette unité prépare les élèves à :

\section{Objectifs cognitifs}

Discuter la problématique de l'accès aux services de santé sexuelle et génésique (y compris pour la grossesse et l'accouchement) dans leur contexte.

Discuter les droits de tous et de toutes à se protéger contre les IST et le VIH.

Expliquer la nature asymptomatique, et les conséquences pour la fécondité, des chlamydiae et de la blennorragie chez les femmes.

Citer les faits clés de la transmission, du diagnostic, des conséquences et du traitement du VIH et sida.

Discuter les conséquences du VIH et du sida pour les familles, les communautés et les pays, ainsi que les droits des personnes vivant avec le VIH et sida.

Citer les principales raisons de l'absence contraceptive même quand une grossesse n'est pas désirée.

Discuter les caractéristiques d'au moins trois méthodes contraceptives, y compris leur effet sur les IST.

Décrire au moins six cas où les femmes peuvent décider d'interrompre une grossesse.

Expliquer pourquoi la mortalité maternelle, y compris post-avortement, est largement évitable.

\section{Objectifs affectifs}

Reconnaître l'inégalité de genre dans la transmission des IST/VIH et les grossesses non désirées.

Réfléchir à ce qu'ils pensent de l'hésitation, et de la responsabilité, à divulguer son état IST et VIH à ses partenaires sexuels.

Réfléchir à ce qu'ils pensent de la contraception et du préservatif, y compris dans la manière dont ils affectent (positivement ou négativement) la relation sexuelle, ainsi qu'aux obstacles à leur usage qu'ils ont rencontrés ou pensent pouvoir rencontrer.

Explorer et discuter leurs sentiments sur l'avortement légal médicalisé.

Objectifs de compétences

Démontrer leur maîtrise de l'usage adéquat du préservatif. 


\section{le droit aux services de santé}

Toute personne a droit aux soins de santé et aux services sociaux nécessaires (Article 25, DUDH, 1948; Article 12, CEDF, 1979 Article 12, PIDESC, 1966 ; Article 24, CIDE, 1989).

« Les adolescentes devraient notamment pouvoir accéder à une information et à des services qui les aident à comprendre leur sexualité et à se protéger contre les grossesses non désirées, les maladies sexuellement transmissibles et les risques de stérilité en résultant. II faudrait également enseigner aux jeunes gens à respecter l'autodétermination des femmes et à partager les responsabilités avec elles dans les questions de sexualité et de procréation » (Paragraphe 7.41, Programme d'action de la CIPD, 1994).

1 Tous les jeunes doivent avoir accès aux services de santé dans le cadre d'une vie sexuelle sans risques, responsable et saine.

2 Tout le monde a droit à des services de santé accessibles, abordables et de bonne qualité. Tout le monde a aussi le droit d'être traité avec respect et confidentialité.

3 De nombreux obstacles rendent cependant souvent ces services de santé inaccessibles. Ces obstacles sont tantôt l'expression de la discrimination et d'un opprobre informel, tantôt celle de politiques officielles.

- Les gouvernements n'assurent pas partout des services de santé gratuits ou abordables.

- Les gouvernements, prestataires ou pharmacies refusent parfois l'accès à certains services de santé et médicaments, sous l'influence, notamment, de convictions politiques ou religieuses.

- Les laboratoires pharmaceutiques imposent parfois des prix inabordables.

- Certains programmes de santé soumettent au consentement parental la prestation de services contraceptifs aux jeunes, en particulier de sexe féminin. 


\section{La mauvaise qualité des soins décourage parfois l'accès aux services proposés.}

Par exemple :

- Les délais d'attente sont parfois extrêmes ou les produits ou services nécessaires ne sont pas disponibles.

- Certains clients (célibataires, pauvres, travailleurs du sexe, issus d'une minorité raciale/ethnique, transsexuels, en relation homosexuelle ou vivant avec le VIH et sida, notamment) sont jugés par les prestataires de santé.

- Les adolescents redoutent souvent que leur famille ou leurs amis découvrent leur visite au centre de santé.

\section{Les normes de genre influencent le recours aux services.}

- Beaucoup de jeunes hommes sont mal à l'aise à l'idée de recourir aux services de santé sexuelle, surtout dans les contextes où ces services s'adressent principalement aux femmes.

- Nombre de femmes et jeunes n’ont ni l'autorité, ni l'argent nécessaires à leur recours aux services.

- Certaines filles et femmes ne sont autorisées à quitter seules leur demeure ou leur village sous aucun prétexte.

\section{Malgré les obstacles, des millions de personnes, même jeunes, recourent aux} services de santé et établissent un bon rapport avec leurs prestataires.

\section{Partout dans le monde, les gens s'organisent pour améliorer la santé dans leurs} communautés.

Par exemple :

- ils organisent des activités de sensibilisation communautaire à la santé pour s'informer les uns les autres ;

- ils établissent des services de santé sexuelle et génésique particulièrement ouverts aux jeunes, et qui mettent l'accent sur le conseil, le consentement éclairé et le respect de la confidentialité ;

- ils sensibilisent la communauté à la fistule obstétricale et militent en faveur de l'assurance de services de réparation chirurgicale [voir l'unité 6, p. 175, et la fiche d'information sur l'Accouchement et l'allaitement] ;

- ils organisent des projets communautaires pour la santé (potagers, puits, programmes d'activité physique, etc.) ;

- ils militent en faveur de meilleurs services de santé et d'accès aux médicaments ; et

- ils militent en faveur de meilleures politiques de santé et d'un meilleur financement des soins. 


\section{Te PARTIE :}

\section{INFECTIONS SEXUELLEMENT TRANSMISSIBLES,}

\section{VIH ET SIDA}

Les gouvernements, les organisations internationales, les donateurs et les ONG doivent lancer des initiatives tenant compte des besoins des femmes face aux maladies sexuellement transmissibles et au VIH et sida ... (Objectif stratégique C3,

Programme d'action de la QCMF, 1995) y compris des stratégies pour mettre fin à la subordination sociale des femmes et des filles et prévenir le VIH et sida et les autres maladies sexuellement transmissibles (Paragraphe 108.e, Programme d'action de la QCMF, 1995). 


\section{infections sexuellement transmissibles (IST) et VIH et sida}

1 L'activité sexuelle peut donner lieu à des conséquences positives aussi bien que négatives.

- Les issues positives en sont le plaisir, l'intimité et (chez les couples hétérosexuels) les grossesses désirées. - Celles négatives peuvent prendre la forme d'un préjudice affectif et physique, d'infections sexuellement transmissibles, y compris le VIH, ou (chez les couples hétérosexuels) de grossesses non planifiées

2 Les infections sexuellement transmissibles (IST) sont des infections qui se propagent à travers l'activité sexuelle. Toutes sont évitables.

[Voir la fiche d'information sur les Infections sexuellement transmissibles.]

- Certaines IST présentent des symptômes, mais ce n'est pas toujours le cas (surtout chez les femmes).

- Même en l'absence de symptômes, une infection peut avoir de graves conséquences pour la santé, y compris la stérilité ou même la mort.

- Ces IST peuvent avoir de graves conséquences : VIH, PVH (verrues génitales), syphilis, blennorragie, chlamydiae, trichomonas et herpès.

- Les rapports buccogénitaux peuvent transmettre les IST, y compris le VIH.

- Les filles sont physiologiquement plus vulnérables à certaines IST que les garçons. Le rapport sexuel anal récepteur accroît le risque d'infection (pour les garçons comme les filles). Certains facteurs sociaux affectent aussi la probabilité de transmission [voir plus loin les raisons de l'absence de contraception].

3 Les personnes sexuellement actives peuvent prendre des mesures pour réduire leur risque de contraction d'IST.

[Voir la section suivante sur les méthodes de protection contre les IST et le VIH.]
Voir la fiche d'information sur les Infections sexuellement transmissibles pour l'élaboration d'un programme détaillé.

VOIR LE VOLUME D'ACTIVITÉS Activité 46

les faits sur les infections sexuellement transmissibles (IST)

Les élèves créent des affiches présentant l'information importante à savoir sur les IST, y compris le VIH et sida. 
4 L'une des infections les plus graves que l'on puisse contracter lors de rapports sexuels est l'infection à $\mathrm{VIH}$, le virus responsable du sida. Le sida est une cause majeure de maladie et de mort dans de nombreuses régions du monde.

[Voir la fiche d'information sur le VIH et le sida.]

- Le VIH affaiblit le système immunitaire du corps, où il favorise l'apparition d'infections et de cancers. En l'absence de traitement, le VIH est mortel.

- Les taux d'infection à VIH varient d'un pays à l'autre et au sein même des pays.

- En beaucoup d'endroits, les taux de VIH sont largement supérieurs parmi les jeunes, de sexe féminin surtout. Les hommes qui fréquentent les travailleuses du sexe et qui ont des rapports homosexuels peuvent aussi être particulièrement vulnérables au virus.

- Le VIH se transmet aussi de manière non sexuelle, notamment lors de l'injection de drogues au moyen d'une aiguille contaminée, de la transfusion de sang contaminé ou par transmission du virus de la femme séropositive à son foetus ou nourrisson.

5 Certaines IST (pas toutes) sont guérissables. Au terme du traitement adéquat, la personne n'est plus contaminée. La prise de mesures préventives appropriées permet d'éviter la réinfection.

6 Un traitement adéquat permet souvent d'atténuer les symptômes et/ou de ralentir fortement la progression des IST incurables (comme I'herpès, l'infection à VIH et le $\mathrm{PVH})$.

REMARQUE: VIH = virus de l'immunodéficience humaine ; sida = syndrome d'immunodéficience acquise ; PVH = papillomavirus humain. Voir les fiches d'information sur les Infections sexuellement transmissibles et le VIH et sida. 


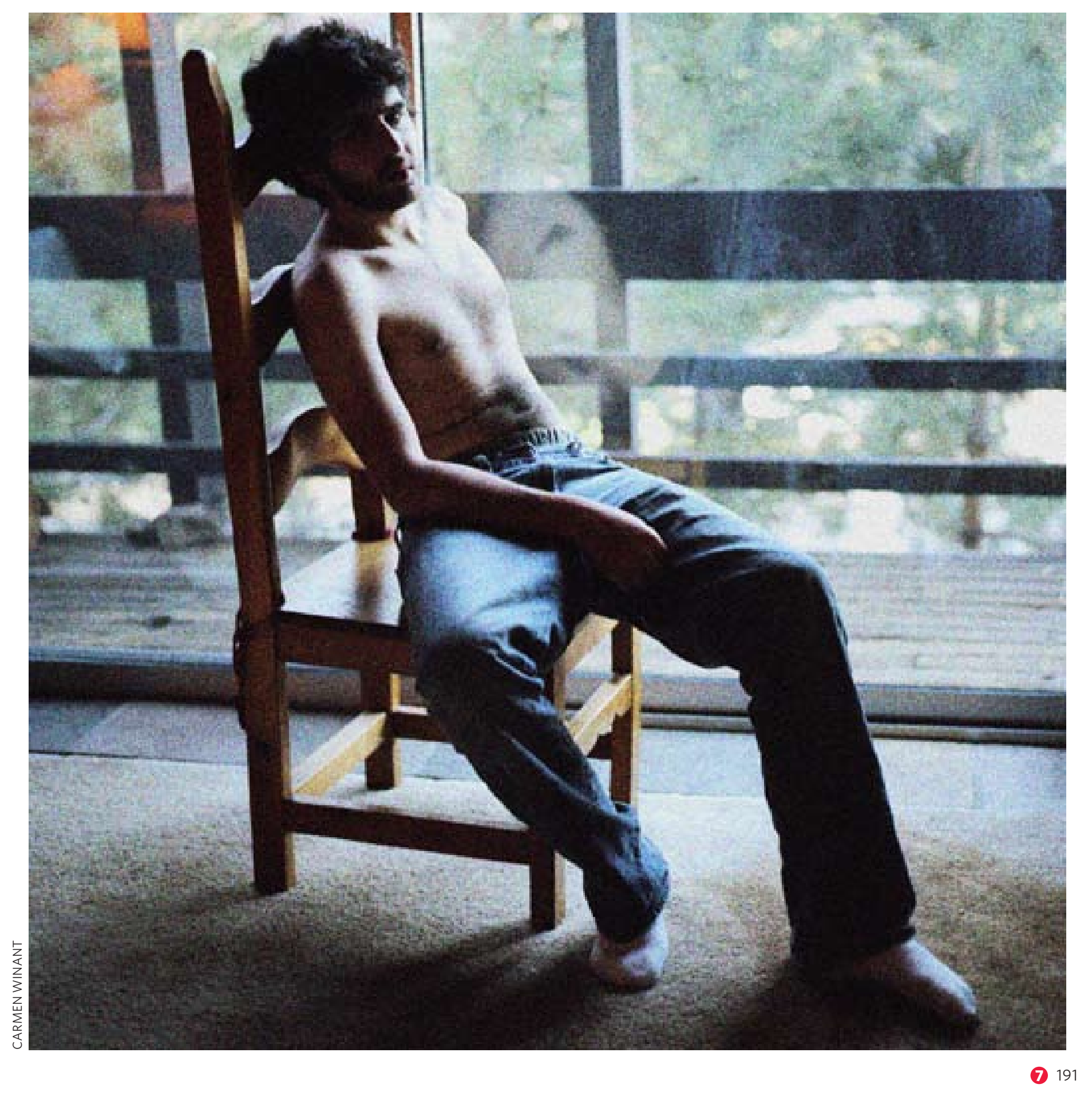




\section{méthodes de protection contre les IST et le VIH}

1 Toutes les IST, y compris l'infection à VIH, peuvent être évitées.

2 Chaque personne a le droit de se protéger contre les IST. II existe plusieurs moyens de se protéger ainsi que ses partenaires, qu'ils soient du même sexe ou de sexe opposé.

3 Le moyen le plus sûr d'éviter les IST est de ne pas avoir de rapports sexuels vaginaux, buccogénitaux ou anaux. Tout le monde a le droit de refuser les rapports sexuels non protégés (ou non désirés). Beaucoup ne peuvent cependant exercer ce droit, surtout parmi les femmes et les filles non autorisées à exiger de leurs partenaires masculins qu'ils utilisent le préservatif.

4 Les deux partenaires peuvent s'entendre sur des formes d'activité sexuelle (telle que la masturbation l'un de l'autre) sans risque de transmission d'IST.

5 Les deux partenaires peuvent s'entendre sur l'usage du préservatif masculin ou féminin. 
6 Les deux partenaires peuvent avoir une relation mutuellement monogame, sans autres partenaires sexuels : ils sont « fidèles » l'un à l'autre. II peut cependant arriver qu'une personne soit déjà infectée (même à son insu) ou ne soit pas parfaitement fidèle. La promesse de fidélité n'élimine donc pas nécessairement le besoin de pratiques sexuelles protégées.

[Voir la section suivante ; voir aussi la fiche d'information sur le VIH et le sida.]

7 L'infection à papillomavirus (PVH) est une IST fréquente. It existe de nombreuses souches du virus. Certaines sont la cause de verrues génitales, d'autres mènent au cancer, du col utérin chez la femme surtout. Les vaccins anti-PVH peuvent protéger les hommes comme les femmes contre beaucoup de ces souches.

8 La circoncision masculine offre à l'homme une certaine protection contre le VIH, mais sans protection directe pour les femmes.

- Le prépuce semble favorable à l'établissement chez l'homme de certains virus et bactéries - y compris le VIH.

- Même circoncis, les hommes peuvent toujours contracter le VIH et contaminer leurs partenaires.

- Parce qu'elle n'apporte aucun avantage direct à la femme et qu'elle n'assure qu'une protection partielle à l'homme, la circoncision n'élimine pas la nécessité du préservatif.

9 De nouvelles techniques de protection seront vraisemblablement disponibles dans le futur. Tout le monde a le droit d'en être informé et d'y avoir accès. 


\section{pourquoi l'absence de protection et le rôle de l'égalité de genre dans la lutte contre le sida}

1 L'absence de protection contre les IST est fréquente.

2 Certaines personnes n'utilisent aucune protection par manque d'information, de compétences ou d'accès aux services.

Par exemple :

- Elles ne sont pas bien informées sur la transmission et la prévention des IST, ou sur l'usage du préservatif.

- Elles ignorent l'existence du préservatif féminin (ou masculin) ou n’ont pas accès au préservatif féminin.

- Elles ne croient pas possible que leur partenaire soit infecté.

- Elles ne croient pas être infectées.

- Si elles ont des rapports homosexuels, entre hommes ou entre femmes, et qu'elles ne considèrent pas ces rapports comme « véritablement » sexuels.

- Elles n'ont pas aisément accès au préservatif ou sont gênées à l'idée de le demander à un prestataire ou pharmacien.

- Elles ont eu des rapports sexuels avec quelqu'un d'autre et ne savent pas comment dire à leur partenaire que l'un d'entre eux ou les deux en ont peut-être contracté une IST ou le VIH.

- Elles sont gênées à l'idée de parler du préservatif avec leur partenaire, ou mal à l'aise à l'idée de le porter.

3 Certaines personnes n'utilisent aucune protection parce qu'elles n'ont pas prévu l'éventualité de rapports sexuels.

- Elles succombent au désir du moment sans avoir de préservatif masculin ni féminin.

- Elles subissent peut-être des rapports sexuels forcés. 


\section{Certaines personnes n'utilisent aucune protection parce qu'elles éprouvent des}

sentiments contradictoires sur l'usage ou la discussion du préservatif.

Par exemple :

- Certaines femmes ou certains couples (y compris ceux dont un partenaire a une IST incurable ou le VIH) désirent une grossesse.

- Certains désirent avoir des rapports protégés mais le préservatif limite leur plaisir.

- Certains désirent protéger leur santé et celle de leur partenaire mais ne veulent pas admettre (ni même envisager) la possibilité que l'un des deux ait eu une relation sexuelle extérieure. Dans certaines circonstances, par exemple :

- la révélation ou la demande relative à une relation extérieure présente un risque de conflit ou même de violence.

- la relation extérieure peut toucher à l'opprobre (un homme marié ayant des relations homosexuelles, par exemple, ou une femme ayant une relation extraconjugale dans un contexte où les normes de genre condamnent gravement l'adultère).

- Le désir de protection d'un couple peut être contraire aux enseignements religieux opposés au préservatif. 


\section{Certaines personnes n'utilisent aucune protection parce que leurs circonstances}

les placent en position d'infériorité sociale, y compris l'inégalité de genre.

Par exemple :

- Les filles en particulier subissent la pression de prouver leur amour en ayant des rapports sans préservatif.

- Même quand il est disponible, une personne peut se sentir poussée par un partenaire à avoir des rapports sexuels sans prendre le temps de mettre le préservatif.

- Une différence d'âge significative entre les partenaires peut mettre le plus jeune en position de faiblesse.

- Les filles et les femmes mariées sont souvent obligées d'avoir des rapports et de produire une grossesse, même si elles estiment ces rapports dangereux.

- Les hommes comme les femmes payés pour avoir des rapports sexuels peuvent l'être davantage s'ils renoncent au préservatif (parfois sous la contrainte). Les filles qui acceptent les faveurs et cadeaux d’hommes plus âgés («sugar daddies ») peuvent aussi y être poussées en échange de cadeaux supplémentaires.

- Parler de sexualité ou de santé sexuelle peut être jugé inapproprié ou tabou pour les femmes et les filles.

- Pour certains, soulever la question du préservatif implique un soupçon d'infidélité et peut provoquer un conflit, la colère ou la violence, au préjudice grave de nombreuses femmes dans le monde.

- Dans certains contextes, les hommes atteints du VIH croient, à tort, que des rapports sexuels non protégés avec une vierge peuvent les guérir. Cette pratique est dangereuse pour la fille et constitue une violation extrême de ses droits fondamentaux.

6 Outre des actes de violence, les rapports sexuels forcés sont rarement protégés et présentent donc un plus grand risque de contraction du VIH et d'autres IST.

[Voir l'unité 2, pp. 70-71 et l'unité 3, pp.106-107 pour plus de détails sur la contrainte sexuelle.]

7 Malgré les obstacles, des millions de personnes, même jeunes, utilisent correctement et efficacement le préservatif. 


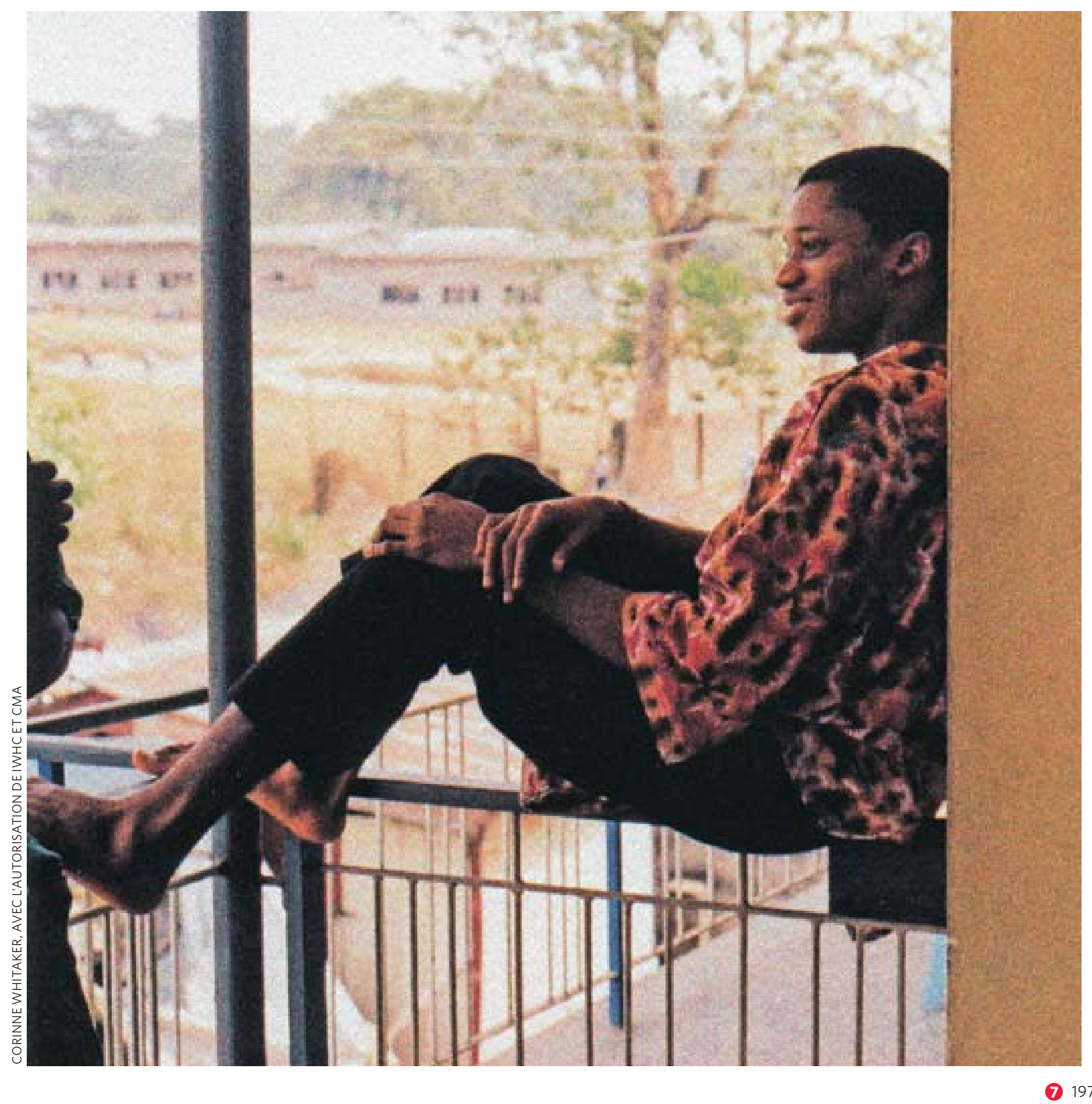

VOIR LE VOLUME D'ACTIVITÉS Activité 47

le genre et le préservatif

Les élèves analysent les obstacles (normes de genre comprises)

à l'usage du préservatif et les moyens de les surmonter. Ils

apprennent aussi comment utiliser le préservatif.

\section{Activité 48}

VOIR LE VOLUME D'ACTIVITÉS

entamer la conversation sur le sexe et la sécurité

Les élèves s'exercent à entamer la conversation sur d'importantes questions de sécurité et de santé sexuelles. 


\section{vivre avec le VIH et sida}

1 Tout le monde a le droit de connaître son propre état VIH et d'obtenir des services de dépistage et conseil confidentiels (ou choisir de ne pas se faire tester).

2 Les personnes atteintes d'IST graves et incurables telles que le VIH peuvent vivre une vie longue et relativement normale et avoir des relations sexuelles sans risques et satisfaisantes, pourvu que soient assurés l'accompagnement social et sanitaire requis et l'attention aux droits des personnes vivant avec le $\mathrm{VIH}$ ou sida.

3 Les personnes vivant avec le VIH et sida doivent recevoir conseil et assistance pour pouvoir assumer de parler de leur état $\mathrm{VIH}$.

Cet accompagnement peut prendre la forme de :

- réunions de personnes vivant avec le VIH et sida ;

- assistance à l'information et protection de leurs partenaires sexuels présents et passés susceptibles d'avoir été infectés [voir la section suivante] ;

- accompagnement affectif (assistance à l'information de la famille, etc.); et

- assurance de bonne nutrition, prise de médicaments et accès aux soins.

VOIR LE VOLUME D'ACTIVITÉS Activité 49

le sida : apprendre des autres

Les élèves écoutent le récit d'une personne séropositive.
4 Certaines personnes souffrent de la révélation de leur séropositivité à leur partenaire ou à leur famille. Bien plus découvrent que leur partenaire et famille se montrent compréhensifs et prêts à les aider.

5 Toute personne séropositive a le droit d'obtenir les services et le traitement nécessaires.

- Les soins requis peuvent inclure l'accès aux médicaments, une attention médicale spéciale en cas de grossesse ou de maladie et des services sociaux avec accompagnement durable.

- Le traitement médical et les soins des séropositifs et sidéens sont coûteux. Les subventions de l'État et de donateurs internationaux sont essentielles aux personnes démunies. 
6 Les personnes vivant avec le VIH et sida ont le droit de vivre à l'abri de l'opprobre et de la discrimination. Ce droit n'est pas toujours respecté.

Par exemple:

- Dans certains pays, elles sont exclues du marché de l'emploi, du logement, et d'autres besoins de base.

- Certaines femmes vivant avec le VIH ou sida n'ont pas accès aux services de santé génésique.

7 Les familles et les communautés aussi « vivent avec » le VIH et le sida, surtout dans les contextes où une proportion relativement élevée de la population est atteinte du virus.

- Dans certaines villes, beaucoup des personnes employées deviennent trop malades pour travailler.

- Des millions de personnes (femmes et filles surtout) soignent les membres de leur famille infectés.

- En certains endroits, les veuves du sida n'héritent pas et ne reçoivent aucune assistance publique. Perdre son mari peut donc impliquer la perte de sa maison et de tout moyen de subsistance.

- Des millions d'enfants sont orphelins de l'un de leurs parents mort du sida ou des deux.

- Les jeunes doivent assumer la réalité du VIH dans leur recherche d'une expérience positive de la sexualité.

8 Partout dans le monde, différents groupes cherchent à protéger les droits des personnes vivant avec le VIH et sida, à soutenir les communautés confrontées à l'épidémie et à faire progresser les efforts de prévention.

Parmi leurs activités :

- apport et défense de l'accompagnement des personnes et familles vivant avec le VIH ou sida ;

- aide aux enfants orphelins d'un parent mort du sida ou des deux ;

- plaidoyer pour un meilleur accès au traitement ;

- sensibilisation au VIH et sida et aux moyens de prévenir la transmission de l'infection ; et

- plaidoyer, recherche et essai d'autres moyens de protection contre le virus. 


\section{droits et responsabilités de prévention des IST et du VIH}

1 Il incombe aux sociétés et aux gouvernements d'assurer les services de santé, le respect de la confidentialité et la protection de tous contre l'opprobre et la discrimination. Nous avons tous droit à ces services et protections.

2 Dans nos relations sexuelles, nous avons tous et toutes le droit de nous protéger des conséquences néfastes de l'activité sexuelle, y compris de la contraction d'une IST ou du VIH ou une grossesse non planifiée.

3 Dans nos relations sexuelles, nous avons tous et toutes la responsabilité de protéger nos partenaires des conséquences néfastes pour leur santé, y compris la contraction d'IST ou du VIH ou une grossesse non planifiée, surtout quand les conséquences possibles sont très graves.

4 Beaucoup d'individus disent à leurs partenaires sexuel(le)s qu'ils sont (ou soupçonnent être) séropositifs, même s'il leur en coûte.

VOIR LE VOLUME D'ACTIVITÉS Activité 50

que faut-il dire?

que faut-il savoir?

Par discussion et composition, les élèves analysent la responsabilité de divulguer son état VIH à un partenaire sexuel.
Ils leur révèlent notamment cette information pour les raisons suivantes :

- Ils désirent protéger leur partenaire.

- Ils auraient voulu qu’un(e) partenaire précédent(e) leur ait divulgué son état.

- Ils recherchent le soutien affectif de leur partenaire.

- Ils craignent que leur partenaire soit informé(e) de leur état par un prestataire de soins de santé ou une autre personne. 
5 La plupart des gens estiment avoir le droit de savoir si leur partenaire est

\section{POINTS DE RÉFLEXION} séropositif(ve) - même si le préservatif est utilisé.

- Ils estiment que leur relation sexuelle doit reposer sur la franchise et l'honnêteté, y compris sur cette question.

- Certains choisiront d'avoir des rapports sexuels indépendamment de l'etat VIH de leur partenaire, d'autres non.

- Certains voudront peut-être explorer les approches de l'intimité sexuelle sans risque de transmission [voir p. 192].

\section{En réalité, pourtant, certains ne révèlent pas à leurs partenaires qu'ils ou elles sont} (ou soupçonnent être) séropositifs(ves).

\section{Par exemple :}

- Ils estiment ne rien devoir dire s'ils utilisent le préservatif et réduisent ainsi grandement le risque de transmettre le virus.

- Ils ne savent pas comment aborder la question.

- Ils ont peur de la réaction de leur partenaire. Ils redoutent par exemple que leur partenaire les accuse d'infidélité sexuelle, réagisse violemment ou les abandonne.

- Ils craignent que d'autres apprennent leur état VIH et de devenir ainsi victimes d'opprobre et de discrimination.

- Ils ne se soucient pas suffisamment du bien-être de leur partenaire.

- Ils croient, à tort, qu'ils ne risquent pas de contaminer leur partenaire.

\section{Un conseiller ou un prestataire de soins de santé en qui on a confiance peut} parfois aider à aborder la question de la séropositivité avec un ou une partenaire. 


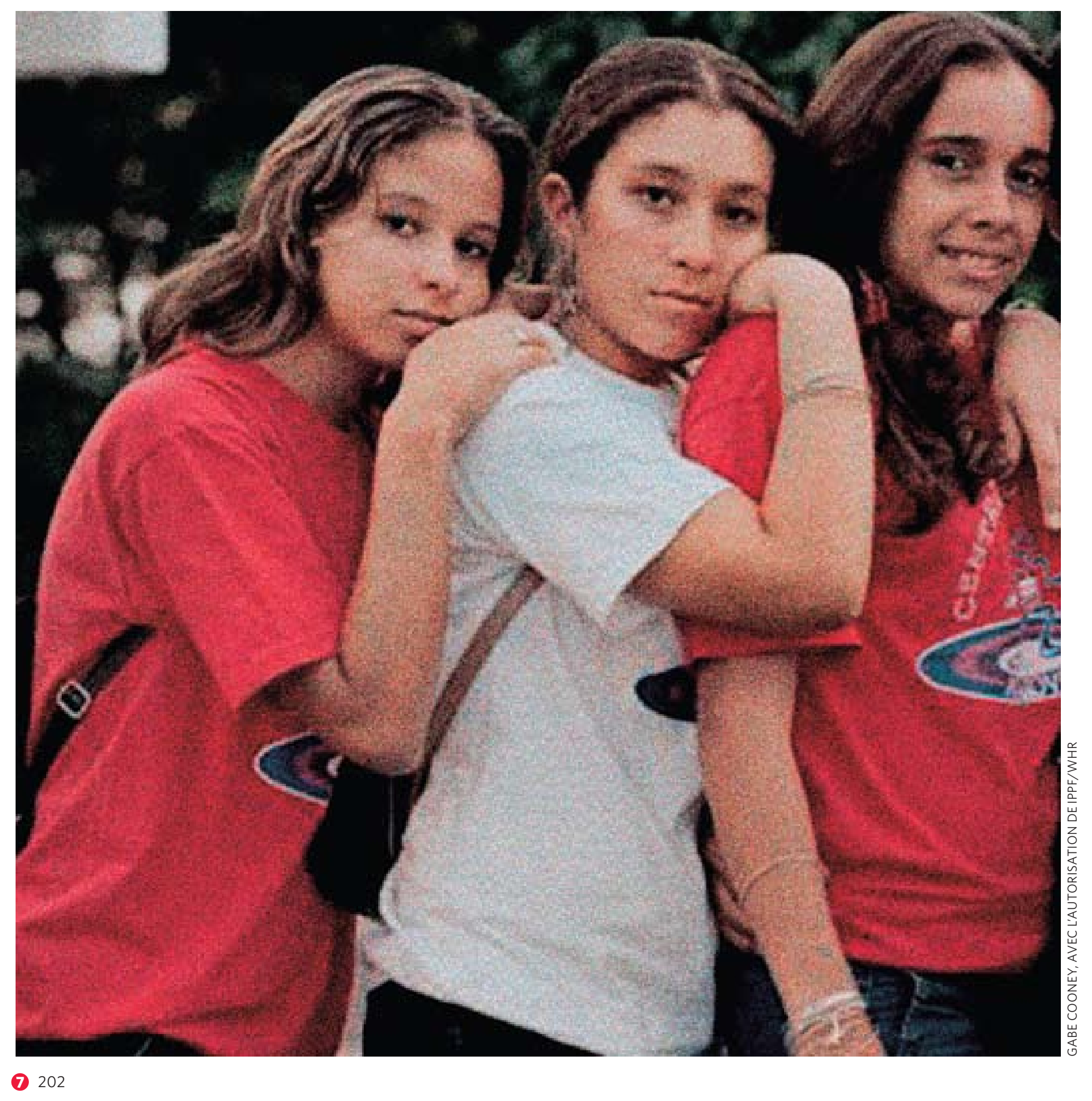




\section{infections de l'appareil génital (IAG)}

1 L'expression « infections de l'appareil génital » (IAG) désigne de manière générale les infections qui affectent les organes génitaux. Elles sont dues à trois grands types de causes.

[Voir la fiche d'information sur les Infections de l'appareil génital.]

2 Certaines IAG se transmettent lors des rapports sexuels. On parle alors généralement d'infections sexuellement transmissibles ou IST.

[Voir la section précédente, à partir de la p. 189.]

3 Certaines IAG sont le résultat d'un déséquilibre des organismes généralement présents dans l'appareil génital.

- Ce type d'IAG est beaucoup plus courant chez les femmes que chez les hommes.

- Il est parfois causé par des pratiques inutiles (telles que les douches vaginales) ou même nuisibles (telles que l'insertion de substances destinées à dessécher le vagin), ou est un effet secondaire de certains médicaments.

4 Certaines IAG se transmettent ou se propagent sous l'effet de certaines procédures médicales et de certains traitements.

- Ce type d'IAG est beaucoup plus courant chez les femmes que chez les hommes.

- Il peut résulter de l'emploi d'instruments médicaux non stériles (mal nettoyés) ou de la propagation d'une infection existante vers l'appareil génital haut lors d’une procédure médicale (l'insertion d'un stérilet, par exemple). 
5 Les IAG peuvent provoquer des symptômes de démangeaison et d'écoulements vaginaux.

6 Diagnostiquées sans tarder, beaucoup d'IAG se traitent et guérissent aisément. Celles non traitées peuvent parfois provoquer de graves conséquences, y compris la stérilité ou même la mort (l'infection génitale haute, notamment).

7 Les femmes courent un plus grand risque que les hommes de souffrir de graves conséquences (y compris la stérilité) en cas d'IAG non sexuellement transmise.

8 Dans les contextes où la prévalence des IAG est extrêmement élevée, la sensibilisation à ces infections et à leur traitement fait souvent défaut.

9 Dans certains pays, les femmes revendiquent l'inscription des IAG au rang des graves problèmes de santé et demandent l'investissement de ressources dans des initiatives de sensibilisation et des services cliniques. 


\section{2e PARTIE: DÉCISIONS DE FÉCONDITÉ PERSONNELLE : LA CONTRACEPTION ET LAVORTEMENT (IVG)}

Les personnes ont le droit de décider librement et en toute responsabilité du nombre et de l'espacement des naissances de leurs enfants et d'avoir accès à l'information, à l'éducation et aux moyens nécessaires pour leur permettre d'exercer ces droits (Article 16.e, CEDF, 1979; Principe 8, Programme d'action de la CIPD, 1994). 


\section{la contraception}

Voir la fiche d'information sur les Méthodes contraceptives pour l'élaboration d'un programme détaillé.
1 Une personne (ou un couple) qui entend avoir des rapports hétérosexuels mais ne désire pas de grossesse peut utiliser la contraception ou avoir une activité sexuelle sans coït.

2 La contraception peut être définie comme toute méthode servant à éviter la grossesse. Les méthodes s'utilisent de façons différentes à différents moments. [Voir la section suivante.]

3 La contraception permet à de nombreuses personnes de profiter de leur vie sexuelle sans s'inquiéter du risque d'une grossesse non désirée. Le préservatif masculin ou féminin protège aussi contre les infections sexuellement transmissibles.

- La contraception permet aux gens de mieux gérer leur corps, leurs relations et leur vie sociale et et économique au sens large.

- La discussion et la pratique de la contraception peut renforcer la confiance et le confort mutuel.

- Partout dans le monde, des millions de personnes pratiquent la contraception.

4 La plupart des gouvernements, comme des individus, reconnaissent les avantages de la contraception et le droit de la pratiquer.

- La plupart des gouvernements et des services de santé assurent des services de contraception à ceux qui les demandent (indépendamment de l'âge, du genre ou de l'état matrimonial). Peu ne respectent pas ce droit fondamental et refusent les soins aux adolescents, aux célibataires ou sans le consentement du mari des femmes mariées.

- Certains groupes religieux s'opposent à toute forme de contraception. La plupart, y compris leurs chefs spirituels, y reconnaissent cependant le droit de l'individu d'utiliser une méthode contraceptive. 
5 Les accords internationaux protègent le droit des individus et des couples à gérer leur fécondité. Ces accords encouragent aussi les garçons et les hommes à partager la responsabilité de la prévention des grossesses non planifiées.

6 Dans le passé, beaucoup d'hommes laissaient les femmes assumer la pleine responsabilité de la contraception. Beaucoup la partagent aujourd'hui.

Par exemple :

-en renonçant aux rapports sexuels sans contraception ;

-en communiquant avec leur partenaire avant d'avoir des rapports sexuels ;

- en s'informant sur les différentes méthodes de contraception;

- en utilisant le préservatif correctement et sans exception ;

- en recourant, au besoin, à d'autres méthodes masculines telles que le retrait ou la vasectomie ;

- en accompagnant leur partenaire féminine dans une clinique de planification familiale; et

-en appuyant le choix contraceptif de leur partenaire.

7 Certaines personnes (même si elles ne désirent pas de grossesse) ne pratiquent pas la contraception par manque d'information correcte ou complète.

Par exemple :

- Elles ne comprennent pas le risque de grossesse qu'elles courent.

- Beaucoup ignorent la période féconde du cycle menstruel de la femme ou de la fille.

- Beaucoup sont mal informées des différentes méthodes contraceptives qui pourraient leur être disponibles ou acceptables ou de l'endroit où se les procurer.

- L'information des prestataires concernant les méthodes appropriées pour les adolescents sont parfois inexactes ou dépassées. 
8 Certaines personnes (même si elles ne désirent pas de grossesse) ne pratiquent pas la contraception par manque d'accès à des services où elles se sentent à l'aise.

Par exemple :

- Certaines s’inquiètent du coût, du caractère privé et de la confidentialité de leur recherche.

- Beaucoup n'ont pas accès à une clinique ou pharmacie où elles puissent acheter des contraceptifs.

- Beaucoup — les minorités ethniques ou raciales, jeunes célibataires et personnes vivant dans la pauvreté surtout — ne sont pas traitées avec respect par les prestataires de services.

9 Certaines personnes (même si elles ne désirent pas de grossesse) ne pratiquent pas la contraception en raison de barrières personnelles ou culturelles (y compris l'inégalité de genre).

- Les normes de la communauté relatives au genre et à la sexualité mettent beaucoup de filles, surtout, mais aussi les garçons mal à l'aise sur les questions de sexe et de contraception.

- Certaines personnes croient que leur partenaire assume la responsabilité de la contraception.

- Certaines s'opposent à la contraception en raison des convictions inculquées par leur famille, leur communauté ou leurs chefs religieux.

- Beaucoup de couples subissent la pression sociale de produire un enfant ; la pression de démontrer leur fécondité et d'avoir des enfants peut être intense sur les femmes.

- Beaucoup — de femmes surtout, mais pas toujours — sont contraints à avoir des rapports sexuels non planifiés.

- Un partenaire peut s'opposer à la contraception et recourir à la pression, la menace ou la ruse pour l'éviter.

10 Certaines personnes (même si elles ne désirent pas de grossesse) ne pratiquent pas la contraception parce qu'elles n'ont pas trouvé de méthode qui leur paraisse acceptable ou sûre. Certaines s'inquiètent par exemple des effets secondaires (réels ou perçus) des différentes méthodes. 


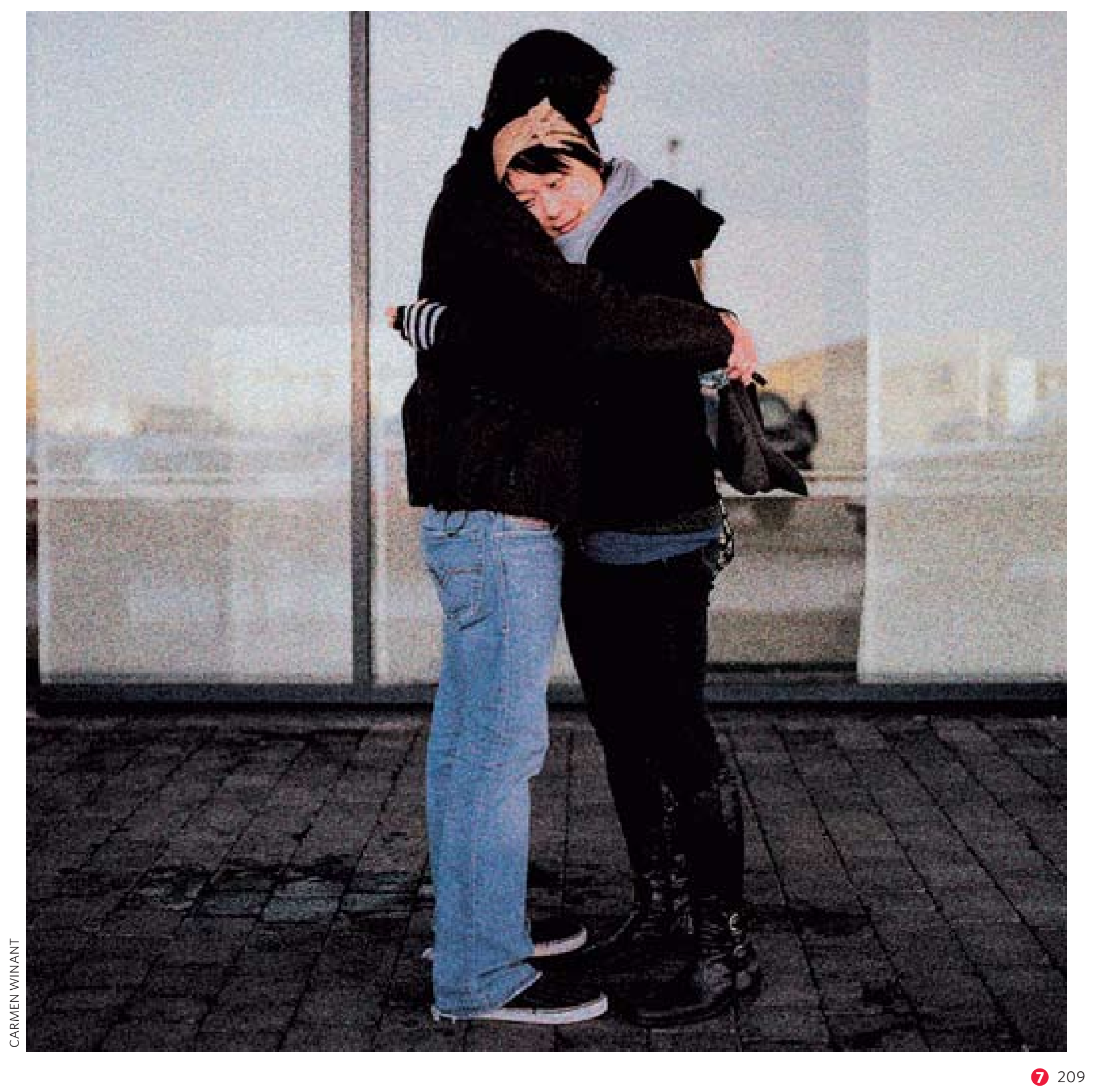




\section{méthodes contraceptives}

Voir la fiche d'information sur les Méthodes contraceptives pour l'élaboration d'un programme détaillé.
1 La plupart des méthodes contraceptives sont destinées aux femmes ; quelquesunes seulement le sont aux hommes. Le choix de méthodes est vaste. Chacun a le droit de consentir librement et en connaissance de cause à la méthode de son choix. Beaucoup de couples opèrent ce choix ensemble.

2 Aucune méthode contraceptive n'est parfaite, et chacune présente ses propres caractéristiques. Certaines méthodes sont sujettes à restrictions médicales.

- Deux méthodes seulement, le préservatif masculin et féminin, protègent contre le VIH.

- Certaines méthodes, mais pas toutes, peuvent affecter le plaisir ou la performance sexuelle.

- Certaines méthodes sont faciles à obtenir. D’autres requièrent une consultation ou même une visite médicale.

- Les méthodes varient dans leur efficacité de prévention de la grossesse.

- Certaines méthodes présentent des risques d'effets secondaires sur la santé de l'utilisatrice.

- Certaines méthodes, mais pas toutes, peuvent être aisément interrompues ou reprises.

- Certaines méthodes conviennent mieux aux personnes dont les rapports sexuels sont peu fréquents.

- Le coût et la disponibilité des méthodes varient aussi.

3 II n'est pas rare d'essayer différentes méthodes pour déterminer celle qui convient le mieux.

- Le prestataire de santé peut indiquer les avantages, les inconvénients et les effets secondaires de chaque méthode.

- Si une personne ne se sent pas à l'aise avec une méthode particulière, elle peut en essayer une autre. 
4 Certaines personnes choisissent les méthodes qui les protègent le mieux contre l'infection. Ces méthodes doivent être mises en place chaque fois que le couple a des rapports sexuels. Elles sont appelées « méthodes barrières » car elles créent une barrière entre l'ovule et le sperme et rendent la fécondation impossible.

- Le préservatif (masculin ou féminin) protège contre la grossesse et le VIH, ainsi que contre plusieurs autres IST parfois préjudiciables à la fécondité à venir.

- En beaucoup d'endroits, les jeunes peuvent obtenir le préservatif gratuitement ou l'acheter en pharmacie ou ailleurs.

- Certains estiment que le préservatif amoindrit le plaisir sexuel. Pour d'autres, la protection assurée contre les grossesses non désirées et les IST (y compris le VIH) compense largement cet inconvénient.

- Pour plus de protection, beaucoup de couples utilisent le préservatif en plus d'une autre méthode contraceptive.

- D’autres méthodes barrières, comme le diaphragme et la cape cervicale, sont destinées aux femmes. Il n'est pas encore établi si la cape ou le diaphragme assure une protection contre les infections.

\section{Certaines personnes choisissent les méthodes (telles que « la pilule », les implants} hormonaux, les injectables, les patchs hormonaux, l'anneau vaginal et le stérilet) les plus efficaces contre la grossesse.

- Ces méthodes ne protègent pas contre les infections sexuellement transmissibles. Leur combinaison avec le préservatif masculin ou féminin peut assurer une protection accrue contre la grossesse et les IST, y compris le VIH.

- Ces méthodes tendent à avoir plus d'effets secondaires. Certaines méthodes hormonales réduisent par exemple l'intérêt sexuel de certaines femmes.

- Ces méthodes présentent plus de risques de complications, mais parfois aussi certains avantages pour la santé.

- Ces méthodes peuvent être plus pratiques d'emploi.

- Ces méthodes peuvent être plus faciles à utiliser pour les femmes, indépendamment de la participation active de leur partenaire. Certaines peuvent même l'être à l'insu du partenaire. 
6 Pour éviter une grossesse non désirée, certaines femmes apprennent à identifier les jours féconds (où elles peuvent se retrouver enceintes) les plus probables de leur cycle menstruel. Les techniques concernées font partie d'un groupe dit de « méthodes de la conscience de la fécondité ». Par exemple, la femme peut apprendre à calculer ses jours de fécondité en fonction de ses cycles menstruels passés. Elle peut observer les changements qui affectent son corps (température et glaires cervicales).

[Voir la fiche d'information sur le Cycle menstruel.]

- Apprendre à identifier sa période féconde prend du temps : la femme doit connaître son cycle menstruel et observer les changements cycliques de son corps.

- Pendant la période féconde du cycle menstruel, les couples peuvent utiliser une méthode contraceptive telle que le préservatif, ou ils peuvent éviter les rapports vaginaux. [Voir la section précédente sur l'appareil génital.]

- Le cycle menstruel de chaque femme est différent. Les hormones, la maladie et d'autres facteurs perturbent souvent la régularité du cycle.

- Les jeunes adolescentes ont souvent des cycles irréguliers qui rendent difficile la pratique efficace de ces méthodes. - Ces méthodes n’offrent aucune protection contre les IST et le VIH.

- Beaucoup de couples trouvent ces méthodes difficiles ou peu pratiques.

7 Pour éviter la grossesse, certains couples décident que l'homme retirera son pénis du vagin de sa partenaire avant d'éjaculer (d'atteindre l'orgasme et d'expulser le sperme). C'est la méthode du « retrait ».

- Pratiquée correctement et avec constance, cette méthode prévient efficacement la grossesse.

- Sa pratique efficace exige une maîtrise et un engagement intenses de la part de l'homme. Pour cette raison, le retrait est lié à plus de grossesses non planifiées que de nombreuses autres méthodes. Sa pratique correcte et constante pose souvent problème aux jeunes.

- Le retrait n'assure aucune protection efficace contre le VIH (et les autres IST). 
8 Certaines personnes choisissent la stérilisation, une chirurgie devant être considérée comme permanente. C'est une méthode contraceptive masculine ou féminine.

\section{Une femme peut obtenir une protection contre la grossesse après avoir eu des} rapports sexuels selon une méthode de « contraception d'urgence ».

[Voir la fiche d'information sur la Contraception d'urgence.]

- La contraception d'urgence est utile dans les cas où le couple n'a pas utilisé de contraceptif, où sa méthode a échoué (rupture du préservatif, par exemple), ou où la femme a subi des rapports forcés.

- La contraception d'urgence peut être efficace jusqu'à cinq jours après les rapports non protégés, mais il vaut mieux y recourir le plus vite possible durant cette période.

- La forme de contraception d'urgence la plus courante contient une dose spécifique d'une hormone utilisée dans beaucoup de contraceptifs oraux. La «pilule du lendemain » est souvent conditionnée et présentée dans le but spécifique de la contraception d'urgence. En certains endroits, elle peut être obtenue sans ordonnance.

- L'insertion d'un stérilet dans les cinq jours suivant les rapports non protégés offre une autre option de contraception d'urgence.

- La contraception d'urgence n'est pas une méthode abortive. Elle n'interrompt pas une grossesse établie.

10 II arrive que la contraception échoue.

- Certaines femmes choisissent alors de poursuivre la grossesse non planifiée. [Voir l'unité 6, pp. 174-177.]

- D’autres femmes choisissent de l'interrompre. [Voir la section suivante.]

VOIR LE VOLUME D'ACTIVITÉS Activité 51

connaissance de la

contraception

Une grille de mots croisés et un jeu aident les élèves à réviser leur connaissance de la contraception. Ils en discutent la responsabilité partagée. 


\section{grossesse non planifiée et avortement (IVG)}

Les accords internationaux affirment la nécessité de reconnaître et de gérer l'impact sur la santé de l'avortement non médicalisé (Paragraphe 106j, Programme d'action de la QCMF, 1995) et, dans les contextes où I'IVG est légale, celle d'assurer sa pratique dans de bonnes conditions de sécurité (Paragraphe 8.25, Programme d'action de la CIPD, 1994; Paragraphe 106k, Programme d'action de la QCMF, 1995).

1 Des millions de femmes et de filles se trouvent confrontées à des grossesses non planifiées, pour de nombreuses raisons : absence de contraception (non disponible ou non pratiquée), pratique incorrecte ou échec.

2 Chaque année, entre 40 et 50 millions de femmes et de filles décident de se faire avorter (interrompre une grossesse).

3 Les femmes et les filles se font avorter pour de nombreuses raisons.

Par exemple :

- Elles n'ont pas les moyens ou la possibilité d'élever un enfant (qu'il s'agisse de leur premier ou non).

- Elles ne désirent pas devenir mères au moment de la grossesse.

- Elles désirent achever leurs études.

- Leur relation avec leur partenaire est difficile ou instable et elles ne désirent pas élever un enfant seules.

- Leur grossesse menace leur santé physique ou mentale.

- Leur grossesse est le résultat de rapports sexuels forcés ou contraints. 
4 Même dans les situations où la femme ou le couple désire poursuivre la grossesse, elle ou il peut finir par l'interrompre pour différentes raisons.

Par exemple :

- La grossesse menace la santé physique ou mentale de la femme.

- Des facteurs génétiques, comportementaux ou environnementaux posent de graves risques médicaux (y compris la mort) au fotus.

- Le couple n'est pas satisfait du sexe du foetus. Ce sentiment se retrouve le plus souvent dans les contextes où la société accorde une plus grande valeur aux fils. [Voir la fiche d'information sur la Sélection du sexe.]

- Certaines femmes ou filles sont poussées à avorter en raison de leur situation personnelle ou économique, de leur état de santé ou pour d'autres raisons. La pression peut être exercée par une autre personne (un parent, petit ami ou prestataire de soins, etc.) Dans les pays soumis à des politiques démographiques contraignantes, l'État peut pousser les femmes à se faire avorter.

5 II existe plusieurs méthodes d'avortement médicalisé. Suivant le stade de la grossesse et l'équipement du prestataire, ces méthodes peuvent impliquer une procédure chirurgicale ou une approche médicamenteuse.

[Voir la fiche d'information sur l'Avortement (IVG).]

6 L'avortement est une procédure simple et sans risque lorsqu'elle est pratiquée dans de bonnes conditions de sécurité : par un prestataire compétent, avec un équipement stérile approprié et avec accès thérapeutique rapide en cas de complications.

- L'avortement médicalisé et sûr est généralement plus probable lorsqu’il est légal.

- Les conditions de l'avortement varient largement suivant l'endroit. À l'échelle mondiale, un peu plus de la moitié des avortements pratiqués sont dans de bonnes conditions médicales.

\section{POINTS DE RÉFLEXION}

La majorité des femmes qui choisissent l'avortement sont mariées et ont déjà au moins un enfant. Elles sont cependant de tous âges, races, ethnicités, religions, conditions économiques et états matrimoniaux. Dans quelles circonstances une femme ou une fille peut-elle décider de se faire avorter?

L'avortement est le moins courant dans les pays qui assurent

l'éducation à la sexualité et l'accès général à la contraception et à l'avortement médicalisé. Quelles sont les raisons pour lesquelles les femmes de ces pays sont moins vulnérables aux grossesses non planifiées? 


\section{Beaucoup mais pas toutes les personnes ni tous les gouvernements soutiennent}

l'accès des femmes à l'avortement légal médicalisé.

Ceux favorables à l'accès légal à l’avortement médicalisé :

- estiment que tout le monde doit avoir accès à toutes les procédures médicales sûres ;

- désirent réduire la mortalité maternelle, y compris celle imputable à l'avortement non médicalisé ;

- estiment que les femmes ont le droit de gérer leur propre vie et que la maîtrise de leur fécondité fait partie intégrante de ce droit ;

- estiment que les couples doivent pouvoir profiter de leur intimité et de leur plaisir sexuel sans procréer ;

- s'inquiètent de la croissance démographique et veulent assurer l'accès des femmes à toutes les méthodes possibles de maîtrise de leur fécondité ; ou

- se soucient des effets économiques de l'avortement non médicalisé (le coût des soins d'urgence aux femmes et filles atteintes de complications, notamment).

Ceux opposés à l'accès à l'avortement :

- ont des convictions religieuses ou personnelles qui l'interdisent ;

- estiment qu'il ne revient pas aux femmes de gérer leur propre vie et leur fécondité ;

- estiment que les rapports sexuels ne doivent pas se pratiquer à des fins autres que la procréation; ou

- pensent, à tort, que l'avortement légal médicalisé accroît la promiscuité sexuelle ou les taux d'IVG.

\section{VOIR LE VOLUME D'ACTIVITÉS}

\section{Activité 52}

\section{se mettre à sa place : la}

\section{décision d'interrompre une}

\section{grossesse}

Les élèves lisent quelques études de cas et discutent les raisons pour lesquelles les femmes se font avorter. 
8 Presque tous les pays du monde ont adopté des lois qui admettent l'IVG dans certaines circonstances précises.

- Dans certains, les femmes peuvent se faire avorter à la demande, généralement jusqu’à un nombre donné de semaines de gestation.

- Dans d'autres, l'avortement n'est autorisé que dans certaines circonstances : pour sauver la vie de la femme ou dans les cas de viols ou d'inceste, par exemple.

- Les lois sur l'avortement font l'objet d'un débat permanent et changent dans de nombreux pays.

\section{Chaque heure de chaque jour, environ huit femmes et filles meurent (et 200} deviennent stériles) faute d'accès à des services d'avortement médicalisé. Ces conséquences tragiques sont pourtant facilement évitables.

- Même si l'avortement est une procédure simple et sûre lorsqu'elle est pratiquée dans de bonnes conditions, près de la moitié se pratiquent dans des conditions non médicalisées.

- L'avortement non médicalisé pose un grave problème de santé publique dans de nombreuses régions du monde. Il affecte les filles et les femmes de tous milieux socioéconomiques, mais surtout celles qui vivent dans la pauvreté. 


\section{PLAIDOYER POUR}

LA SANTÉ SEXUELLE,

LES DROITS ET

LÉGALITÉ DE GENRE 


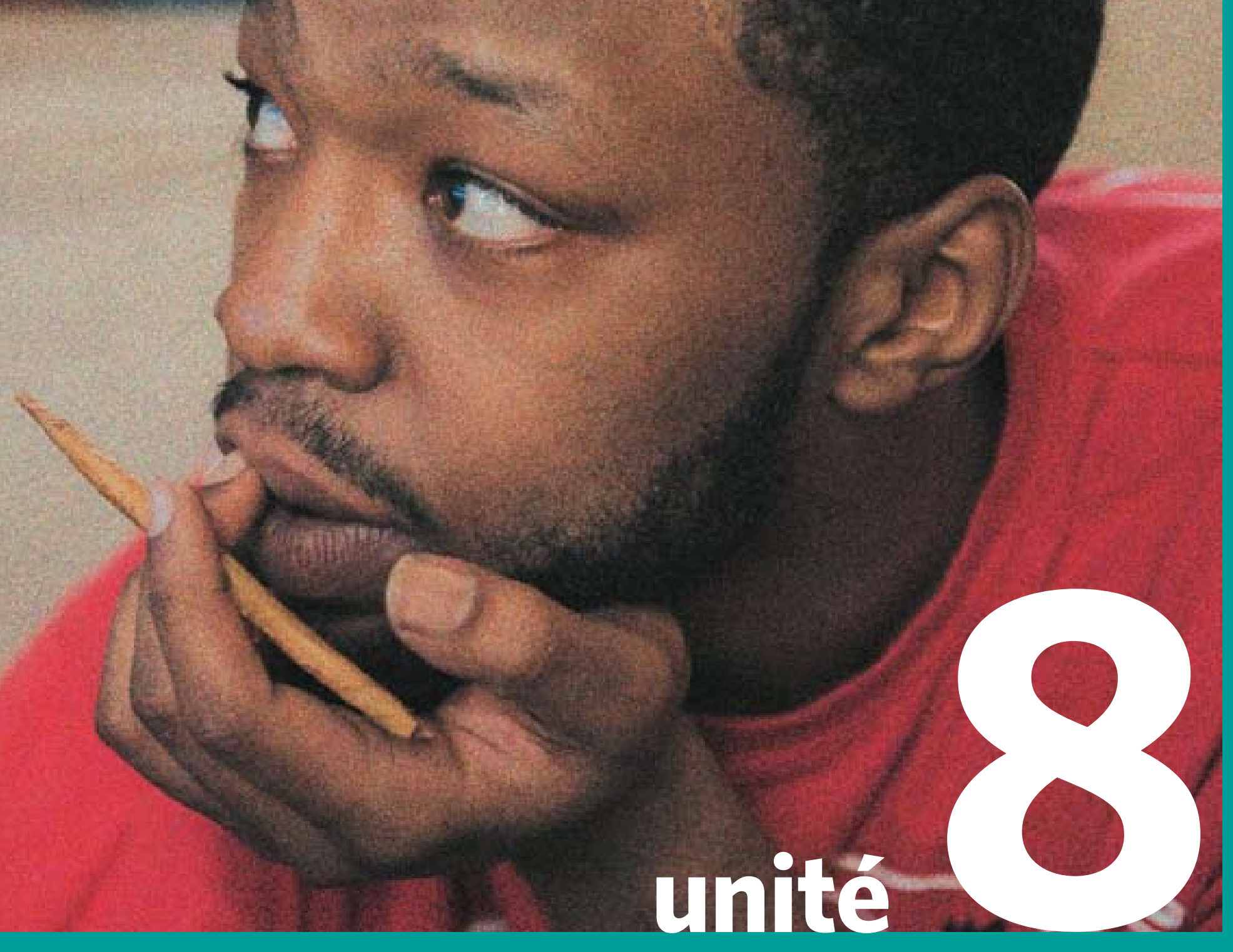




\section{panorama}

Ce module spécial permet aux enseignants de soutenir l'initiative pratique de leurs élèves dans leur vie, à l'école et dans leur communauté. L’expérience doit viser le changement dans les domaines de la santé sexuelle (y compris le VIH et sida), les droits humains et l'égalité de genre. Les élèves peuvent réfléchir à leurs propres comportements, discerner ce qu'ils estiment juste ou injuste et prendre les mesures - petites ou grandes - qui changeront quelque chose dans leur vie ou dans celle d'autrui. Ce type d'engagement personnel et civique aide à s'assumer en tant que citoyen responsable et à promouvoir une culture démocratique. 


\section{PLAIDOYER POUR LA SANTÉ SEXUELLE, LES DROITS ET L'ÉGALITÉ DE GENRE}

Cette unité a pour but de vous aider à guider vos élèves dans l'entreprise de projets d'action « pratique ». Même s'ils ne peuvent entreprendre eux-mêmes un projet de plaidoyer, la première partie de cette unité peut être utile à l'introduction au plaidoyer et au changement social.

Sur la base de la matière présentée dans les unités précédentes de ce volume, aidez vos élèves à réfléchir et à s'informer sur différentes questions.

Cette unité met l'accent sur des questions particulières (l'égalité de genre, les droits des personnes vivant avec le VIH et sida et la violence), mais elle peut être appliquée à d'autres projets d'action.

Familiarisez-vous avec au moins un effort de plaidoyer dans votre région et tirez-en des exemples concrets du pourquoi et comment les gens œuvrent pour le changement social.

Ce module inclut des « questions de réflexion » que vos élèves trouveront peut-être compliquées ou envahissantes. Veillez à sélectionner celles qui conviennent à votre audience.

Recherchez l'encouragement et le conseil d'autrui pour mieux guider vos élèves à travers ce module.

\section{POUR LE MODULE-PROJET « PASSER À L'ACTION » :}

Encouragez vos élèves à commencer petit. Rappelez-leur que le changement en vaut la peine, aussi petit soit-il. Aidez-les à comprendre sa place dans de plus grands mouvements.

Encouragez vos élèves à travailler en équipe et veillez à ce que l'équipe donne à chacun l'occasion de participer et de s'engager.

N'oubliez pas que votre première responsabilité est d'assurer la sécurité de vos élèves. Bien que le changement exige parfois une action audacieuse, même les petits pas peuvent paraître menaçants à certains membres de la communauté. Tandis que vos élèves conçoivent leurs projets, renseignezvous auprès des dirigeants de votre établissement et de la communauté concernant toute résistance possible et cherchez à assurer le soutien de personnes influentes aux efforts de vos élèves. Veillez à ce qu'ils ne prennent pas de risques inutiles et aidez-les, au besoin, à choisir un autre sujet. Préparez aussi une liste de contacts et ressources auxquels ils puissent faire appel. 


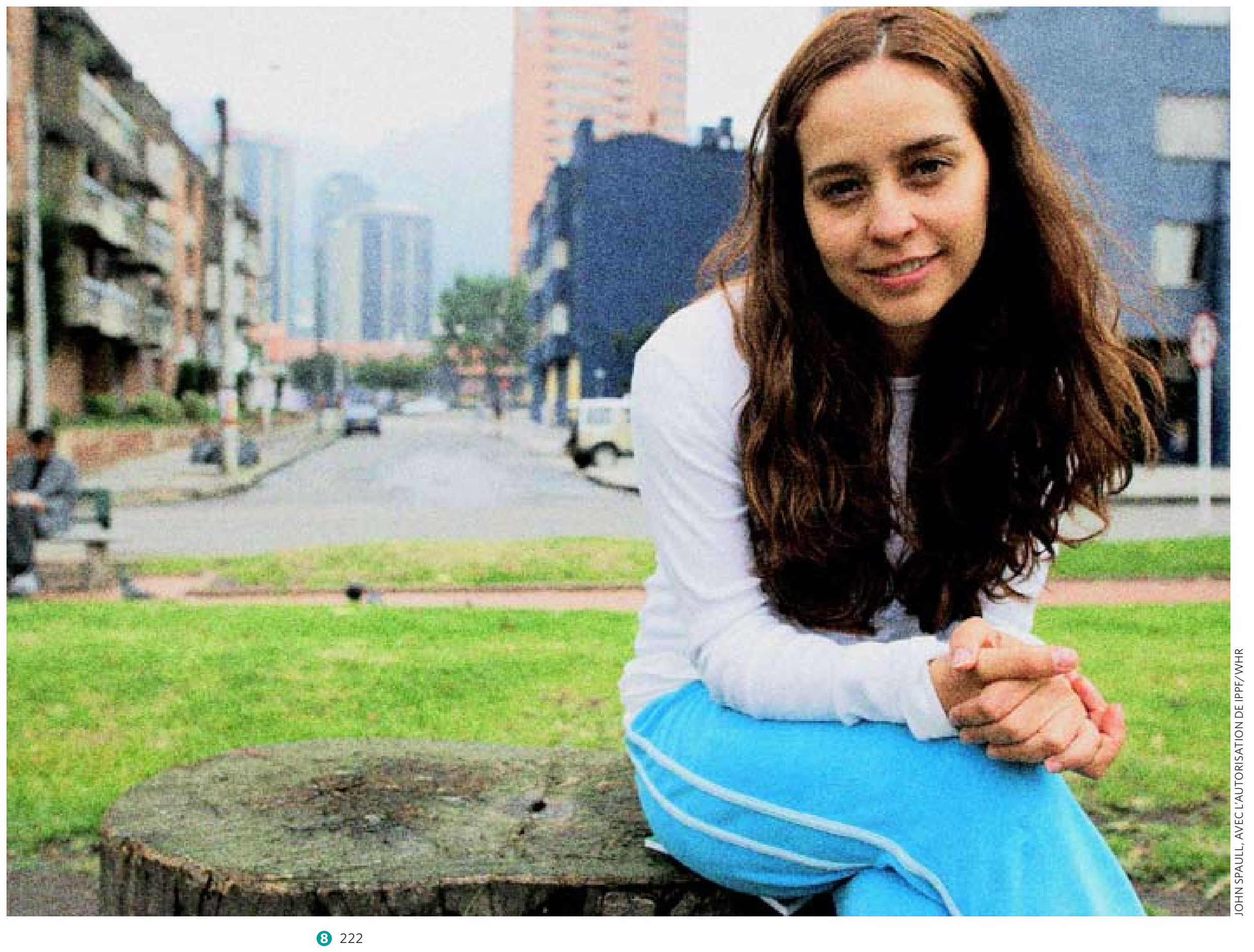




\section{PLAIDOYER POUR LA SANTÉ SEXUELLE, LES DROITS ET L'ÉGALITÉ DE GENRE}

Le matériel couvert dans cette unité prépare les élèves à :

\section{Objectifs cognitifs}

Citer au moins une manière de lutter contre la discrimination ou l'injustice dans leur propre vie.

Citer au moins une manière de lutter contre la discrimination ou l'injustice dans la communauté.

Citer au moins une manière de lutter contre la discrimination ou l'injustice au niveau national ou mondial.

\section{Objectifs affectifs}

Réfléchir à leurs propres préjugés et motivations de changement.

Devenir sensibles aux situations d'injustice, de discrimination, de marginalisation ou d'inégalité.

Réfléchir à leurs expériences et sentiments dans la lutte pour la promotion de la santé sexuelle, des droits humains ou de l'égalité de genre.

\section{Objectifs de compétences}

S'informer sur une question de santé sexuelle, droits humains ou égalité de genre qui les préoccupe. Élaborer un plan d'action concret au service d'un monde plus juste.

Mettre en œuvre les étapes de ce plan d'action. 


\section{réfléchir à ses propres attitudes}

1 Nous avons tous l'espoir de réaliser tout notre potentiel humain. Les normes sociales établies et les stéréotypes peuvent cependant limiter ce potentiel. Ces normes et stéréotypes ont souvent trait au genre, à la race, à l'âge, à la classe sociale, à la religion, à l'identité sexuelle et aux aptitudes ou limitations physiques des personnes.

2 Dans une certaine mesure, tout le monde absorbe et transmet les stéréotypes largement acceptés. Absorber la discrimination (ou l'oppression), c'est admettre les stéréotypes et les normes comme vraies, même si on en est victime. Certains en reconnaissent le caractère néfaste mais doutent de leur capacité à faire changer les choses.

3 On peut défier les stéréotypes de genre et ceux qui affectent d'autres aspects de la vie. On doit pour ce faire pouvoir et oser identifier comment ils ont affecté notre identité, notre développement personnel et nos choix. 
Voir le glossaire en fin d'unité 1 , pour la définition de quelques termes utilisés dans cette unité.

\section{Nous pouvons tous et toutes réfléchir à nos opinions, valeurs et idées personnelles, et les soumettre à une analyse critique.}

La liste ci-dessous présente quelques questions difficiles mais importantes que nous pouvons tous nous poser dans notre réflexion sur les normes et la justice de nos communautés à l'égard du genre et de la sexualité :

- Quels sont les adjectifs que j’utilise pour me décrire? S’agit-il de mots généralement utilisés pour décrire les garçons et les hommes ou les filles et les femmes?

- Certains sentiments, comme la colère ou la douceur, me paraissent-ils inappropriés pour les filles ou pour les garçons? Par exemple?

- Ai-je tendance à croire que je devrais développer (ou non) certaines aptitudes en raison de mon sexe?

- Ai-je tendance à croire que les garçons et les filles ont naturellement des aptitudes intellectuelles différentes?

- Ai-je tendance à écouter plus attentivement les idées de quelqu'un suivant son sexe?

- Suis-je d'avis que les filles n'ont pas besoin de faire de sport autant que les garçons ? Pourquoi ?

- Certains comportements sexuels me paraissent-ils acceptables pour un sexe et pas pour l'autre?

- Ai-je des préjugés sur la sexualité des personnes d’autres groupes ethniques ou raciaux? Si oui, sur quoi repose mon attitude?

- Quelle est mon opinion d'une personne qui s'identifie au genre opposé à celui qui lui a été attribué à la naissance ?

- Quelle est mon opinion du fait que les filles doivent remplir plus de tâches ménagères que les garçons ?

- Est-il acceptable qu'un homme gagne plus qu'une femme qui accomplit le même travail ?

- Si j'étais adulte, voterais-je pour une femme candidate à la présidence ? Pourquoi ou pourquoi pas?

- Engagerais-je un homme pour prendre soin de petits enfants? Pourquoi ou pourquoi pas?

- Me paraît-il acceptable de taquiner gentiment une personne que je pense être homosexuelle ? Pourquoi ?

- Me semble-t-il que le blâme d'un viol va parfois à la fille ou à la femme ? Si oui, dans quelles circonstances?

- Sur quelles bases ai-je formé mes opinions ? Où ai-je appris à former ces attitudes? 
5 On peut aussi s'interroger sur la justice et les normes des communautés à l'égard du VIH et sida. Ces questions peuvent être difficiles, mais elles sont importantes.

Par exemple :

- Ai-je des préjugés à l'égard des personnes vivant avec le VIH et sida ? Où les ai-je appris?

- Que penserais-je si j’apprenais que mon frère ou ma sour était séropositif?

- Quelle est mon opinion des personnes qui paient pour avoir des rapports sexuels, et de celles qui les leur vendent?

Mon opinion est-elle similaire ou différente à l'égard des deux et pourquoi ?

- Dans quelle mesure me revient-il de défendre la dignité et les droits des personnes séropositives ?

- Dois-je assumer la responsabilité de me soumettre à un test de dépistage du VIH ?

- Si je suis séropositif(ve), la responsabilité me revient-elle de le dire à mes partenaires sexuel(le)s, même si nous utilisons le préservatif?

6 Chaque jour, nous prenons des décisions sur la manière dont nous réagissons aux autres et dont nous les traitons, sans réfléchir à ce qui est juste ou éthique, et sans réfléchir non plus aux autres décisions que nous pourrions prendre. Être juste et équitable, c'est traiter tout le monde avec un respect égal, par principe d'éthique personnelle et de respect des droits humains. 


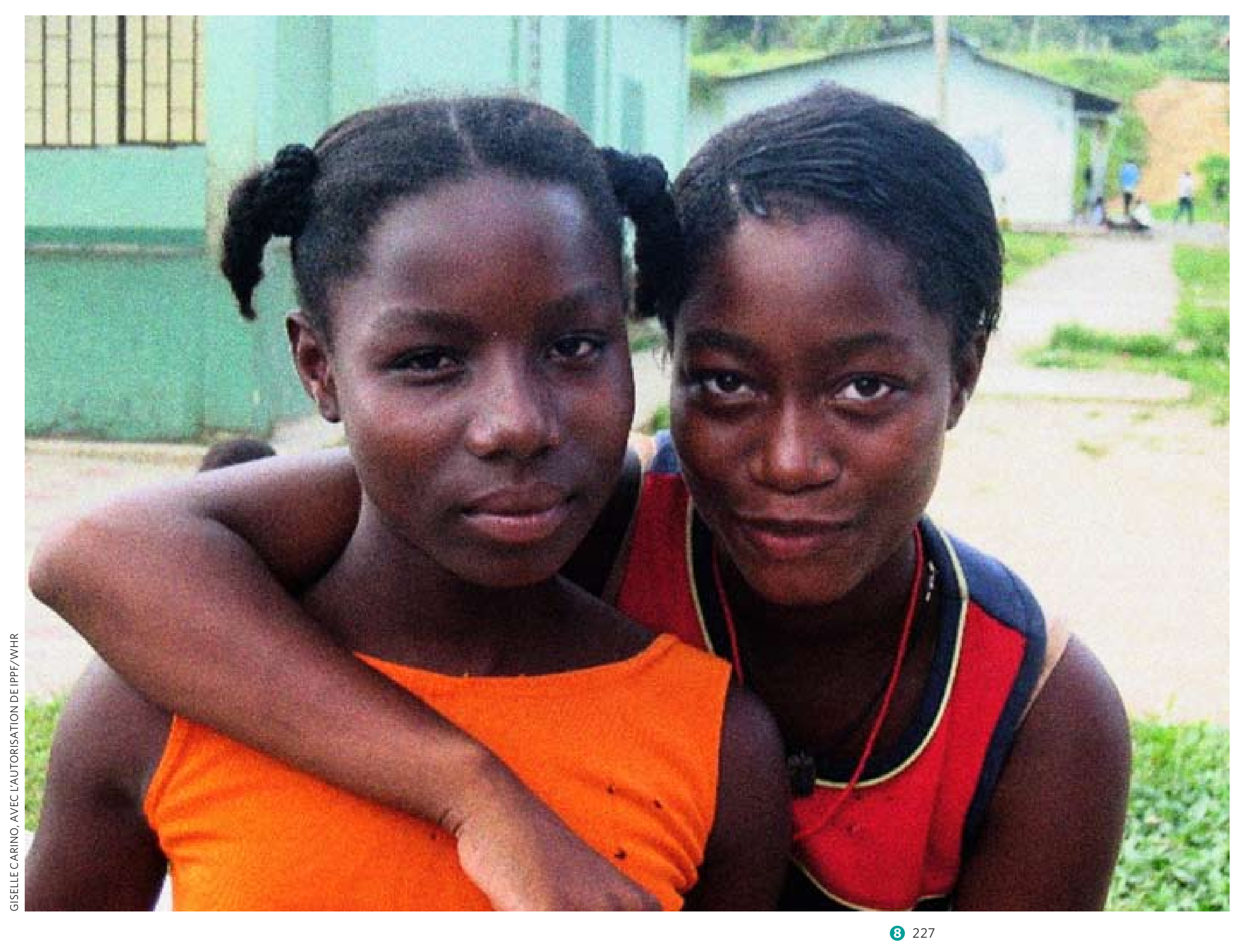




\section{reconnaître ce qui est juste ou non}

1 Pour lutter contre la discrimination, il faut savoir la reconnaître, en soi-même comme dans le monde qui nous entoure.

2 II n'est pas toujours simple de reconnaître la discrimination. Elle est parfois évidente (dans une remarque dégradante ou dans les cas de violence conjugale), mais elle peut être plus subtile et difficile à relever (quand on ignore l'opinion d'une personne en raison de son sexe, notamment).

3 On peut se poser la question suivante quand on pense réagir, peut-être, sur la base de stéréotypes ou de préjugés : «Pourquoi ce jugement ? 》 Cette question peut provoquer une réflexion utile et aider à reconnaître la discrimination à la base de certains comportements. 


\section{changer le monde autour de nous}

1 On ressent tous une certaine pression culturelle à se conformer et à « laisser les choses telles qu'elles sont ».

- Certaines personnes acceptent le statu quo, même quand la situation est injuste : peut-être ne s'en inquiètent-elles pas, ne savent-elles pas comment s'y prendre, ou ne désirent-elles pas prendre le risque d'agir.

- D'autres élèvent leur voix contre l'injustice au sein de leurs propres relations et familles, à l'école, dans leur communauté ou dans leur société, parfois au risque de conséquences affectives, économiques, légales, sociales ou corporelles.

2 Les personnes qui croient en l'égalité sociale peuvent adopter différentes approches. II est rarement efficace de s'attaquer à toute la structure sociale. II est plus utile de contribuer aux petites démarches importantes, même dans les contextes profondément conservateurs.

3 II peut être passionnant et autonomisant de faire la différence. Le plaidoyer favorise aussi les nouvelles rencontres.

Par exemple, tout le monde peut :

- exprimer des attitudes, des valeurs et des opinions conformes à ses convictions ;

- respecter les droits fondamentaux de tous et de toutes;

- s'élever contre la discrimination; et

- à petits et à grands pas, marquer chaque jour un changement dans la vie de quelqu'un. 
4 On peut s'élever contre l'injustice (y compris l'inégalité de genre) que l'on observe dans ses propres relations et dans sa vie.

Par exemple :

- On peut arrêter de dénigrer ou de ridiculiser les personnes qui sont différentes de nous. On peut s'opposer à ceux qui le font. On peut devenir plus sensible aux attitudes irrévérencieuses ou dégradantes présentées dans les médias (paroles de chanson, vidéos, émissions télévisées, bandes dessinées, etc.).

- Un homme peut demander à ses parents de ne plus harceler sa femme (leur belle-fille) et sa famille dans le but d'accroître sa dot.

- Une personne peut encourager un parent à embaucher, s'il est employeur, des personnes séropositives.

- Un adolescent peut faire pression sur ses amis pour qu'ils arrêtent de taquiner ou de brimer quelqu'un.

- On peut accepter ouvertement les membres de sa famille dont la sexualité n'est pas conforme à la norme sociale.

- Tout le monde peut devenir plus sensible aux sentiments des personnes issues d'origines et de situations différentes. L’ouverture d'esprit et l'écoute sont essentielles à l'établissement de relations ancrées dans le respect.

\section{On peut aussi décider de lutter contre l'injustice qu'on observe dans sa communauté et dans la société.}

On peut par exemple :

- donner son appui à une personne injustement marginalisée ; et

- informer personnellement les gens et les sensibiliser aux injustices locales. 
6 On peut se joindre aux efforts locaux pour la justice et l'égalité sexuelle et de genre.

On peut par exemple :

- contribuer aux efforts de traitement équitable des personnes vivant avec le VIH et sida ;

- convaincre les membres de la communauté de renoncer à l'excision des filles ;

- former des groupes de veille de quartier pour lutter contre la violence familiale ;

- créer des espaces sûrs où les victimes de la violence familiale peuvent trouver de l'aide ; et

- militer en faveur de l'éducation à la sexualité et au genre dans les écoles.

\section{On peut se joindre aux campagnes nationales pour la justice et l'égalité.}

Par exemple :

- pour aider les filles à rester à l'école ;

- pour sauver la vie de filles et de femmes en décriminalisant l'avortement ;

- pour réformer les lois qui pénalisent les personnes sur la base de leur identité sexuelle ;

- pour que l'État investisse davantage dans la prévention et le traitement des problèmes de santé maternelle (la fistule obstétricale, notamment);

- pour exiger l'exécution des lois qui font des abus et du viol conjugal un crime ; et

- pour assurer l'exécution des lois de protection de l'égalité de genre (y compris face à l'opposition de mouvements conservateurs ou religieux).

\section{On peut soutenir ou rejoindre les efforts mondiaux pour le changement social.}

Par exemple :

- White Ribbon Campaign (mouvement mondial d'hommes et de garçons contre les violences faites aux femmes);

- campagnes artistiques et culturelles (telles que Dance4Life) de sensibilisation au VIH et sida ;

- mouvements contre la traite des femmes et des filles [voir la fiche d'information sur le Trafic sexuel] ; et

- réseaux de jeunes pour les droits et les services de santé sexuelle et génésique. 


\section{Types d'action entrepris en faveur du changement social :}

- Recherche

- Sensibilisation des autres, individuellement et en groupes

- Éducation des décideurs

- Communication avec les journalistes

- Rédaction et signature de lettres et pétitions

- Assistance aux campagnes électorales

- Pression sur les représentants élus en faveur de meilleurs lois et normes d'exécution

- Défense devant les tribunaux des droits des personnes sujettes à discrimination ou abus

- Parades et défilés

- Proclamations et déclarations de position

- Manifestations et grèves

- Piquets de grève et boycott

- Composition et interprétation de pièces de théâtre et de chansons engagées

-Établissement de services directs dans le but de montrer l'exemple

- Organisation d'ateliers à l'intention des prestataires de santé, de la police et d'autres acteurs de l'espace public en vue de les sensibiliser à de meilleures approches 


\section{obstacles au plaidoyer}

1 II peut être difficile et dangereux d'œuvrer pour la justice. II faut souvent confronter l'opinion publique ou l'autorité et le pouvoir. Le plaidoyer fait parfois courir un risque d'opprobre, d'emprisonnement ou de violence.

2 En raison de ces risques, il n'est pas toujours possible de confronter ou de contester directement la discrimination.

3 On peut alors envisager un mode d'action moins risqué, sans jamais oublier toutefois que ce qui est sûr dans un contexte ne l'est pas nécessairement dans un autre.

Quelques exemples de réponses (y compris par les jeunes) à la discrimination :

- rechercher un moyen d'en amoindrir l'effet pour soi-même ou pour les autres ;

- en parler avec une personne de confiance expérimentée ;

- créer une page Web ou un blog; et

- rechercher quelques alliés avec lesquels on peut ensuite s'adresser à une autorité. 


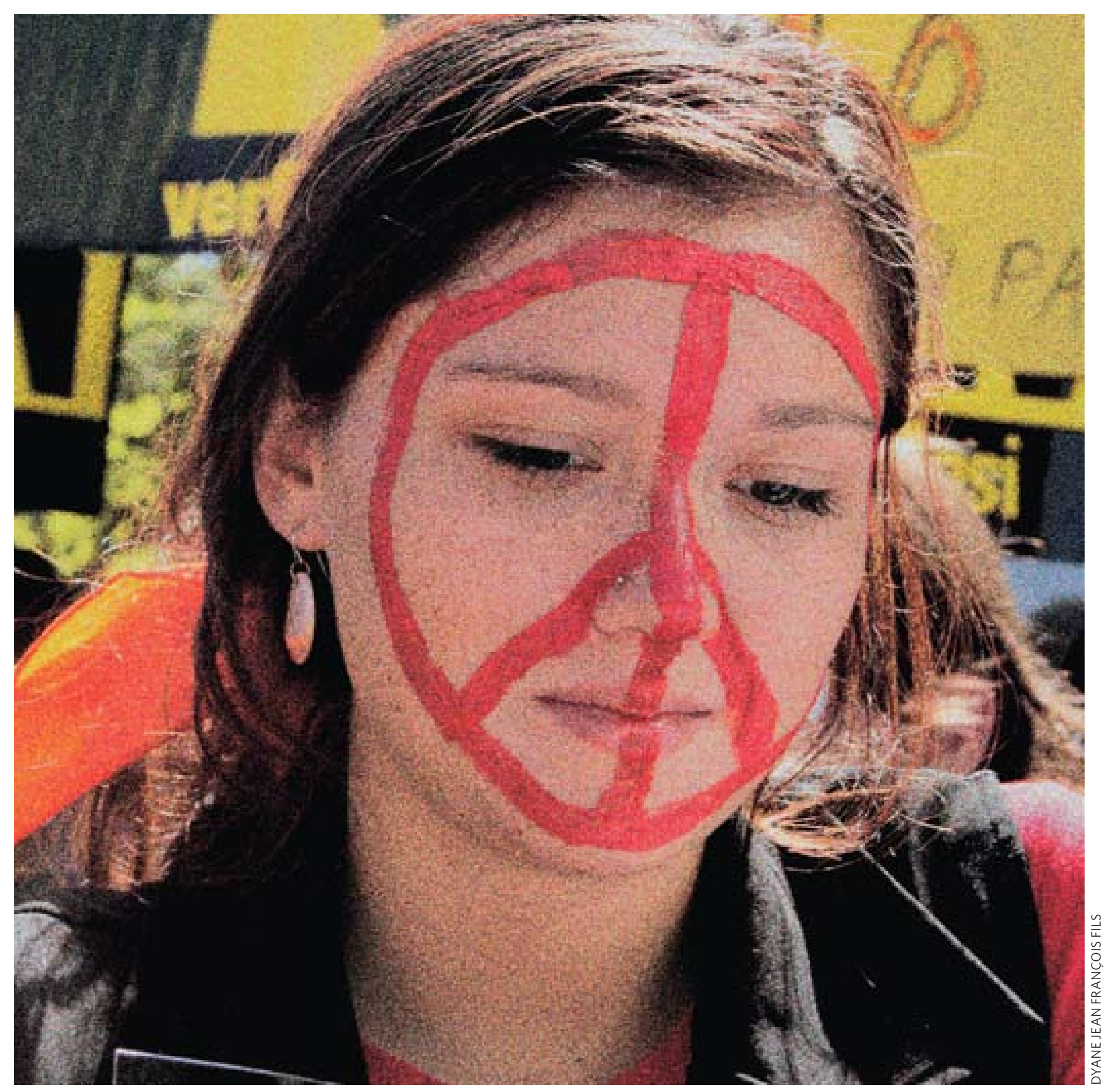




\section{le sens et la puissance du plaidoyer dans la vie}

1 On contribue généralement plus efficacement au changement social quand on poursuit une cause qui nous est chère, parce qu'on la connaît et qu'elle nous affecte directement.

2 On peut apprendre à changer le monde autour de soi. Les compétences apprises s'appliquent à de nombreuses situations.

3 Qu'on la poursuive dans nos choix personnels quotidiens ou dans le cadre de campagnes sociales organisées, la défense de la justice et des droits humains peut donner du sens à la vie et aider à s'assumer. 


\section{passer à l'action : projet d'apprentissage pratique}

On peut apprendre à changer le monde autour de soi, même à tout petits pas et dans les contextes les plus conservateurs. Les compétences apprises s'appliquent à de nombreuses situations.

Les jeunes peuvent être de puissants et efficaces agents du changement.

Les étapes ci-dessous sont importantes au changement social.

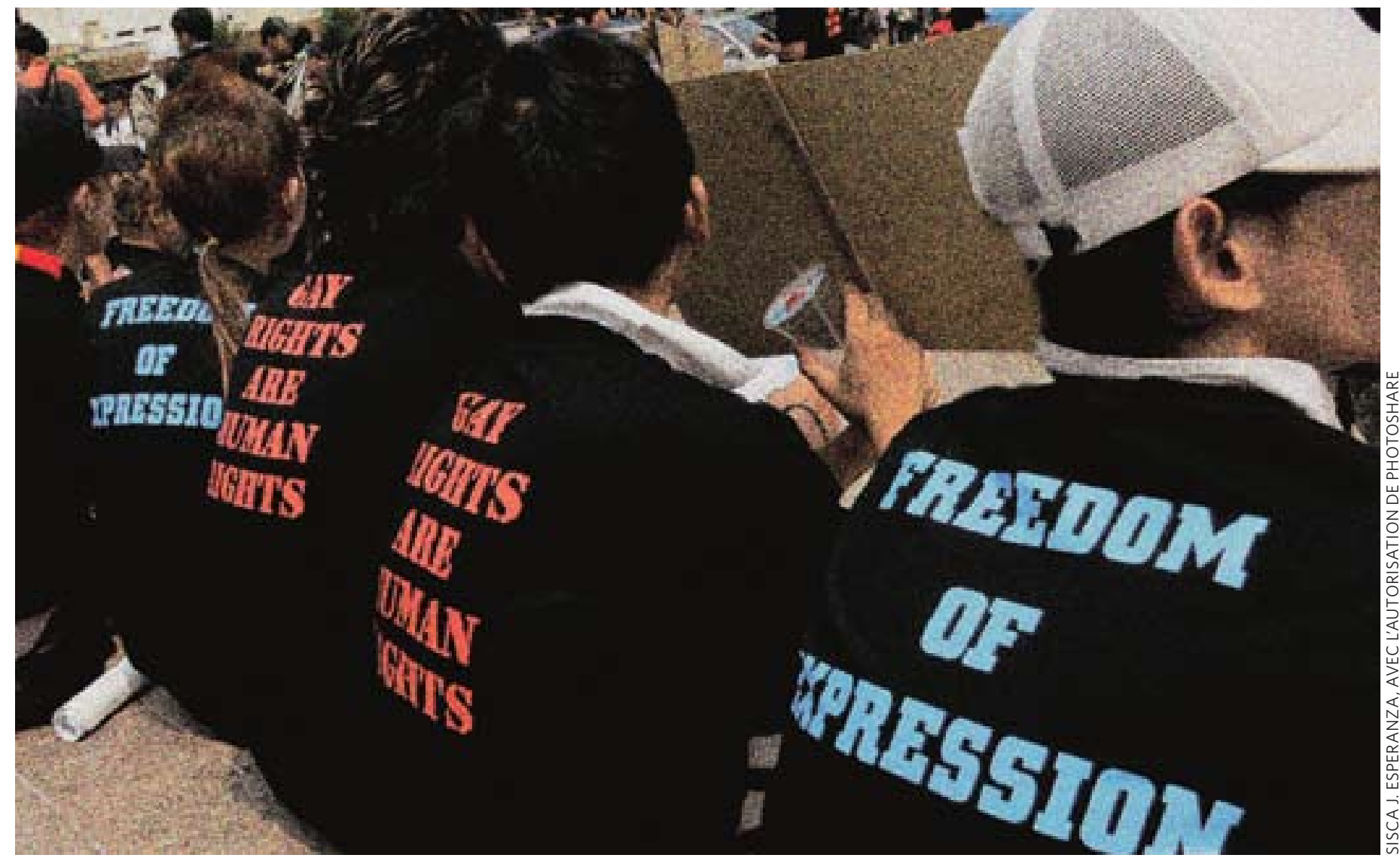

(8) 236 
Étape 1 : Identifiez une cause ou un problème qui vous tient à cœur. Réfléchissez à vos raisons. Il peut s'agir d'un problème qui vous concerne personnellement ou non, qui affecte quelques membres de votre famille ou de votre classe, une partie ou la totalité de votre communauté, ou bien encore d'un problème de grande envergure, à l'échelle nationale ou mondiale.

\section{Étape 2 : Recherchez et analysez l'information disponible sur le sujet et identifiez} toute personne ou organisation déjà vouée à la cause.

Par exemple :

- Renseignez-vous sur l'action locale ou nationale déjà entreprise, et sur la manière de vous joindre à l'initiative.

- Demandez à d'autres personnes ce qu'elles pensent du problème.

- Si possible, informez-vous davantage en lisant la documentation existante sur le problème.

- Identifiez les racines profondes du problème.

- Examinez les institutions, les politiques, les lois, les règles, les normes culturelles et les allocations de ressources qui font que le problème persiste (votre « carte politique » du problème).

Étape 3 : Définissez le changement recherché. Quels sont vos buts à court et à long terme? Faites preuve d'imagination mais soyez aussi réaliste.

Par exemple :

- changer vos propres attitudes ou comportements;

- informer et sensibiliser votre entourage ;

- encourager les gens à changer et à assumer la responsabilité du respect des droits d'autrui ;

- changer les règles d'une institution communautaire ; et

- faire en sorte que certaines personnes aient accès à un programme ou bénéficient d'un service dont elles ont besoin.
VOIR LE VOLUME D'ACTIVITÉS Activité 54

une cause qui me tient à coeur

Les élèves identifient une cause ou un problème social qui leur tient à cœur. 
Étape 4 : Cherchez à identifier une personne capable de vous aider, par ses conseils ou son aide directe, à prendre les mesures nécessaires au changement : un parent, le directeur de votre école, un dirigeant local ou un représentant élu.

- En parlant à d'autres personnes, vous pouvez les motiver à vous soutenir ou à participer à votre effort. Vous pouvez bénéficier de leurs compétences et de leurs conseils, et vous ne devez pas tout faire par vous-même.

- Veillez à prêter attention aux perspectives différentes de chacun.

\section{Étape 5 : Joignez-vous à une organisation ou recherchez des partenaires. Le} nombre fait la force!

- Les efforts collectifs - y compris la voix de ceux qui ne sont généralement pas entendus — reçoivent souvent plus d'attention et sont plus efficaces que les efforts individuels.

- Il est généralement plus facile de poursuivre le changement — même mineur — avec la coopération et le soutien moral d'autres personnes.

Étape 6 : Identifiez votre audience clé (les personnes que vous voulez atteindre). Rendez votre message aussi clair que possible.

\section{Étape 7 : Réfléchissez aux actions possibles et susceptibles de faire changer les} choses, sans oublier le meilleur moyen d'atteindre votre audience.

Par exemple :

- rencontrer le directeur de votre école ou un dirigeant communautaire local ;

- rédiger un article pour le journal de votre école ;

- organiser un concert ou une soirée dansante pour récolter des fonds pour le changement ;

- organiser des séances d'information dans la communauté ou dans vos classes ; et

- devenir actif ou organiser la participation politique locale, en rédigeant et distribuant par exemple des tracts, en organisant un spectacle de rue ou en aidant une campagne politique sensible à vos valeurs. 
Étape 8 : Discutez, étudiez et comparez soigneusement toutes les actions possibles. Choisissez celles les plus réalistes et efficaces et élaborez votre plan d'action.

[Voir l'unité 5, pp. 151-153.]

Étape 9 : Considérez les obstacles que vous risquez de rencontrer dans votre communauté.

Par exemple :

- Vous serez peut-être ignoré(e).

- Vous n’obtiendrez peut-être pas toutes les ressources dont vous avez besoin.

- Vous n’aurez peut-être pas suffisamment d'alliés.

Étape 10 : Veillez à ce que vos actions ne vous causent aucun préjudice, pas plus qu'à autrui. Demandez à un adulte de confiance et à d'autres jeunes leaders s'ils y voient des risques que vous n'avez peut-être pas considérés.

Quelques risques potentiels :

- Opprobre social ou sanction, à la maison, à l'école ou dans la communauté.

- Hostilité ou même agression physique de la part d'un opposant.

- Conséquences financières ou légales.

Étape 11 : Au besoin, révisez votre plan pour être sûr(e) qu'il ne portera atteinte à personne. 
Étape 12 : Identifiez vos opposants. Informez-vous de leurs arguments et activités. Préparez-vous à les contrer de manière juste et honnête.

\section{Étape 13 : Finalisez votre plan d'action.}

Étape 14 : Identifiez et assemblez les ressources humaines et matérielles nécessaires à la réalisation de votre plan.

Quelques exemples de ressources humaines:

- personnes pouvant aider à établir le contact avec le gouvernement local ;

- personnes sachant comment écrire un communiqué de presse ;

- personnes pouvant aider à lancer un site Internet ; et

- autres participants nécessaires à la communication de votre message.

Quelques exemples de ressources matérielles :

- argent ou dons de nourriture à servir ou à vendre ;

- équipements ou fournitures nécessaires (peuvent être empruntés) ; et

- assistance aux déplacements.

Étape 15 : Réalisez votre plan d'action. 


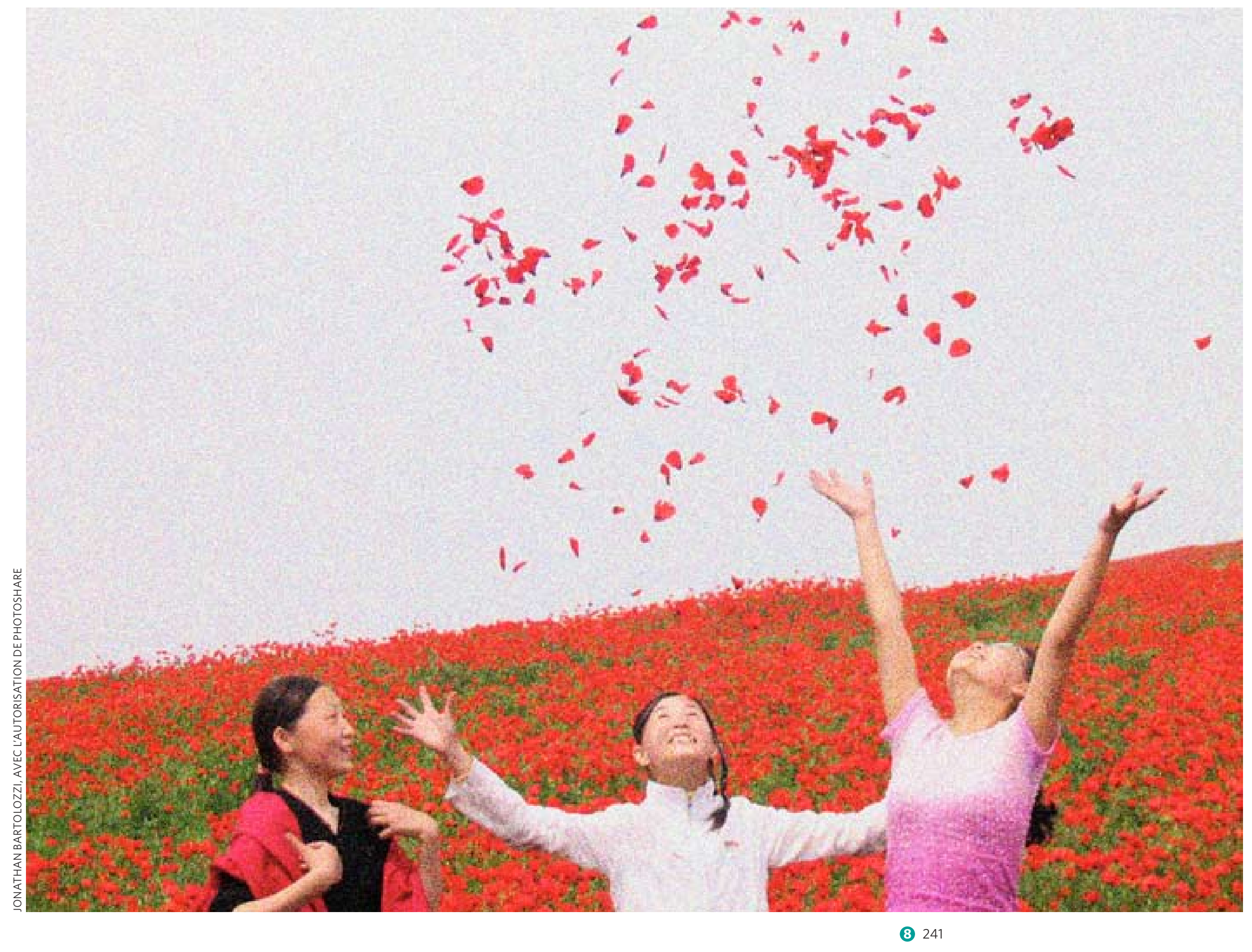


Étape 16 : Évaluez l'efficacité des tâches réalisées par rapport à vos objectifs à court et à long terme. Apportez les ajustements nécessaires et demandez, au besoin, le conseil et l'appui d'autres personnes.

Étape 17 : Ne vous découragez pas. Le changement social demande généralement un travail de longue haleine.

II est possible de changer les choses. II y a toujours quelque chose à faire, même à petite échelle. Ne perdez pas courage, même si la tâche paraît monumentale.

N'oubliez surtout pas, tandis que vous essayez de changer le monde autour devous, de rester juste et d'ancrer tous vos actes et échanges dans le respect. 
«Soyez le changement que vous voulez voir dans le monde. »

« Nul n'est tenu d'achever le travail commencé. Mais nul n'est libre non plus de l'abandonner. » — Adapté de Rabbi Tarfon, Mishnah, Avot

« Il faut avoir un rêve. Si vous n'avez pas de rêve, comment peut-il devenir réalité ?»

- Oscar Hammerstein, "Happy Talk" 


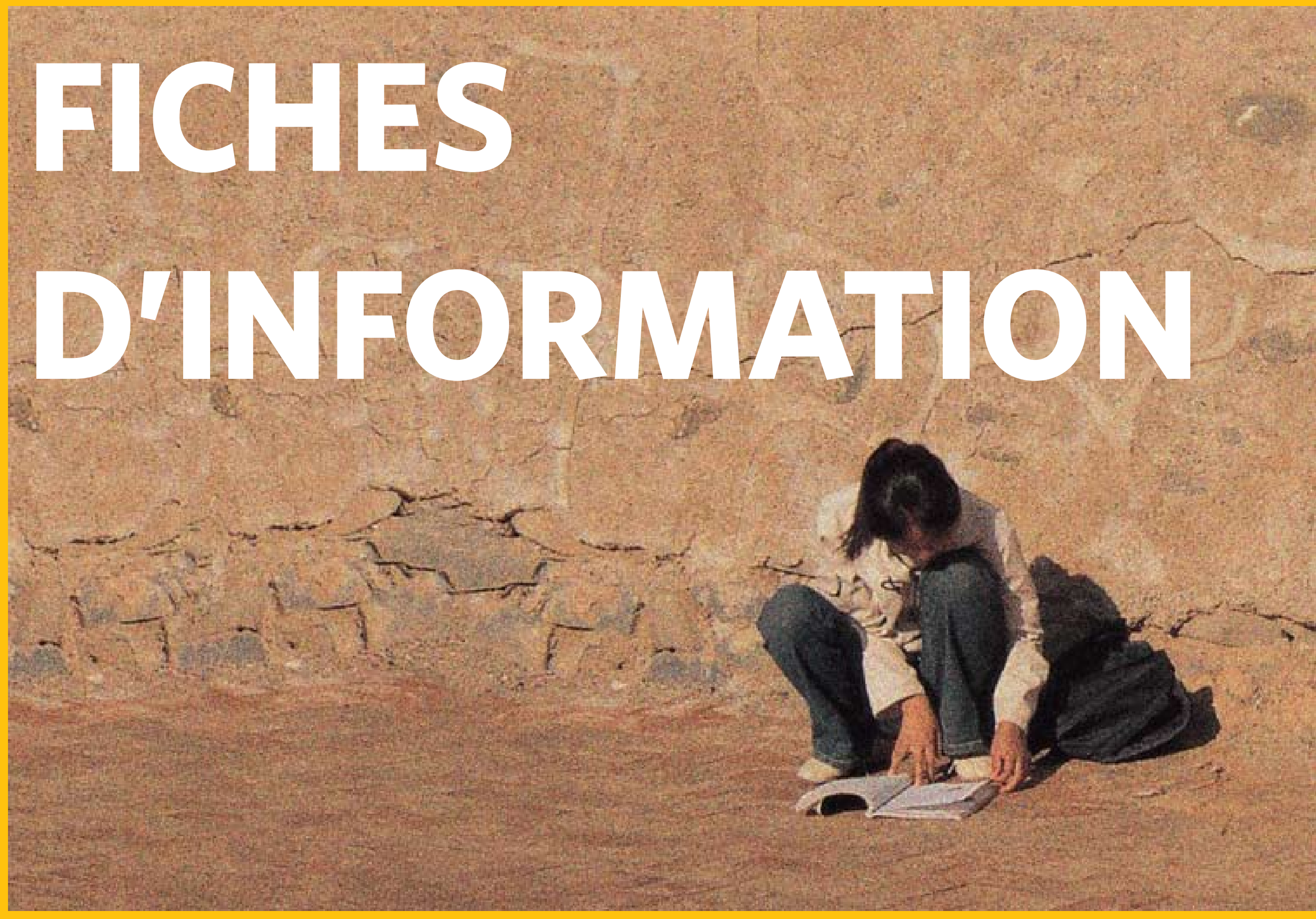


247 accords de l'ONU

248 accouchement et allaitement maternel

250 anatomie et plaisir sexuel

251 appareil sexuel et génital — féminin

253 appareil sexuel et génital - masculin

255 avortement

256 cancers de l'appareil génital

257 contraception d'urgence (CU)

258 cycle menstruel

260 infections de l'appareil génital non transmises par voie sexuelle

261 infections sexuellement transmissibles (IST)

263 méthodes contraceptives

267 mutilation génitale des filles

268 nutrition, activité physique et abus de substances toxiques

270 puberté féminine

272 puberté masculine

273 reproduction et grossesse

275 sélection du sexe

276 stérilité et procréation assistée

277 trafic sexuel

278 VIH (virus de l'immunodéficience humaine) et sida (syndrome d'immunodéficience acquise)

280 violence, y compris sexuelle, à l'encontre des femmes et des filles 


\section{Comment se concluent les accords et traités de l'ONU ?} L'ONU commence par convoquer une conférence mondiale. L'étape suivante consiste à préparer la rencontre de hauts représentants des pays, d'experts techniques et d'organisations non gouvernementales $(\mathrm{ONG})$, pour la négociation du contenu d'un document écrit. Les ONG n'ont pas de rôle ni de voix officiels, mais participent souvent activement à la définition de la teneur des documents. L'ONU organise la conférence officielle des délégations des États Membres, qui finalisent et approuvent les documents. Ces documents peuvent revêtir la forme de traités (obligatoires) ou de déclarations ou programmes d'action non obligatoires. Dans les deux cas, les États peuvent choisir de signer le document et promettre ainsi d'en respecter et exécuter les dispositions. Dès le moment où un État ratifie un traité, cet État y est légalement lié.

\section{En quoi les accords et traités de l'ONU font-ils une} différence?

Les États produisent régulièrement un rapport sur leur état de conformité (ou non) avec un traité sur les droits humains. Les violations de ces traités peuvent souvent être jugées au niveau des tribunaux nationaux ou relèvent dans certains cas de la compétence des autorités onusiennes ou régionales sur les questions des droits humains. Beaucoup d'ONG font référence aux accords internationaux dans leur activisme en faveur de meilleures lois, politiques et programmes dans leur pays. Elles assument aussi parfois la responsabilité de la surveillance de conformité de leur État. Les accords d'aide ou de commerce international sont parfois liés aussi au respect de certaines conventions sur les droits humains.

\section{Parmi les plus grands documents officiels sur la question} des droits humains :

La Déclaration universelle des droits de l'homme, adoptée par l'Assemblée générale de l'ONU en 1948, reconnaît le principe que « tous les êtres humains naissent libres et égaux en dignité et en droits » et énumère les droits humains garantis à tous. Notamment, le droit à la vie et à la sécurité, à la liberté personnelle, économique, sociale et culturelle, à l'éducation et au travail. Avec le Pacte international relatif aux droits économiques, sociaux et culturels et le Pacte international relatif aux droits civils et politiques, elle forme la Charte internationale des droits de l'homme.

La Convention internationale des droits de l'enfant (CIDE), adoptée en 1989, vise à protéger les droits individuels des enfants : à la protection contre la violence, au meilleur état de santé possible et à l'éducation, notamment. La CIDE énumère les droits et les obligations des familles et des gouvernements à assurer ces garanties.

\section{La Convention sur l'élimination de toutes les formes de discrimination à l'égard des femmes, adoptée en 1979,}

reconnaît les droits des femmes et cherche à mettre fin à la discrimination des femmes à tous les niveaux de la société. Elle couvre les droits concernant la participation à la vie politique, la santé, l'éducation, l'emploi, le mariage, la famille et l'égalité devant la loi. La Quatrième Conférence sur les femmes, (Beijing, 1995) a recentré les efforts pour l'égalité des femmes, adoptant un Programme d'action dont les thèmes touchent à l'autonomisation des femmes, la pauvreté, la fillette et les violences faites aux femmes.

\section{La Conférence internationale sur la population et le} développement (CIPD), tenue au Caire en 1994, a adopté un Programme d'action définissant les priorités en matière de démographie et développement, couvrant la santé sexuelle et génésique, l'éducation, les droits humains, l'environnement, la migration, le VIH et le sida. Les objectifs de la CIPD incluent l'accès universel aux soins de santé génésique et à l'éducation, surtout pour les filles, et la réduction de la mortalité infantile et maternelle. Ce document offre un instrument important aux défenseurs, civils et gouvernementaux, des droits génésiques.

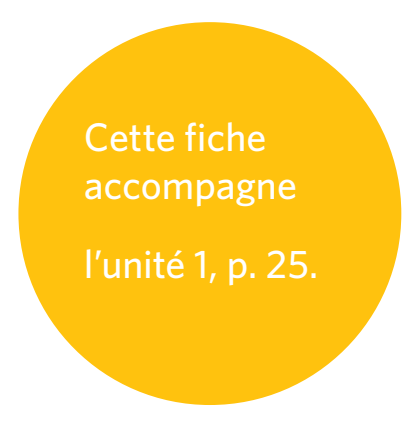




\section{Que se passe-t-il pendant l'accouchement ?}

Quand une femme est sur le point d'accoucher, son corps se met en «travail». Le travail commence souvent par l'un ou plusieurs des symptômes suivants : écoulement vaginal muqueux clair ou rose ; écoulement vaginal du liquide amniotique et contractions de l'utérus perçues comme un durcissement du ventre. Les contractions deviennent de plus en plus intenses. Le col de l'utérus s'ouvre et les contractions utérines aident à expulser le bébé à travers le col et le vagin. Le travail dure généralement entre 5 et 18 heures, mais sa durée varie d'une femme à l'autre. Il devient généralement douloureux (bien que la perception de la douleur varie aussi et puisse dépendre de la préparation de la femme pendant la grossesse), épuisant et parfois aussi source d'anxiété. Beaucoup de femmes y vivent cependant une expérience merveilleuse et inoubliable.

\section{Qu'est-ce qu'une césarienne ?}

Une césarienne est une méthode chirurgicale d'accouchement, qui consiste à pratiquer une incision à travers l'abdomen et l'utérus de la mère pour en extraire l'enfant. L'opération se pratique généralement lorsqu'un accouchement vaginal mettrait la vie ou la santé de la mère ou de l'enfant en danger. Il arrive qu'elle soit aussi pratiquée au bénéfice du médecin plutôt que de la femme ou de l'enfant, notamment pour permettre l'accouchement à un moment qui lui convient. Les césariennes inutiles peuvent accroître les risques pour la santé de la mère ou de l'enfant, y compris le risque de mort.
De quelle aide ont besoin les femmes pour accoucher ? Où qu'elle accouche - chez elle, dans un dispensaire ou à l'hôpital — la femme a besoin de l'aide d'une personne qualifiée telle qu'une sage-femme ou un médecin. De bonnes conditions et l'accès à des soins d'urgence sont aussi nécessaires en cas de complications. Les conditions et pratiques d'accouchement varient dans le monde. Dans certains pays, toutes les femmes ont accès à une assistance qualifiée; dans d'autres, la plupart accouchent chez elles sans l'aide d'une personne qualifiée, dans des conditions inadéquates et sans soins de secours en cas d'urgence. En certains endroits, les femmes qui accouchent reçoivent l'aide d'autres femmes ; ailleurs, leur mari ou partenaire les accompagnent. Certaines femmes accouchent seules, sans aucune assistance.

\section{Quelles sont les conséquences d'un accouchement sans assistance qualifiée?}

Parce que des complications se présentent dans environ $15 \%$ des accouchements, le manque d'assistance qualifiée et d'accès à des soins d'urgence est la cause de maladies et de morts inutiles. Chaque année, plus d'un demi-million de femmes meurent et 8 à 15 millions souffrent de graves lésions, telles que la fistule obstétricale, suite à une grossesse ou un accouchement. Presque tous les décès enregistrés le sont dans le monde en développement, et presque tous seraient évitables sous assistance qualifiée à l'accouchement et accès opportun à des soins d'urgence en cas de complications, pratique de la planification familiale pour éviter les grossesses non planifiées et accès à l'avortement sans risques. 


\section{Qu'est-ce que la fistule obstétricale et comment affecte -t-elle les femmes?}

Une fistule obstétricale est une ouverture entre le vagin et la vessie ou le rectum, parfois les deux, qui permet l'écoulement continu d'urine et/ou de matières fécales. Quand le travail d'une femme ne progresse pas et qu'elle n'a pas accès à une césarienne, la pression prolongée de la tête de l'enfant sur le tissu entre la vessie et le vagin ou le rectum peut provoquer une ouverture, appelée fistule.

Dans la plupart des cas, l'enfant meurt sous l'effet du travail prolongé. Pour la femme, l'odeur d'urine ou fécale est constante et humiliante. Beaucoup de femmes et de filles sont abandonnées par leur mari et évitées par leur famille, leurs amies et leur communauté. Non traitée, la fistule peut être cause de problèmes médicaux chroniques tels que la formation d'ulcères, les maladies rénales et les lésions nerveuses au niveau des jambes.

Près de 100 mille cas de fistule obstétricale surviennent chaque année, principalement en Afrique subsaharienne et en Asie. La fistule affecte de manière disproportionnée les femmes et les filles pauvres, en particulier celles dont le bassin est étroit parce que leur croissance n'est pas terminée ou a été compromise par la malnutrition. Bien que la fistule soit généralement chirurgicalement réparable, on estime à deux millions le nombre de femmes vivant avec une fistule non traitée.

\section{Importance de l'allaitement maternel}

Le lait maternel est le seul aliment qui convient parfaitement à l'enfant, et en particulier au nouveau-né. Le premier lait, appelé colostrum, de couleur jaune, est riche en nutriments et en anticorps, pour protéger le nouveau-né contre les maladies et les infections. Le colostrum aide aussi à nettoyer l'intestin du bébé. L'allaitement au sein dans l'heure qui suit la naissance aide à arrêter le saignement de l'utérus et favorise la production de lait. De plus, le lait maternel est toujours sain, prêt et à bonne température. Il rapproche la mère de son enfant et il ne coûte rien. (L'OMS recommande l'allaitement maternel exclusif pendant les six premiers mois de la vie, puis, si possible, sa combinaison avec l'apport d'aliments sûrs et nourrissants.)

\section{Que peut faire une femme enceinte séropositive à VIH} pour réduire le risque de transmission du virus à l'enfant ?

Une femme séropositive enceinte peut transmettre le virus à son enfant pendant la grossesse, le travail, l'accouchement ou l'allaitement. Si elle allaite sans prendre de médicaments préventifs, le risque de transmission est de 20 à $45 \%$. Mais il existe aujourd'hui des médicaments préventifs efficaces contre la transmission du VIH de la mère à l'enfant pendant et après la grossesse. Une femme séropositive enceinte ou qui désire le devenir doit demander l'avis d'un médecin sur les médicaments à prendre et à quel moment. Il convient aussi pour les mères séropositives de parler avec leurs prestataires des options d'alimentation de leur nouveauné qui puissent réduire le risque de transmission par le lait maternel. Si la mère n'a pas régulièrement accès à l'eau potable et au lait maternisé, il vaut mieux allaiter exclusivement pendant les six premiers mois, puis sevrer l'enfant tout d'un coup. La combinaison de l'allaitement maternel et du lait maternisé ou des aliments pour bébés présente le plus grand risque de transmission de la mère à l'enfant. En prenant des médicaments préventifs et en suivant les directives appropriées, la mère séropositive peut réduire le risque. 

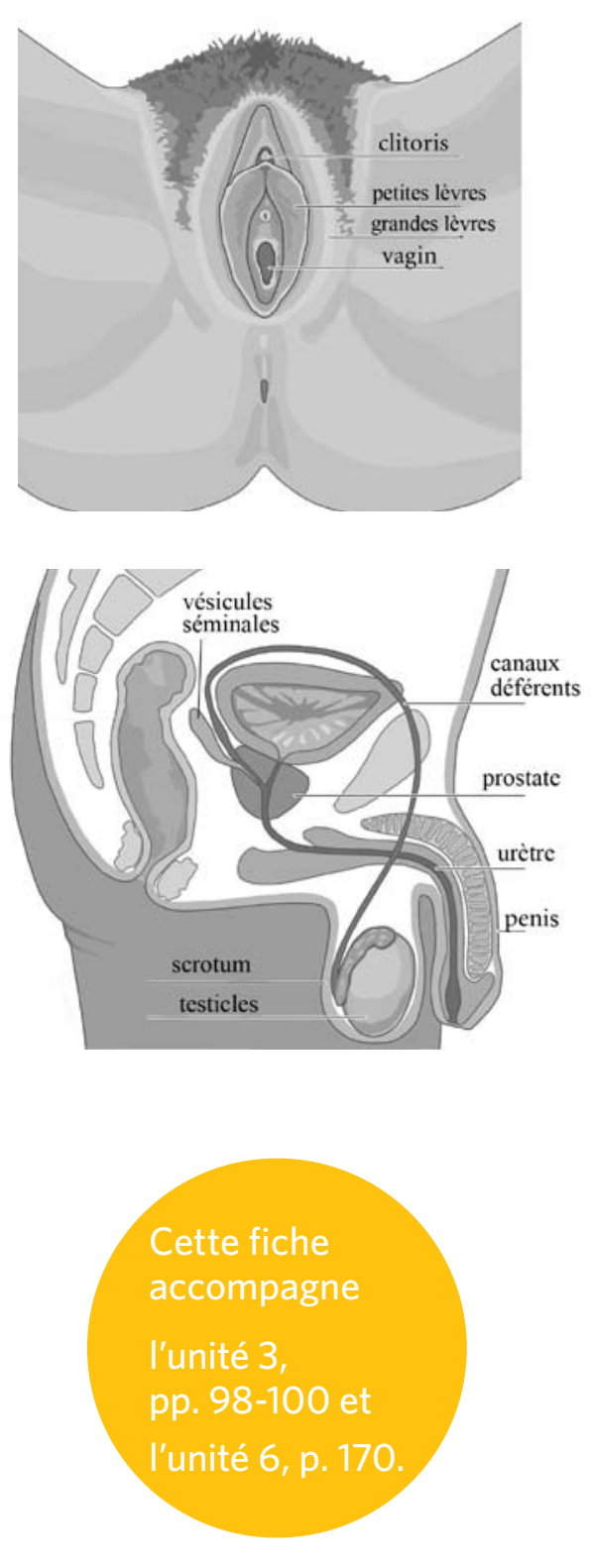

La réponse sexuelle est unique à chacun. Elle est souvent affectée par le vécu, les attitudes culturelles et les sentiments envers le partenaire sexuel et la situation particulière. L'âge, l'état physique (y compris la maladie ou la fatigue), l'alcool, la drogue ou la prise de médicaments et l'état affectif (y compris le sentiment de bien-être ou l'anxiété) peuvent affecter la réponse sexuelle. Ces facteurs sont autant d'exemples du rôle essentiel du cerveau dans l'excitation sexuelle.

\section{Que se passe-t-il lors de l'excitation sexuelle?}

Lexcitation sexuelle désigne la réponse du corps au désir, à l'anticipation et à la participation à l'acte sexuel. Elle commence par une stimulation sexuelle causée, par exemple, par une caresse, une odeur, une image, un goût, un son, une pensée ou un fantasme qui évoque un sentiment érotique. Toucher ou caresser le pénis ou le scrotum est souvent source d'excitation masculine. Côté féminin, l'organe le plus sensible est le clitoris, riche en terminaisons nerveuses et dont la seule fonction est le plaisir sexuel. Le pénis comme le clitoris se gonflent de sang et se dressent en réponse à l'excitation. Cet engorgement en accroît la taille et la sensibilité.

L'excitation sexuelle implique aussi la réponse d'autres organes. Le cœur bat plus vite, les muscles se raidissent, la tension artérielle monte, la peau rougit et le bout des seins durcit parfois. Chez les femmes, le vagin s'humidifie et s'étend. Chez les hommes, le scrotum se resserre contre le corps, une glande émet un liquide qui nettoie l'urètre et la vessie se ferme pour éviter le mélange d'urine et de sperme. Pendant l'expérience sexuelle, le niveau d'excitation peut augmenter et baisser. L'excitation peut durer quelques minutes ou plusieurs heures.

Si la stimulation sexuelle continue, l'excitation peut s'intensifier et mener à l'orgasme. Juste avant l'orgasme, la respiration, la tension artérielle et le rythme cardiaque augmentent. L'excitation et l'arrivée à l'orgasme prennent souvent plus de temps chez les femmes que chez les hommes. Bien que certaines femmes perçoivent les zones sensibles du vagin (le "point $G$ »), la plupart atteignent l'orgasme par stimulation directe du clitoris plutôt que par pénétration.

\section{Que se passe-t-il pendant l'orgasme?}

L'orgasme est le point culminant du plaisir sexuel. Il s'accompagne d'une série de contractions rythmiques dans la région du bassin, de contractions et de sensations de plaisir dans le corps et d'un relâchement soudain de la tension sexuelle. Avec l'orgasme, le corps dégage aussi des substances chimiques appelées endorphines, à l'origine d'un sentiment de bien-être. L'expérience de l'orgasme varie grandement d'une personne à l'autre et d'un orgasme à l'autre. Certaines femmes peuvent avoir plusieurs orgasmes en peu de temps, et même en ressentir le désir pressant. Le vagin se lubrifie davantage après l'orgasme.

Chez les hommes, l'orgasme s'accompagne généralement mais pas toujours de l'éjaculation. Lors de celle-ci, la prostate, les vésicules séminales et les canaux déférents se contractent et émettent leurs sécrétions liquides, qui se mélangent aux spermatozoïdes produits par les testicules pour former le sperme. À ce moment, les hommes sentent que l'éjaculation est irréversible. Les muscles du bassin se contractent et expulsent le sperme par le pénis à travers l'urètre. Après l'éjaculation, l'érection n'est plus possible pendant un certain temps, variant de quelques minutes à 24 heures, suivant l'âge.

\section{Que se passe-t-il en cas d'excitation sexuelle sans \\ orgasme?}

Après l'orgasme, le sang quitte les organes congestionnés. La tension artérielle et le rythme cardiaque reviennent à leurs niveaux de repos et la tension musculaire s'apaise. En l'absence d'orgasme, l'afflux de sang peut causer une gêne temporaire qui disparaît d'elle-même, généralement en moins d'une heure, sans effet durable. 


\section{Qu'est-ce que l'appareil sexuel et génital ?}

L’appareil sexuel et l'appareil génital ont certains organes en commun mais pas tous. L'appareil sexuel comprend ceux impliqués dans l'activité et le plaisir sexuels ; l'appareil génital féminin fait référence à ceux impliqués dans la grossesse et l'accouchement.

\section{Description et fonction des organes de l'appareil sexuel et génital féminin}

La vulve inclut tous les organes génitaux externes visibles de la femme (voir l'illustration ci-dessous).

Le clitoris (1) est un petit organe en forme de bourgeon recouvert de tissu en forme de petit « capuchon".

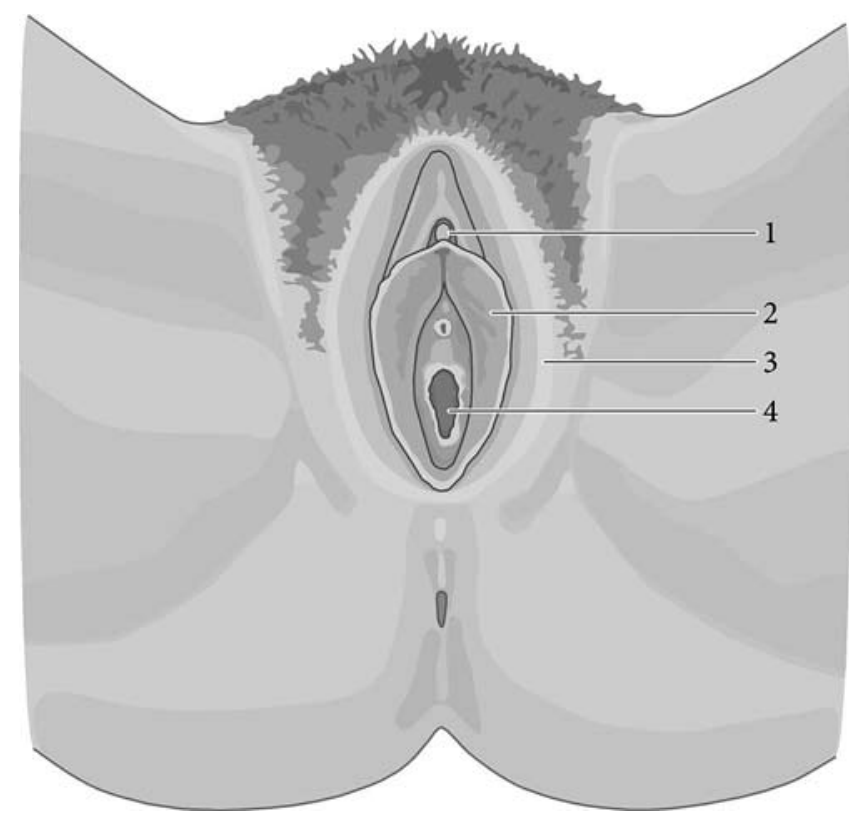

Le seul rôle du clitoris est le plaisir sexuel de la fille ou de la femme : il contient un riche réseau de terminaisons nerveuses fort sensibles. Lors de l'excitation sexuelle et pendant l'orgasme, le clitoris (et les organes génitaux en général) se gonflent de sang, causant l'érection du clitoris. Les femmes peuvent sentir des contractions vaginales pendant l'orgasme.

Les grandes lèvres (\#3) couvrent et protègent l'orifice vaginal. Les petites lèvres (\#2) gonflent aussi lors de l'excitation sexuelle.

Le vagin (\#4) est un canal élastique menant de la vulve au col et à l'utérus. Le vagin d'une femme sexuellement excitée se lubrifie. Pauvre en terminaisons nerveuses, le vagin est peu sensible. Lors de rapports sexuels vaginaux, le pénis pénètre dans le vagin. Si l'homme éjacule, le sperme entre dans le vagin et remonte, à travers le col, jusqu'à l'utérus et aux trompes de Fallope, où la fécondation a lieu en présence d'un ovule. Le flux menstruel quitte le corps à travers le vagin, de même que l'enfant au moment de l'accouchement. Le vagin s'autonettoie. Il n'est pas nécessaire de le doucher et il ne faut pas y introduire de substances pour le dessécher ou le resserrer (elles peuvent être néfastes).

L'hymen (non illustré) est une fine membrane qui obstrue partiellement l'orifice vaginal. Il se déchire aisément lors de la pratique de sports ou d'autres activités physiques et peut se détendre si la fille utilise des tampons. Un hymen déchiré ou détendu n'indique donc pas si la fille ou la femme a eu des rapports sexuels.

Le col utérin ou col de l'utérus (\#5) est la partie inférieure de l'utérus qui s'étend dans la partie supérieure du vagin. L’orifice du col relie le vagin à l'utérus. Le flux menstruel s'écoule, depuis l'utérus, à travers cet orifice. Le sperme le franchit pour atteindre l'utérus. Le col sécrète une glaire

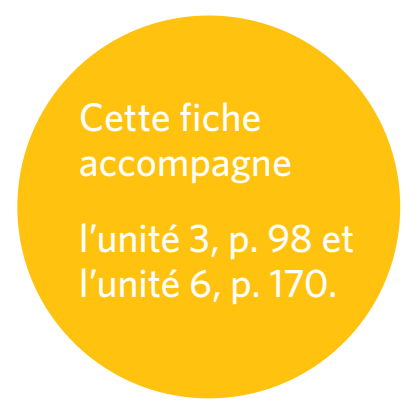




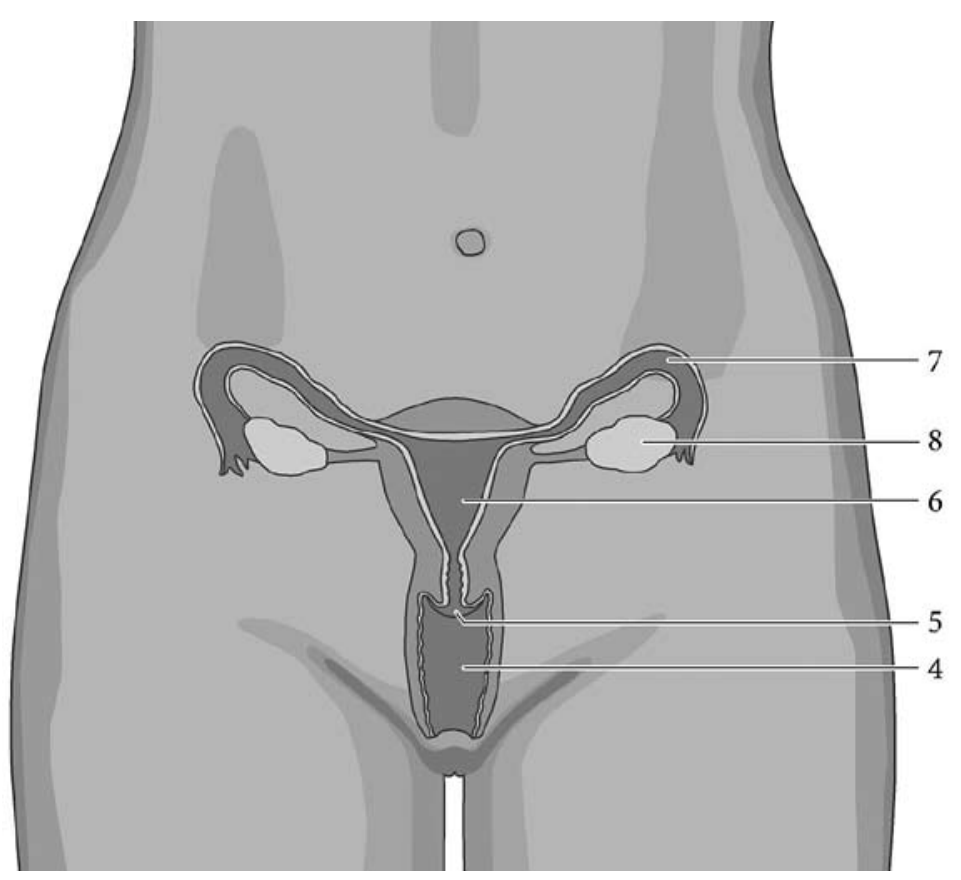

qui aide le sperme à pénétrer dans l'utérus. La glaire cervicale change pendant le cycle menstruel. Les femmes peuvent apprendre à reconnaître leur période féconde selon les caractéristiques de leur glaire. Lors de l'accouchement, le col se détend pour laisser passer l'enfant.

L'utérus (\#6) est un organe musculaire creux en forme de poire inversée qui repose par-dessus la vessie. Sa muqueuse (l'endomètre) s'épaissit en s'engorgeant de sang et de tissu pendant la première phase du cycle menstruel. En l'absence

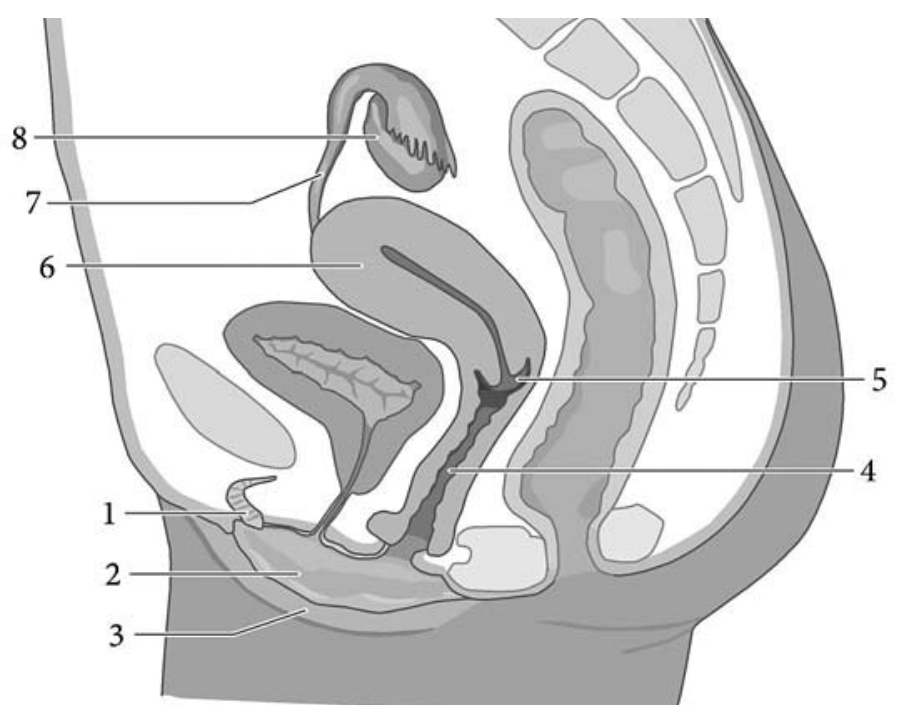

d'embryon, la muqueuse se décompose et forme le flux menstruel. Cependant, si un embryon s'y niche, un foetus se développe dans l'utérus.

Les trompes de Fallope (\#7) sont deux tubes étroits de 10 à $12 \mathrm{~cm}$ de long à travers lesquels l'ovule passe de l'ovaire à l'utérus et dans lesquels il peut être fécondé.

Les ovaries (\#8), deux organes représentant chacun la taille d'une amande ou d'un raisin, conservent les ovules immatures dans leurs follicules, produisent et sécrètent les hormones féminines (œstrogène et progestérone) et libèrent les ovules mûrs. 


\section{Qu'est-ce que l'appareil sexuel et génital ?}

L'appareil sexuel et l'appareil génital ont certains organes en commun mais pas tous. L'appareil sexuel comprend ceux impliqués dans l'activité et le plaisir sexuels. L'appareil génital masculin inclut ceux qui produisent, conservent ou transportent les spermatozoïdes nécessaires à la reproduction.

\section{Description et fonction des organes de l'appareil sexuel} et génital masculin

Le penis (\#1) remplit plusieurs fonctions. Il participe à la sensation sexuelle, correspondant en ce sens au clitoris dela femme. Le pénis peut se remplir de sang, durcir et se mettre en érection en réponse à la stimulation sexuelle. La fonction reproductrice du pénis consiste à déposer le sperme dans

vagin. Sa troisième fonction est la sécrétion d'urine. L'extrémité du pénis est recouverte d'une couche de peau appelée

"prépuce ». La circoncision, ablation du prépuce, est pratiquée dans de nombreuses populations.

Les testicles (\#2), deux glandes en forme de boules contenues dans le scrotum, produisent les spermatozoïdes et l'hormone testostérone mâle. Le scrotum et les testicules sont sensibles au toucher et peuvent être source de plaisir.

Le scrotum (\#3), ou les bourses, poches de peau lâche, contient et protège les testicules. Froid, il se resserre contre le corps pour garder les testicules à bonne température pour la production des spermatozoïdes.

L'urètre (\#4) est un tube qui s'étend de la vessie à la pointe du pénis. Il s'agit du conduit par lequel le sperme (mélange de liquide séminal, liquide prostatique et spermatozoïdes) est propulsé lors de l'éjaculation. L'urine s'écoule aussi par ce conduit mais une valve, au fond de la vessie, se ferme lorsque

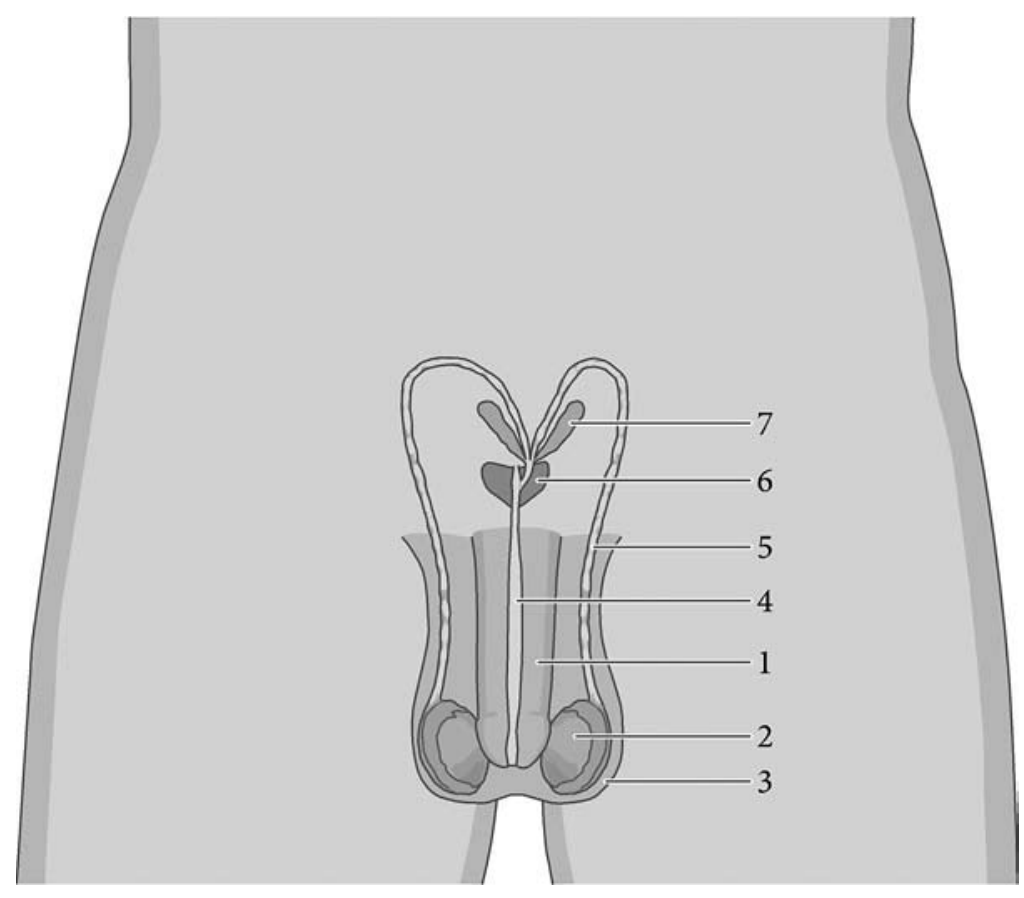

le pénis est en érection pour éviter le passage d'urine pendant l'éjaculation.

L'épididyme (non numéroté mais visible) est un tube pelotonné sur lui-même, qui repose au-dessus de chaque testicule et conserve les spermatozoïdes mûrs jusqu'au moment de l'éjaculation.

Les canaux déférents(\#5) sont les deux conduits fins et longs qui transportent les spermatozoïdes vers l'urètre. Ils se contractent lors de l'éjaculation.

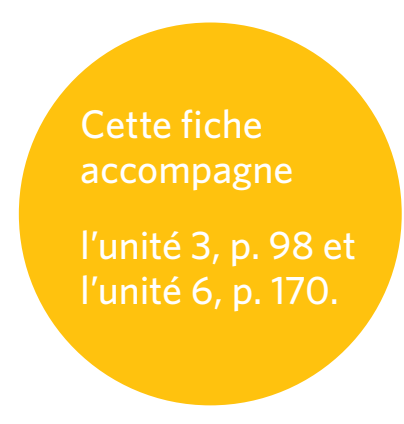


La prostate (\#6) est une glande dont la sécrétion entre dans la composition du sperme, dont elle favorise le mouvement. Pour beaucoup d'hommes, la stimulation de la prostate est source de plaisir sexuel.

Les vésicules séminales (\#7) produisent une grande partie du liquide entrant dans la composition du sperme. Ce liquide nourrit les spermatozoïdes.

Les glandes de Cowper (non indiquées) produisent un épais liquide alcalin, appelé « liquide pré-éjaculatoire », dont le rôle est de neutraliser l'acide présent dans l'urètre avant l'éjaculation.

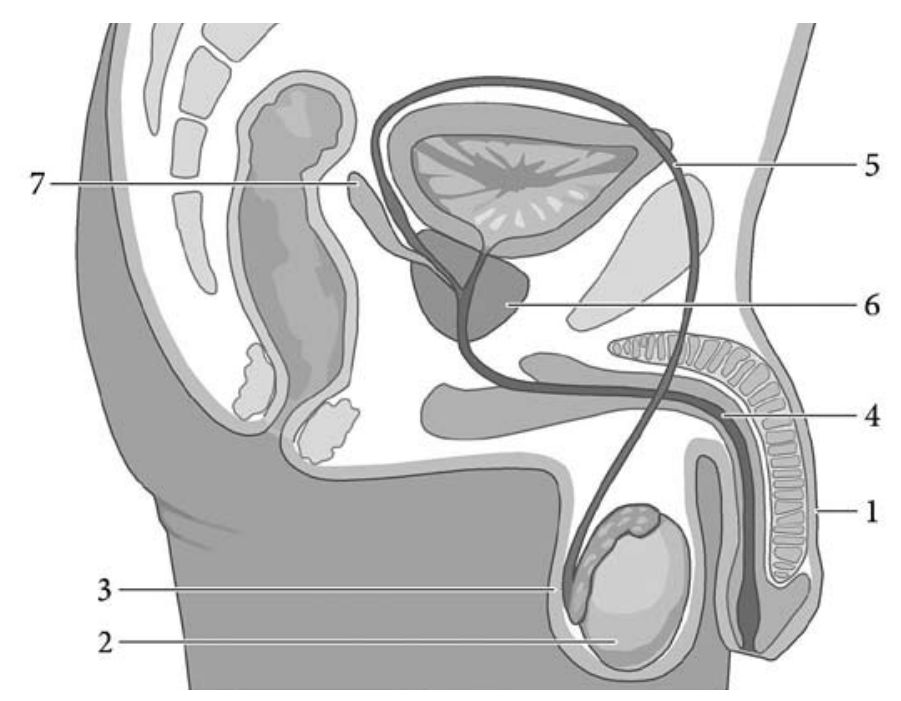




\section{Qu'est-ce que l'avortement ?}

Lavortement marque la fin d'une grossesse avant que le foetus ne soit viable. Une grossesse qui s'interrompt d'elle-même est un avortement spontané ou une fausse couche. L'avortement peut aussi être provoqué quand une femme ou une fille désire interrompre une grossesse. On parle alors d'avortement provoqué ou d'interruption volontaire de grossesse (IVG). La décision d'avorter peut être prise pour différentes raisons, personnelles ou de santé.

\section{Fréquence de l'avortement}

L'avortement est très courant. Environ une grossesse sur cinq aboutit sur un avortement spontané (souvent avant que la femme ne sache même qu'elle est enceinte). Un nombre à peu près égal - environ une grossesse sur cinq — aboutit sur un avortement provoqué. La plupart des avortements, spontanés ou provoqués, interviennent avant la fin de la huitième semaine de gestation.

\section{Comment se pratique l'avortement provoqué (IVG) ?}

Il existe deux grandes méthodes d'avortement provoqué. La première est une brève procédure effectuée par un prestataire de soins de santé, au moyen d'instruments servant à aspirer ou extraire le contenu de l'utérus (la muqueuse riche en sang où se loge l'embryon ou, à un stade plus avancé, le foetus; cette muqueuse s'élimine naturellement pendant les règles quand la femme n'est pas enceinte). La seconde méthode implique la prise d'une ou plusieurs pilules qui provoquent des contractions utérines et le saignement menstruel. La femme expulse ainsi la muqueuse utérine et, avec elle, l'embryon. Il arrive qu'une partie de la muqueuse reste dans l'utérus. Il faut alors procéder à l'aide d'instruments médicaux (comme décrit plus haut). Les deux méthodes sont efficaces si elles sont accomplies dans des conditions adéquates.

\section{L'avortement est-il sûr?}

Pratiqué dans de bonnes conditions, l'avortement est une procédure simple et sûre. Elle doit être effectuée par un prestataire de soins qualifié doté d'un équipement adéquat et selon une technique et des normes d'hygiène appropriées. L'avortement est le plus sûr en début de grossesse. Pendant la première moitié de la grossesse (moment où se pratiquent presque toutes les IVG), la procédure est plus sûre que la grossesse et l'accouchement.

En beaucoup d'endroits, pourtant, l'avortement est pratiqué par des personnes non qualifiées, souvent dans des conditions non conformes aux normes médicales les plus minimes. La procédure fait alors courir de grands risques. À l'échelle mondiale, près de la moitié des IVG ne sont pas médicalisées et, de celles-ci, presque toutes (95\%) sont pratiquées dans les pays en développement. Le risque est souvent le plus grand dans les milieux ruraux. Près de 70000 femmes et filles meurent chaque année, inutilement, des complications d'un avortement non médicalisé.

\section{L'avortement est-il légal ?}

Dans la plupart des pays, l'avortement provoqué est légal dans certaines circonstances ou dans toutes. Il est généralement plus sûr quand il est légal. Quand il est criminalisé, les procédures à risques sont courantes et les femmes et les filles en souffrent les complications.

Pénaliser l'avortement n’en réduit pas la fréquence. En fait, certains des pays dont les lois sont les plus restrictives présentent les plus hauts taux d'avortement.

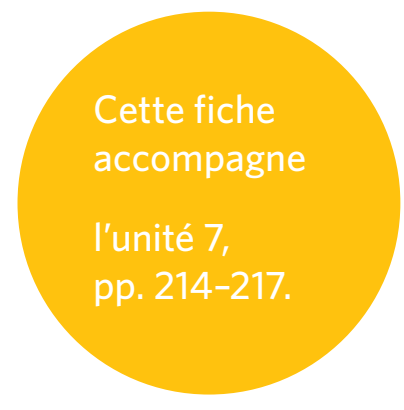


Les cancers de l'appareil génital peuvent affecter les hommes comme les femmes. Quelques-uns des plus courants sont décrits ci-dessous.

\section{Cancers de l'appareil génital féminin}

Le cancer du sein est le plus courant et le plus mortel chez les femmes des pays développés et en développement. Il représente 1/10e des nouveaux cancers déclarés chaque année dans le monde. En deuxième place, le cancer du col utérin frappe principalement dans les pays en développement où on dénombre, faute de dépistage adéquat, les quatre cinquièmes des cas et des décès résultants. Pour tous les types de cancer, le diagnostic et le traitement précoces rendent la guérison plus probable.

\section{Dépistage du cancer du sein}

Le cancer du sein se dépiste par examen manuel et mammographie. Les femmes de plus de 20 ans devraient s'examiner et se palper les seins une fois par mois pour y détecter les changements. Les écoulements teintés de sang ou purulents des mamelons ou les nouvelles grosseurs dures doivent être examinés par un prestataire de santé. Les directives de dépistage du cancer du sein (examens et procédures cliniques) varient largement, suivant les facteurs de risque individuels et les ressources locales. Le mammogramme est une radiographie du sein capable de détecter les changements potentiellement cancéreux. La mammographie ne détecte cependant pas tous les cancers et peut aussi détecter des anomalies non cancéreuses, comme déterminé par d'autres tests. En cas d'anomalie, une biopsie (analyse en laboratoire) est effectuée pour déterminer s'il s'agit d'un cancer. Huit grosseurs sur 10 ne sont pas cancéreuses. Le cancer du sein peut être traité par une intervention chirurgicale, par radiothérapie et/ou par chimiothérapie (médicaments).

\section{Prévention du cancer du col utérin}

Le cancer du col de l'utérus est pour la plupart causé par certains types de papillomavirus (PVH ou HPV, voir la la fiche relative aux IST). Il existe un vaccin contre certains $\mathrm{HPV}$, à administrer de préférence aux filles jeunes, avant qu'elles ne deviennent sexuellement actives. Le préservatif réduit aussi le risque d'infection. Un frottis (test de Papanicolaou), effectué lors d'un examen pelvien peut détecter les cellules ou lésions précancéreuses, aisément traitables. Il convient, si possible, de tester régulièrement les femmes sexuellement actives.

\section{Cancer de l'ovaire}

Le cancer de l'ovaire affecte davantage les femmes des pays développés et de plus de 55 ans. Il ne présente souvent aucun symptôme avant d'atteindre un stade relativement avancé. Les méthodes diagnostiques et de traitement en sont encore à un stade de développement initial.

\section{Cancers de l'appareil génital masculin}

L’organe génital masculin le plus vulnérable au cancer est la prostate. Le cancer de la prostate affecte généralement les hommes plus âgés et il progresse lentement. Le cancer du testicule affecte davantage les hommes jeunes (de 18 à 35 ans); il est cependant moins courant et est généralement guérissable s'il est détecté tôt. Les hommes peuvent aussi apprendre à se palper pour identifier les grosseurs anormales au niveau des testicules. Quelques souches de papillomavirus (mais pas les souches qui causent les verrues) peuvent mener un cancer du pénis ou de l'anus. 


\section{Qu'est-ce que la contraception d'urgence ?}

La contraception d'urgence $(\mathrm{CU})$ fait référence aux méthodes qui permettent d'éviter une grossesse après un rapport sexuel non protégé. Par exemple : après un échec contraceptif (rupture de préservatif), usage incorrect d'une méthode, acte sexuel sans contraception ou viol. La contraception d'urgence permet d'éviter une grossesse si elle est prise ou pratiquée dans les cinq jours qui suivent le rapport non protégé. Son efficacité est d'autant plus grande qu'elle est prise ou pratiquée tôt durant cette période. La contraception d'urgence n'est pas un avortement.

\section{Quelles sont les méthodes contraceptives d'urgence ?} Pilules - Les pilules progestatives (à base d'une hormone contenue dans de nombreuses pilules contraceptives) sont la méthode de CU la plus courante. En 2009, la recommandation est de prendre une pilule contenant $1,5 \mathrm{mg}$ de cette hormone ou deux pilules de $0,75 \mathrm{mg}$ chacune. La ou les pilules peuvent être prises en une ou deux doses, dont la première aussitôt que possible après le rapport sexuel non protégé et la seconde, 12 heures plus tard. La méthode est parfois présentée en tant que telle sous emballage de deux pilules. Elle est parfois appelée «la pilule du lendemain ». La prise de pilules contraceptives ordinaires à forte dose pendant une période limitée peut aussi être utile, mais le dosage dépend du type et de la marque et doit être déterminé par un prestataire de soins qualifié.

Stérilet - Autre méthode contraceptive d'urgence, le stérilet cuivre peut être introduit dans l'utérus par un prestataire de soins qualifié dans les cinq à sept jours suivant l'acte sexuel non protégé. Le stérilet n'est cependant pas indiqué pour les femmes exposées au risque d'une infection sexuellement transmissible. Dans certains pays, il n'est pas approuvé non plus pour la contraception d'urgence.

\section{Fonctionnement}

La pilule contraceptive d'urgence empêche l'ovulation (voir la fiche relative au cycle menstruel), l'union d'un ovule et d'un spermatozoïde ou la nidation d'un ovule fécondé dans l'utérus (voir la fiche relative à la reproduction et la grossesse). Elle n'est pas abortive, car elle ne fonctionne pas si la femme est déjà enceinte.

Le stérilet au cuivre semble opérer par perturbation de la nidation.

\section{Efficacité}

L'efficacité de la pilule contraceptive d'urgence dépend du type de pilule utilisé et de la rapidité de son administration après le rapport non protégé. Plus les pilules sont prises rapidement, plus elles sont efficaces. L'efficacité des pilules CU est estimée à environ $90 \%$. L'insertion d'un stérilet d'urgence est efficace à $99 \%$.

\section{La contraception d'urgence protège-t-elle contre les \\ infections sexuellement transmissibles?}

La contraception d'urgence n'apporte aucune protection contre les infections sexuellement transmissibles, y compris le VIH. 


\section{cycle menstruel (parfois appelé cycle œstral)}

\section{Qu'est-ce que le cycle menstruel ?}

À la puberté, les filles commencent à vivre leurs cycles de fécondité. Contrairement aux hommes, les femmes ne sont fécondes que certains jours de ce cycle. La durée du cycle varie d'une personne à l'autre, mais elle est généralement d'environ un mois. Durant chaque cycle, le corps de la femme passe par de nombreuses étapes. La plus évidente est le saignement menstruel, également appelé menstruation ou «les règles ».

La menstruation est souvent considérée comme le point culminant du cycle, mais il s'agit d'un aspect seulement d'une transformation étonnante, par laquelle le corps se prépare à une éventuelle grossesse. Production de glaire cervicale, maturation et libération d'un ovule et transformation de la paroi utérine : ces changements sont gérés par les hormones, substances chimiques naturelles produites par les glandes du corps et transportées dans le sang.

Ces changements hormonaux affectent de nombreuses parties du corps féminin, mais aussi comment les femmes se sentent et se comportent. Savoir de quoi il retourne peut réconforter la fille ou la femme et lui donner un meilleur sentiment de maitrise de son corps. De simples techniques aident à identifier le moment de l'ovulation et des règles.

\section{Quels changements affectent le corps pendant le cycle?}

\section{Avant l'ovulation}

Menstruation - Les règles marquent le début d'un nouveau cycle. Pendant la menstruation, l'utérus élimine sang et tissu, qui s'écoulent par le vagin. Le premier jour des règles est le premier jour du cycle. Le saignement dure généralement entre quatre et six jours.
Dessèchement - Après les règles, le vagin peut paraître sec parce que les niveaux hormonaux sont faibles et que le col produit, au plus, peu de glaire.

Glaire épaisse/épaississement de la muqueuse utérine - Au bout de quelques jours, le corps libère plus d'hormones et la femme peut remarquer un écoulement vaginal de glaire, d'abord blanchâtre ou jaunâtre et parfois collante. En même temps, sans qu'elle le sente, la muqueuse de l'utérus commence à s'épaissir et un ovule « mûrit ».
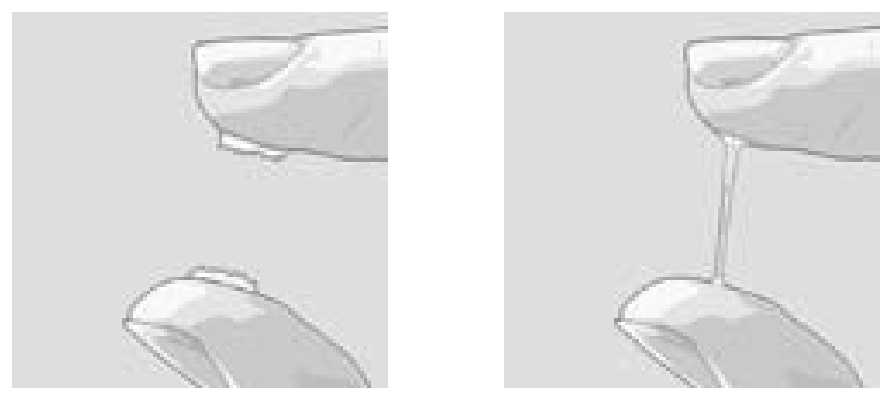

\section{Ovulation}

Glaire claire/ovulation - Tandis que l'ovule mûrit, la glaire devient plus claire et glissante, souvent comme du blanc d'œuf cru, qui s'étire entre les doigts. Cette glaire claire nourrit le sperme et l'aide à progresser vers l'ovule. À ce moment, le désir sexuel de la femme s'intensifie parfois. La libération de l'ovule par l'ovaire porte le nom d'ovulation. La fille ou la femme peut tomber enceinte durant les jours précédents et aux alentours de l'ovulation. On appelle parfois ces jours les « jours féconds». 
D'autres changements affectent le corps féminin aux alentours de cette période. Certaines femmes éprouvent un plus grand désir sexuel et un plus grand bien-être pendant quelques jours. Certaines ressentent un pincement ou une légère gêne du côté de l'abdomen où l'ovaire expulse l'ovule.

\section{Après l'ovulation}

Post-ovulation - Après l'ovulation, l'ovule peut survivre un un jour. La glaire redevient épaisse et crémeuse ou collante. Pendant les 14 jours suivants (plus ou moins), les hormones gardent en place la muqueuse utérine épaissie. La température du corps monte légèrement.

Menstruation - En l'absence de grossesse au bout de ces 14 jours, les niveaux hormonaux baissent. La muqueuse utérine s'élimine et la température du corps redescend.

Cette élimination de la muqueuse, la menstruation, marque le début d'un nouveau cycle. (En cas de grossesse, le corps continue à produire des hormones pour maintenir la muqueuse utérine en place pendant neuf mois.)

\section{Combien de temps dure le cycle menstruel ?}

Pendant un an ou deux après les premières règles, la longueur du cycle peut varier. Plusieurs mois peuvent s'écouler entre deux menstruations. Même à l'âge adulte, la durée du cycle peut varier d'une femme ou d'un cycle à l'autre. Des facteurs tels que les voyages, le stress, la dépression, la malnutrition et la maladie peuvent l'affecter. Le plus souvent, toutefois, la femme commence un nouveau cycle tous les 24 à 36 jours.

La partie du cycle allant du début du flux menstruel à l'ovulation peut varier grandement, de quelques jours seulement à plusieurs mois ou même plus. Le plus souvent, cette période varie entre une et trois semaines. Par contre, la partie du cycle allant de l'ovulation à la menstruation suivante ne varie pas : elle est toujours d'environ 14 jours.
Autrement dit, dès le moment où l'ovulation se produit, la fille ou la femme sait, sauf si elle tombe enceinte, qu'elle aura ses règles dans environ 14 jours.

\section{Quels sont les jours féconds du cycle?}

La période féconde inclut le jour de l'ovulation et les cinq jours précédents. Le sperme peut survivre dans l'appareil génital féminin jusqu'à cinq ou six jours, tandis que l'ovule (s'il n'est pas fécondé) survit jusqu'à 24 heures. Il est difficile de prédire les jours féconds étant donné que la première phase du cycle (de la menstruation à l'ovulation) est celle dont la durée est la plus variable. Certaines femmes apprennent à observer la variation de leur glaire (et de leur température) pour déterminer le moment probable où elles ovulent. Certaines ressentent une légère douleur au moment de l'ovulation. Beaucoup de femmes et filles utilisent les techniques de la "conscience de la fécondité » pour mieux gérer leurs menstruations. Connaître ses jours féconds peut être utile à la femme qui désire ou non une grossesse. La pratique correcte de ces techniques nécessite toutefois une instruction, un suivi et une observation permanente soignée. [Voir aussi la fiche relative à la contraception pour plus de détails sur les techniques de conscience de la fécondité.]

\section{Combien de cycles menstruels dans la vie d'une femme?}

À l'approche de 40-45 ans, les niveaux hormonaux des femmes changent. Elles finissent par ne plus libérer d'ovules et la menstruation cesse. Cette phase, appelée ménopause, marque la fin de la fécondité. L'âge de la ménopause varie d'une femme à l'autre et suivant l'endroit : vers 45 ans, en général, dans les pays en développement et vers 50 ans dans les autres.

[Voir aussi la fiche relative à la puberté féminine.] 


\section{infections de l'appareil génital non transmises par voie sexuelle}

\section{Comment définir les infections de l'appareil génital ?}

Les infections de l'appareil génital (IAG) sont dues à trois causes principales :

- la transmission sexuelle [voir les fiches relatives aux IST et $\mathrm{VIH}]$;

- l'introduction ou la propagation accidentelle de bactéries dans l'utérus lors d'une procédure médicale telle que

l'insertion d'un stérilet ou lors d'un accouchement; et

- la prolifération d'organismes normalement présents dans le vagin. Les plus courantes de ces infections, dites endogènes, sont la candidose et la vaginose bactérienne.

\section{Candidose}

La candidose, aussi appelée mycose génitale, est causée par un champignon, par développement du candida naturellement présent dans le vagin. Les signes en sont d'épaisses pertes blanches, une démangeaison ou rougeur intense de la vulve et du vagin et l'irritation vaginale lors des rapports sexuels, mais l'infection est parfois asymptomatique. La candidose est aisément traitable. Elle affecte plus souvent les femmes dont le système immunitaire est faible, enceintes ou sous traitement antibiotique. Elle est parfois source de démangeaisons et de gêne chez l'homme aussi. D'autres parties humides du corps peuvent être affectées.

\section{Vaginose bactérienne}

Le vagin abrite normalement de "bonnes » et «mauvaises » bactéries vivant en équilibre. La vaginose bactérienne (VB) est le résultat d'une prolifération anormale de bactéries nuisibles qui perturbent l'équilibre biochimique du vagin. Les symptômes les plus courants sont les fines pertes grises, blanches, jaunâtres ou verdâtres ; la mauvaise odeur, surtout après les rapports sexuels ou pendant les règles, ou les démangeaisons et douleurs vaginales. Plus de la moitié des femmes ne présentent aucun symptôme. Traitable, la VB ne cause généralement pas de complications mais elle peut être grave et accroître la vulnérabilité aux VIH et autres IST, à l'infection génitale haute [voir la fiche relative aux IST] et, chez les femmes enceintes, à un risque accru d'accouchement avant terme ou de poids insuffisant à la naissance.

\section{Comment réduire l'incidence des infections de l'appareil génital transmises par voies autres que sexuelles?}

Les femmes doivent éviter les douches vaginales, l'insertion vaginale d'herbes, agents ou produits « dessicatifs » ou « resserrants »; et la prise inutile d'antibiotiques. Elles doivent toujours s'essuyer d'avant en arrière (de l'orifice urinaire vers l'anus) pour éviter la propagation de microbes de l'anus vers le vagin ou l'orifice urinaire. Les sous-vêtements synthétiques (en polyester) et les pantalons serrants qui restreignent la circulation de l'air doivent être évités.

\section{Comment une procédure médicale peut-elle causer une infection de l'appareil génital ?}

Les IAG peuvent aussi résulter de l'introduction de bactéries dans l'utérus par un instrument non stérile, ou du transport par un instrument d'une infection vaginale ou cervicale vers l'utérus, où elle se propage. Ces IAG peuvent résulter de procédures telles que l'IVG ou l'insertion d'un stérilet, ou d'un accouchement. Non traitées, elles peuvent donner lieu à une grave infection génitale haute. Les services médicaux doivent veiller à entretenir des conditions stériles lors de telles procédures. Il est essentiel de procéder au dépistage (et au traitement) de toutes infections préexistantes avant l'insertion d'un instrument à travers le col de l'utérus. 


\section{infections sexuellement transmissibles (IST)}

\section{Définition}

Les infections sexuellement transmissibles (IST) sont des infections transmises principalement par le contact sexuel (vaginal, oral et anal). Différents organismes peuvent causer les IST (voir le tableau à la page suivante). Certains parasites (poux du pubis et gale) peuvent aussi se transmettre par contact sexuel. Les IST font partie du groupe plus large des infections de l'appareil génital ou IAG. [Voir la fiche relative aux IAG].

\section{Modes de transmission non sexuels}

Certaines IST se transmettent par simple contact de la peau, par l'échange de liquides corporels, par transmission de la mère à l'enfant avant la naissance, au moment de l'accouchement ou à travers l'allaitement maternel.

\section{Conséquences des IST}

Les IST peuvent avoir de graves conséquences pour la santé des hommes comme des femmes (voir le tableau). Beaucoup d'IST courantes sont cependant difficiles à détecter chez les femmes et certaines ont des conséquences plus graves pour les femmes que pour les hommes. Par exemple, la propagation de chlamydia ou de la blennorragie vers les organes génitaux supérieurs est cause courante de stérilité féminine. Certaines IST rendent plus probable la contraction ou la transmission du VIH. Certaines, mais pas toutes, sont curables. D'autres, comme le VIH, ne le sont pas. L'obtention rapide d'un traitement élimine ou réduit les conséquences de la plupart des IST.

\section{Pour prévenir la contraction ou la transmission d'IST}

- Se faire tester par un prestataire de santé pour détecter la présence d'une IST.

- Si oui, obtenir le traitement approprié et informer tou(te)s ses partenaires sexuel(le)s récent(e)s pour qu'ils ou elles se fassent aussi tester.

- Déterminer si un(e) partenaire a une IST et, si oui, veiller à ce qu'il ou elle se fasse tester et traiter.

- Parler à son ou sa partenaire des possibilités d'intimité sexuelle sans risque de transmission d'une infection.

- Utiliser le préservatif masculin ou féminin et éviter le contact sexuel propice à l'infection. Le préservatif protège contre la plupart des IST (y compris le VIH), mais pas toutes.

- Se faire vacciner contre les IST pour lesquelles il existe un vaccin : actuellement, contre l'hépatite $B$ et certains papillomavirus (HPV).

\section{Quand se faire tester?}

Une personne court le risque de contracter une IST et doit se faire tester dans les circonstances suivantes :

- elle présente les symptômes d'une IST ;

- son ou sa partenaire sexuel(le) a une IST ou en présente les signes ;

- elle a plusieurs partenaires sexuel(le)s ;

- elle a un nouveau (une nouvelle) partenaire depuis trois mois ;

- elle a un(e) partenaire qui en a (peut-être) d'autres; et/ou

- elle a un(e) partenaire qui vit ailleurs ou qui voyage beaucoup.

Le dépistage précoce est important. Une personne diagnostiquée peut se faire traiter et aider ses partenaires récent(e)s à se faire tester aussi. Un couple ne doit pas reprendre son activité sexuelle tant que les deux partenaires n'ont pas été testés et achevé le traitement nécessaire. Certaines IST ne se révèlent pas immédiatement dans les résultats : un deuxième test peut être nécessaire.

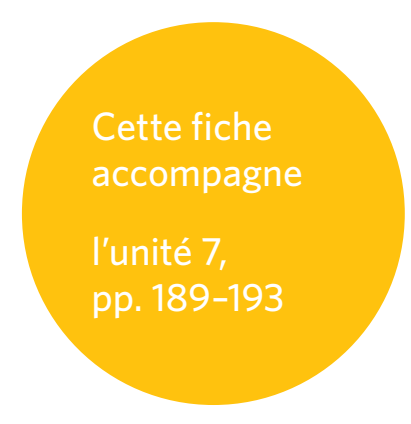


Remarque : L'information présentée ici peut changer en fonction de l'avance de la recherche, des tests et des approches de traitement. Pour toutes mises à jour et renseignements complémentaires, voir < www.who.int/topics/sexually_transmitted_infections/fr/ $>$.
IST Symptômes féminins
Symptômes masculins

Guérissable?

Vaccin?

Chancre mou

Plaies douloureuses au niveau des organes génitaux; ganglions gonflés dans l'aine.

Oui

Les femmes sont souvent asymptomatiques.

Chlamydia

\section{La plupart des femmes sont asymptomatiques.}

Les femmes qui ont des symptômes peuvent avoir des pertes vaginales anormales ou une sensation de brûlure quand elles urinent.

\section{Souvent asymptomatique. Les}

hommes qui ont des symptômes peuvent observer un écoulement pénien purulent ou avoir une sensation de brûlure quand ils urinent.

Les hommes ont souvent un écoulement

anormal ou une sensation de brûlure quand

ils urinent. Certains n'ont pas de symptômes.
Oui. Non traitée, cette IST peut mener à une infection génitale haute chez la femme, susceptible de la rendre stérile. Les

complications sont rares chez l'homme.

Non

Non

\section{Blennorragie}

\section{La plupart des femmes sont} asymptomatiques. Sinon, écoulements vaginaux anormaux et sensation de brûlure quand elles urinent.
Hepatitis B Certaines personnes ont des symptômes grippaux, la jaunisse et des urines foncées ; d'autres ne présentent aucun symptôme.
Oui. Non traitée, cette IST peut mener à une Non infection génitale haute chez la femme et

à la stérilité chez la femme comme chez l'homme.

Il n'existe à ce jour aucun médicament contre

l'hépatite $\mathrm{B}$, mais le corps élimine souvent

l'infection de lui-même. Elle mène parfois à une maladie chronique du foie. Les bébés et les petits enfants courent un risque d'infection chronique beaucoup plus grand.

\begin{tabular}{ll}
\hline $\begin{array}{l}\text { Herpès (virus } \\
\text { herpès simplex) }\end{array}$ & $\begin{array}{l}\text { Épisodes récurrents de lésions douloureuses au niveau des organes } \\
\text { génitaux ou de l'anus. }\end{array}$ \\
\hline $\begin{array}{l}\text { VIH (virus de } \\
\text { l'immunodéficience }\end{array}$ & $\begin{array}{l}\text { Le VIH ne présente généralement pas de symptômes dans les premiers temps. } \\
\text { Il mène généralement au sida. Les sidéens sont vulnérables à différentes infections, } \\
\text { cancers et autres affections graves. }\end{array}$
\end{tabular}

Papillomavirus Peut être asymptomatique. Certaines souches sont la cause de verrues génitales,

(PVH ou HVP) d'autres de cancers: de la tête, du cou et de l'anus, du pénis chez l'homme et — le plus souvent — du col utérin chez la femme.
Non, mais les symptômes peuvent être traités. Non

Non, le sida est une maladie chronique mortelle, mais le traitement antirétroviral en ralentit remarquablement la progression.

Non, mais les symptômes peuvent être traités. Certaines cancers secondaires au papillomavirus peuvent être soignés. Non

Oui

Oui. Les vaccins anti-PVH protègent hommes et femmes contre beaucoup des souches du virus.

\section{Syphilis}

\section{Trichomonase}

Commence par une ou plusieurs lésions indolores au niveau des organes génitaux, du rectum ou de la bouche. La deuxième phase peut présenter éruption cutanée, lésions au niveau des muqueuses, fièvre et malaise. La phase latente commence quand ces symptômes disparaissent.
Oui, si traitée durant les premières phases. En Non

l'absence de traitement, l'infection reste dans le corps. Le stade avancé de la syphilis attaque les organes internes et peut être mortel.
Les femmes observent parfois des pertes vaginales bulleuses de couleur jaune verdâtre fort odorantes. Les démangeaisons ou gênes sexuelles ou urinaires sont aussi possibles.
Les hommes sont généralement asymptomatiques; il y a parfois un léger écoulement pénien ou une légère brûlure au passage de l'urine ou à l'éjaculation.

\section{Non}




\section{méthodes contraceptives}

\section{méthodes temporaires « contrôlées par l'utilisateur » qui empêchent les spermatozoïdes d'atteindre l'ovule}

\begin{tabular}{|c|c|c|c|}
\hline MÉTHODE & Description & $\begin{array}{l}\text { Protection } \\
\text { anti-IST/VIH }\end{array}$ & Autres caractéristiques \\
\hline Préservatif masculin & $\begin{array}{l}\text { Fin capuchon en latex qu'on déroule sur le pénis en } \\
\text { érection pour empêcher le sperme de pénétrer dans } \\
\text { le vagin. }\end{array}$ & Oui & $\begin{array}{l}\text { Il s'agit de l'une des deux méthodes offrant une double protection, } \\
\text { contre la grossesse et l'infection. Il peut donc protéger aussi contre } \\
\text { le risque de stérilité et le cancer du col utérin. } \\
\text { Il protège l'homme ou le garçon ainsi que sa partenaire. } \\
\text { Il se procure aisément. } \\
\text { Il doit être mis en place lors de l'acte sexuel, avant la pénétration. } \\
\text { Certains trouvent qu'il réduit la sensation. } \\
\text { Il risque de fuir ou de se déchirer, surtout s'il est mal posé. }\end{array}$ \\
\hline Préservatif féminin & $\begin{array}{l}\text { Poche en plastique lubrifié à double anneau : le } \\
\text { premier reste à l'extérieur du vagin et recouvre une } \\
\text { partie des lèvres; le second s'introduit dans le vagin, } \\
\text { où il recouvre le col de l'utérus. Le préservatif forme } \\
\text { une poche qui reçoit le sperme. }\end{array}$ & Oui & $\begin{array}{l}\text { Il peut être mis en place plusieurs heures avant l'activité sexuelle. } \\
\text { Il protège la femme ou la fille ainsi que son partenaire. } \\
\text { Il se remarque lors des rapports sexuels et son insertion peut } \\
\text { nécessiter une certaine pratique. } \\
\text { Il coûte cher par rapport au préservatif masculin. }\end{array}$ \\
\hline $\begin{array}{l}\text { Diaphragme ou } \\
\text { cape cervicale }\end{array}$ & $\begin{array}{l}\text { Diaphragme : Dôme peu profond en caoutchouc } \\
\text { souple qu'on remplit de spermicide et qu'on } \\
\text { introduit dans le vagin avant le rapport sexuel. Il } \\
\text { recouvre le col de l'utérus pour y empêcher l'entrée } \\
\text { du sperme, que le spermicide tue aussi. }\end{array}$ & $\begin{array}{l}\text { Il n'a pas encore été } \\
\text { établi si la cape ou le } \\
\text { diaphragme assure une } \\
\text { protection contre les } \\
\text { infections. }\end{array}$ & $\begin{array}{l}\text { Il peut être mis en place avant le début de l'activité sexuelle. } \\
\text { Il ne se procure pas facilement. } \\
\text { Il risque de se déloger pendant le rapport. } \\
\text { Il doit être adapté par un prestataire de soins de santé. }\end{array}$ \\
\hline & $\begin{array}{l}\text { Cape cervicale : Cupule en latex qu'on pose, dans } \\
\text { le vagin, comme un dé à coudre sur le col de } \\
\text { l'utérus, où il se maintient par succion et fait ainsi } \\
\text { barrière au sperme. Il convient de l'utiliser avec un } \\
\text { spermicide. }\end{array}$ & & \\
\hline Spermicides & $\begin{array}{l}\text { Mousses chimiques, crèmes, gelées, films ou } \\
\text { suppositoires qu'on introduit dans le vagin avant } \\
\text { le rapport sexuel pour créer une barrière et tuer } \\
\text { le sperme. Le spermicide s'utilise seul ou avec une } \\
\text { méthode barrière telle que le préservatif, pour une } \\
\text { meilleure efficacité. }\end{array}$ & Non & $\begin{array}{l}\text { L’usage répété du spermicide nonoxinol-9 (N-9) peut provoquer des } \\
\text { lésions génitales et accroître ainsi le risque de transmission du VIH. } \\
\text { Les spermicides ne doivent pas être utilisés par les femmes qui } \\
\text { courent un haut risque de contraction du VIH. } \\
\text { Certains sont coulants et désagréables. }\end{array}$ \\
\hline
\end{tabular}

Remarque : Cette fiche accompagne le contenu de l'unité 7, pp. 210-213.

Pour plus de détails concernant les effets secondaires, l'efficacité et l'emploi, voir <www.who.int/reproductivehealth/publications/family_planning/9780978856304/fr/index.html>. 
méthodes durables internes au corps

\section{MÉTHODE \\ Description}

Contraceptifs oraux (II pilule i)
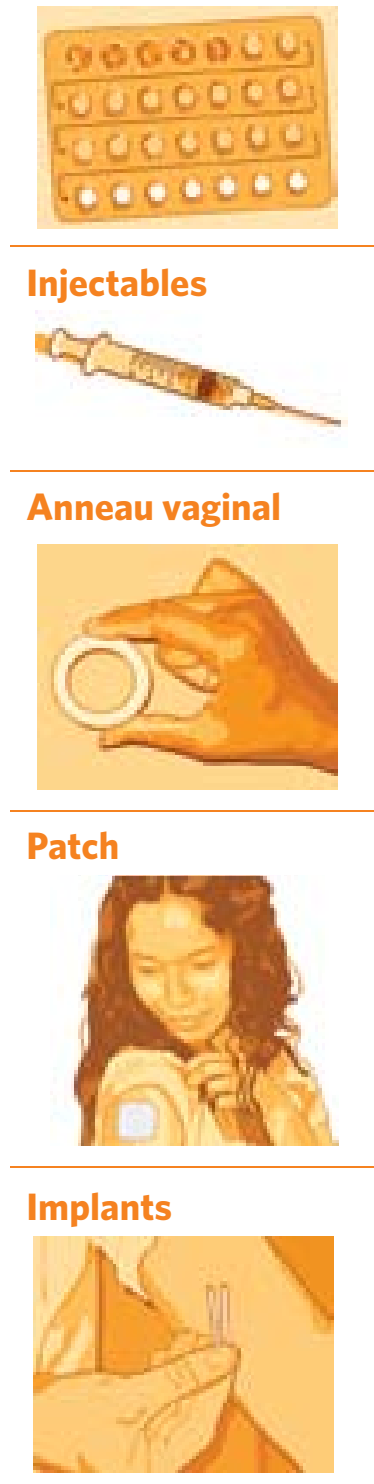

Simple ou double petit bâtonnet souple implanté dans le haut du bras de la femme et qui libère une faible dose progestative constante pendant trois à cinq ans, pour épaissir la glaire cervicale et empêcher l'ovulation.
Petites pilules contenant des hormones synthétiques (œstrogène et progestatif ou progestatif seul) qui empêchent l'ovulation et gênent la migration du sperme par épaississement de la glaire cervicale. La femme avale une pilule chaque jour pendant 21 ou 28 jours suivant la marque et le type.

Protection

anti-IST/VIH

Non

Injection administrée à intervalles réguliers, de un ou trois mois généralement, contenant une

hormone synthétique progestative qui empêche l'ovulation et épaissit la glaire cervicale.

Fin anneau souple que la femme introduit dans le vagin et qui libère lentement un œestrogène et un progestatif, pour arrêter l'ovulation et épaissir la glaire cervicale.

\section{Autres caractéristiques}

La femme ne doit rien introduire ou appliquer au moment des rapports sexuels.

La pilule peut réduire les crampes menstruelles et le risque de certains types de cancer, d'anémie, de problèmes de seins et d'infection génitale haute.

La femme ne doit pas oublier de prendre sa pilule.

La fécondité se rétablit généralement rapidement quand la femme arrête de prendre la pilule.

La méthode peut être utilisée sans que d'autres le sachent. La femme ne doit rien introduire ou appliquer au moment des rapports sexuels.

L'injectable peut réduire le risque de certains types de cancer. La fécondité se rétablit quelques mois après l'arrêt.

La femme ne doit rien introduire ou appliquer au moment des rapports sexuels.

La fécondité se rétablit immédiatement à l’arrêt de la méthode.

$\begin{array}{lll}\begin{array}{l}\text { Petit carré adhésif appliqué sur la peau et qui libère } \\ \text { lentement un progestatif et un œestrogène à travers }\end{array} & \text { Non } & \begin{array}{l}\text { La femme ne doit rien introduire ou appliquer au moment des } \\ \text { rapports sexuels. }\end{array} \\ \begin{array}{l}\text { la peau, pour empêcher l'ovulation et épaissir la } \\ \text { glaire cervicale. }\end{array} & \begin{array}{l}\text { Le patch est moins efficace pour les femmes pesant plus de } 90 \mathrm{~kg} . \\ \text { La fécondité se rétablit rapidement à l'arrêt de la méthode. }\end{array}\end{array}$

Le patch est moins efficace pour les femmes pesant plus de $90 \mathrm{~kg}$.

\section{Non}

Les implants peuvent être retirés à tout moment, mais ils doivent être mis en place et retirés par un prestataire formé.

La femme ne doit rien introduire ou appliquer au moment des rapports sexuels.

La fécondité se rétablit immédiatement après le retrait. 


\begin{tabular}{|c|c|c|c|}
\hline Stérilet & $\begin{array}{l}\text { Petit dispositif, généralement en forme de T, introduit } \\
\text { dans l'utérus par un prestataire de soins. Certains } \\
\text { libèrent une hormone progestative et d'autres } \\
\text { contiennent du cuivre, aux effets contraceptifs. Le } \\
\text { stérilet empêche le sperme d'atteindre l'ovule. Certains } \\
\text { types restent efficaces pendant } 10 \text { ans. }\end{array}$ & Non & $\begin{array}{l}\text { Cette méthode, imperceptible, n'interrompt pas l'acte sexuel. } \\
\text { En cas d'infection présente au moment de l'insertion, ou si les } \\
\text { conditions de l'insertion ne sont pas stériles, une infection pelvienne } \\
\text { peut se développer et accroître le risque de stérilité. } \\
\text { Le corps expulse parfois le stérilet. } \\
\text { Il doit être introduit et retiré par un prestataire compétent. }\end{array}$ \\
\hline
\end{tabular}

\section{" méthodes naturelles » - méthodes requérant des comportements spécifiques et une bonne compréhension de son corps}

\begin{tabular}{|c|c|c|c|}
\hline MÉTHODE & Description & $\begin{array}{l}\text { Protection } \\
\text { anti-IST/VIH }\end{array}$ & Autres caractéristiques \\
\hline $\begin{array}{l}\text { Méthode de } \\
\text { l'aménorrhée } \\
\text { lactationnelle }\end{array}$ & $\begin{array}{l}\text { Méthode réservée exclusivement aux femmes } \\
\text { qui allaitent. La lactation provoque dans le corps } \\
\text { la production d'hormones capables d'empêcher } \\
\text { l'ovulation. Pour la contraception, cette méthode } \\
\text { n'est efficace que pendant les six premiers mois } \\
\text { d'allaitement ou, s'il intervient plus tôt, jusqu'au } \\
\text { moment où la menstruation réapparaît, et que } \\
\text { si l'enfant n'est nourri qu'au lait maternel et à la } \\
\text { demande. }\end{array}$ & Non & $\begin{array}{l}\text { L'allaitement maternel est gratuit et bénéfique à la santé de la mère et } \\
\text { de l'enfant. } \\
\text { La méthode de l'aménorrhée lactationnelle (MAMA) peut être } \\
\text { difficile pour les femmes qui doivent s'éloigner régulièrement de leur } \\
\text { enfant. }\end{array}$ \\
\hline Retrait & $\begin{array}{l}\text { Le retrait du pénis, hors et à distance du vagin avant } \\
\text { l'éjaculation, évite l'entrée du sperme dans le vagin. } \\
\text { Cette méthode peut être efficace si elle est utilisée } \\
\text { correctement et sans exception. }\end{array}$ & Non & $\begin{array}{l}\text { Le retrait est toujours disponible et gratuit. } \\
\text { Il est considérablement plus efficace que l'absence de retrait. } \\
\text { Il dépend de la maîtrise qu'a l'homme de son corps et de sa capacité } \\
\text { à prédire l'éjaculation ; les femmes n'ont aucun contrôle sur cette } \\
\text { méthode. } \\
\text { Il interrompt l'acte sexuel et peut amoindrir le plaisir. }\end{array}$ \\
\hline $\begin{array}{l}\text { Méthode de } \\
\text { conscience de la } \\
\text { fécondité - glaire } \\
\text { cervicale }\end{array}$ & $\begin{array}{l}\text { Le col de l'utérus sécrète une glaire observable } \\
\text { quand la femme s'essuie ou sur le fond de culotte. } \\
\text { Le type et la quantité de cette glaire change au cours } \\
\text { du cycle menstruel. La femme peut apprendre à } \\
\text { reconnaître le type de glaire qui indique qu'elle } \\
\text { est vraisemblablement féconde ou non. Pendant } \\
\text { la période féconde, elle peut utiliser une méthode } \\
\text { contraceptive barrière ou s'abstenir de tous rapports } \\
\text { sexuels (voir la fiche relative au cycle menstruel). }\end{array}$ & Non & $\begin{array}{l}\text { Cette méthode donne à la femme une meilleure conscience et } \\
\text { compréhension de son corps. } \\
\text { Elle lui permet de prédire le début de son prochain cycle menstruel. } \\
\text { Elle peut aussi aider les couples qui désirent concevoir à identifier } \\
\text { leurs jours les plus féconds. } \\
\text { Elle est acceptable aux groupes religieux opposés aux autres méthodes. } \\
\text { Elle demande un certain temps d'apprentissage, une discipline } \\
\text { d'observation journalière et la coopération du partenaire de la femme. }\end{array}$ \\
\hline
\end{tabular}




\section{Méthode de conscience de la fécondité \\ -température

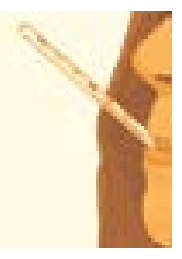

Méthodes de

conscience de la

fécondité - calendrier,

jours fixes ou collier

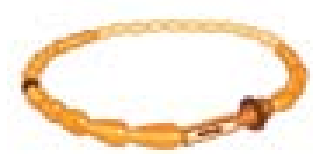

La température du corps de la femme augmente légèrement au moment de l'ovulation. En prenant sa température chaque matin avant de se lever ou de commencer à s'activer, la femme peut identifier quand l'ovulation est passée. Le moment de

l'ovulation n'est pas prévisible, mais quelques jours plus tard, la femme sait qu'elle n'est plus féconde pour le reste du cycle. Elle peut jusqu'alors utiliser une méthode barrière ou pratiquer l'abstinence.
Non

Beaucoup de femmes ont un cycle menstruel de durée assez régulière. Le « collier » du cycle (pour la méthode des jours fixes) et le calendrier sont deux méthodes qui permettent à la femme d'identifier ses jours féconds, pendant lesquels elle peut s'abstenir de tous rapports sexuels ou utiliser une méthode barrière.

\section{Non}

Cette méthode convient le mieux aux femmes dont le cycle est régulier.

Elle peut aussi aider les couples qui désirent concevoir à identifier leurs jours les plus féconds.

Elle nécessite la coopération du partenaire de la femme.

\section{méthodes chirurgicales permanentes}

$\begin{array}{ll}\text { METHODE } & \text { Description } \\ \text { Vasectomie, } & \begin{array}{l}\text { Simple opération pratiquée en clinique de jour, } \\ \text { consistant à couper et obturer les canaux déférents. } \\ \text { masculine }\end{array} \\ \begin{array}{l}\text { Les spermatozoïdes se réabsorbent sans risques } \\ \text { dans le corps de l'homme plutôt que de se mélanger } \\ \text { au sperme. L'opération ne change rien à la capacité } \\ \text { d'avoir des rapports sexuels, de ressentir du plaisir } \\ \text { sexuel ou d'éjaculer. }\end{array}\end{array}$

\section{Protection anti-IST/VIF \\ Autres caractéristiques}

Non

La vasectomie n'est efficace qu'au bout de trois mois après l'intervention.

Il s'agit d'une méthode permanente.
Stérilisation féminine, ligature des trompes

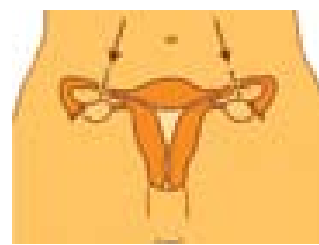

Procédure chirurgicale qui consiste à couper et ligaturer ou obturer les trompes de Fallope et à empêcher ainsi la rencontre d'un ovule et d'un spermatozoïde. L'opération ne change rien à la capacité d'avoir des rapports sexuels ou de ressentir du plaisir sexuel. 


\section{Qu'est-ce que la mutilation génitale des filles ?}

La mutilation génitale des filles, y compris l'excision, désigne l'ablation chirurgicale d'une partie ou de la totalité des organes génitaux féminins extérieurs. Elle se pratique sur les filles à différents âges, le plus souvent vers sept à dix ans. Elle peut impliquer, en tout ou en partie :

- l'ablation partielle ou totale du clitoris ;

- l'ablation totale ou partielle du clitoris et des petites lèvres de la vulve ;

- la suture des deux côtés de la vulve, ne laissant qu'une petite ouverture pour permettre l'écoulement de l'urine et du flux menstruel (infibulation); et

- d'autres pratiques nuisibles, telles que le perçage,

l'étirement ou la brûlure du clitoris et des lèvres, le raclage ou l'ablation de tissu vaginal, ou l'introduction de matières corrosives dans le vagin pour le faire saigner ou le resserrer.

\section{Conséquences sur la santé}

La MGF s'accompagne souvent de conséquences graves sur la santé physique, sexuelle et mentale, variables suivant la procédure pratiquée, les conditions de sa réalisation et l'état physique de la fille ou de la femme. Dans l'immédiat, il peut y avoir infection, hémorragie, douleur profonde, choc, difficulté d'uriner et blessure des tissus. Le saignement excessif et l'infection peuvent être mortels. À long terme, la MGF peut causer des difficultés menstruelles, de rapports et de jouissance sexuels, de fécondité, d'accouchement, d'excrétion urinaire et fécale et de santé mentale, y compris la peur et la dépression.

\section{Raisons de la MGF}

Les raisons invoquées varient, mais sont souvent affaire de tradition et de maintien des normes de genre. En tant que rite de passage traditionnel, la MGF est signe d'acceptation sociale des filles et de nubilité. La MGF est aussi pratiquée pour réduire le désir sexuel des femmes, pour qu'elles n'aient pas de rapports en dehors du mariage ; pour renforcer leur identité culturelle; par souci de conformité aux attitudes culturelles locales de «beauté "; et pour des raisons de croyance religieuse, bien qu'aucune religion ne l'impose.

\section{Où se pratique la MGF et combien de femmes sont affectées?}

La MGF se pratique dans 28 pays d'Afrique et dans plusieurs d'Asie et du Moyen-Orient, ainsi que parmi les populations immigrantes d'Europe, d'Australie, du Canada et des ÉtatsUnis. On estime entre 100 et 140 millions le nombre de filles et de femmes qui ont subi la mutilation, et à deux à trois millions celui de filles qui en courent le risque chaque année.

\section{Quels sont les droits humains violés?}

La MGF est une forme de violence faite aux filles et aux femmes. Elle viole ou met en péril la jouissance du droit à la vie ; le droit à l'intégrité physique ; le droit à la meilleure santé possible ; le droit à ne pas subir de traitements cruels, inhumains ou dégradants, $y$ compris la violence physique ou mentale, les blessures ou les abus ; le droit de vivre dans la dignité, sans préjudice de genre; et les droits de l'enfant au développement, à la protection et à la participation.

\section{Mesures prises pour mettre fin à la MGF}

Les organismes internationaux, autorités gouvernementales et de nombreuses ONG s'efforcent d'enrayer la MGF. Beaucoup de pays et de communautés l'interdisent.

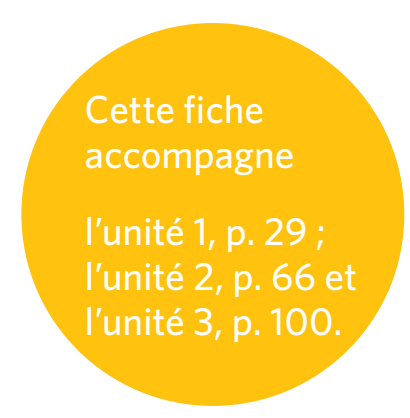




\section{nutrition, activité physique et abus de substances toxiques}

\section{nutrition}

\section{Importance de la nutrition pendant l'adolescence}

Une nutrition adéquate est particulièrement importante à l'adolescence car il s'agit d'une période de croissance rapide. Les filles qui deviennent mères et qui allaitent pendant l'adolescence ont besoin d'un apport nutritif considérable.

\section{Causes et conséquences principales des problèmes de nutrition}

Le manque d'accès à une alimentation nourrissante suffisante est la cause principale des problèmes de nutrition, plus graves encore quand la nourriture est distribuée de manière inégale dans les familles (quand les fils sont mieux nourris que les filles, par exemple, ou quand l'épouse et les filles sont nourries en dernier.) La malnutrition nuit aux capacités d'apprentissage et affaiblit la résistance aux infections. Elle mine la santé des mères et des enfants et est souvent mortelle. Les os de ses victimes peuvent s'affaiblir et se fragiliser avec l'âge.

D’autres problèmes de nutrition affectent davantage les pays développés : la consommation excessive d'aliments riches en matières grasses et en sucres y est cause d'obésité et contribue à de nombreux problèmes de santé, dont le diabète, l'hypertension artérielle et les maladies du cour. Les régimes compulsifs sont aussi problématiques, surtout quand les médias créent et vantent des idéaux irréalistes de taille et d'apparence corporelle. Les troubles de l'alimentation tels que l'anorexie

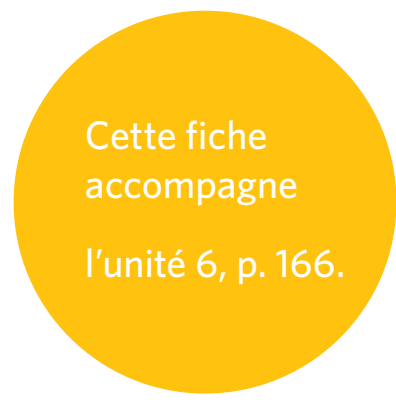
prise de laxatifs après avoir mangé) peuvent nuire sérieusement à la santé, mortellement parfois. Ces troubles sont plus courants chez les filles.

\section{Pour une meilleure alimentation}

- Apprendre la valeur nutritive des aliments et opérer de bons choix.

- Demander aux marchés et fast-foods qu'ils proposent des choix sains à prix raisonnable.
- Organiser des marchés de producteurs proposant des aliments locaux frais dans les milieux urbains défavorisés.

- Encourager la distribution équitable des aliments dans les familles.

- Encourager l'étiquetage clair et exact des produits alimentaires.

- Surveiller les pratiques publicitaires des fast-foods.

\section{activité physique}

\section{Importance de l'activité physique}

Une activité physique saine aide à protéger contre les maladies telles que l'obésité, le diabète, certains cancers et l'hypertension artérielle, au profit aussi du bien-être psychologique. Le sport est aussi source d'interaction sociale et de divertissement. Pour les filles, le sport ou l'exercice favorisent une image corporelle positive et offre une occasion d'amitié, d'entrain et de reconnaissance publique. Le bilan social et de santé des adolescentes qui font du sport est souvent meilleur - y compris au niveau des résultats scolaires et des grossesses non planifiées - que pour celles qui n’en font pas.

\section{Rôle des stéréotypes dans l'activité physique et la pratique sportive}

L'occasion de faire du sport ou de participer à une activité physique devrait être donnée à tous, indépendamment de toute considération de talent, d'aptitude physique, de sexe, ou de condition économique. Pourtant, les filles, les personnes handicapées et celles extrêmement pauvres ont rarement l'occasion d'y participer. À cause du sexisme, les filles bénéficient de moins d'occasions de participation. Par exemple : dans les écoles, certains sports d'équipe ne sont proposés qu’aux garçons ; les filles bénéficient d’un accès, ou d'un équipement, inférieur ; et les sports féminins sont moins reconnus et moins bien financés. Cette discrimination est contraire aux droits des filles. Heureusement, des efforts de plaidoyer et de changement des lois commencent à confronter 
ces inégalités au niveau local, national et international et les attitudes discriminatoires commencent à changer.

\section{Types d'activité physique préjudiciables à la santé}

Lactivité qui exige de longues heures de travail ardu (porter de lourdes charges ou tâches répétitives exigeant chaque fois de se courber, par exemple) peuvent être nuisibles. L'activité physique professionnelle peut aussi être dangereuse dans certaines conditions : $s$ 'il faut respirer des substances toxiques ou travailler sous une chaleur extrême, notamment. Les sports, de contact surtout, présentent aussi des risques.

\section{abus de substances toxiques}

\section{Quelles drogues et pourquoi?}

À part les médicaments, certaines drogues sont consommées à des fins récréatives : alcool, tabac, caféine, marijuana, inhalants (essence, colle et détachants), cocaïne et héroïne. Ces drogues affectent l'esprit et le corps, parfois de manière permanente. Certaines sont plus dangereuses que d'autres, et leurs effets varient d'une personne à l'autre. L'alcool et le tabac sont les drogues les plus utilisées au monde. De plus en plus de filles et de femmes fument depuis quelques années. Les gens se droguent pour différentes raisons :

- pour réduire leur anxiété dans les situations sociales;

- pour paraitre mûrs et sûrs d'eux ;

- pour éviter certains sentiments ou problèmes, comme l'ennui et la solitude;

- pour s'intégrer socialement ou s'amuser ;

- pour se stimuler l'esprit ou rester éveillés ;

- pour intensifier leurs perceptions sensorielles («trip »);

- pour réduire leur appétit ou ne pas manger (maigrir) ;

- pour se détendre ou dormir ; et

- pour faire face à un traumatisme.

\section{Qu'est-ce que la dépendance ?}

Une personne qui se drogue régulièrement peut devenir dépendante. Beaucoup de drogues créent une dépendance, y compris les médicaments tels que les antidouleurs, les pilules minceur et les somnifères, et la dépendance n'est pas toujours reconnue. Il est souvent difficile ou impossible d'arrêter la prise d'une drogue quand la dépendance s'installe. Pour la vaincre, il faut détermination, volonté, confiance en soi et appui d'autrui, souvent à travers un traitement professionnel ou la participation à un programme thérapeutique.

\section{Conséquences graves de la drogue}

La toxicomanie des adolescents représente un problème majeur de santé publique dans de nombreux pays. La drogue donne souvent lieu à de graves problèmes. Notamment :

- cause d'accidents en cas de conduite sous l'influence de l'alcool ou d'autres drogues;

- comportements regrettables pour cause de mauvais jugement et de désinhibition sous l'effet de la drogue ; - rapports sexuels non protégés contre les IST, le VIH ou la grossesse, par manque de jugement ;

- contraction du VIH ou de l'hépatite par partage d'aiguilles pour l'injection de drogues; et

- overdose toxique ou mortelle.

Les toxicomanes recourent parfois à des mesures désespérées, dégradantes ou illégales pour obtenir l'argent qui leur permette d'acheter leur drogue. Les chiqueurs de tabac, les fumeurs et leurs proches peuvent attraper le cancer ou d'autres maladies mortelles. Chez la femme enceinte, certaines drogues, légales comme illégales, peuvent nuire au fotus. 


\section{puberté féminine}

Pour les filles, la puberté commence entre l'âge de 8 et 13 ans, environ deux ans plus tôt que pour les garçons. Elle se termine entre 16 et 17 ans, ou quand la croissance du squelette est terminée.

\section{Changements survenant à la puberté}

Les changements de la puberté varient d'une personne à l'autre en termes de moment, de chronologie et de rapidité, mais ils suivent généralement l'ordre suivant :

- Les seins commencent à bourgeonner, souvent d'un seul côté d'abord. Le développement complet prend environ deux ans.

- La pilosité pubienne apparaît, progressivement plus épaisse, plus drue et bouclée.

- À l'intérieur du corps de la fille, la surface du vagin s'épaissit et l'utérus et les ovaires grossissent. [Voir la fiche relative à l'appareil sexuel et génital féminin.]

- La première menstruation survient généralement deux à trois ans après le début du développement des seins. Les règles sont souvent irrégulières pendant les deux premières années. Dès que la fille ovule, elle peut se retrouver enceinte.[Voir la fiche relative au cycle menstruel].

- Des poils poussent sous les bras et la sueur prend une odeur de transpiration adulte.

- Le col de l'utérus commence à produire une glaire qui s'écoule par le vagin. Normale, cette glaire est le signe de changements naturels ayant trait à la fécondité et la menstruation.

Les filles traversent aussi une période de croissance rapide, leur bassin et leurs hanches s'élargissent, les tissus adipeux (gras) s'épaississent et la peau devient plus grasse, favorisant l’apparition d’acné.
Comme pour les garçons, les intérêts et les sentiments des filles peuvent changer à la puberté. Durant les jours qui précèdent la menstruation, elles ressentent souvent d'intenses sentiments de joie, de tristesse, de sensibilité ou de colère, notamment.

\section{Gérer la menstruation}

La menstruation est naturelle et normale pour une fille ou une femme en bonne santé. Les premières règles peuvent marquer un événement heureux, surtout quand la fille sait à quoi s'attendre. Beaucoup vivent malheureusement l'arrivée de leurs premières règles dans l'inquiétude ou la peur parce que personne ne leur en a expliqué le sens ni la marche à suivre. Certains parents ne peuvent en parler à l'aise. $\mathrm{Ou}$ bien la fille a absorbé les messages culturels ou religieux qui associent la menstruation à l'impureté. Il s'agit pourtant d'une façon dont le corps se renouvelle et entretient sa fécondité.

Pendant la menstruation, la fille peut généralement poursuivre toutes ses activités ordinaires. Le bain est important et il convient de laver la vulve à l'eau et au savon doux pour en éliminer les résidus de sang.

La manière dont les femmes absorbent leur flux menstruel varie suivant l'endroit. Beaucoup utilisent des serviettes hygiéniques pour absorber le sang. En certains endroits, elles achètent des serviettes jetables. En d'autres, elles emploient des serviettes réutilisables faites d'étoffes pliées, qu'il importe de bien laver à l'eau et au savon après chaque emploi. Il importe aussi de disposer d'un endroit privé (à domicile comme à l'école) où changer ou laver ses serviettes. 
Beaucoup de filles et de femmes utilisent des tampons, avec ou sans serviettes. Un tampon est une petite masse de coton (ou autre matière absorbante) de forme souvent semblable à celle d'un doigt, qui s'insère confortablement dans le vagin pour absorber le flux menstruel. Le tampon doit être remplacé au moins deux fois par jour. Laisser un tampon en place pendant plus d'un jour peut provoquer une infection grave et parfois mortelle. (L'insertion de tout objet impur dans le vagin peut causer une infection grave.)

La quantité du saignement — le flux menstruel — varie d'un jour et d'une personne à l'autre. Le flux peut être le plus intense durant les premiers jours de la menstruation. Certaines filles et femmes ont des règles douloureuses (crampes abdominales, parfois fortes et accompagnées de nausées). Un léger analgésique (ibuprofène, par exemple) peut être utile.

Un bain, ou la pose d'une bouteille en plastique ou d'une bouillotte remplie d'eau chaude sur le bas du ventre ou du dos aident parfois aussi.
Quelques jours avant leurs règles, certaines filles et femmes ressentent différentes formes de gêne, telles que seins douloureux, constipation, fatigue, boutons et sentiments intenses plus difficiles à gérer que d'habitude. Ces symptômes ne se répètent pas nécessairement de mois en mois. Pour

beaucoup, la gêne prémenstruelle et les crampes menstruelles tendent à diminuer quand elles font régulièrement de l'exercice tout au long du mois.

La menstruation est souvent source de questions et de difficultés pour les filles. Il peut être utile d'en parler à un prestataire de santé, à une parente ou à une amie.

[Voir aussi la fiche relative au cycle menstruel et celle relative à l'appareil sexuel et génital féminin.] 
Pour les garçons, la puberté commence entre l'âge de 10 et 13 ans, un an ou deux après les filles. Elle se termine généralement un peu avant ou après 20 ans, quand la croissance osseuse est terminée.

\section{Changements survenant à la puberté}

Comme les filles, les garçons peuvent voir changer leurs sentiments et leurs intérêts à la puberté. Des changements physiques surviennent aussi, généralement dans cet ordre :

- Les testicules et le pénis augmentent de volume.

- La pilosité pubienne apparait, progressivement plus épaisse, plus drue et bouclée.

- La voix commence à muer, généralement de manière progressive mais parfois soudaine aussi.

- Environ un an après le grossissement des testicules, le garçon peut commencer à éjaculer (émettre un liquide blanc laiteux appelé sperme à travers le pénis).

- Des poils poussent sous les bras et la sueur prend une odeur de transpiration adulte.

- La pilosité faciale (moustache et barbe) apparaît.

Les garçons traversent aussi une période de croissance rapide et de musculation. La peau devient plus grasse, favorable à l'apparition d'acné. Chez la moitié des garçons environ, les seins grossissent temporairement, mais cela disparaît après un an ou deux.

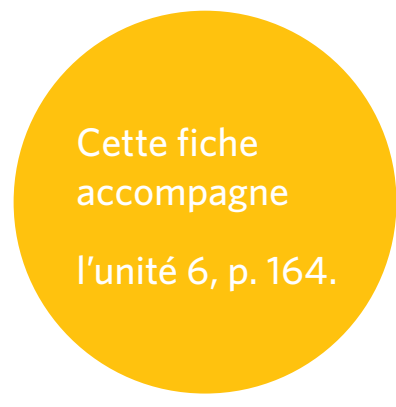

\section{D'où viennent les érections ?}

Les érections se produisent pendant toute la vie. Elles sont causées par le sang qui remplit le tissu spongieux du pénis sous l'effet d'une stimulation sexuelle, d'un effort de levage ou autre, d'un rêve, du froid, de vêtements serrés, de la peur ou de l'excitation, ou d'une vessie pleine au réveil. Une érection peut se produire sans raison apparente, à la puberté surtout. Les garçons ont souvent des érections soudaines et spontanées, parfois plusieurs fois par jour, sous l'effet de la hausse ou variation de la testostérone.
Avoir une érection sans éjaculation peut causer un sentiment de « lourdeur » temporaire, mais qui n'est pas du tout nuisible. Si le pénis en érection n'est pas touché, l'érection se résorbe d'elle-même.

\section{Que se passe-t-il pendant l'éjaculation ?}

Avant l'éjaculation, les glandes de Cowper émettent une goutte ou deux de liquide à travers le pénis. Il s'agit du liquide pré-éjaculatoire, qui nettoie l'urètre. Ce liquide seul ne contient pas assez de spermatozoïdes pour causer une grossesse (sauf si le sperme d'une éjaculation récente est encore présent). Le VIH peut cependant être présent dans ce liquide.

La pleine éjaculation implique l'émission de sperme, contenant généralement des centaines de millions de spermatozoïdes dans l'équivalent d'une cuiller à café de liquide. L'éjaculation s'accompagne (pas toujours) du plaisir de l'orgasme. Un garçon qui peut éjaculer peut causer une grossesse.

\section{Qu'est-ce que l'éjaculation nocturne ?}

L'érection est courante pendant le sommeil et environ $80 \%$ des garçons et des hommes éjaculent parfois. Il s'agit de l'« l'éjaculation nocturne », fréquente pendant la puberté mais également présente chez l'homme adulte. Un garçon ou un homme qui se masturbe ou qui a des rapports sexuels réguliers est moins susceptible d'avoir ce type d'éjaculation.

L'éjaculation nocturne (et la masturbation) ne sont absolument pas nuisibles. Elles peuvent détendre et être source de plaisir. Il ne s'agit pas non plus d'un « gaspillage » de sperme. Les testicules produisent des spermatozoïdes en permanence et l'éjaculation nocturne aide le corps à s'en débarrasser

[Voir aussi la fiche relative à l'appareil sexuel et génital masculin.] 


\section{Comment tombe-t-on enceinte?}

Pour qu'une grossesse soit possible, il faut qu'il y ait fécondation, par union d'un ovule et d'un spermatozoïde. La fécondation n'est possible que durant la phase féconde du cycle menstruel de la femme. [Voir la fiche relative au cycle menstruel.]

Pendant la phase féconde de la femme, l'un de ses deux ovaires libère un ovule : c'est l'ovulation. En l'espace de quelques minutes, les « franges ", à l'extrémité de la trompe de Fallope, se mettent à cerner l'ovule et à l'attirer dans le conduit de la trompe. Pendant la phase féconde, le col de l'utérus se met aussi en position favorable à la pénétration du sperme. Il sécrète une grande quantité de glaire cervicale claire, qui nourrit le sperme et l'aide à survivre pendant plusieurs jours. Cette glaire facilite aussi la navigation des spermatozoïdes vers la trompe de Fallope, pour les aider à atteindre l'ovule.

Lors des rapports sexuels, l'éjaculation projette le sperme à proximité du col, qu'il pénètre en quelques secondes. Si la femme est féconde, certains spermatozoïdes peuvent atteindre l'ovule dans la trompe en l'espace de cinq minutes, tandis que d'autres survivent dans la glaire claire du col. Jusqu'à cinq jours après l'éjaculation, ils continuent ainsi à quitter le col et peuvent féconder un ovule. Une femme qui ovule plusieurs jours après avoir eu des rapports non protégés peut donc toujours avoir des spermatozoïdes vivants au niveau du col, capables d'atteindre la trompe et de féconder l'ovule.
Après l'ovulation, la fécondation doit cependant se produire en l'espace de 24 heures, car l'ovule ne peut survivre plus longtemps. La fécondation a lieu dans la trompe de Fallope. Le spermatozoïde qui pénètre l'ovule crée aussitôt une barrière chimique aux autres. L'ovule fécondé poursuit sa descente vers l'utérus, propulsé par les contractions et par les « cils» de la trompe.

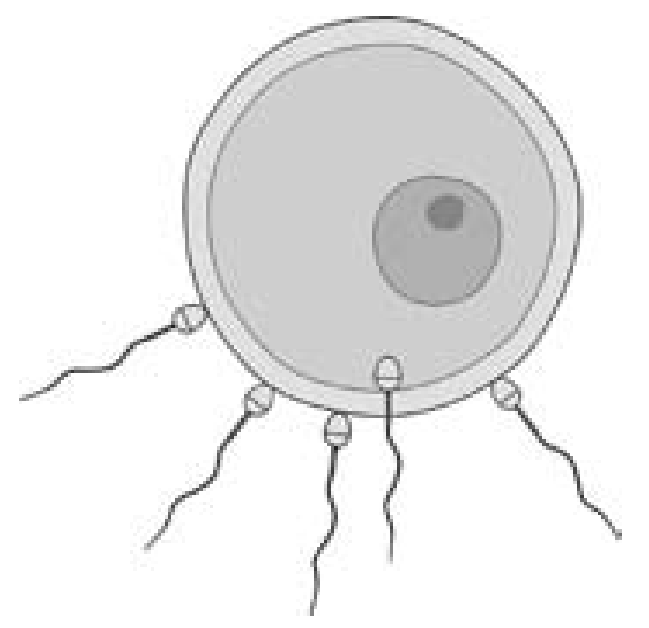

\section{Que se passe-t-il après la fécondation ?}

Dans la trompe de Fallope, l'ovule fécondé, ou zygote, se divise et grossit, tandis qu'il progresse vers l'utérus, pendant environ cinq jours. Après sa première division, le zygote devient un «embryon ». Dans les deux jours qui suivent l'arrivée dans l'utérus, l'embryon se niche dans sa muqueuse. Cette implantation (la nidation) marque le début de la grossesse.

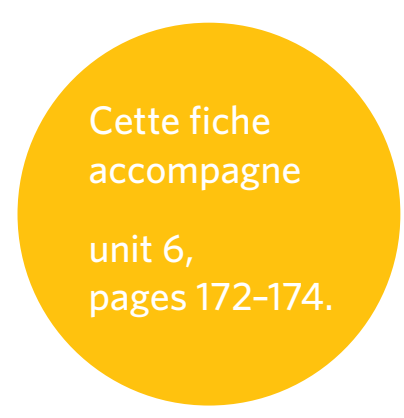




\section{Comment la femme sait-elle qu'elle est enceinte?}

Les premiers signes de grossesse diffèrent d'une femme et d'une grossesse à l'autre. Ils peuvent être :

- l'absence de menstruation;

- les seins douloureux ou enflés ;

- les mamelons sensibles :

- le besoin fréquent d'uriner ;

- une fatigue inhabituelle;

- des nausées et vomissements ;

- des crampes au bas du ventre;

- un sentiment de ballonnement ;

- des changements d'appétit ; et

- une intense émotivité.

La grossesse peut être confirmée par un test administré par un prestataire de santé ou acheté en pharmacie. Les femmes qui ont appris à détecter le moment où elles ovulent peuvent prédire assez bien le jour de leur menstruation et peuvent donc être conscientes d'une grossesse dès le premier jour de retard de leurs règles.

\section{Que se passe-t-il pendant la grossesse ?}

Après la nidation, l'embryon (appelé «blastocyste » à ce stade) produit aussi le sac amniotique et le placenta. Le sac apporte un milieu liquide protecteur au foetus grandissant. Le placenta lui apporte les nutriments et l'oxygène en provenance de la mère ; il élimine aussi les déchets. Le cordon ombilical relie le placenta au foetus.

La grossesse humaine dure 38 semaines à partir de la fécondation (environ 40 semaines à partir des dernières règles). La grossesse se divise en trois périodes d'environ trois mois chacune, appelées trimestres.
Pendant le premier trimestre, jusqu'à la 12e semaine, tous les organes et structures majeurs du corps se forment : cerveau, cœur, poumons, yeux, oreilles, bras et jambes. Au bout de la 8e semaine, l'embryon est appelé « foetus ». Les femmes ont souvent la nausée pendant ce premier trimestre.

Au deuxième trimestre, de la 13e à la 27 ou 28e semaine environ, le foetus grandit rapidement. Aux environs de la 19e semaine, la femme le sent généralement bouger. La plupart des femmes commencent à gagner du poids pendant ce trimestre.

Durant le troisième trimestre, le foetus continue à prendre du poids et ses mouvements sont plus forts et fréquents.

\section{Comment favoriser une grossesse saine?}

Si une femme ou une fille choisit de poursuivre une grossesse, il importe tout particulièrement qu'elle évite tous médicaments inutiles, drogues et alcool. Il faut qu'elle prenne les suppléments de vitamines et minéraux recommandés (fer et acide folique surtout), y compris, si possible, avant la grossesse. Il faut aussi qu'elle consulte un prestataire de soins prénatals qui la suive médicalement et l'informe sur sa grossesse, les signes de danger potentiels et l'accouchement. Les femmes séropositives doivent suivre un traitement anti-VIH pour prévenir l'infection de leur foetus et rester elles-mêmes en bonne santé. Les médicaments anti-VIH sont essentiels pendant le travail et l'accouchement, pour réduire le risque de transmission du VIH à l'enfant. 


\section{Qu'est-ce que la sélection du sexe ?}

La sélection du sexe est une pratique qui consiste à identifier le sexe d'un foetus et à choisir de poursuivre ou d'interrompre la grossesse suivant le résultat du test.

\section{Pourquoi?}

La raison principale de la pratique est l'importance supérieure accordée, dans certaines sociétés, aux fils par rapport aux filles. Dans certains contextes, les fils assurent la postérité de la famille et de son nom ; ils héritent le patrimoine familial, assurent le revenu de la famille, subviennent aux besoins de leurs parents âgés et accomplissent les rites funéraires. Dans ces sociétés, les filles sont en revanche censées quitter leur famille biologique pour aller vivre avec celle de leur mari. Les politiques d'État qui restreignent le nombre d'enfants admis par femme contribuent peut-être à la décision d'avortement des foetus de sexe féminin.

Dans les sociétés qui préfèrent les garçons aux filles, les femmes subissent souvent une pression intense de produire des fils. La naissance d'un fils rehausse leur statut. À défaut de produire un héritier, elles peuvent être blâmées, violentées ou même abandonnées. Dans certains cas, les femmes sont même forcées à faire identifier le sexe de leur fotus et à se faire avorter s'il est féminin.

\section{Comment?}

Différentes procédures, initialement conçues pour aider le suivi d'une grossesse, permettent aux prestataires d'identifier le sexe d'un fotus. Dans certains contextes, ces procédures servent aujourd'hui souvent et spécifiquement à identifier le sexe et à interrompre la grossesse s'il est féminin.
Avant la grossesse : Dans certains cas, les spécialistes de la fertilité permettent aux parents de sélectionner le sexe de l'enfant avant la grossesse. Des techniques spéciales servent à séparer les spermatozoïdes mâles des femelles dans un échantillon de sperme. (Le sexe de l'enfant est déterminé par le spermatozoïde du père, pas par l'ovule de la mère.) Seul le sperme du sexe désiré est retenu, pour insémination artificielle de la femme ou fécondation in vitro.

\section{Pendant la grossesse : Plusieurs procédures permettent} d'identifier le sexe du fotus pendant la grossesse. Au moyen d'ultrasons, l'échographie produit une image du fotus sur un écran d'ordinateur. L'amniocentèse (analyse du liquide amniotique par prélèvement dans le sac à l'aide d'une aiguille) offre une autre méthode, et le prélèvement des villosités choriales (extraction et analyse d'un échantillon de tissu placentaire), une autre encore.

Après la grossesse : Certains couples recourent à des mesures draconiennes après l'accouchement : l'enfant peut être abandonné ou même tué s'il est de sexe féminin.

\section{Conséquences}

La sélection du sexe est le résultat de la discrimination de genre, qu'elle perpétue d'ailleurs. Dans les régions qui la pratiquent couramment (en Chine et en Inde, notamment), on observe une population masculine beaucoup plus nombreuse que celle des filles avec, pour conséquence, un manque de jeunes femmes à marier. Même interdite par la loi, la pratique existe toujours et inquiète profondément les défenseurs des droits des femmes et les gouvernements.

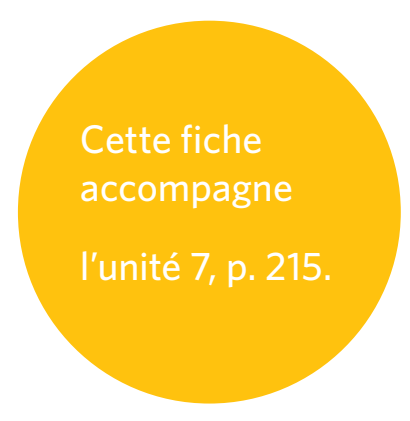




\section{Qu'est-ce que la stérilité ?}

Un couple est stérile quand il ne produit pas de grossesse après avoir eu des rapports sexuels réguliers non protégés pendant un an, même s'il a déjà eu des enfants. Environ un couple sur dix se trouve dans cette situation.

\section{Quelle sont les principales causes de stérilité et comment s'en protéger?}

Si la femme est souvent blâmée, l'homme est stérile dans près de $50 \%$ des cas, ou les deux partenaires contribuent au problème. Les causes principales de la stérilité féminine sont l'obstruction des trompes (sous l'effet, notamment, d'une IST non traitée ou d'une autre condition, telle que l'endométriose) et les problèmes hormonaux. Côté masculin, il s'agit de problèmes de production suffisante de sperme sain (pour diverses raisons). L'usage du préservatif quand une grossesse n'est pas désirée protège contre la stérilité causée par les IST. L'âge peut aussi entrer en jeu. Les femmes en particulier sont moins fécondes avec l'âge (au-delà de 35 ans surtout).

\section{Premières mesures à prendre}

Le couple stérile doit commencer par déterminer le moment fécond du cycle de la femme et avoir des rapports sexuels quand sa glaire cervicale est abondante, claire, glissante et filante. Il convient de traiter tout problème de santé, de bien manger et se reposer, et d'éviter tabac, drogues, alcool et caféine. Le sperme de l'homme peut être examiné en clinique pour déterminer s'il contient suffisamment de spermatozoïdes et son scrotum examiné afin d'y détecter la présence d'une varice susceptible d'affecter la production. La femme peut être examinée à la recherche d'une affection ou d'une infection traitable.

\section{Autres traitements possibles}

D'autres traitements sont possibles suivant la cause de la stérilité. Si la femme n'ovule pas, certains médicaments peuvent être prescrits. Si une trompe est bloquée ou en présence d'autres conditions, une intervention chirurgicale peut être utile. De même chez l'homme, la chirurgie peut corriger le problème d'une varice au niveau du scrotum.

\section{Qu'est-ce que la procréation assistée ?}

La procréation assistée désigne le recours à des techniques de pointe pour aider la fécondation. L'insémination artificielle consiste à introduire le sperme de l'homme dans le vagin de la femme au moment de l'ovulation. Pour la fécondation in vitro, on joint ovules et sperme dans une capsule de laboratoire et on introduit le ou les ovules fécondés qui en résultent dans l'utérus de la femme. Autre méthode encore, une "mère porteuse » peut mener une grossesse (généralement établie par fécondation in vitro) à terme quand la femme ne peut le faire elle-même. Ces techniques compliquées de procréation assistée sont extrêmement coûteuses.

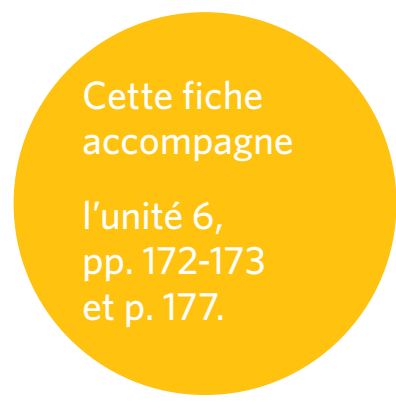




\section{Qu'est-ce que le trafic sexuel ?}

Le trafic sexuel concerne le recrutement, le transport, la vente ou l'achat d'êtres humains dans le but de les exploiter sexuellement par prostitution, pornographie, strip-tease, spectacles érotiques, tourisme sexuel ou mariage forcé. La plupart des victimes sont les filles et les jeunes femmes. Des tactiques contraignantes, de déception, fraude, intimidation, isolation, menace, force physique et asservissement pour dettes, trompent et contrôlent les victimes. Certaines filles et femmes sont vendues au commerce du sexe par leurs parents, leur mari ou leur petit ami.

\section{Étendue du problème}

L'étendue exacte du trafic sexuel est inconnue car il s'agit d'une pratique illégale, généralement cachée et donc difficile à cerner. De plus, les différentes définitions du phénomène compliquent les efforts de dénombrement des personnes affectées dans le monde. Il s'agit pourtant d'une industrie en pleine expansion, signalée dans toutes les régions du monde, extrêmement lucrative et liée aux réseaux mafieux.

\section{Conséquences}

Les victimes endurent souvent des traitements brutaux et dégradants, y compris la privation de nourriture et de liberté, les raclées, le viol (parfois collectif), l'usage forcé de drogues, l'avortement et la stérilisation forcée, les menaces de violence contre elles-mêmes et leur famille et les menaces de révélation de leurs circonstances à leurs parents et amis. Les conséquences de santé en sont les blessures physiques (os fracturés, commotions, brûlures, déchirures vaginales et anales); la toxicomanie et l'alcoolisme ; les IST, VIH compris ; les fausses couches et la stérilité. Le traumatisme physique et affectif extrême des victimes peut donner lieu à des réactions psychologiques aiguës telles que la séparation entre le physique et le mental, le stress post-traumatique et les pensées suicidaires. Les victimes courent le risque de mort prématurée par homicide, suicide, drogue et alcool ou VIH.

\section{Prévention}

La gestion des nombreuses conséquences du trafic sexuel passe par l'adoption de mesures de prévention, de poursuite des auteurs et de soins des victimes.

\section{Mesures préventives :}

- autonomisation des femmes;

- ouverture de débouchés scolaires, de formation professionnelle et d'emploi aux femmes et aux filles ;

- organisation de campagnes de sensibilisation ciblées sur les victimes potentielles;

- formation des enseignants, délégués à la jeunesse et autres à l'identification des filles vulnérables et au travail avec leur famille et communauté ;

- adoption de lois et approche éducationnelle qui réduisent la demande favorable au trafic sexuel ; et

- établissement de programmes de prévention coopératifs entre les pays fournisseurs, destinataires et de transit.

Mesures de poursuite des auteurs :

- renforcement des lois, des peines et de leur application ;

- formation de divisions policières vouées à la recherche et à l'arrestation des auteurs; et

- mise en ouvre de solides systèmes de protection des témoins.

Les services aux victimes doivent répondre à leurs besoins immédiats : protection, soins médicaux, réparation légale, logement, emploi et conseil. Les victimes du trafic ne doivent pas être pénalisées, criminalisées ou arrêtées. Elles doivent être assistées sans conditions, indépendamment de leur statut légal. Les États doivent accorder des ressources suffisantes et prioritaires à la lutte contre le trafic sexuel et, à long terme, contre ses causes profondes, en particulier la pauvreté, l'inégalité et la discrimination de genre.

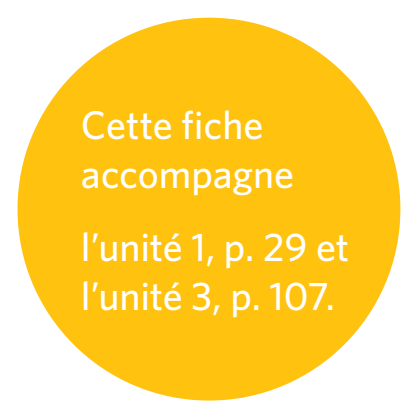


Voir aussi la fiche sur les infections sexuellement transmissibles.

\section{VIH (virus de l'immunodéficience humaine) et sida (syndrome d'immunodéficience acquise)}

\section{Quelle est la différence entre le VIH et le sida ?}

Le VIH (virus de l'immunodéficience humaine) est un virus qui attaque et détruit le système immunitaire d'une personne. Affaibli par le VIH, le corps ne peut plus se défendre contre la maladie et devient vulnérable à de graves infections et cancers parfois mortels. On parle alors de sida (syndrome d'immunodéficience acquise). Les personnes atteintes du VIH peuvent aussi recevoir le diagnostic du sida si leurs analyses de sang révèlent une insuffisance immunitaire.

\section{Comment se transmet le VIH ?}

Le VIH est présent dans les liquides corporels des personnes infectées. Une personne séropositive peut transmettre le virus à travers son sperme (y compris le liquide pré-éjaculatoire), ses sécrétions vaginales, son lait ou son sang. Le virus se transmet le plus souvent lors de l'échange de sperme et de sécrétions vaginales durant l'acte sexuel. Il peut se transmettre lors de rapports vaginaux ou anaux entre un homme et une femme, mais aussi lors de rapports anaux entre deux hommes. La présence d'une infection sexuellement transmissible peut accroître le risque de contraction ou de transmission sexuelle $\mathrm{du}$ VIH. Le virus se transmet aussi par transfusion de sang contaminé ou partage d'aiguilles contaminées pour l'injection de drogues ou de stéroïdes, le perçage ou le tatouage. Une mère séropositive peut transmettre le virus à son enfant pendant la grossesse, l'accouchement ou l'allaitement. Les relations buccogénitales présentent aussi un risque de transmission.

L'utilisation d'instruments contaminés lors de manucures, pédicures ou pour le rasage peut présenter un risque de transmission, fort improbable toutefois. Toucher, embrasser, éternuer, tousser ou partager de la nourriture, une boisson ou des couverts ne présentent aucun risque de transmission du VIH, pas plus que le contact au travail, à l'école ou à domicile, que la fréquentation d'un bassin de natation ou de toilettes publiques, ou que les piqûres d'insecte, la salive, les larmes ou la sueur. L'urine et les matières fécales ne transmettent pas le VIH si elles ne contiennent pas de sang.

\section{Comment prévenir le VIH?}

Aucun vaccin ni cure n'existe actuellement contre le VIH. La prévention est donc essentielle.

La transmission sexuelle peut être prévenue par abstinence de rapports sexuels non protégés ou usage du préservatif masculin ou féminin à chaque rapport. Une autre approche consiste à se limiter à un(e) seul(e) partenaire sexuel(le), en lui restant «fidèle ». Cette approche n'est valable que si les deux partenaires sont vraiment monogames et qu'ils sont tous deux séronégatifs. Beaucoup de personnes ignorent malheureusement qu'elles - ou leur partenaire - sont déjà infectées. Le seul moyen d'être certain de son état est de se faire tester. Personne ne peut de plus garantir que son ou sa partenaire n'en aura jamais d'autres. Aussi l'approche de la fidélité est-elle souvent risquée. Pour les hommes, la circoncision offre une certaine protection contre le VIH, sans toutefois éliminer le risque. Pour les femmes, la circoncision masculine ne présente à ce jour aucun avantage direct connu. Le préservatif reste donc de rigueur.

La transmission par aiguille contaminée peut aussi être prévenue moyennant l'usage d'une aiguille neuve ou stérile à chaque injection ou perçage de la peau.

Transmission mère-enfant - Il convient en tout cas de tester les femmes enceintes. Celles séropositives peuvent prendre des médicaments préventifs pour réduire le risque de contamination de leur enfant pendant la grossesse et l'accouchement. La transmission du virus peut aussi survenir après l'accouchement, à travers le lait maternel. Les mères séropositives doivent obtenir l'avis d'un prestataire de santé pour prévenir la transmission pendant la grossesse et l'accouchement, et concernant aussi leurs options d'allaitement. [Voir la fiche relative à l'accouchement et l'allaitement.] 


\section{Peut-on guérir ou traiter l'infection à VIH ?}

L'infection à VIH peut être traitée mais pas guérie. Le traitement actuel est un traitement antirétroviral (ART), combinaison médicamenteuse qui réduit le niveau du VIH dans le sang et ralentit la destruction du système immunitaire. Les ART ont amélioré la qualité de vie et la longévité de nombreuses personnes séropositives. Le traitement amoindrit aussi la maladie et la mortalité associées au sida, stade le plus avancé de l'infection à VIH. Tout le monde ne répond pas de la même manière aux médicaments. Sans eux, la progression du VIH vers le sida prend généralement un à 10 ans, et une personne atteinte du sida vit moins d'un an.

\section{Comment savoir si on est - soi-même ou son partenaire sexuel - séropositif?}

La seule manière de savoir son état VIH est de se faire tester. La seule manière de savoir si un(e) partenaire sexuel(le) est séropositif(ve) passe aussi par un test de dépistage et la révélation du résultat. Des millions de personnes séropositives semblent en parfaite santé, n'ont aucun symptôme et ignorent qu'elles transmettent le virus à d'autres.

Le test de dépistage détecte la présence ou non dans le sangde cellules spéciales (appelées anticorps anti-VIH). Le test détecte généralement ces anticorps dans les six à huit semaines suivant l'exposition au virus. Dans de rares cas, il faut jusqu'à six mois pour déceler les anticorps.

Si le test VIH est positif, la personne présente des anticorps anti-VIH et est infectée. Si le premier test est positif, un second test, différent, en confirme les résultats.

Un test négatif veut dire que la personne n'est pas infectée. Ou bien il se peut qu'elle ait contracté le VIH mais qu'elle n'ait pas encore produit suffisamment d'anticorps pour que le test soit positif. Une personne dont le test est négatif mais qui pense avoir été exposée récemment au virus devrait se faire retester quelques mois plus tard.

\section{Quelle est I'utilité du test de dépistage du VIH ?}

Le test de dépistage est important pour plusieurs raisons. Un résultat négatif peut représenter un soulagement immense. Il peut aussi encourager la personne à adopter un comportement sexuel plus sûr. Si le résultat est positif, la personne peut rechercher les soins et le traitement appropriés. Le traitement peut améliorer la qualité de la vie et prolonger significativement la vie d'une personne séropositive. Les personnes testées peuvent aussi informer et protéger leurs partenaires. Pour une femme enceinte ou qui désire le devenir, il est important de connaître son état VIH afin de réduire, au besoin, le risque de transmission à son enfant. [Voir la fiche relative à l'accouchement et l'allaitement maternel.]

\section{De quelle assistance ont besoin les personnes vivant avec} le VIH et le sida?

Un résultat de dépistage positif peut être source de peur, de confusion et de dépression. Découvrir qu’on est séro-positif est un événement qui change la vie, et il faut du temps pour s'adapter à cette réalité. Les personnes vivant avec le VIH ont besoin d'un solide accompagnement, par leurs parents, leur conjoint ou partenaire, leur famille et leurs amis, conseillers, assistants sociaux, autres personnes dans le même cas ou leaders spirituels ou religieux. Elles doivent trouver un médecin respectueux et bien informé sur le VIH et le sida, et avoir accès au traitement médical dont elles ont besoin. Elles doivent s'informer autant que possible sur le VIH et le sida, et sur la manière de protéger leur propre santé et celles de leurs partenaires sexuels. Pour garder une santé optimale, elles doivent bien manger, rester actives, se reposer adéquatement, éviter les excès de tabac et d'alcool et les drogues récréatives. Elles doivent surtout adopter des pratiques sexuelles toujours sûres, pour se protéger contre les infections sexuellement transmissibles et éviter de contaminer d'autres personnes. 


\section{violence, y compris sexuelle, à l'encontre des femmes et des filles}

\section{Étendue du problème}

Tristement, la violence à l'encontre des femmes et des filles (parfois appelée violence de genre ou sexiste) est fort répandue et représente un grave problème de santé publique et de droits humains. Son incidence varie largement dans le monde, mais dans certains contextes, entre un et deux tiers des femmes sont battues, forcées à avoir des rapports sexuels ou victimes d'autres violences aux mains d'un partenaire intime durant leur vie. Des centaines de milliers de femmes et de filles font l'objet, chaque année, d'un trafic international. Près de 140 millions ont subi une forme de mutilation génitale et trois millions en courent annuellement le risque en Afrique. Ces 10 prochaines années, plus de 100 millions de filles seront mariées, encore enfants, dans le monde en développement. En zone de guerre, la violence à l'encontre des femmes (y compris le viol systématique) est signalée pendant et après tous les conflits armés.

\section{Conséquences de la violence à l'encontre des femmes}

Conséquences de santé :

- douleurs et blessures graves, d'os fracturés, brûlures, œil au beurre noir, coupures, bleus, maux de tête et douleurs abdominales et musculaires, parfois pendant des années ;

- problèmes de santé mentale tels que dépression, anxiété et troubles de l'alimentation;

- dysfonctionnement sexuel, y compris rapports douloureux, absence de désir et peur de l'acte sexuel ; et

- problèmes de santé génésique tels que fausses couches, IST et infection à VIH, grossesse non planifiée et plus grande prise de risques sexuels parmi les adolescentes.

Blessures graves, homicide volontaire et suicide lié à la violence contribuent tous aux taux de mortalité féminine. Dans une communauté, la violence à l'encontre des femmes peut perpétuer l'idée fausse de la supériorité des hommes. La violence de genre crée un climat de peur et d'insécurité dans les familles, les communautés et les milieux de travail.

\section{Stratégies efficaces de lutte contre la violence à l'encontre des femmes}

Transformation des attitudes et autres efforts de prévention - participation des hommes aux efforts de changement des attitudes culturelles relatives à la virilité et à la violence ;

- intégration de la sensibilisation au genre, y compris à la violence sexiste, dans l'enseignement formel et informel ;

- initiatives telles que la campagne annuelle 16 jours

d'activisme contre la violence de genre ;

- sensibilisation des femmes et des filles à leurs droits légaux ;

- autres activités d'autonomisation des femmes et des filles; et

- fin des mariages d'enfants, qui placent de nombreuses filles en position de vulnérabilité.

Services : Les femmes victimes de la violence et leurs enfants doivent avoir accès à divers services, idéalement en un même endroit : permanences téléphoniques, conseil, réseaux d'appui, refuges sûrs, services juridiques et soins de santé, y compris de contraception d'urgence pour les victimes de viol.

Formation : Les prestataires de soins formés peuvent aider à détecter les abus et assister les victimes en leur offrant aide et orientation médicale, psychologique et juridique.

Changement des lois :

- engagement politique à travers les déclarations de hauts représentants de l'État, appuyées par la prise de mesures concrètes et l'engagement de ressources :

- adoption et mise en ouvre de lois relatives à la violence contre les femmes et évaluation de leur application ;

- élaboration de directives et protocoles et formation systématique de la police, du parquet et des juges ;

- formation d'unités de police et de tribunaux spécialisés ; et

- adoption de politiques d'arrestation et de poursuites rigoureuses, ainsi que de sanctions appropriées.

Élargissement de la connaissance : La recherche et la documentation de la violence à l'encontre des femmes et des filles renforcent la reconnaissance du problème et la volonté de le résoudre. 


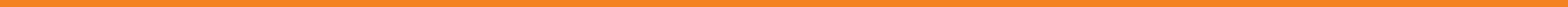

\section{UN SEUL
PROGRAMME

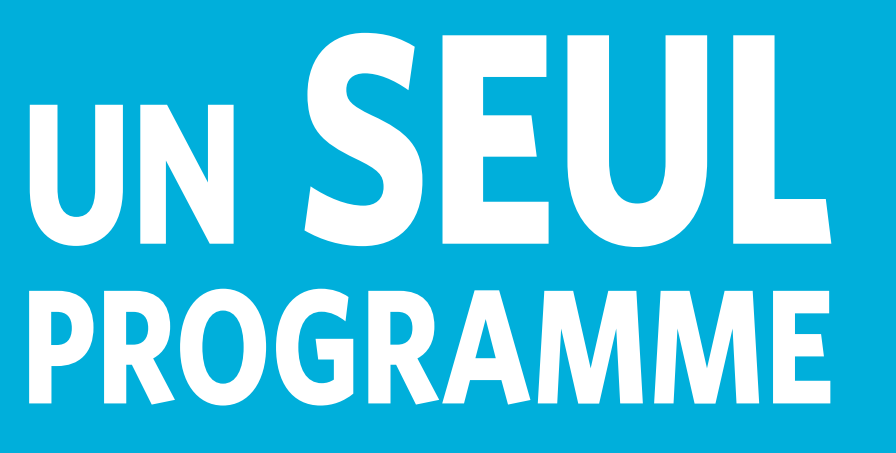

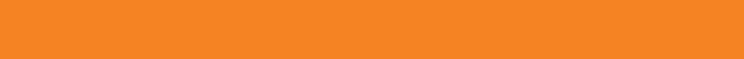

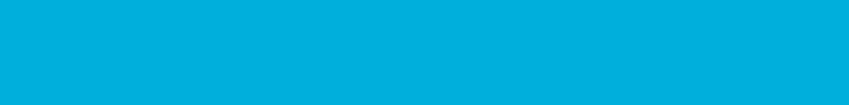

